\title{
Tracing Motivations: A Comparative Analysis of Lone-Actor Terrorism and Rampage Shootings in North America and Europe Between 2o10- 2018
}

\author{
By \\ Eleni Kate Turnbull
}

A thesis submitted to Victoria University of Wellington in fulfilment of the requirements for the degree of Master of Arts in Criminology

\author{
Institute of Criminology
}

Victoria University of Wellington 


\begin{abstract}
Lone-actor terrorism and rampage shooting events attract a substantial amount of interest and concern from scholars, the public, and the media. Empirical research on lone-actor terrorism from a criminological perspective to date is limited, and it is crucial to investigate what is known about these incidents to further our understanding of these relatively rare but extremely high-impact events. The current research aims to investigate key differences between lone-actor terrorists and rampage shooters on a wide range of characteristics, and seeks to explore whether there are similar underlying mechanisms for these events. Little is known about the comparative nature of these events worldwide, and the present study addresses this gap in knowledge by offering the first quantitative analysis of lone-actor terrorism and rampage shooting incidents in North America and Europe within the recent time period of 2010-2018. An open-source data collection strategy was employed and searches of online databases and additional materials were undertaken to gather information on incidents, which resulted in a comprehensive sample of 155 perpetrators who were responsible for 134 incidents. To compare characteristics between groups, a series of bivariate and multivariate tests were conducted through SPSS, which allowed for conclusions to be drawn based upon statistical analysis of the data. The current study found significant differences between groups on a wide range of variables. Results revealed that the majority of lone-actor terrorism incidents occurred across Europe, whereas rampage shootings were more likely to occur within North America. Rampage shootings were more likely to involve the use of firearms compared to lone-actor terrorism incidents, whereas lone-actor terrorism incidents were more likely to involve the use of explosives and vehicles. Additionally, lone-actor terrorists were more likely to commit an attack as a result of political and/or religious motivations, whereas rampage shooters were more likely to be motivated by emotional triggers, relationship and/or domestic issues, and personal grievances. These findings offer insights into the underlying mechanisms of these events and the various behaviours and experiences of lone-actor terrorists and rampage shooters. Future research into these areas could lead to important prevention implications, and could be used to monitor and reduce lone-actor terrorism and rampage shooting events.
\end{abstract}




\section{Acknowledgements}

First and foremost, I would like to thank my supervisor Dr. Russil Durrant for the ongoing support, patience, and encouragement you have given me since the beginning of last year. Thank you for providing me with constant feedback on my writing and for your perseverance during the data collection and analysis phases of this project. The guidance, knowledge, and advice you have provided has not gone unappreciated, and I could not ask for a more understanding and attentive supervisor. Thank you for helping me acknowledge the times when I needed to reduce my workload and for being understanding and supportive during the difficult times throughout the last few months. Thank you for granting me the opportunity to work under your supervision and for making this thesis a reality, I have learnt so many valuable skills throughout the year and will always appreciate this experience.

I would also like to thank my amazing friends, partner, and Mum. I am forever grateful for your unconditional love, support, guidance, and reassurance over the last year. Thank you for always being there for me whenever I needed you, and for cheering me up whenever I needed help taking my mind off things. You have been my constant pillars of support and have continuously encouraged me to succeed and persevere throughout the challenging times, and for this I am extremely grateful. 


\section{Table of Contents}

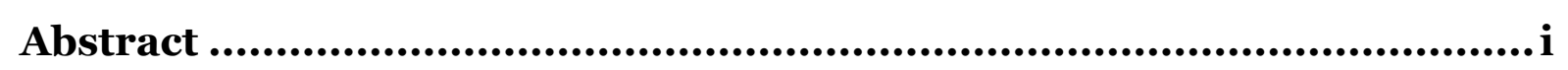

Acknowledgements ..................................................................................ii

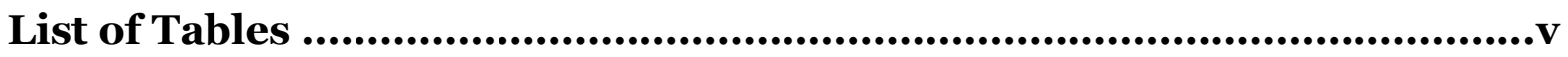

List of Figures ............................................................................... vii

The Nature and Extent of Lone-Actor Terrorism and Rampage Shootings .................. 3

What are Rampage Shootings?.....................................................................................

What is Lone-Actor Terrorism?

Frequency of Rampage Shooting Incidents ........................................................

Frequency of Lone-Actor Terrorism Incidents .................................................

Characteristics of Rampage Shooting and Lone-Actor Terrorism Incidents................11

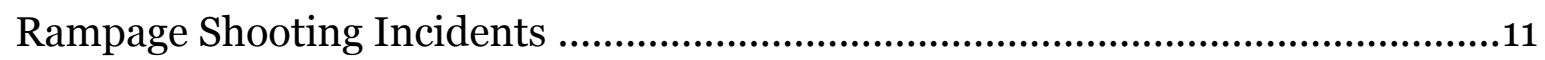

Lone-Actor Terrorism Incidents ................................................................ 15

Comparison of Rampage Shooting and Lone-Actor Terrorism Incidents ................... 19

Theoretical Explanations of Rampage Shooting and Lone-Actor Terrorism Incidents

.

Theoretical Explanations of Rampage Shootings …............................................26

Theoretical Explanations of Lone-Actor Terrorism..................................................33

Present Study .................................................................................................

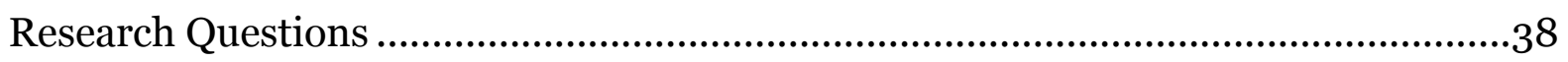

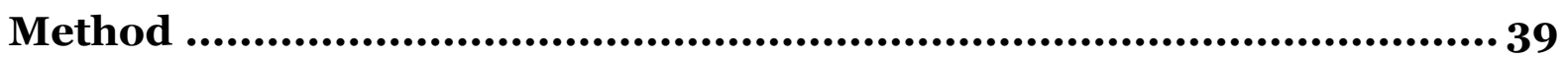

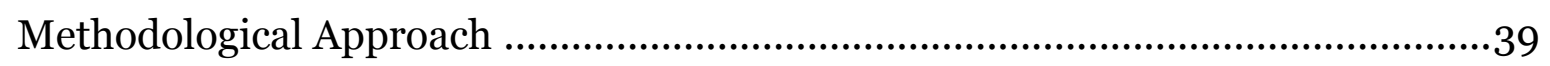

Inclusion and Exclusion Criteria .................................................................... 40

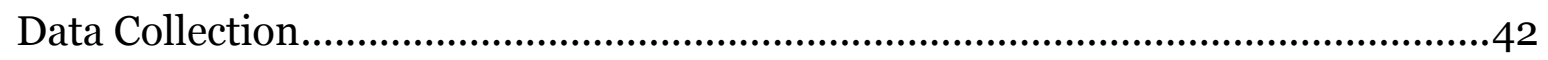

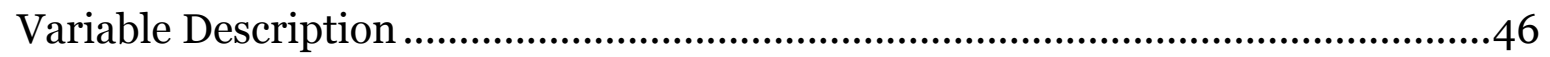

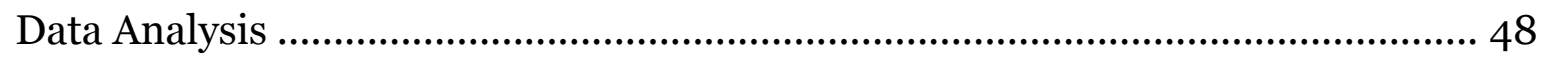

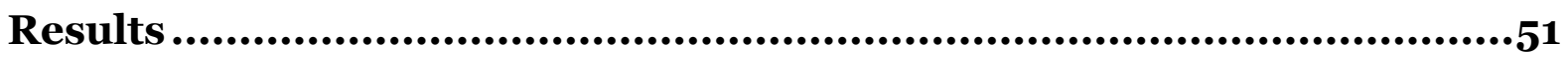

Event Characteristics ..................................................................................... 51

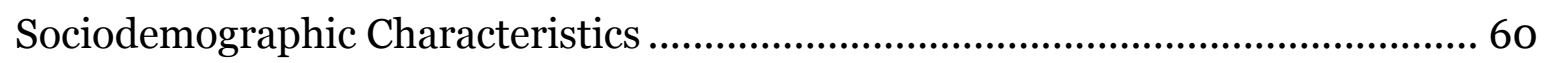

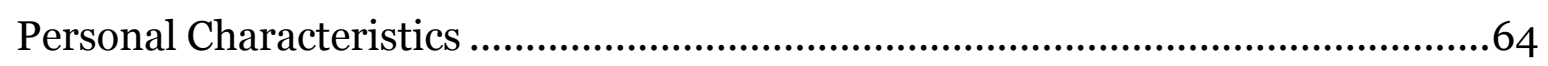

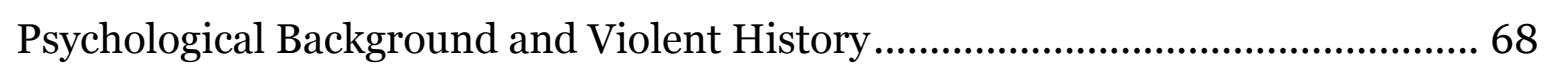




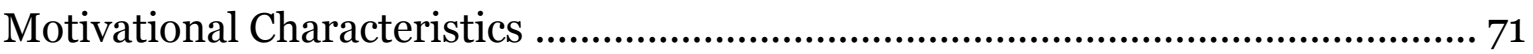

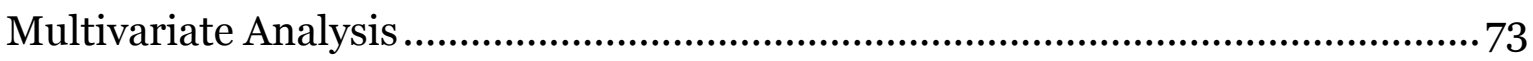

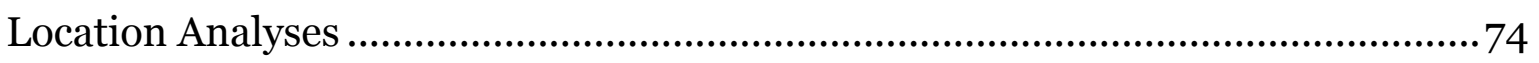

Location analyses for mental health status................................................... 81

Discussion ...........................................................................................90

Lone-Actor Terrorism versus Rampage Shootings: Event Characteristics............... 90

Significant Differences Between Groups......................................................... 90

Non-Significant Differences Between Groups .................................................. 95

Sociodemographic Characteristics of Lone Actor versus Rampage Shooting

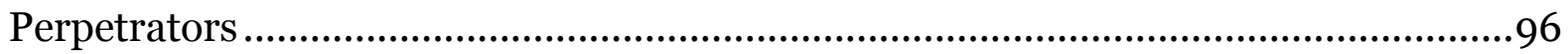

Significant Differences Between Groups......................................................96

Non-Significant Differences Between Groups .................................................... 98

Personal Characteristics of Lone Actor versus Rampage Shooting Perpetrators .......99

Significant Differences Between Groups........................................................99

Non-Significant Differences Between Groups ..............................................103

Psychological Characteristics of Lone Actor versus Rampage Shooting Perpetrators .104

Significant Differences Between Groups........................................................104

Non-Significant Differences Between Groups ................................................ 105

Motivational Characteristics of Lone Actor versus Rampage Shooting Perpetrators .108

Significant Differences Between Groups......................................................108

Non-Significant Differences Between Groups ................................................... 110

Summary of Key Findings ...............................................................................112

The Role of Location in Lone Actor and Rampage Shooting Events .......................115

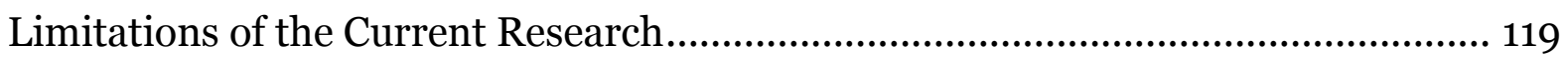

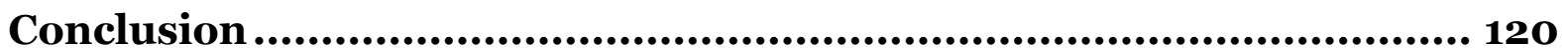

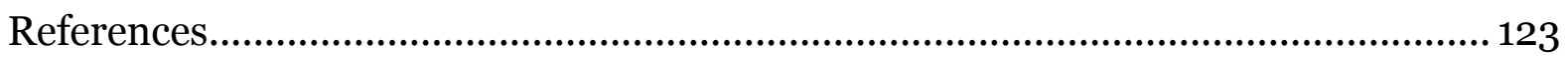

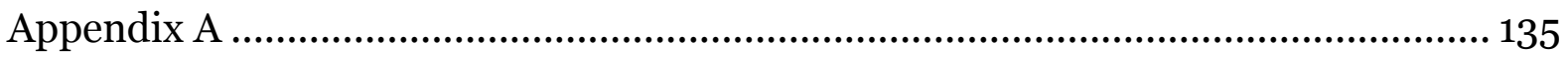

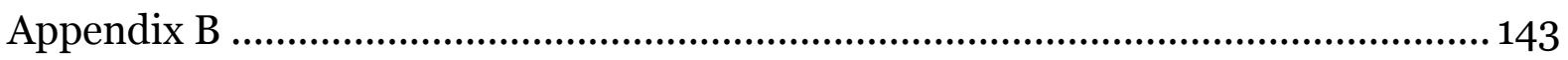

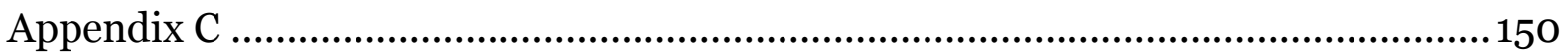




\section{List of Tables}

Table 1. List of the Worst Rampage Shootings Within the U.S. and Europe Since 1999

Table 2. List of the Worst Lone-Actor Terrorism Events Within the U.S. and Europe Since 2009.

Table 3. Summary of the Key Features of the Main Studies on Rampage Shooting Events

Table 4. Summary of the Key Features of the Main Studies on Lone-Actor Terrorism

Events 16

Table 5. Summary of Previous Studies With Comparisons Between Rampage

Shootings, Lone-Actor Terrorism, and Other Types of Homicide Events.... .23

Table 6. Databases Used for Lone-Actor Terrorism and Rampage Shooting Data ....39

Table 7. Event Characteristics of Lone-Actor Terrorism Events Versus Rampage Shooting Events 52

Table 8. Significant Variables in Bivariate Analyses Comparing Rampage Shootings and Lone-Actor Terrorism 56

Table 9. Sociodemographic Characteristics of Lone-Actor Terrorism Versus Rampage

Shooting Perpetrators 61

Table 10. Personal Characteristics of Lone-Actor Terrorism Versus Rampage

Shooting Perpetrators.

Table 11. Psychological Background and Violent History of Lone-Actor Terrorism

Versus Rampage Shooting Perpetrators. 69

Table 12. Motivational Patterns of Lone-Actor Terrorism Versus Rampage Shooting Perpetrators.

Table 13. Logistic Regression Analysis Predicting Key Psychological Aspects of

Rampage Shooting Versus Lone-Actor Terrorism Perpetrators. .74

Table 14. Event Characteristics of Lone-Actor Terrorism and Rampage Shooting

Events in North America Versus Europe. 77

Table 15. Psychological Background and Violent History of Lone-Actor Terrorism and Rampage Shooting Perpetrators In North America Versus Europe .82

Table 16. Motivational Patterns of Lone-Actor Terrorism and Rampage Shooting Perpetrators in North America Versus Europe 
Table 17. Sociodemographic Characteristics of Lone-Actor Terrorism and Rampage Shooting Perpetrators in North America Versus Europe........................................87

Table 18. Personal Characteristics of Lone-Actor Terrorism and Rampage Shooting Perpetrators in North America Versus Europe ................................................ 88 Table 19. Similarities and Differences Between Lone-Actor Terrorism and Rampage Shooting Groups 113 


\section{List of Figures}

Figure 1. Case selection flowchart 45

Figure 2. Average number of fatalities for lone actor and rampage shooting incidents across the years (2010 to 2018) .57

Figure 3. Average number of casualties for lone actor and rampage shooting incidents across the years (2010 to 2018) .58

Figure 4. Lone actor and rampage shooting incidents across the years (2010 to 2018) 60

Figure 5. The number of lone actor terrorism and rampage shooting perpetrators who fall under each age group

Figure 6. Total number of lone actor and rampage shooting incidents in North America versus Europe between 2010 to 2018

Figure 7. Average number of fatalities for North American versus European incidents across the years (2010 to 2018) .76

Figure 8. Average number of casualties for North American versus European incidents across the years (2010 to 2018) 80 
Nikolas Cruz was a 19 year-old student living in Parkland, Florida. Cruz suffered from a traumatic childhood, and had a long history of mental health issues and behavioural problems. During his teenage years Cruz experienced extreme social isolation which exacerbated his depression, and he experienced various issues at school. On the $14^{\text {th }}$ of February 2018, Cruz opened fire on students at his previous school, Marjory Stoneman Douglas High School, killing 17 individuals and injuring a further 17. A combination of precipitating events occurred within Cruz's life in the months leading up to the shooting (i.e. his mother's death, a breakup with his girlfriend, and worsening mental health issues). Cruz told the police that he had transitioned from wanting to kill himself to wanting to kill others, and claimed that he heard 'evil voices' inside his head which told him to harm people the morning of the attack. Cruz's motivations for the attack are elusive, however he resembles other rampage shooting perpetrators in terms of his mental health issues, lack of meaningful social connections, and extreme social isolation (Dearen, Breed, \& Lush, 2018; Follman, Aronsen, \& Pan, 2019).

Anders Behring Breivik was 32 years old and lived in Oslo, Norway. On the $22^{\text {nd }}$ of July 2011, Breivik detonated an explosive device outside the Oslo office of the Prime Minister of Norway, killing eight and injuring hundreds. Breivik then boarded a ferry to Utoya island where a summer camp organized by the Norwegian Labour Party was taking place. Upon arrival, he shot and killed 69 camp attendees and wounded many others, making it the worst mass killing in Norway's history. Breivik stated that his main motive was his militant ideology and resentment of Muslims and left-wing liberals. Breivik displayed antisocial personality traits such as bizarre and grandiose thoughts and a lack of empathy, and was socially isolated. He appeared to suffer from paranoia, as he claimed that his actions were in self-defence as his victims were conspiring to deconstruct Norway's cultural identity. Similar to many lone-actor terrorists, Breivik dedicated a high-level of planning to his attacks, and the sophistication and deadly nature of the attacks he committed demonstrates how loneactor terrorists represent a serious security threat (Berwick, 2011; Wold, 2012). 
The above case studies illustrate two relatively rare events that represent violence in its most extreme form. Rampage shootings and lone-actor terrorism events both attract intense interest and concern from scholars, the media, and the public (Duwe, 2007; Osbourne \& Capellan, 2016; Taylor, 2018). These events both involve the killing (or attempted killing) of multiple individuals in semi-public or public places, and are typically carried out by lone perpetrators. These events also involve the infliction of significant harm to the victims, and generate substantial fear among members of the public. The occurrence of these events is a world-wide issue, and there has been an extensive amount of research conducted within the literature on these types of events (Fox, Brook, Stratton, \& Hanlon, 2016; Hilal, Densley, Li, \& Ma, 2014; Meloy, Hempel, Mohandie, Shiva, \& Gray, 2001; Taylor, 2018). A wide range of factors and motivations can drive individuals to perpetrate these offences, and researchers assert that these events result from highly complex interactions between biological, psychological, and sociological factors (Allely, Minnis, Thompson, Wilson, \& Gillberg, 2014; Fox \& DeLateur, 2014; Osborne \& Capellan, 2016; Taylor, 2018). However, the motivations behind these events can be obscure and difficult to comprehend. Two distinct academic literatures have emerged relating to these events: rampage shootings, which are classified as a type of mass murder, and lone-actor terrorism events, which are classified as a type of terrorism. Although these individuals may be similar in terms of their behaviours, the key distinction between these groups is the ideological element to the event: lone-actor terrorists are often driven by ideological motivations, whereas rampage shooters are driven by non-ideological motivations (Osbourne \& Capellan, 2016).

Although both rampage shooting and lone-actor terrorism events are statistically rare, the magnitude of these events and the mystery which surrounds them has resulted in a substantial amount of media attention. It is crucial to examine what is known about rampage shooting and lone-actor terrorism events, as research conducted into these areas can lead to important implications for prevention (Duwe, 2007; Osbourne \& Capellan, 2016; Taylor, 2018). The current study aims to contribute to the literature by offering a quantitative examination of the similarities and differences between rampage shooting and lone-actor terrorism events. A particular focus of this research is to examine to what extent both types of violent events reflect similar underlying psychological and social processes. 


\section{The Nature and Extent of Lone-Actor Terrorism and Rampage Shootings}

\section{What are Rampage Shootings?}

Rampage shootings are public mass shootings that have been subject to a growing research literature (Langman, 2009; Lankford, 2016a, 2016b; Lankford \& Hakim, 2011; Newman \& Fox, 2009; Rocque \& Duwe, 2018). A common definition used within the literature to describe rampage shootings, and the definition that will be used in the current study, is: "the killing of multiple persons at least partly in public space by a single physically present perpetrator using (potentially) deadly weapons in a single event without any cooling-off period" (Bockler, Seeger, Sitzer, \& Heitmeyer, 2013, p. 4). However, discrepancies exist regarding various parts of the definitions used. Some researchers state that at least four individuals (excluding the perpetrator) must have been killed for an event to constitute a rampage shooting, whereas other studies state that the number of fatalities should be at least three (Duwe, 2007, 2017; Duwe, Kovandzic, \& Moody, 2002). While recognising the limitations of using certain definitions, the current study will include events which resulted in at least three fatalities, excluding the perpetrator. ${ }^{1}$ There is also debate surrounding the period of time which constitutes a brief cooling-off period, however a common time frame used is that the incident must have been carried out in a period of no longer than 24 hours (Duwe, 2007, 2017; Duwe et al., 2002), which is the period that will be employed in the current study.

Definitions of rampage shootings can also include sub-categories, such as workplace or school shootings, and researchers state that an advantage of operationalizing definitions is that this allows for classification based on specific behaviours of the shooters (Newman, 2004). Rampage school shootings are often defined as incidents where the student(s) attend, or formally attended, the school where the attack took place; where a gun was brought to school with the intention of shooting somebody; where the incident was carried out on a school-related 'public

\footnotetext{
${ }^{1}$ The reasoning behind this decision will be discussed in the methods section of this research.
} 
stage;' and which resulted in there being multiple victims (Larkin, 2009; Newman, 2004)..$^{2}$

Although rampage shootings are a rare type of mass murder, emphasising their rarity does not diminish the impact they can have on public safety perceptions (Duwe, 2007, 2017). Rampage shootings are often the most newsworthy types of mass murder as they are highly visible acts of violence, and have a higher body count than homicides in general. Rampage shootings are also more likely to involve victims who are strangers in comparison to other mass murders. As a result of this, they are perceived as a more tragic form of mass murder due to the indiscriminate selection of victims, which conveys to the public that any individual can become a victim of a mass shooting (Duwe, 2017). Due to the large amount of interest, concern, and publicity that occurs in the aftermath of a rampage shooting, attempts are often made to promote a better understanding of these incidents by interpreting shootings in a broader context. The perceived surge in rampage shootings in recent years has resulted in school and workplace policies evolving to better address threats and manage risk, and threats directed at classmates or co-workers are now taken more seriously. Alongside this, these institutions have also adopted security measures in attempt to reduce the incidence and severity of mass shootings, such as implementing procedures for reporting and assessing arising threats (Duwe, 2017).

Rampage shootings are often carried out by individuals with mental health issues, who use firearms to facilitate an attack in a public location (i.e. a workplace or school) (Duwe, 2007). As a result of this, mass shootings have been constructed as a problem which encompasses workplace violence, school shootings, gun control, and mental health, and proposals to reduce mass shootings often focus on these factors (Duwe, 2000, 2017). However, due to the rarity of rampage shootings it can be challenging to accurately predict who will commit a mass public shooting, or develop policies to reduce the incidence and severity of these (Duwe, 2017). Researchers who study violence prevention argue that mass shootings occur too infrequently to allow for statistical modelling and predictability, which are factors at the centre of effective public health interventions (Swanson, 2011).

2 The current study's definition will also include the sub-categories of workplace or school shootings. 


\section{What is Lone-Actor Terrorism?}

Lone-actor terrorism can be defined as: "the threat or use of violence by a single perpetrator (or small cell), not acting out of purely personal or material reasons, with the aim of influencing a wider audience, and who acts without any direct support in the planning, preparation, and execution of the attack, and whose decision to act is not directed by any group or other individuals (although possibly inspired by others)" (Bakker \& de Roy van Zuijdewijn, 2015, Executive Summary, ๆ 4).3 Although this is a common definition used in studies to define this phenomenon, the way in which loneactor terrorism is defined has generated a huge amount of debate within the criminological literature. Researchers often refer to lone-actor terrorists in multiple ways, such as lone-operator terrorists, freelancers, solo terrorists, individual terror cells, and lone wolves 4 (Borum, Fein, \& Vossekuil 2012). Using varying terminologies to reference lone-actor terrorists raises cause for concern as there are key variations between these individuals.

Although the term 'lone actor' suggests the actions of a single individual, definitions of lone-actor terrorists have ranged from individuals operating independently, to individuals acting in dyads, triads, or small cells, and individuals who carry out an attack themselves (i.e. do not have affiliations with far-right groups) but were influenced by a larger group or organisation (Bakker \& de Roy van Zuijdewijn, 2015; Corner, Gill, \& Mason, 2016; Ellis et al., 2016; Spaaij, 2011). Loneactor terrorists are often considered as a subset of terrorists in general, however distinctions between terrorist ideology, personal motivation, or criminal intent can be difficult to draw (Spaaij, 2011). Some researchers believe that because lone-actor terrorists are thought of as individuals who act out of political motivations and use terrorist tactics, that these attacks should only include religiously or politicallymotivated acts which are aimed to influence public decision-making (Bakker \& de Graaf, 2010). In comparison, other researchers choose to include school shootings and other attacks committed by individuals as a result of various grievances, and have proposed that lone-actor terrorism should be understood as part of a wider

3 This definition will also be employed in the current study in order to separate this form of terrorism from group-based terrorism events.

4 Lone wolves also operate individually, however differ from lone actors as they may belong to a group or affiliate with individuals within a group context (Gruenewald, Chermak, \& Freilich, 2013a). 
phenomenon of lone actor grievance-fuelled violence (de Roy van Zuijdewijn \& Bakker, 2016; McCauley, Moskalenko, \& Van Son, 2013).

Assigning motivations to individual terror attacks is a major area of confusion regarding lone-actor terrorism, as this is subjective and open to interpretation (Quillen, 2002). Lone-actor terrorism attacks are rare and difficult to study, and the empirical research base for lone-actor terrorism from a criminological perspective to date is limited. 5 This has resulted in a lack of systematic reviews and statistical analyses of data on lone-actor terrorism events, and a lack of new data being generated (Chermak \& Gruenewald, 2015; Lankford, 2016a, 2016b; Liem, van Buuren, de Roy van Zuijdewijn, Schonberger, \& Bakker, 2018; McCauley et al., 2013; Rocque \& Duwe, 2018; Spaaij, 2010). The lack of empirical literature on lone-actor terrorism hampers distinctions and differentiations other types of homicide research have (for example, the assessment of homicides by subtypes such as distinguishing motives), as subgroups of lone-actor terrorists tend to be too small to be able to statistically assess differences within these groups (Ellis et al., 2016; Liem, van Buuren, de Roy van Zuijdewijn, et al., 2018).

Despite the contested definitions of lone-actor terrorism, a common feature of these attacks is that the perpetrators aim to have a societal impact through their violence, whether this is guided by religious or political motivations, or by personal motivations such as notoriety or revenge (Liem, van Buuren, de Roy van Zuijdewijn, et al., 2018). Alongside this, most studies refer to lone-actor terrorism attacks as incidents where the perpetrator(s) operate individually or as part of a small cell, do not belong to an organized terrorist group or network, and act without direct support or command from outside groups (however, they may be inspired by the ideology of a group) (Gruenewald et al., 2013a, 2013b). ${ }^{6}$

5 This is the outcome of several factors, such as focus being placed on group-based terrorism, difficulties with accessing official or self-reported data, existing debates surrounding definitional ambiguity, and the lack of academic consensus on a definition for lone-actor terrorism.

${ }^{6}$ The details regarding the operational definitions and inclusion criteria for both rampage shooting and lone-actor terrorism events used for the purpose of the current study will be included in the 'Method' section. Note that the key distinction between rampage shooting and lone-actor terrorism groups is that lone-actor terrorism events contain an ideological component or motivation. 


\section{Frequency of Rampage Shooting Incidents}

Approximately $31 \%$ of all global mass shooting incidents occur in America (Lankford, 2016b). Rampage shooting victims account for approximately one percent of all homicide victims in the U.S. each year, and these incidents account for just over $12 \%$ of all mass killings (Duwe, 2007). Long-term trends in the frequency of mass shootings in general occurring in the U.S. indicate that they accelerated rapidly during the late 1900s, as these incidents increased from 13 in the 1970s, to 30 in the 1980 s, and peaked with 37 in the 1990s (Duwe, 2007). From the years 2000 to 2013, Duwe found that there were 53 mass public shootings within America (Duwe, 2017). Duwe (2000) argued that the body count of victims can have a significant impact on the extent to which rampage shootings are reported. Duwe found that on average, the mass public shootings in his study resulted in at least six fatalities and five casualties per event, which he argues is greater in comparison to mass murders in general (Duwe, 2000, 2007) (see Table 1 for a list of the deadliest rampage shootings in recent history). Despite the infrequent nature of rampage shooting events, a common debate within the literature is whether rampage shootings are on the rise, and findings on this issue to date have been mixed. Some researchers have argued that rampage shootings are not on the rise (Duwe, 2007, 2017), however others assert that they are becoming more frequent and claim that shootings targeted at individuals who serve a symbolic purpose appear to have increased (Rocque \& Duwe, 2018). 
Table 1

List of the Worst Rampage Shootings Within the U.S. and Europe Since 1999

\begin{tabular}{|c|c|c|c|c|}
\hline Date & Incident name & $\begin{array}{l}\text { Number of } \\
\text { fatalities }^{\mathrm{a}}\end{array}$ & $\begin{array}{l}\text { Number of } \\
\text { casualties }^{b}\end{array}$ & Name of offender(s) \\
\hline $01 / 10 / 17$ & $\begin{array}{l}\text { Las Vegas Strip } \\
\text { massacre }\end{array}$ & 58 & 546 & Stephen Craig Paddock \\
\hline $16 / 04 / 07$ & $\begin{array}{l}\text { Virginia Tech } \\
\text { shooting }\end{array}$ & 32 & 23 & Seung-Hui Cho \\
\hline $14 / 12 / 12$ & $\begin{array}{l}\text { Sandy Hook } \\
\text { Elementary } \\
\text { massacre }\end{array}$ & 27 & 2 & Adam Lanza \\
\hline $05 / 11 / 17$ & $\begin{array}{l}\text { Texas First Baptist } \\
\text { Church massacre }\end{array}$ & 26 & 20 & Devin Patrick Kelley \\
\hline $14 / 02 / 18$ & $\begin{array}{l}\text { Stoneman Douglas } \\
\text { High School } \\
\text { shooting }\end{array}$ & 17 & 14 & Nikolas J. Cruz \\
\hline 03/04/09 & $\begin{array}{l}\text { Binghamton } \\
\text { shootings }\end{array}$ & 13 & 4 & Jiverly Wong \\
\hline 20/04/99 & $\begin{array}{l}\text { Columbine High } \\
\text { School massacre }\end{array}$ & 13 & 24 & Eric Harris and Dylan Klebold \\
\hline $07 / 11 / 18$ & $\begin{array}{l}\text { Thousand Oaks } \\
\text { shooting }\end{array}$ & 12 & 10 & Ian David Long \\
\hline $16 / 09 / 13$ & $\begin{array}{l}\text { Washington Navy } \\
\text { Yard shooting }\end{array}$ & 12 & 8 & Aaron Alexis \\
\hline $20 / 07 / 12$ & $\begin{array}{l}\text { Aurora theatre } \\
\text { shooting }\end{array}$ & 12 & 70 & James Eagan Holmes \\
\hline $02 / 06 / 10$ & Cumbria shootings & 12 & 11 & Derrick Bird \\
\hline $18 / 05 / 18$ & $\begin{array}{l}\text { Santa Fe High } \\
\text { School shooting }\end{array}$ & 10 & 13 & Dimitrios Pagourtzis \\
\hline
\end{tabular}

Note. These shootings were identified using the current study's database of rampage shootings, and additional web searches were conducted to identify events that occurred before 2010.

aThis number is excluding the perpetrator(s) death.

bDue to the high number of casualties in certain events, casualty numbers can differ between sources.

Duwe (2014) asserts that this debate is a complicated issue and often leads to debates concerning changes in gun laws, heightened security at institutions, and mental health reform. Duwe argues that what needs to be explained is why there were fewer mass public shootings prior to the 1970s than any other time during the past century, and why the rate was lower between 1994 and 2004 than any other time in 
the past 40 years (Duwe, 2007). Duwe suggests that determining why shootings dropped during these time periods can shed light on whether it is possible to reduce this type of violence in the future. The majority of the debate surrounding whether mass shootings can be reduced is centred around gun laws; one side of this debate have argued that tightening these laws would reduce mass shootings, whereas the other side have supported the loosening of gun laws and restrictions. However, Duwe argues that neither approach would likely have much of an impact on the frequency of rampage shootings (Duwe, 2007).

\section{Frequency of Lone-Actor Terrorism Incidents}

Lone-actor terrorism is a rare phenomenon and is less common and deadly than terrorist attacks conducted by groups or organizations. However, in recent years research indicates that the frequency of lone-actor terrorism events appear to be on the rise in Western countries, and these trends suggest an increasing threat (Lindekilde, O'Connor, \& Schuurman, 2017; McCauley et al., 2013; Pantucci, Ellis, \& Chaplais, 2015). Between the years 2000 and 2014, there was a noticeable increase in lone-actor terrorism events across Europe, and recent lethal attacks across Europe have added to these concerns (Ellis et al., 2016). From 2000 to 2016, there were 66 lone-actor terrorism events carried out in Europe alone (Liem, van Buuren, \& Schonberger, 2018).

In the U.S., there have been approximately 124 lone-actor terrorism attacks since 1940 (Hamm \& Spaaij, 2017). Between 1968 and 2010 these attacks in the U.S. and other Western countries increased at a growth of 143\%, and of these attacks, 57\% occurred in the U.S. (Spaaij, 2010, 2011). Researchers have found that since the early 2000s, fewer lone-actor terrorists have expressed public support for extremist organizations, and only $42 \%$ of lone-actor terrorists state that they support specific groups (Hamm \& Spaaij, 2015). Spaaij (2010) conducted a cross-national analysis of the main features of lone-actor terrorism and lone-wolf terrorism between 1968 and 2007, and found that incidents are significantly more prevalent in the U.S. than other countries (see Table 2 for a list of the deadliest acts of lone-actor terrorism in recent history). 
Table 2

List of the Worst Lone-Actor Terrorism Events Within the U.S. and Europe Since 2009

\begin{tabular}{|c|c|c|c|c|}
\hline Date & Incident name & $\begin{array}{l}\text { Number of } \\
\text { fatalities }^{\mathrm{a}}\end{array}$ & $\begin{array}{l}\text { Number of } \\
\text { casualties }^{b}\end{array}$ & Name of offender(s) \\
\hline $14 / 07 / 16$ & Bastille Day attack & 87 & 433 & Mohamed Lahouaiej-Bouhlel \\
\hline $22 / 07 / 11$ & Utoya Island attack & 69 & 60 & Anders Behring Breivik \\
\hline $12 / 06 / 16$ & $\begin{array}{l}\text { Orlando nightclub } \\
\text { massacre }\end{array}$ & 50 & 53 & Omar Mateen \\
\hline $22 / 05 / 17$ & $\begin{array}{l}\text { Manchester Arena } \\
\text { bombing }\end{array}$ & 21 & 800 & Salman Abedi \\
\hline $02 / 12 / 15$ & $\begin{array}{l}\text { San Bernardino } \\
\text { shooting }\end{array}$ & 16 & 22 & $\begin{array}{l}\text { Syed Rizwan Farook and } \\
\text { Tashfeen Malik }\end{array}$ \\
\hline $17 / 08 / 17$ & Barcelona attack & 14 & 131 & Younes Abouyaaqoub \\
\hline $03 / 05 / 12$ & $\begin{array}{l}\text { Makhachkala } \\
\text { checkpoint bombing }\end{array}$ & 13 & 50 & Muslimat Aliyev \\
\hline 05/11/09 & Fort Hood shooting & 13 & 33 & Nidal Hasan \\
\hline $19 / 12 / 16$ & $\begin{array}{l}\text { Breitscheidplatz } \\
\text { Christmas Market } \\
\text { shooting }\end{array}$ & 12 & 48 & Anis Amri \\
\hline $27 / 10 / 18$ & $\begin{array}{l}\text { Pittsburgh synagogue } \\
\text { shooting }\end{array}$ & 11 & 7 & Robert Gregory Bowers \\
\hline 07/01/15 & $\begin{array}{l}\text { Charlie Hebdo } \\
\text { shooting }\end{array}$ & 10 & 12 & $\begin{array}{l}\text { Cherif Kouachi and Said } \\
\text { Kouachi }\end{array}$ \\
\hline 03/06/17 & London bridge attack & 9 & 48 & $\begin{array}{l}\text { Khuram Shazad, Rachid } \\
\text { Redouane, and Youssef Zaghba }\end{array}$ \\
\hline
\end{tabular}

Note. These shootings were identified using the current study's database of lone-actor terrorism events, and additional web searches were conducted to identify events that occurred before 2010. aThis number is excluding the perpetrator(s) death.

bDue to the high number of casualties in certain events, casualty numbers can differ between sources. 


\section{Characteristics of Rampage Shooting and Lone-Actor Terrorism Incidents}

The following section describes event and offender characteristics of rampage shooting and lone-actor terrorism incidents found in previous studies. Previous research regarding rampage shooting and lone-actor terrorism events often vary in terms of findings. It is important to note that the diversity of findings can occur as a result of the nature of the research data used in individual studies, and the different definitions, methodologies, inclusion/exclusion criteria, and datasets that are employed in each study.7

\section{Rampage Shooting Incidents}

Event characteristics. Previous research indicates that the majority of rampage shooters use firearms as their weapon of choice (Kalish \& Kimmel, 2010; Meloy et al., 2001). In terms of fatalities, Meloy et al. (2004) found that adult offenders killed more individuals on average in comparison to adolescent offenders. In his study on fame-seeking rampage shooters in the U.S., ${ }^{8}$ Lankford (2016a) found that these individuals tend to kill and injure significantly more victims (on average they killed seven individuals and injured eight), in comparison to other shooting offenders who on average kill three individuals and injure four (Lankford, 2015, 2016a) (see Table 3 for a summary of the main studies on rampage shootings events and perpetrators). Strikingly, 44\% of adolescents discussed the attack with at least one person before the event, and 58\% made threatening statements regarding the murder to third parties (Meloy et al., 2001). Researchers found that direct threats were not often made to the targets of an attack (Meloy et al., 2004), however in 37\% of incidents the perpetrators talked to the victims prior to the attack as a way of demonstrating power and control (Meloy et al., 2001). In comparison to this, Newman and Fox (2009) found that threats were present in the majority of shooting incidents in their study. Researchers found that the most common rampage shooting attack sites were open commercial locations, followed by military settings, schools, and public streets (Lankford, 2015; 2016b).

7 To provide a sense of the methods used in previous studies, a summary of the main studies mentioned in the following section are listed in Tables 3 and 4.

${ }^{8}$ Lankford defines fame-seeking shooters as individuals who seek fame and glory through committing an attack. 
Mass shooters in the U.S. attacked significantly more often at offices, factories, warehouses, schools, and open commercial sites; in comparison, shooters in other countries attacked more often in military settings and other locations (Lankford, 2016b).

Table 3

Summary of the Key Features of the Main Studies on Rampage Shooting Events

\begin{tabular}{|c|c|c|c|c|}
\hline $\begin{array}{l}\text { Author(s) } \\
\text { and year }\end{array}$ & Scope of research & Inclusion criteria & Data sources & $\begin{array}{l}\text { Number of } \\
\text { incidents } \\
\text { and/or } \\
\text { offenders }\end{array}$ \\
\hline $\begin{array}{l}\text { Meloy, } \\
\text { Hempel, } \\
\text { Mohandie, } \\
\text { Shiva, and } \\
\text { Gray (2001) }\end{array}$ & $\begin{array}{l}\text { Comprehensive } \\
\text { examination of } \\
\text { offence and } \\
\text { offender } \\
\text { characteristics of } \\
\text { adolescent mass } \\
\text { murderers in } \\
\text { North America } \\
\text { between 1958- } \\
1999\end{array}$ & $\begin{array}{l}\text { Adolescent mass } \\
\text { murderers (19 years or } \\
\text { under) who acted alone } \\
\text { or in pairs, and } \\
\text { intentionally killed } \\
\text { three or more victims } \\
\text { in one event. } \\
\text { Individuals must have } \\
\text { used a firearm, cutting } \\
\text { instrument, or blunt } \\
\text { object, with or without } \\
\text { other weapons }\end{array}$ & $\begin{array}{l}\text { Data was collected } \\
\text { from various } \\
\text { computer databases, } \\
\text { as well as primary } \\
\text { and secondary data } \\
\text { sources }\end{array}$ & $\begin{array}{l}27 \text { mass } \\
\text { murders in } \\
\text { total }\end{array}$ \\
\hline $\begin{array}{l}\text { Meloy, } \\
\text { Hempel, } \\
\text { Gray, } \\
\text { Mohandie, } \\
\text { Shiva, and } \\
\text { Richards } \\
\text { (2004) }\end{array}$ & $\begin{array}{l}\text { Comparative } \\
\text { analysis of offence } \\
\text { and offender } \\
\text { characteristics of } \\
\text { adolescent and } \\
\text { adult mass } \\
\text { murderers in } \\
\text { North America } \\
\text { between 1949- } \\
1999\end{array}$ & $\begin{array}{l}\text { All perpetrators must } \\
\text { have intentionally } \\
\text { killed three or more } \\
\text { victims in a continuous } \\
\text { event. Adolescent mass } \\
\text { murderers must have } \\
\text { been } 19 \text { years or under, } \\
\text { and adult mass } \\
\text { murderers must have } \\
\text { been at least } 18 \text { years } \\
\text { old, and must have } \\
\text { used a firearm with or } \\
\text { without another } \\
\text { weapon }\end{array}$ & $\begin{array}{l}\text { Data was collected } \\
\text { from various } \\
\text { psychiatric, medical, } \\
\text { social, and criminal } \\
\text { databases. } \\
\text { Supplementary } \\
\text { materials were also } \\
\text { used, including } \\
\text { academic books, } \\
\text { scientific articles, } \\
\text { and newspaper } \\
\text { articles }\end{array}$ & $\begin{array}{l}64 \text { mass } \\
\text { murderers in } \\
\text { total }\end{array}$ \\
\hline $\begin{array}{l}\text { Taylor } \\
(2016)\end{array}$ & $\begin{array}{l}\text { Comprehensive } \\
\text { study of mass } \\
\text { murder offenders } \\
\text { and motivations } \\
\text { in the U.S. } \\
\text { between 2007- } \\
2011\end{array}$ & $\begin{array}{l}\text { Mass murder offences } \\
\text { which resulted in at } \\
\text { least four fatalities, and } \\
\text { were motivated by } \\
\text { emotional triggers, } \\
\text { relationship and/or } \\
\text { domestic issues, } \\
\text { financial issues, mental } \\
\text { health issues, criminal } \\
\text { gain, and political } \\
\text { motivations }\end{array}$ & $\begin{array}{l}\text { Secondary data was } \\
\text { used from the FBI's } \\
\text { Supplementary } \\
\text { Homicide Reports } \\
\text { (SHRs), and } \\
\text { incidents were also } \\
\text { identified from the } \\
\text { USA Today. } \\
\text { Supplementary } \\
\text { materials used } \\
\text { included media } \\
\text { reports and } \\
\text { newspaper articles }\end{array}$ & $\begin{array}{l}152 \text { mass } \\
\text { murders in } \\
\text { total }\end{array}$ \\
\hline
\end{tabular}


Table 3 (continued)

\begin{tabular}{|c|c|c|c|c|}
\hline $\begin{array}{l}\text { Lankford } \\
\text { (2016b) }\end{array}$ & $\begin{array}{l}\text { Comparative } \\
\text { analysis of mass } \\
\text { shooters in the } \\
\text { U.S. and other } \\
\text { countries between } \\
\text { 1966-2012 }\end{array}$ & $\begin{array}{l}\text { Mass shooters who } \\
\text { attacked anywhere } \\
\text { worldwide, and killed } \\
\text { at least four victims. } \\
\text { Incidents must have } \\
\text { involved a firearm, be } \\
\text { aimed toward } \\
\text { strangers, and not } \\
\text { solely occur in } \\
\text { domestic settings. } \\
\text { Incidents must not be } \\
\text { primarily gang-related, } \\
\text { drive-by shootings, or } \\
\text { hostage-related } \\
\text { incidents }\end{array}$ & $\begin{array}{l}\text { The primary data } \\
\text { source used was the } \\
\text { NYPD's } 2012 \text { Active } \\
\text { Shooter Report, and } \\
\text { this was combined } \\
\text { with other open } \\
\text { source materials such } \\
\text { as previous } \\
\text { scholarship, media, } \\
\text { and government } \\
\text { reports }\end{array}$ & $\begin{array}{l}292 \text { mass } \\
\text { shooters in } \\
\text { total }\end{array}$ \\
\hline $\begin{array}{l}\text { Osbourne } \\
\text { and } \\
\text { Capellan } \\
\text { (2016) }\end{array}$ & $\begin{array}{l}\text { Examination of } \\
\text { active shooter } \\
\text { events in the U.S. } \\
\text { between 2002- } \\
\text { 2012, through } \\
\text { rational choice } \\
\text { perspective \& } \\
\text { crime script } \\
\text { analysis }\end{array}$ & $\begin{array}{l}\text { Active shooter events } \\
\text { where an individual (or } \\
\text { multiple individuals) } \\
\text { actively engaged in } \\
\text { killing people in a } \\
\text { confined and populated } \\
\text { area. Firearms must } \\
\text { have been the primary } \\
\text { weapon used }\end{array}$ & $\begin{array}{l}\text { Incidents were } \\
\text { identified using the } \\
\text { NYPD's } 2012 \text { Active } \\
\text { Shooter Report. } \\
\text { Information was } \\
\text { supplemented with } \\
\text { open-source } \\
\text { materials and online } \\
\text { searches }\end{array}$ & $\begin{array}{l}149 \text { events in } \\
\text { total }\end{array}$ \\
\hline
\end{tabular}

Meloy et al. (2001) found that the most common outcome of an attack was the perpetrator being captured, followed by the perpetrator committing suicide, and the perpetrator being killed. Duwe (2007) states that the rate of suicidal behaviour for rampage shooters is more than 10 times higher than homicide offenders in general, and states that many shooters are tormented individuals who want to end their lives of misery and pain as well as seek revenge on individuals who they believe were to blame for their misery. Lankford (2015) found that more offenders died when attacking at factory, warehouse, or open commercial locations, and more offenders survived when they attacked at office buildings, schools, and other location types (Lankford, 2015). Meloy et al. (2004) found that $59 \%$ of adolescents and $90 \%$ of adults had a precipitating or triggering event occur prior to the incident. Researchers found that $81 \%$ of adolescent shooters knew their victims, compared to only $50 \%$ of adult shooters (Meloy et al., 2004). Similarly, Meloy et al. (2001) found that offenders within the U.S. knew their victims in $81 \%$ of incidents.

Offender characteristics. Previous research indicates that rampage shooting offenders are almost exclusively male, predominantly White, and single 
(Duwe, 2017; Lankford, 2015; McCauley et al., 2013; Meloy et al., 2001; Rocque \& Duwe, 2018; Taylor, 2016). Research indicates that the average age for rampage shooters is 34 years, however this differs between studies (Duwe, 2017; Lankford, 2016a, 2016b; Meloy et al., 2004; Osbourne \& Capellan, 2016). Contrary to public opinion, mass shootings rarely involve a sudden 'explosion' of rage, and instead are usually preceded by a large amount of deliberation (Duwe, 2017; Fox and DeLateur, 2014). Hostile (i.e. expressive, impulsive, or reactive aggression) and instrumental aggression (i.e. cold-blooded, pre-meditated, or proactive aggression) can be used to distinguish between different types of violent offenders (Bushman \& Anderson, 2001; Durrant, 2018; Meloy, 2006). Researchers assert that hostile aggression often occurs in response to an immediate threat, is characterised by strong emotional arousal, and is directed at harming or exacting revenge on the victim. In comparison to this, instrumental aggression involves using aggression to obtain a particular goal, and this is usually planned and lacks high levels of emotional arousal. However, these forms of aggression can exist on a continuum, and both forms can be present in any situation (Bushman \& Anderson, 2001; Meloy, 2006).

Researchers state that rampage shooting perpetrators are often raised in oppressive social environments, have experienced troubled childhoods, and suffer from personal crises (Meloy, 2001). Duwe (2017) found that 67\% of shooters experience a traumatic event (often the loss of a job or relationship) that ultimately precipitates the violence. Newman and Fox (2009) found that the majority of shootings provided evidence that indicated the shooters' marginalization (i.e. they were 'loners,' bullied, failed to meet 'masculinity criteria,' or felt marginalized). Rampage shooters often share characteristics such as social isolation, blame externalisation, substance abuse, resentment, interest in weaponry and war, and a fascination with violence (Fox \& DeLateur, 2014; Meloy et al., 2001, 2004; Newman \& Fox, 2009). Researchers have found that these individuals also tend to exhibit high rates of mental illness, in particular paranoid schizophrenia, delusional disorder, and depression (Declercq \& Audenaert, 2011; Fox et al., 2016; Lankford \& Hakim, 2011; Meloy et al., 2004). In his examination of mass public shootings between 1915 and 2013 , Duwe found that just over $60 \%$ of shooters were either diagnosed with a mental disorder or displayed signs/symptoms of mental illnesses prior to the attack, which is three times higher than that of the general population (Duwe, 2017; Substance Abuse 
and Mental Health Services Administration, 2013). Alongside this, Duwe argues that the rate of untreated mental illness indicates a significant problem as nearly two thirds of individuals did not receive the care they needed (Duwe, 2017).

Previous research asserts that violent acts can occur as a result of instrumental or predatory motives. Researchers found that mass shootings are often acts of predatory violence, shown by threats, violent fantasies, weapons, and the absence of emotions (Meloy et al., 2001). Researchers have asserted that motives for mass shootings in general can be organised around five main themes: revenge (i.e. individuals who seek payback for failures they experience in their personal lives); power (i.e. individuals who are motivated by attempting to hold power over society through their attack); loyalty (i.e. individuals who murder their loved ones due to a misguided sense of responsibility); terror (i.e. individuals who commit an attack to send a strong message of terror to individuals in positions of power); and profit (i.e. individuals who commit murder as a means to an end to gain financial rewards, such as committing murder following a robbery to eliminate witnesses) ${ }^{9}$ (Declercq \& Audenaert, 2011; Fox et al., 2016; Lankford \& Hakim, 2011; Meloy et al., 2004; Osbourne \& Capellan, 2016; Rocque \& Duwe, 2018). Researchers argue that of these motivations, revenge is the most common, as mass shooting perpetrators often see themselves as victims of injustice and seek revenge against individuals they hold responsible for the unfair treatment they have received (Bowers, Holmes, \& Rhom, 2010).

\section{Lone-Actor Terrorism Incidents}

Event characteristics. Previous literature on lone-actor terrorism has found that these incidents are often carried out in public places, and involve firearms or explosives (firearms tend to be more common in the U.S., whereas other countries use hijacking as their preferred method) (Gruenewald \& Pridemore, 2012; Liem, van Buuren, de Roy van Zuijdewijn, et al., 2018; Spaaij, 2010). Researchers have found that lone-actor terrorists often target civilians, military, or religious targets, and tend to victimize individuals they have no prior relationships with (Capellan, 2015; Gruenewald et al., 2013a, 2013b; Liem, van Buuren, de Roy van Zuijdewijn, et al.

9 Themes such as loyalty, terror, and profit will not be as relevant in the current study due to the nature of the research and the inclusion criteria for cases. 
(2018). Capellan (2015) found that lone-actor terrorists were more likely to target, injure, and kill multiple victims in comparison to 'common' homicide offenders, and suggest that certain victim and situational aspects are unique to acts of lone-actor terrorism (see Table 4 for a summary of the main studies on lone-actor terrorism).

Table 4

Summary of the Key Features of the Main Studies on Lone-Actor Terrorism Events

\begin{tabular}{|c|c|c|c|c|}
\hline $\begin{array}{l}\text { Author(s) and } \\
\text { Year }\end{array}$ & $\begin{array}{l}\text { Scope of } \\
\text { Research }\end{array}$ & Inclusion Criteria & Data sources & $\begin{array}{l}\text { Number of } \\
\text { Incidents }\end{array}$ \\
\hline $\begin{array}{l}\text { Meloy and Gill } \\
\text { (2016) }\end{array}$ & $\begin{array}{l}\text { Examination of } \\
\text { lone-actor } \\
\text { terrorists within } \\
\text { the U.S. and } \\
\text { Europe between } \\
\text { 1990-2014 }\end{array}$ & $\begin{array}{l}\text { Lone actors who } \\
\text { engaged in (or actively } \\
\text { planned to engage in) } \\
\text { acts of terrorism, and } \\
\text { were either convicted } \\
\text { or died as a result of the } \\
\text { event }\end{array}$ & $\begin{array}{l}\text { Data was collected } \\
\text { from academic } \\
\text { literature, } \\
\text { LexisNexis, the } \\
\text { Global Terrorism } \\
\text { Database (GTD), and } \\
\text { convicted offenders } \\
\text { lists }\end{array}$ & $\begin{array}{l}111 \text { lone } \\
\text { actors in } \\
\text { total }\end{array}$ \\
\hline $\begin{array}{l}\text { Gill, Horgan, } \\
\text { and Deckert } \\
\text { (2014) }\end{array}$ & $\begin{array}{l}\text { Examination of } \\
\text { the } \\
\text { characteristics } \\
\text { and motivations } \\
\text { of lone-actor } \\
\text { terrorists in the } \\
\text { U.S. and Europe } \\
\text { post-1990s }\end{array}$ & $\begin{array}{l}\text { Lone actors (or isolated } \\
\text { dyads) who engaged in } \\
\text { (or planned to engage } \\
\text { in) acts of terrorism, } \\
\text { and were either } \\
\text { convicted or died as a } \\
\text { result of the event. } \\
\text { Lone actors must have } \\
\text { carried out the event } \\
\text { independently, without } \\
\text { the support of a group }\end{array}$ & $\begin{array}{l}\text { Data was collected } \\
\text { using the GTD, open } \\
\text { source news reports } \\
\text { and accounts, online } \\
\text { public records, } \\
\text { scholarly articles, } \\
\text { search engines (i.e. } \\
\text { LexisNexis) }\end{array}$ & $\begin{array}{l}119 \text { lone } \\
\text { actors in } \\
\text { total }\end{array}$ \\
\hline $\begin{array}{l}\text { Corner and Gill } \\
\text { (2015) }\end{array}$ & $\begin{array}{l}\text { Comparative } \\
\text { analysis of } \\
\text { mental illness } \\
\text { amongst lone- } \\
\text { actor terrorists } \\
\text { and group-based } \\
\text { terrorists in the } \\
\text { U.S. and Europe } \\
\text { post-1990s }\end{array}$ & $\begin{array}{l}\text { Lone actors (or isolated } \\
\text { dyads) who were } \\
\text { convicted or died as a } \\
\text { result of the offence }\end{array}$ & $\begin{array}{l}\text { Data was collected } \\
\text { using the Mother } \\
\text { Jones database, } \\
\text { LexisNexis, scholarly } \\
\text { and academic } \\
\text { articles, public } \\
\text { records, and } \\
\text { government and } \\
\text { expert witness } \\
\text { reports }\end{array}$ & $\begin{array}{l}119 \text { lone } \\
\text { actors and } \\
119 \text { group- } \\
\text { based } \\
\text { offenders } \\
\text { in total }\end{array}$ \\
\hline
\end{tabular}


Table 4 (continued)

\begin{tabular}{|c|c|c|c|c|}
\hline $\begin{array}{l}\text { Gruenewald, } \\
\text { Chermak, \& } \\
\text { Freilich } \\
\text { (2013b) }\end{array}$ & $\begin{array}{l}\text { Comparison of } \\
\text { far-right } \\
\text { homicide } \\
\text { incidents and } \\
\text { 'loners' with } \\
\text { other types of } \\
\text { violent extremist } \\
\text { offenders within } \\
\text { the U.S. between } \\
\text { 1990-2010 }\end{array}$ & $\begin{array}{l}\text { Ideologically-motivated } \\
\text { homicides committed } \\
\text { by far-right extremists } \\
\text { who carried out the } \\
\text { event to further their } \\
\text { belief system. } \\
\text { Perpetrators must have } \\
\text { carried out the event } \\
\text { without support from a } \\
\text { group. Events must } \\
\text { have resulted in arrest }\end{array}$ & $\begin{array}{l}\text { Data was collected } \\
\text { from the Extremist } \\
\text { Crime Database } \\
\text { (ECDB) }\end{array}$ & $\begin{array}{l}139 \text { events } \\
\text { in total }\end{array}$ \\
\hline
\end{tabular}

Researchers found that lone-actor terrorists were more likely to be killed by police and to participate in suicide mission attacks compared to other far-right offenders (Gruenewald et al., 2013b). Capellan (2015) found that between 30 and 40\% of offenders committed suicide, and arresting a lone-actor terrorist frequently required lethal force in comparison to other shooting offenders (Capellan, 2015). Meloy and Gill (2016) found that 22\% of incidents committed by lone-actor terrorists were original, compared to $14 \%$ which were inspired by 'copy-cat' individuals. Researchers found that $59 \%$ of offenders produced letters and/or public statements prior to committing their attack which labelled their ideologies and motivations. Alongside this, $22 \%$ of offenders provided a directly communicated threat prior to their attack (Meloy \& Gill, 2016).

Offender characteristics. Researchers argue that there is no single profile for lone-actor terrorists, however state that the majority of these events are committed by single and unemployed males in their late 20s to mid 30s (Capellan, 2015; Corner \& Gill, 2015; Gill et al., 2014; Gruenewald \& Pridemore, 2012; Hamm \& Spaaij, 2015; Horgan, Gill, Bouhana, Silver, \& Corner, 2016; Meloy \& Gill, 2016). Researchers found that $25 \%$ of perpetrators' highest educational achievement was attending or completing high school; 33\% attended tertiary education; 22\% had an undergraduate degree; six percent had a Masters; and eight percent had a PhD (Gill et al., 2014). Liem, van Buuren, de Roy van Zuijdewijn, et al. (2018) suggest that relatively high levels of education can partially explain why lone-actor terrorists are often successful in designing, planning, and implementing attacks. Researchers have found that these events involve higher levels of planning, training, and research, and are rarely 
impulsive or sudden (Capellan, 2015; Gill et al., 2014; Gruenewald et al., 2013a; Liem, van Buuren, de Roy van Zuijdewijn, et al., 2018).

Gruenewald and Pridemore (2012) asserted that lone-actor terrorism is primarily a White male phenomenon, where perpetrators are fuelled by the need to reestablish their threatened dominant position within society. Researchers state that a higher number of lone-actor terrorists have previous criminal convictions than members of formal terrorist organizations. Gill et al. (2014) found that $41 \%$ of loneactor terrorists in their study had previous convictions, and 63\% of these had previously been to jail (Gill et al., 2014). Similarly, Gruenewald et al. (2013a) found that $64 \%$ of lone-actor terrorists in their study had prior arrests. Previous research indicates that lone-actor terrorists within the U.S. and Europe are significantly more likely to suffer from a mental illness compared to group actors (Corner \& Gill, 2015; Liem, van Buuren, de Roy van Zuijdewijn, et al., 2018). Researchers also found that lone actors with a mental illness were more likely to have been a victim of prejudice, experienced a history of violence, and expressed a desire to harm others (Corner \& Gill, 2015). Researchers have found that lone actors appear to be more socially isolated than mass murderers in general (Horgan et al., 2016; Liem, van Buuren, de Roy van Zuijdewijn, et al., 2018), and Meloy and Gill (2016) found that 55 percent of lone-actor terrorists in their sample were socially isolated. Researchers suggest that in their social exclusion, lone-actor terrorists feel deprived of values they believe they are entitled to, and form grievances against the governments who are responsible for their discrimination and injustices (Hamm \& Spaaij, 2015). Researchers assert that a critical observation needs to be made when it comes to operationalizing social isolation; in this era, individuals can feel connected to online groups and contacts who may share similar interests and ideologies, whilst being considered by conventional standards as socially isolated (Liem, van Buuren, de Roy van Zuijdewijn, et al., 2018).

The majority of the literature centred around why individuals commit loneactor terrorism attacks focuses on looking internally at individuals, such as the rationality of decision-making and cost-benefit analyses, mental health, or isolation factors (Peddell, Eyre, McManus, \& Bonworth, 2016). Lone-actor terrorists are often motivated by grievances, external pressures, or personal reward, however possessing a grievance was seen as the overriding motivational characteristic (Peddell et al., 2016). Fein and Vossekuil (1999) found that there is a diversity of motivations for lone- 
actor terrorism, such as searching for notoriety, revenge, attention, suicide, and personal fixation. Joosse (2007) found that lone-actor terrorists can be interested in upgrading their violence by adding political motivation, when in reality they were motivated by personal motives, in order to construct a narrative to legitimize their crimes. Organizations, groups, and networks also claim that they were behind violent acts, even when these incidents are only loosely connected to their ideological cause, as this can give groups an image of strength (Liem, van Buuren, de Roy van Zuijdewijn, et al., 2018). Researchers state that the majority of lone-actor terrorists are religiouslyinspired, followed by right-wing extremists, and single-issue terrorists (Ellis et al., 2016; Gill et al., 2014; Gruenewald et al., 2013a; Liem, van Buuren, de Roy van Zuijdewijn, et al., 2018; Meloy \& Gill, 2016). Interestingly, Ellis et al. (2016) found that almost half of lone-actor terrorists in their sample exhibited "leakage," meaning that they gave an indication of either their extreme views, intention to act, or even some attack details in advance. Researchers found that in $82 \%$ of incidents, other individuals were aware of the offenders' grievances, and in $64 \%$ of cases family and friends were aware of their intent to engage in terrorism-related activities (Meloy \& Gill, 2016).

\section{Comparison of Rampage Shooting and Lone-Actor Terrorism Incidents}

Previous research reveals a number of differences between characteristics of lone-actor terrorists and rampage shooters (refer to Table 5 later in this section for a list of these studies). In terms of the specific targets of events, researchers have found that lone-actor terrorism attacks are often aimed toward strangers and civilians, whereas rampage shooters are less likely to attack individuals they do not have a relationship with (Capellan, 2015; Gruenewald, 2011; Gruenewald \& Pridemore, 2012; Liem, 2010, Liem, van Buuren, \& Schonberger, 2018). Targets of lone-actor terrorism incidents also tend to represent either strategic targets (i.e. military objects) or targets chosen to send an ideological message of terror (Fein \& Vossekuil, 1999; Gruenewald \& Pridemore, 2012; Liem, 2010). Researchers have found that the most common outcome of a rampage shooting was the perpetrator's arrest, followed by suicide, and lethal force (Meloy et al., 2001). In comparison to this, lone actors were more likely to be killed by the police, as their arrest required lethal force more often than arresting a rampage shooter (Capellan, 2015; Gruenewald et al., 2013a). Previous research has 
found that rampage shooting and lone-actor terrorism events also differ regarding the weapons used in the commission of the event. The majority of rampage shootings are carried out using firearms (Kalish \& Kimmel, 2010; Meloy et al., 2001), whereas loneactor terrorism events often involve the use of explosives (Gruenewald \& Pridemore, 2012; Liem, van Buuren, de Roy van Zuijdewijn, et al., 2018; Spaaij, 2010). In terms of mental health issues, researchers have found that rampage shooters are more likely to suffer from a mental illness compared to lone actors (Corner \& Gill, 2015; Duwe, 2017; Fox et al., 2016; Lankford \& Hakim, 2011; Liem, van Buuren, \& Schonberger, 2018; Meloy et al., 2004; Rocque \& Duwe, 2018).

Previous research indicates that the main difference between these groups of perpetrators are the motivations behind the event. Researchers argue that lone actors are more likely to be driven by financial rewards and religious or ideological motives, in comparison to rampage shooters (Lankford, 2015; Lankford \& Hakim, 2011; McCauley et al., 2003; Osbourne \& Capellan, 2016; Taylor, 2016). Fein and Vossekuil (1999) state that the high prevalence of suicide among lone-actor terrorists can be understood as a willingness of perpetrators to die in the 'mission' while carrying out their attack, which differs from suicide following other events. Alongside this, loneactor terrorists also tend to believe they will receive rewards for engaging in violence (Lankford, 2015; Lankford \& Hakim, 2011; McCauley et al., 2013; Osborne \& Capellan, 2016; Taylor, 2016). Researchers assert that although the victims of lone-actor terrorism attacks are predominantly strangers, these victims often represent certain groups the perpetrator wants to target through their attack (Lankford \& Hakim, 2011; Liem, van Buuren, \& Schonberger, 2018). Liem, van Buuren, and Schonberger (2018) argue that the labelling of these victims as strangers risks losing sight of underlying lone-actor terrorism motivations that may help us understand how lone actors and rampage shooters truly differ from one another.

Researchers argue that the difference between lone-actor terrorists and rampage shooters can be summarized by instrumental versus expressive motivations (Salfati, 2000). Lone actors are mostly driven by instrumental motivations, where they are focused on achieving a particular goal. Comparably, rampage shooters usually react to anger-inducing events and are motivated by their desire to inflict harm on their victims (Liem, van Buuren, de Roy van Zuijdewijn, et al., 2018; Liem, van Buuren, \& Schonberger, 2018). Researchers assert that the expressive nature of the 
violent events can be observed in the direction of the aggression. While lone actors tend to victimize strangers in public places using firearms or explosives, rampage shooters rarely attack strangers, and tend to commit their offences in less public locations with firearms as their only weapon (Capellan, 2015; Gruenewald, 2011; Gruenewald \& Pridemore, 2012; Horgan et al., 2016). However, researchers also argue that there are exceptions to the expressive versus instrumental dynamic, as lone actors can also be driven by expressive motivations and personal grievances, where they are not motivated to achieve a particular goal. These perpetrators are argued to have more in common with rampage shooters who attack victims they have a grievance toward (i.e. estranged intimate partners, friends, or acquaintances) (Leenars \& Reed, 2016; McCauley et al., 2013).

Although there are numerous differences in the characteristics of rampage shooting perpetrators versus lone-actor terrorists, these groups are also similar in various ways. Lone actors and rampage shooters often share similar profiles in that they are predominantly White males in their 30 sho live dysfunctional lives and are usually single or divorced (Capellan, 2015; Lankford, 2015; Lankford \& Hakim, 2011; McCauley et al., 2013; Osborne \& Capellan, 2016; Taylor, 2016). The troubled childhoods and lives that perpetrators in both groups often suffer from are strongly related to violent criminality, and this is an important link between the two types of offenders. These offenders have usually grown up surrounded by oppressive social environments, and this can increase the likelihood of violence due to feeling trapped, vulnerable, and oppressed. Both groups also tend to suffer from low self-esteem which can lead to engagement in violence and/or suicide, and often experience personal crises prior to the event. Furthermore, both groups tend to show a history of interest in violence and weapons (McCauley et al., 2013), and tend to blame other individuals for their issues, and become motivated by desires for revenge against those who have harmed them. Researchers argue that a significant similarity between the two groups is the rare motive of fame and glory, where individuals respond to their failure to achieve success by seeking fame and glory through extreme acts of violence (Lankford \& Hakim, 2011; Levin \& Madfis, 2009). Researchers argue that these individuals realize that committing large-scale attacks against innocent people will guarantee them fame, and the media attention surrounding their attack provides them with what they wanted (Lankford \& Hakim, 2011). 
Numerous studies have specifically looked at both rampage shootings and loneactor terrorism events (or events similar to these), focusing on similar variables and characteristics as the current study (see Table 5). In examining differences between ideological active shooters ${ }^{10}$ versus non-ideological active shooters ${ }^{11}$ in the U.S., Capellan (2015) argued that the main differences between these groups were the ideological motivations behind the attacks, and found that 70 percent of lone actors were motivated by ideological extremism. Capellan asserts that lone actors often experience no clear precipitating event prior to the incident, and engage in higher levels of planning, training, and research in preparation for the event, compared to their non-ideological counterparts. Capellan also found that ideological lone actors were more likely to attack individuals and locations they have no relationship to. Alongside this, lone actors were more likely to use guns and additional weapons, and kill a higher number of people in their attacks, in comparison to non-ideological perpetrators. In terms of the outcome of incidents, Capellan found that the majority of shooting incidents conclude with the perpetrator either committing suicide or surrendering. Comparably, lone actors were more likely to be killed, and were more likely to encounter lethal resistance than non-ideological perpetrators (Capellan, 2015).

In their comparison of assassins ${ }^{12}$ and school attackers ${ }^{13}$ in the U.S., McCauley et al. (2013) found that prior to their attacks, school attackers tended to experience depression, a personal crisis, and held a perceived grievance. School attackers were also more likely to experience 'unfreezing' in comparison to assassins, which occurred following a change of circumstances and left individuals in a personal crisis. During this process, individuals suffered from disconnection and often experienced radical changes in their beliefs and behaviours. Researchers found that school attackers were also more likely to suffer from mental health issues in comparison to assassins. In

${ }^{10}$ Capellan refers to lone actors as 'loners' who act without ties to any group.

${ }^{11}$ Non-ideological active shooters are similar to rampage shooters in the current study, however Capellan describes these individuals using different terminology. 12 Researchers refer to 'assassins' as individuals who exhibit some form of political and grievance-fuelled motivations in their attack, and these individuals are similar to lone-actor terrorists.

13 Researchers use the terminology 'school attackers' in a similar way to the current study's classification of rampage shooters, and school attackers are seen as those who act out of a sense of grievance. However this study also refers to school attackers as 'lone actors' in the sense that they carry out the event independently. 
terms of motivations, school attackers were more likely to hold a grievance against their targets, when compared to assassins (McCauley et al., 2013).

Table 5

Summary of Previous Studies With Comparisons Between Rampage Shootings, Lone-Actor Terrorism, and Other Types of Homicide Events

\begin{tabular}{|c|c|c|c|}
\hline $\begin{array}{c}\text { Author(s) and } \\
\text { year }\end{array}$ & $\begin{array}{l}\text { Scope of } \\
\text { research }\end{array}$ & Inclusion criteria & Main findings \\
\hline Capellan (2015) & $\begin{array}{l}\text { Examination of } \\
\text { ideological and } \\
\text { non-ideological } \\
\text { active shooters } \\
\text { within the U.S. } \\
\text { between 1970- } \\
2014\end{array}$ & $\begin{array}{l}\text { Active shooters (i.e. } \\
\text { individuals who } \\
\text { actively engaged in } \\
\text { killing or attempting to } \\
\text { kill people) who used a } \\
\text { firearm as the primary } \\
\text { weapon }\end{array}$ & $\begin{array}{l}\text { The main differences between the } \\
\text { groups were motivates behind the } \\
\text { event; ideological shooters were } \\
\text { more likely to be motivated by } \\
\text { ideological extremism. Ideological } \\
\text { shooters rarely experienced } \\
\text { precipitating events prior to the } \\
\text { attack, and engaged in higher levels } \\
\text { of planning and preparation for the } \\
\text { event than non-ideological shooters. } \\
\text { Ideological shooters were also more } \\
\text { likely to kill more individuals and } \\
\text { commit suicide following the event }\end{array}$ \\
\hline $\begin{array}{l}\text { McCauley, } \\
\text { Moskalenko, } \\
\text { and Van Son } \\
\text { (2013) }\end{array}$ & $\begin{array}{l}\text { Comparison of } \\
\text { assassins and } \\
\text { school attackers } \\
\text { in the U.S. }\end{array}$ & $\begin{array}{l}\text { Assassins who } \\
\text { displayed both political } \\
\text { and grievance-fuelled } \\
\text { motivations in their } \\
\text { attacks; and school } \\
\text { attackers who acted out } \\
\text { of a sense of grievance } \\
\text { and carried out the } \\
\text { event independently }\end{array}$ & $\begin{array}{l}\text { School attackers were more likely to } \\
\text { experience depression, a personal } \\
\text { crisis, and hold a grievance prior to } \\
\text { the event, in comparison with } \\
\text { assassins. Alongside this, school } \\
\text { attackers were more likely to suffer } \\
\text { from mental health issues, and to } \\
\text { experience 'unfreezing' compared to } \\
\text { assassins }\end{array}$ \\
\hline $\begin{array}{l}\text { Lankford and } \\
\text { Hakim (2011) }\end{array}$ & $\begin{array}{l}\text { Comparison of } \\
\text { rampage } \\
\text { shooters in the } \\
\text { U.S. and } \\
\text { volunteer suicide } \\
\text { bombers in the } \\
\text { Middle East }\end{array}$ & $\begin{array}{l}\text { Volunteer suicide } \\
\text { bombers in the Middle } \\
\text { East who carry out } \\
\text { terrorist attacks, and } \\
\text { rampage shooters in } \\
\text { the U.S. }\end{array}$ & $\begin{array}{l}\text { Five main differences were found } \\
\text { between the groups. As opposed to } \\
\text { rampage shootings, suicide terrorism } \\
\text { was approved within the } \\
\text { perpetrators communities, and } \\
\text { suicide bombers tended to be } \\
\text { motivated by religious beliefs and }\end{array}$ \\
\hline
\end{tabular}


Table 5 (continued)

\begin{tabular}{|c|c|c|c|}
\hline & & & $\begin{array}{l}\text { financial rewards. Rampage shooters } \\
\text { were more likely to be male than } \\
\text { suicide bombers (these individuals } \\
\text { had a higher number of perpetrators } \\
\text { who were women), and rampage } \\
\text { shooters were more likely to suffer } \\
\text { from mental health issues compared } \\
\text { to suicide bombers }\end{array}$ \\
\hline $\begin{array}{l}\text { Liem, van } \\
\text { Buuren, de Roy } \\
\text { van Zuijdewijn, } \\
\text { Schonberger, } \\
\text { and Bakker } \\
\text { (2018) }\end{array}$ & $\begin{array}{l}\text { Comparison of } \\
\text { lone actor } \\
\text { terrorists versus } \\
\text { common } \\
\text { homicide } \\
\text { offenders in } \\
\text { Europe between } \\
\text { 2000-2016 }\end{array}$ & $\begin{array}{l}\text { Lone-actor terrorists } \\
\text { who acted alone or in a } \\
\text { small cell, who } \\
\text { committed an attack } \\
\text { without direct support } \\
\text { from other groups. The } \\
\text { target must have } \\
\text { extended beyond } \\
\text { immediate victims. } \\
\text { Motivations must not } \\
\text { have been purely } \\
\text { personal or for material } \\
\text { gain. Homicide } \\
\text { offenders who killed at } \\
\text { least one individual in } \\
\text { their attacks were } \\
\text { included }\end{array}$ & $\begin{array}{l}\text { Lone-actor terrorists were more like } \\
\text { to target strangers in comparison to } \\
\text { homicide offenders. Homicide } \\
\text { offenders were more likely to have a } \\
\text { history of violence, and were less } \\
\text { educated when compared to lone- } \\
\text { actor terrorists. The majority of lone- } \\
\text { actor terrorism events were also } \\
\text { religiously-motivated, whereas this } \\
\text { was rarely a motivation in common } \\
\text { homicide events }\end{array}$ \\
\hline $\begin{array}{l}\text { Horgan, Gill, } \\
\text { Bouhana, } \\
\text { Silver, and } \\
\text { Corner (2016) }\end{array}$ & $\begin{array}{l}\text { Comparative } \\
\text { analysis of lone- } \\
\text { actor terrorists } \\
\text { and solo mass } \\
\text { murderers }\end{array}$ & $\begin{array}{l}\text { Lone-actor terrorists } \\
\text { who acted alone or in a } \\
\text { small cell, and solo } \\
\text { mass murderers who } \\
\text { killed at least four } \\
\text { individuals in their } \\
\text { attacks }\end{array}$ & $\begin{array}{l}\text { Mass murder events were more } \\
\text { likely to lack meaningful planning } \\
\text { and preparation in comparison to } \\
\text { lone-actor terrorism events, and } \\
\text { mass murderers were more likely to } \\
\text { experience precipitating events prior } \\
\text { to the attack. Lone-actor terrorists } \\
\text { were also more likely to be motivated } \\
\text { by ideological motives, whereas mass } \\
\text { murderers tended to be motivated by } \\
\text { personal grievances }\end{array}$ \\
\hline
\end{tabular}

In their exploratory study, Lankford and Hakim (2011) compared rampage shooters in the U.S. with volunteer suicide bombers ${ }^{14}$ in the Middle East, and found five main differences between the two groups. Rampage shootings were not approved of within communities, whereas suicide terrorism was seen as a form of 'martyrdom.' Rampage shootings also lacked religious motive, whereas suicide bombers often believed they would receive 'heavenly rewards' for their violence. Alongside this,

14 Researchers also refer to 'volunteer suicide bombers' as 'suicide terrorists' who carry out terrorist attacks. These perpetrators can fall under a sub-group of loneactor terrorism and are similar to lone-actor terrorists in the current study. 
rampage shooters were rarely driven by financial motivations, in comparison to suicide bombers, and researchers argued that this is a reflection of the cultural differences between groups. Rampage shooters were almost exclusively male, in comparison to the higher portion of suicide bombers who were women, and researchers argue that this is to do with the 'interaction effect' between community approval and gender, where males are socialized to be aggressive. Lastly, researchers found that rampage shooters often suffered from mental health issues, whereas these were not common among suicide bombers (Lankford \& Hakim, 2011).

In their empirical analysis of lone-actor terrorists versus 'common' homicide offenders ${ }^{15}$ across Europe, Liem, van Buuren, de Roy van Zuijdewijn, et al. (2018) found that lone actors were more likely to target strangers in their events, in comparison to homicide offenders who predominantly targeted non-random victims. In terms of previous violence, researchers found that homicide offenders were more likely to have a history of violence than lone actors. Lone actors differed from homicide offenders in terms of their motivations behind the event; the majority of lone-actor terrorism events were religiously-motivated, whereas this was a rare motivation for homicide offenders. Researchers found that the two groups did not differ significantly in terms of sociodemographic characteristics such as relationship and employment status, and mental health issues, however found that homicide offenders tended to be less educated than lone actors (Liem, van Buuren, de Roy van Zuijdewijn, et al., 2018).

Horgan et al. (2016) conducted a comparative analysis of lone-actor terrorists and solo mass murderers, ${ }^{16}$ and found that both groups are similar in terms of sociodemographic characteristics, and both engage in largely public acts of violence using similar weapons. Mass murder events were more likely to be impulsive and lack meaningful planning in comparison to lone-actor terrorism events, as mass murder incidents often resulted from precipitating events and emotional conflicts which occurred prior to the attack. Researchers found that the fundamental difference

\footnotetext{
15 Researchers refer to 'common' homicide offenders as offenders who held nonideological motivations, and included events which resulted in at least one fatality. This group of individuals is similar to rampage shooters in the current study, however is inclusive of all types of homicide.

${ }^{16}$ Researchers use the terminology 'solo mass murderers,' however these individuals are similar to rampage shooters in the current study, except their study only includes events with four or more fatalities.
} 
between lone actors and mass murderers were their motivations for carrying out the event, as unlike lone actors, mass murderers lacked ideological motives, and tended to be motivated by personal grievances (Horgan et al., 2016).

Previous research indicates that lone-actor terrorists differ from rampage shooters on key characteristics. However, the extent to which these two groups of offenders are truly different is unknown, and it is possible that these two groups may be reasonably similar in relation to key social and psychological processes (Capellan, 2015). This is where the current study offers a contribution to the existing literature on rampage shootings and lone-actor terrorism events and perpetrators, as discussed at the end of this chapter.

\section{Theoretical Explanations of Rampage Shooting and Lone- Actor Terrorism Incidents}

Numerous theoretical explanations exist within the literature to explain loneactor terrorism and rampage shooting events. To better understand the motivations behind these events, typologies and models have been developed to help explain various research findings on lone-actor terrorism and rampage shooting attacks (Corner \& Gill, 2015; Fox \& Levin, 2015; Klarevas, 2016; Langman, 2009; Lankford, 2015; Peddell et al., 2016). Although theoretical explanations for these events can often place emphasis on individual-level processes and theories rather than social or environmental influences, researchers argue that no variables on their own are sufficient in explaining rampage shootings or lone-actor terrorism (Anisin, 2018; Rocque \& Duwe, 2018).

\section{Theoretical Explanations of Rampage Shootings}

Psychological and sociological explanations. Psychological and sociological explanations often focus on how mental illnesses and environmental stressors can contribute to violent acts (Gill et al., 2014; Langman, 2009; Meloy et al., 2004). Certain psychological explanations assert that mental illness cannot explain lethal actions offenders engage in as the vast majority of mentally-ill individuals are non-violent. However, researchers argue that mental illness can be a critical contributing factor as it can exacerbate personal problems by reducing the offender's ability to cope. As a result of this, the perceptions of individuals struggling with 
schizophrenia, psychopathy, depression, paranoia, or other psychological issues, can easily be distorted (Langman, 2009). This distortion can lead to offenders experiencing exaggerated perceptions of their own persecution and can contribute to their decision to target individuals who symbolize their persecutors (Langman, 2009; Newman \& Fox, 2009). This idea is also illustrated in stress models within the literature, which assert that mentally-ill individuals are more susceptible to negative reactions to stressors (Borum et al., 2012; Peddell et al., 2016; Roberts et al., 2011).

In terms of rampage school shootings, researchers contend that there are three main types of school shooters: psychopathic, psychotic, and traumatized shooters (Langman, 2009; Newman \& Fox, 2009). Psychopathic school shooters are described as individuals who feel no emotional connection to others, are unable to feel guilt or remorse, and enjoy inflicting pain on others. Psychotic shooters are categorised as individuals who experience a 'break' with reality, and suffer from schizophreniaspectrum disorders (including symptoms such as paranoid delusions, delusions of grandeur, and auditory hallucinations). Traumatized shooters are individuals who often come from broken homes characterized by substance abuse and criminality, and these individuals have usually experienced abuse and often suffer from a major stressor which can lead to a violent attack (Langman, 2009).

In his article, Knoll (2010) discusses the psychology of revenge and focuses on revenge fantasies in 'pseudocommando' mass murderers. Knoll states that this type of murderer dedicates a high amount of planning to the event, carries out the attack in public, and often uses multiple weapons during the commission of the event. These perpetrators are often driven by a significant amount of anger and resentment, and often decide to carry out their attack due to beliefs they have been mistreated (Knoll, 2010). Knoll argues that these individuals are socially isolated 'loners' who spend a significant amount of time ruminating over past humiliations, which often evolve into fantasies about exacting violent revenge. Knoll (2010) also states that the expression of revenge may have an evolutionary basis, and can be traced back to a psychophysiological response designed to enhance survival. Upsets to self-esteem or narcissism are responded to as though they were a threat to the individual's survival (McCullough, 2008). Knoll suggests that vengeful rage is a reaction to intolerable feelings of humiliation and powerlessness, and when a potential perpetrator's ego is hurt the individual seeks revenge through violence. Revenge fantasies can generate a 
vicious cycle, as these fantasies provide sustenance to the perpetrator's self-esteem and give them a sense of power and control. The revenge fantasy serves as a defence against shame, loss, and powerlessness, and these feelings lead to the planning of the event in attempt to transfer their pain to others (Knoll, 2010).

The 'copy-cat' or contagion effect has been related to rampage shootings within the criminological literature. This effect can be related to social learning theory in the sense that some incidents involve pairs of individuals who may play a role in convincing one another to engage in a violent act. The contagion effect centres around the social-psychological notion of imitation, ${ }^{17}$ and the attempt by young individuals to imitate high-profile rampage shootings they were inspired by, in which their behaviour has changed to become similar to that of the initiator (Meloy et al., 2001; Wheeler, 1966). This effect is a social phenomenon promoted by how the media report news and the speed in which this travels in modern society. Researchers argue that rampage shootings have been subject to this phenomenon due to the sensationalization of violence, and assert that journalists should be able to convey information whilst remaining unbiased, and should not use emotionally-charged crimes to incite passion (Faria, 2013).

Cumulative strain theory. Strain theories (in particular, cumulative strain theory) are especially relevant to rampage shootings. Cumulative strain theory is an extension of strain theory, and utilizes insights from various criminological theories to propose a five-stage sequential model. This theory asserts that each stage in the model is needed for a shooting to occur, and explains how certain individuals can become involved in perpetrating mass murder (Levin \& Madfis, 2009). This theory refers to the term 'cumulative strain' to place emphasis on how these factors interact and build upon one another in a cumulative way. Researchers state that the first stage (chronic strain) is a persistent theme in the life experiences of rampage shooters (Fox \& Levin, 2015). When strains intensify and persist across a long period of time they become chronic; once this occurs it can lead to anger, aggression, a lack of prosocial support systems, social isolation, and eventual uncontrolled strain. These chronic, repeated,

${ }_{17}$ Although the contagion effect can also be referred to as imitation, imitation differs from this effect in that it is learned via reward and punishment, and is generalized across situations. Imitation can be learned through copying behaviours (Wheeler, 1966). 
and uncontrolled strains can lead to feelings of hostility and suspicion toward others, and these feelings can result in blame externalisation. In extreme cases, this generates a vicious cycle of despair, isolation, and deflection of responsibility (Levin \& Madfis, 2009). Deflection of responsibility often occurs in an effort to reduce the impact of chronic strain and loneliness. However, this is problematic as isolation from conventional relationships often enhances an individual's tendency to engage in blame externalisation, and this further increases isolation. If these events are accompanied by an acute strain or negative event in an individual's life, this can spark a shooting rampage (Fox \& Levin, 2015; Levin \& Madfis, 2009; Madfis \& Arford, 2008; Rocque \& Duwe, 2018). Acute strains occur in the majority of mass shooting incidents, and are often particularly troubling events, especially when an individual lacks the ability to cope with adversity. In the individual's mind this loss is seen as catastrophic, and this serves as a catalyst to the attack (Madfis \& Arford, 2008; Vossekuil, Fein, Reddy, Borum, \& Modzeleski, 2004).

The next stage in the model is the planning stage of the attack, and this is where the individual often fantasises about committing a mass shooting in what is described as a masculine solution to regain feelings of control (Levin \& Madfis, 2009). During this stage the potential offender is inspired to exact revenge on individuals they perceived to have wronged them, and wants to convey that they cannot be diminished. This stage is often lengthy and involved, and is when individuals prepare the logistics of the attack. At this stage, subsequent events and strains may also change the timing and logistics of the attack. The final stage is the massacre itself, where the perpetrator carries out the violent act they have been planning (Levin \& Madfis, 2009).

The trinity of violence theory. The trinity theory contends that all acts of violence involve a combination of vulnerable victims, ill intentions, and harmful capabilities. In short, Klarevas (2016) argues that for a rampage shooting to occur, three components are needed: the availability of a weapon which is capable of killing many individuals in a short period of time, a motivated offender, and a target (Klarevas, 2016; Rocque \& Duwe, 2018). Klarevas contends that breaking down each of the trinity's three components can provide insights into important questions such as why individuals commit mass shootings, why certain targets are selected, and how weapons are utilized. Understanding how the trinity of violence theory can apply to rampage shootings allows researchers to consider effective ways to tackle this 
problem. Researchers argue that if all three elements are necessary to stage an attack, then all that is needed is taking away one element and the attack will be prevented. Researchers claim that each element of the trinity offers a unique strategy (prevention, protection, and preclusion), and the model suggests that society can be made safer by dissuading perpetrators, defending targets, and denying weapons (Klarevas, 2016). Similar to the underlying mechanisms of the trinity of violence theory, Newman's (2004) comprehensive theory of school shootings consists of individual and schoollevel factors which can contribute to the occurrence of school shootings. Newman argues that there are five necessary factors which interact to result in school shootings: the individual views themselves as a social outcast; the individual has psycho-social problems; the individual holds cultural scripts that support violence as a problemsolving method; the school has poor surveillance systems to prevent potential shooters; and guns must be easily accessible (Newman \& Fox, 2009).

Culture of hegemonic masculinity. The culture of hegemonic masculinity has been applied to rampage shootings within school environments. This theory centres around the idea that young males who feel humiliated and mistreated eventually retaliate with deadly acts of violence in an attempt to demonstrate their masculinity (Kimmel \& Mahler, 2003; Newman \& Fox, 2009). Kimmel and Mahler (2003) state that masculinity is the greatest risk factor in school violence, and argue that in order to understand school shootings, focus must be placed on the content of the shootings (i.e. stories/narratives that accompany violence, relationships among students, and school and gender cultures). Researchers state that this culture of hegemonic masculinity can create a sense of aggrieved entitlement which encourages violence in order to avenge a perceived challenge to their masculine identity. This sense of entitlement also frames suicide as an appropriate behaviour that perpetrators engage in to highlight their violent masculinity (Kalish \& Kimmel, 2010).

When challenges to a young male's masculine identity affect an individual to the point of suicidal ideation, perpetrating a mass shooting can be seen as an instrumental way for them to achieve power (Kalish \& Kimmel, 2010). Researchers assert that these males are transformed into offenders through a sense of entitlement and making others hurt as much as themselves. These individuals are inspired by revenge against those who have wronged them and want compensation for the humiliation they have suffered, which they associate with emasculation. Kalish and 
Kimmel (2010) found that nearly all of the individuals who committed violence were constantly bullied and 'gay baited' due to being seen as different from other males. This results in their growing masculinity being threatened, and individuals often feel isolated and hopeless as they have been denied traditional male status and their sexuality has been questioned (Kalish \& Kimmel, 2010). The cybernetic theory of violence can also help explain how extreme experiences of humiliation can lead to a mass shooting. This theory asserts that the majority of violence is caused by the interaction between emotion and alienation, where shame and humiliation is seen as the primary cause of all violence. The social loop of rejection and isolation can lead to alienation. The more alienated an individual feels, the more likely this is to lead to repeated rejection and cause a negative spiral which can lead to self-perpetuating loops that result in either complete withdrawal or extreme violence (Scheff, 2011).

Andriolo (1998) states that 'masked suicide' is when men have access to a socially-approved form of taking their own life through public and highly-ritualised behaviours that are closely aligned with cultural ideals. This theory of masked suicide can shed light on how rampage school shootings are seen, and indicates how suicide by mass murder can be an instrumental way of living up to cultural ideals. Additionally, this theory helps us appreciate the instrumental nature of shootings which result in suicide. Young men are socialised to embrace behaviours designed to assert their masculinity, and are taught to use violence in response to threats against one's manhood (Kalish \& Kimmel, 2010). School shootings are a public display of violence and can be a way of sending a message that the shooter feels marginalised. As well as masked suicides being a public performance, they also confirm cultural values. If young males live in a culture that condones violence as a way to enact masculinity, then using lethal violence in order to prove one's masculinity is an example of supporting and conforming to those values (Kalish \& Kimmel, 2010; Kimmel \& Mahler, 2003).

Gun culture and shootings. Cultural attitudes surrounding gun culture in the U.S. have also been linked to rampage shootings. The availability of guns has been seen as a contributing factor toward rampage shootings, as it is easier for mass shooting offenders to gain access to multiple high-powered weapons and large amounts of ammunition. Alongside this, researchers have found that offenders within the U.S. are more likely to arm themselves with multiple weapons than offenders who 
attack elsewhere (Lankford, 2016b). Researchers state that Americans believe that the purpose of their right to bear arms is to ensure that they are able to protect themselves from tyranny; however, offenders often believe they are committing morallyjustifiable acts of self-defence or retribution against a system that has repeatedly victimized them (Lankford, 2016b).

Following the 2012 Sandy Hook Elementary School shooting rampage in Connecticut, the debate on the role of firearms within America has returned, and researchers state that politicians are calling for gun control without taking into account other psychological factors that can contribute to gun violence (Kleck, 2009). Faria (2013) argues that some of the most deadliest mass shooters in history have been characterized as 'loners' who were in desperate need of psychiatric evaluation. Faria states that this indicates that rampage shootings are the result of the failure of the mental health system as well as the sensationalization of violence by the media and popular culture. Faria argues that Jared Loughner (the perpetrator of the 2011 Arizona shooting) displayed signs of mental illness prior to the shooting, however these went unnoticed despite Loughner being classified as mentally 'deranged' and in desperate need of treatment. Faria argues that incidents like this represent cases of criminal insanity, associated with failures in the mental health system rather than issues with gun control (Faria, 2013).

Metzl and MacLeish (2015) argue that although individuals with violent tendencies should not be permitted access to potentially harmful weapons, notions that mental illness can cause mass shootings or that psychiatric attention can prevent shootings, are more complex than they appear. Researchers state that connections between mental illness and gun violence are more complicated than current public opinion suggests. Research suggests that mass shooters are often mentally ill and socially marginalized, that enhanced mental health attention can prevent crimes, and that mass shootings often shed light on the need for heightened mental health investment and improved procedures for gun access (Metzl and MacLeish, 2015). However, these assumptions can be problematic, as the notion that mental illness causes gun violence can stereotype a diverse population of individuals diagnosed with mental illnesses, and oversimplifies the relationship between violence and mental illness (Metzl and MacLeish, 2015). Researchers state that there is little evidence that supports the notion that individuals diagnosed with mental illnesses are more likely 
to commit gun crimes. Furthermore, Nestor (2002) contends that serious mental illnesses such as schizophrenia can reduce the risk of gun violence over time, as often individuals suffering from these illnesses also suffer from social isolation and withdrawal.

Providing theoretical explanations to rare events such as rampage shootings can prove challenging. By themselves, existing theoretical explanations (such as the presence of mental health issues), psychological and sociological explanations, and situational factors (such as access to firearms), are inadequate in explaining what drives an individual to commit a rampage shooting. A limited number of comprehensive explanations have been developed thus far to understand rampage shootings, and explanations often focus on independent key factors which result in an incomplete understanding of these events. The diversity of approaches and the inherent challenges to providing theories for an unusual and rare phenomenon gives rise to the possibility of integrating certain aspects and levels of analysis (such as psychological explanations and states, precipitating factors, cultural scripts, and access to firearms). An integrated theoretical perspective will need to recognise various factors, such as: key underlying psychological states and processes and how these have been shaped by evolutionary, developmental, and cultural factors; precipitating or contributing factors (and how specific situations, events, or experiences can lead to a mass shooting); and access to weapons, available targets, and cultural scripts relating to rampage shootings, in order to investigate offending patterns of rampage shooting perpetrators.

\section{Theoretical Explanations of Lone-Actor Terrorism}

Theoretical explanations behind lone-actor terrorism often focus on acts of group-based terrorism or terrorism as a whole. As a result of this, it is important to note that theoretical explanations for terrorism may not always apply to lone-actor terrorism events and the circumstances and factors which drive lone-actor terrorists to carry out extreme acts of violence.

Evolutionary perspectives. Previous research has taken a number of different approaches to applying evolutionary theory to criminal behaviour and exploring how individuals engage in violence under certain circumstances (Brown, Dickins, Sear, \& Laland, 2011; Durrant \& Ward, 2015), however the most prominent 
approach has been evolutionary psychology (Durrant, 2018). Evolutionary psychology is concerned with the application of evolutionary principles and knowledge to the human mind and behaviour, and this approach suggests that criminality is the outcome of evolved psychological mechanisms (Durrant, 2018; Liddle, Bush, \& Shackelford, 2011). Within the literature, researchers have explored the relationship between evolutionary psychology and terrorism, and researchers argue that understanding evolutionary psychological perspectives can increase our understanding of terrorism by explaining why the inclination for this behaviour exists in the first place (Liddle et al., 2011). Evolutionary psychologists claim that perceptions of grievance and the desire for revenge can be powerful motivations in certain situations. The individual seeking revenge often experiences higher levels of fulfilment when they see their perceived victims suffer (Liddle \& Shackelford, 2009). Lone-actor terrorists often frame their disputes in religious terms and are often motivated to sacrifice themselves for a cause; this is related to the 'devoted actor' hypothesis, which centres around an individual's willingness to make costly sacrifices (Juergensmeyer, 2003; Liddle et al., 2011). This model asserts that when individuals (or their values) are fused with a larger group identity, these individuals become willing to protect these sacred values through extreme acts of sacrifice and violence if they perceive themselves to be under threat from outside groups (Atran, Sheikh, \& Gomez, 2014; Gomez et al., 2017).

Psychological explanations. Previous research has demonstrated that although terrorists tend to be psychologically stable (McCauley \& Moskalenko, 2011), mental illness may be related to lone-actor terrorism as a key causal factor that combines with other factors to produce complex pathways to violence (Gill \& Corner, 2016; LaFree, Jenson, James, \& Safer-Lichtenstein, 2018). Previous studies have found empirical links between mental illness and violent political behaviour, especially regarding lone-actor terrorists, and have argued that mental illness may be a risk factor for violence. Gruenewald et al. (2013a) found that $40 \%$ of far-right lone actors reported a history of mental illness, and these lone actors were more likely to have a reported mental health issue compared to other far-rightists. Similarly, Gill et al. (2014) found that just over $30 \%$ of lone actors in their sample had a history of mental illness or personality disorder. 
Situational explanations. Situational explanations of crime (and lone-actor terrorism in particular) contend that although long-term risk factors can cause a higher predisposition to engage in violence, it is short-term risk factors and proximate stressors which act as precursors to committing violence. Researchers argue that short-term factors are more significant when dealing with lone-actor terrorists, as the majority of these individuals are impacted by stressors they have experienced either within the 12 months preceding an attack or days and hours before the attack took place (Gill et al., 2014; Meloy et al., 2004). The general strain theory of terrorism (Agnew, 2010) can also be used to explain lone-actor terrorism attacks; this theory infers that individuals who act within a group experience collective strains or stressors that are caused by those with greater perceived power. These stressors provoke action, however group involvement can alleviate stressors and provide individuals with an outlet for rage and discontent. Researchers argue that because lone-actor terrorists often do not possess the support structure to reduce these stressors, they are more vulnerable to the effects these can have (Agnew, 2010).

Radicalization theories. Radicalization theories and pathways have been used within previous research to explain how the desire to retaliate to perceived personal grievances can propel lone actors into seeking redress and compensation, can drive grievances that influence radicalization, and can influence pre-attack behaviours. There are various theories and pathways that attempt to explain how an individual becomes a lone-actor terrorist. Researchers state that there is a complex interplay of mechanisms and circumstances at play, and each individual has a unique combination of psychological processes and contributory factors. In short, researchers argue there is no single explanation behind lone-actor terrorism (Peddell et al., 2016; Spaaij, 2011). Lone-actor radicalization can take on various forms according to different configurations of social ties and relationships with the individual's immediate social environment. Particular radicalization patterns can influence attack planning, preparation, and specific preferences for pre-attack behavioural choices (Peddell et al., 2016).

There are two broad recurrent patterns of radicalization; peripheral and embedded. Peripheral lone-actor terrorists are those who adopt certain religious or political beliefs, however fail to integrate with collective networks and groups. Although they believe in some of the ideologies and beliefs these groups incorporate, 
they never progress to active membership or engagement (Lindekilde et al., 2017). The peripheral-withdrawn subtype of actors are those who lack the confidence to join potential groups and networks. In comparison to this, the peripheral-anti-social subcategory consists of individuals which often get rejected despite repeated efforts to engage, due to exhibiting negative personality traits such as narcissism. Lastly, the peripheral-volatile actors are individuals who are not part of groups due to their unreliability and erratic behaviours (Peddell et al., 2016).

In comparison to the peripheral radicalization patterns, embedded lone-actor terrorists are those who were fully engaged members of radical groups but became disembedded and detached for various reasons. Researchers often conclude that radicalisation is a social process, where external voices influence individuals by legitimising and encouraging lone-actor terrorism acts (Peddell et al., 2016). These ideas can have important implications for counterterrorism practitioners and academics as understanding patterns of lone actor radicalization can provide potential new avenues for prevention. Researchers suggest that this information can be used for risk assessment purposes, assist in the prioritization of resources, and provide guidance on the timing of interventions (Lindekilde et al., 2017).

Social movement theory is a prominent theoretical framework which aims to explain the processes entailed in social mobilisation and provide insight into the processes underpinning social movements. This theory stresses the crucial role of structural and network factors, in addition to individual attitudinal factors, in motivating an individual toward activism. Researchers state that individuals join a movement because they succumb to overwhelming social forces and rational and strategic processes. This theory applies to lone-actor terrorists as online resources can function as a social influence in the absence of terrorist or group affiliations (Brady et al., 1999; Peddell et al., 2016). In comparison to social movement theory, conversion theory focuses on how individuals modify existing beliefs to follow a new ideology, and focuses more on the individual process of the transformation of beliefs and ideologies (Peddell et al., 2016).

Previous research has rarely incorporated insights from criminological theories into the study of lone-actor terrorism, and the application of these theories to acts of lone-actor terrorism is warranted. More attention should be given to criminological 
explanations of lone-actor terrorism, and more focus is needed on assessing the strengths and limitations of applying general criminological theories to groups such as lone actors. Similar to rampage shooting events, evolutionary, psychological, and situational explanations behind lone-actor terrorism explain how individuals can be motivated to perpetrate violent acts in particular circumstances, and how experiencing negative risk factors or stressors can increase an individual's susceptibility to engaging in violence.

\section{Present Study}

The current research aims to explore incidents of lone-actor terrorism and rampage shootings within Europe and North America between 2010 and 2018. Although mass murder is an area which is frequently studied within criminological literature, research on lone-actor terrorism from a criminological perspective to date is limited (Liem, van Buuren, de Roy van Zuijdewijn, et al., 2018). Although rampage shootings and lone-actor terrorism events have been researched on their own or in combination with other types of violent crime, to my knowledge research has yet to be published regarding a comparison of these two types of events in Europe and North America. Existing empirical studies on lone-actor terrorism events have primarily focused on distinguishing between lone actor and group-based terrorists (Gruenewald, Chermak, \& Freilich, 2013a, 2013b; Spaaij \& Hamm, 2015), and are primarily U.S. based despite lone-actor terrorism being considered a significant national security threat in both Europe and North America (Liem, van Buuren, de Roy van Zuijdewijn, et al., 2018; Meloy \& Gill, 2016; Peddell et al., 2016; Spaaij, 2010).

To date, there has been little analysis of how these two behaviourally-similar phenomena may, or may not, reflect similar underlying psychological and social processes. Despite a growing academic literature on these events, there still remains relatively few in-depth empirical studies on rampage shooting and lone-actor terrorism events. The apparent lack of non-U.S. data has come to the forefront due to the recent terror attacks which occurred throughout Europe in 2017. Little is known about the comparative nature of mass murder offences worldwide, and comparing incidents in both North America and Europe will allow comparisons to be made regarding distinctive locations, and variations which occur between events in these different areas (Lankford, 2016a). I believe this research will make a unique 
contribution to criminological literature and assist in filling the research gap on loneactor terrorism and rampage shooting events in recent years. The aim of the present study, therefore, is to add to the empirical literature on rampage shooting and loneactor terrorism with an updated dataset that provides a comparison of these events. Moreover, the current study will focus on exploring the characteristics of rampage shooting and lone-actor terrorist perpetrators and how they differ in terms of characteristics and motivations, to allow for the exploration of whether there are similar underlying mechanisms for these events. The current study will contribute to the theoretical explanations of these events, and ultimately contribute to efforts to prevent these types of incidents from occurring.

\section{Research Questions}

Using quantitative research methods, the current research will investigate underlying characteristics and motivations behind lone-actor terrorism and rampage shooting incidents which have occurred in North America and Europe between 2010 and 2018. By conducting a comparative analysis of these incidents, this study will provide a unique insight into rampage shooting events and the often-neglected area of lone-actor terrorism. The overarching aim and focus of the current research is to explore key differences between lone-actor terrorists and rampage shooting offenders and compare these two different types of events. The following questions will also guide my research:

1. How do lone-actor terrorists and rampage shooters differ from one another in terms of key psychological and social factors such as mental illness and strain?

2. To what extent do the motivational patterns of lone-actor terrorists differ from those of rampage shooters?

3. What role does geographical location play in lone-actor terrorism and rampage shooting incidents?

i. Are there important differences in the traits or behaviours between European and North American lone-actor terrorist offenders?

ii. Are there important differences in the traits or behaviours between European and North American rampage shooting offenders? 


\section{Method}

\section{Methodological Approach}

To conduct this research I performed a quantitative analysis of lone-actor terrorism and rampage shooting incidents throughout North America and Europe during the period January 2010 to May 2018. An open-source data collection strategy was used to select incidents which met the inclusion criteria for this study, and archival data was gathered from various online databases such as the Global Terrorism Database (GTD) and Mother Jones (see Table 6 for a full list of databases used). ${ }^{18}$ Supplementary materials were utilized to search for additional incidents that did not appear within the databases and to add to existing information, and this allowed for a complete depiction of the incidents and resulted in a comprehensive sample.

\section{Table 6}

Databases Used for Lone Actor Terrorism and Rampage Shooting Data

\begin{tabular}{lll}
\hline \multicolumn{1}{c}{ Database } & \multicolumn{1}{c}{ Database information } & \multicolumn{1}{c}{ Web link } \\
\hline $\begin{array}{l}\text { Global Terrorism } \\
\text { Database (GTD) }\end{array}$ & $\begin{array}{l}\text { Useful for data on } \\
\text { European and American } \\
\text { lone-actor terrorists }\end{array}$ & $\begin{array}{l}\text { http://www.start.umd.edu/gtd/ } \\
\text { NewUser.aspx }\end{array}$ \\
$\begin{array}{l}\text { American Lone Wolf } \\
\text { Terrorism Database } \\
\text { (1940-2013) }\end{array}$ & $\begin{array}{l}\text { Useful for data on } \\
\text { American lone-actor } \\
\text { terrorists }\end{array}$ & $\begin{array}{l}\text { https://www.ncjrs.gov/ } \\
\text { pdffiles1/nij/grants/248691.pdf }\end{array}$ \\
$\begin{array}{l}\text { Mother Jones } \\
\begin{array}{l}\text { Database (1982- } \\
\text { 2012) }\end{array}\end{array}$ & $\begin{array}{l}\text { Useful for data on U.S. } \\
\text { rampage shootings }\end{array}$ & $\begin{array}{l}\text { https://www.motherjones.com/ } \\
\text { politics/2012/12/mass-shootings } \\
\text {-mother-jones-full-data/ }\end{array}$ \\
$\begin{array}{l}\text { Stanford Mass } \\
\text { Shootings in } \\
\begin{array}{l}\text { America (MSA) } \\
\text { (1932-2014) }\end{array}\end{array}$ & $\begin{array}{l}\text { Useful for data on rampage } \\
\text { shootings in America }\end{array}$ & $\begin{array}{l}\text { htps:/github.com/Stanford } \\
\text { GeospatialCenter/MSA/blob/ } \\
\text { master/Data/Stanford_MSA_Database.csv }\end{array}$ \\
$\begin{array}{l}\text { Kaggle U.S. Mass } \\
\text { shootings Database }\end{array}$ & $\begin{array}{l}\text { Useful for data on U.S. } \\
\text { rampage shootings }\end{array}$ & $\begin{array}{l}\text { https://www.kaggle.com/zusmani/ } \\
\text { us-mass-shootings-last-50-years/data }\end{array}$ \\
\hline
\end{tabular}

18 Open-source data is information that is available to the public. Archival data is existing data and information obtained from stored records. 
Table 6 (continued)

\begin{tabular}{|c|c|c|}
\hline $\begin{array}{l}\text { FBI active shooter } \\
\text { reports }\end{array}$ & $\begin{array}{l}\text { Useful for data on U.S. } \\
\text { rampage shootings }\end{array}$ & $\begin{array}{l}\text { https://www.fbi.gov/about/ } \\
\text { partnerships/office-of-partner- } \\
\text { engagement/active-shooter-resources }\end{array}$ \\
\hline $\begin{array}{l}\text { NYPD active shooter } \\
\text { reports }\end{array}$ & $\begin{array}{l}\text { Useful for data on U.S. } \\
\text { rampage shootings }\end{array}$ & $\begin{array}{l}\text { https://www.alicetraining.com/ } \\
\text { resources/item/nypd-active-shooter } \\
\text {-report-and-recommendations/ }\end{array}$ \\
\hline $\begin{array}{l}\text { OpenDataSoft } \\
\text { Database }\end{array}$ & $\begin{array}{l}\text { Useful for data on U.S. } \\
\text { rampage shootings }\end{array}$ & $\begin{array}{l}\text { https://public.opendatasoft.com/ } \\
\text { explore/dataset/mass-shootings-in- } \\
\text { america/information }\end{array}$ \\
\hline
\end{tabular}

\section{Inclusion and Exclusion Criteria}

The definitions of lone-actor terrorism and rampage shootings that are used in the current study are mentioned in the introduction section. For the purposes of the current study, a narrow definition of lone-actor terrorism was adopted in order to isolate this phenomenon from other forms of terrorism.

Lone-actor terrorism. Inclusion criteria for lone-actor terrorism incidents consisted of the following: (1) perpetrators must have been acting alone (or in a small cell) and must have committed the offence without direct support from a group;19 (2) perpetrators must have been convicted or died in the commission of their attack; (3) incidents must have been carried out with the intention of influencing a wider audience; and (4) incidents must have occurred between January 2010 and May 2018, as this time period is recent and allows for the comparison of a large number of cases. The following incidents were excluded from analysis: (1) incidents with less than one fatality; (2) incidents which occurred solely in family or domestic settings; (3) incidents which fit homicide categories such as serial, spree, ${ }^{20}$ felony-related, hostage, gang-motivated, and organizational genocide or terrorism; (4) incidents where charges were dropped or perpetrators were found not guilty; and (5) incidents where there is confusion surrounding the perpetrator's identity.

Rampage shootings. Inclusion criteria for rampage shootings consisted of the following: (1) events must have been isolated (i.e. not part of another event) and must have been carried out in a public location; (2) victims must have been randomly

19 This ensures the exclusion of incidents of group-based terrorism.

${ }^{20}$ For the purposes of this study, spree incidents are classified as incidents which occurred over a period of longer than 24 hours. 
or symbolically-chosen; (3) firearms must have be used (with or without other weapons); (4) the intent must have been to harm more than one individual; and (5) incidents must have occurred between January 2010 and May 2018. The following incidents were excluded from analysis: (1) incidents with less than three fatalities (not including the perpetrator); (2) incidents which occurred solely in family or domestic settings; (3) incidents which fit homicide categories such as serial, spree, felonyrelated, hostage, and gang-motivated incidents; (4) incidents where charges were dropped or perpetrators were found not guilty; (5) incidents where there is confusion surrounding the perpetrator's identity; and (6) incidents which fit the criteria for loneactor terrorism (i.e. the perpetrator(s) did not act out of purely personal or material reasons).

The rationale for choosing the above criteria was to ensure the final sample of cases was large enough for analysis and that there was a comparable number of both lone-actor terrorism and rampage shooting incidents. The specific criteria allowed for comparative analysis at a greater level of precision and for clear focus on the specific phenomenon, and were selected based on previous research on lone-actor terrorism and rampage shootings. The exclusion criteria were similar for lone-actor terrorism and rampage shooting incidents. Lone-actor terrorism incidents with less than one fatality were excluded from analysis, as lowering the number of fatalities required for inclusion ensured that the sample size of these events was comparable with that of rampage shooting events. Alongside this, there is no reason to believe that lone-actor terrorism events which result in three or more fatalities involve perpetrators with different psychological profiles than events which resulted in one fatality, as the number of fatalities is theoretically irrelevant to the causes of lone-actor terrorism (Capellan, 2015). Similar to previous research (Meloy et al., 2001; Meloy et al., 2004), the current study excluded rampage shooting incidents with less than three fatalities from analysis, as this separates rampage shootings from single-victim homicides in general. Although there is less consensus regarding whether the minimum number of fatalities required for a rampage shooting should be three or four, the underlying psychological and sociological processes behind these events are not associated with the ability of the perpetrator to kill four instead of three victims, and incidents with three victims are just as theoretically relevant (Fox et al., 2016; Silver, Horgan, \& Gill, 2019). Both types of events were excluded if they occurred solely in family or domestic 
settings, ${ }^{21}$ appeared to result from underlying crimes, or fit other homicide categories, as incidents in other homicide categories are often driven by different motivations and are not always intended to be a mass murder event (Silver et al., 2019). Both types of incidents were also excluded if there was confusion surrounding the perpetrator's identity, as the current study required an adequate amount of accurate event and individual-level information.

\section{Data Collection}

Lone-actor terrorism. Data on lone actor events was gathered from multiple databases containing useful information about European and North American incidents, such as the American Lone Wolf Terrorism Database (ALWTD) and the GTD, which is available online for public use (see Table 6). To navigate the GTD the 'advanced search' setting was utilized to search for specific incidents which matched inclusion criteria for the current study (for example, the 'region' category was used to search for incidents which occurred within North America and Europe). The key information surrounding each incident was examined (i.e. attack, target, weapon, and perpetrator information) and any incidents that were committed by a group or did not meet the overall inclusion criteria were excluded.

Supplementary materials were used to identify additional lone actor incidents and to add to existing incident information, such as: supplementary online searches; online newspaper articles from various newspapers (these included, but were not limited to, the New York Times (US), USA Today (US), and The Guardian (US and UK); search engines (such as Newztext, Lexis Nexis, and Factiva); government, scholarship, and media reports; academic literature; and electronic documents. News media searches were conducted using search terms such as 'terrorism,' 'attack,' and 'lone actor.' To add to existing incident information, personalised searches were also conducted using search terms relevant to individual cases, such as 'Charleston church shooting' or 'Dylann Storm Roof.'

Rampage shootings. Data on rampage shooting incidents was mostly gathered from Mother Jones and Stanford Mass Shootings in America (MSA) databases (see Table 6). The Mother Jones database includes information on mass

${ }^{21}$ These murders are treated as conceptually distinct from other forms of mass murder. 
shootings within the U.S. between 1982 and 2018, and was able to be downloaded in Excel format which allowed for easy navigation of the full dataset. Information on a wide range of incident variables was included in this database, such as location, number of injuries and fatalities, mental health status, weapons used, and sources used to gather the information. The format of this database meant that search terms were unable to be used to narrow down searches. However, to make the selection process easier variables were ordered based on the type of information needed (for example, the dates were placed in ascending order), and narrowing down variables made it easier to locate relevant incidents from this large database.

The MSA database was created in response to the 2012 Sandy Hook Elementary School shooting, and includes mass shooting incidents with three or more shooting victims. Alongside the database itself, the MSA dataset also includes a data dictionary where each variable is listed alongside the variable type and definitions. This dataset is only available online and was unable to be downloaded, and as a result of this search terms were not able to be used. To begin the selection process, the brief descriptions of each incident were assessed and incidents which occurred between 2010 and 2018 were checked to determine whether they met the inclusion criteria. Similar to Mother Jones, the MSA dataset included a wide range of variable information, such as the number of civilian and enforcement injuries and fatalities, the relationship between the perpetrator and victim, motivation details, and personal details about the perpetrators such as mental health status.

A drawback that arose during the selection process was that Mother Jones and MSA databases only contain information on North American mass shooting incidents. Consequently, rampage shootings which occurred across Europe were identified solely through additional materials, and these materials were also used to supplement existing information and identify additional rampage shootings within North America. Similar to lone actor incidents, these supplementary materials included: additional online searches; online newspaper articles; search engines; government, scholarship, and media reports; academic literature; and electronic documents. News media searches were conducted using search terms such as 'shooting,' 'mass shooting,' 'rampage shooting,' and 'attack.' If incidents overlapped (i.e. were already identified from another database) and there was conflicting information across sources, further searches were conducted using additional materials to determine the correct 
information and the reliability of sources. Personalised searches were also conducted to gather data on individual incidents, using search terms such as 'Stoneman Douglas High School shooting' and 'Nikolas Cruz.'

Sample. Following the selection process for both lone actor and rampage shooting incidents, the initial sample included 168 incidents for both lone actor ( $n=$ 106) and rampage shooting events $(n=62)$. Of these incidents, 34 were excluded from analysis as upon assessment they did not meet the inclusion criteria for the current study (see Figure 1). The reasons for exclusion were as follows: the perpetrators who committed the attack did so as a direct order from an ideological group or individual, or belonged to an ideological group or larger terrorist network $(n=16)$; the incidents were not committed in a public or semi-public place $(n=7)$; there was confusion surrounding the perpetrator's identity, their identity was unknown, or very little information was available $(n=8)$; the incident occurred as a result of a hostage-taking situation $(n=1)$; the incident was part of another attack $(n=1)$; and the only incident fatality was the perpetrator $(n=1)$. Excluding incidents which did not meet inclusion criteria resulted in a final sample of 155 perpetrators involved in 134 incidents ( 76 lone actor and 58 rampage shooting incidents) in the period January 2010 to May 2018. Each incident was assigned a case identification number, and all available variable information was entered into Excel, alongside a codebook which outlined key information about the variables and how these were coded. Variable information was refined using a random sample of a small number of incidents, and once variables had been refined they were tested with a small sample of approximately ten incidents. 
Lone actor events from GTD: 87

Lone actor events from ALWTD: 1

Lone actor events from Mother Jones: 1

Lone actor events from supplementary materials: 17

Rampage shooting events from Mother Jones only: 4

Rampage shooting events from MSA only: 3

Rampage shooting events from Kaggle only: 1

Rampage shooting events from combination of databases: 42

Rampage shooting events from supplementary materials: 12

Total: 168

168: Incidents assessed for eligibility

Excluded based on not meeting inclusion criteria: 34

Reasons for exclusion:

Directly ordered to commit the attack or belonged to ideological group/terrorist network: 16

Occurred in a private or domestic setting (not semi-public or public place): 7

Confusion surrounding identity, identity unknown, or little information on identity: 8

Hostage-taking situation: 1

Part of another attack: 1

No other fatalities apart from perpetrator(s): 1

80: Lone actor events ( 36 from North America, 44 from Europe)

54: Rampage shooting events (44 from North America, 10 from Europe)

Lone actor events from GTD: 63

Lone actor events from ALWTD: 1

Lone actor events from Mother Jones: 1

Lone actor events from supplementary materials: 15

Rampage shooting events from Mother Jones only: 4

Rampage shooting events from MSA only: 2

Rampage shooting events from Kaggle only: 1

Rampage shooting events from combination of databases: 37

Rampage shooting events from supplementary materials: 10

Total: 134

Figure 1. Case selection flowchart. 


\section{Variable Description}

Incidents were coded on 53 variables which reflect event, sociodemographic, and personal characteristics (see Appendix B, Tables 1 and 2 for a full list of variable information). The variables and codebook used in the current study were developed based on an extensive review of the literature on mass shootings, as well as a review of other existing codebooks used by researchers conducting similar research. Event characteristics included variables such as the number of fatalities and casualties for each incident, the location of the incident, modus operandi, and the level of planning behind the attack. Sociodemographic characteristics included variables such as age, gender, race/ethnicity, ${ }^{22}$ educational level, religious affiliation, and relationship and job status'. Perpetrators were also coded on personal characteristics, including variables such as criminal history, mental health issues (including diagnosis and treatment details), previous abuse, previous violent acts, antisocial personality traits, and indications of possible precipitating events.

Social isolation was assessed indirectly and this was coded as present if individuals close to the perpetrator mentioned the perpetrator's social isolation. Mental health status variables were important variables to include in the current study due to the increasing recognition that mental illness can be an important precipitant for mass murder incidents (Dutton, White, \& Fogarty, 2013). In the current study mental health status was categorised into four categories: the first indicates evidence of mental health issues and/or disorders through an official diagnosis by a mental health professional; the second indicates that mental health issues and/or disorders may be present, through mention of sources close to the perpetrator; the third indicates that there is no evidence nor indication of mental health issues; and the fourth indicates that the perpetrator's mental health status is unknown.

The current study also incorporated numerous motivations that were reported across studies to provide a comprehensive overview of the motivations behind lone actor and rampage shooting incidents (Taylor, 2018). Perpetrator motivations were categorized into seven groups that were either based on the perpetrator's accounts of

${ }^{22}$ Due to the complexity of coding for race/ethnicity, and in particular coding for Middle Eastern individuals, a decision was made to not code specifically for ethnicities such as Middle Eastern or Arab as these are rarely cited by sources. Accordingly, these ethnicities are listed under the 'other' category. 
their expressed motivation for the attack, or their acquaintances, friends, or families' accounts of their motivations. The emotional triggers category includes any event that occurred in the week prior to the incident that triggered the perpetrator's emotions in a negative way, and contributed to their decision to carry out the attack. The second category, relationship/domestic issues, refers to perpetrators who experienced issues within their relationship or domestic environment prior to the incident that may have contributed to the attack. The third and fourth categories revenge/payback and personal grievances refer to perpetrators who either committed an attack to seek revenge and/or payback for perceived wrongs they experienced by the victims, or who perceived to have suffered from a personal grievance. The fifth category, criminal gain, concerns perpetrators who committed the attack with the intent to gain some sort of benefit or reward in exchange for doing so. The sixth category, political or religious motivations, refers to perpetrators who carried out an attack due to political or religious motivations or grievances, with the intention of opposing and/or challenging the government or some other organised group, in some manner. The final category, unclear, was coded as present if the motivations behind the attack are unknown and/or unclear. The seven motivation categories are not mutually exclusive, and many perpetrator's motivations were coded as present for multiple categories due to committing the attack as a result of a combination of factors. ${ }^{23}$

A number of variables in the current study had 'no' or 'unknown' listed as specific categories within each variable. The category 'no' was met when there were no clear indications of the characteristic or behaviour for an event or the perpetrator of an event. This category appeared within variables such as whether there were specific target(s) for the event, whether a perpetrator had children and/or dependents, whether they displayed a fascination with weapons and/or war, and whether they were motivated by any of the seven motivational characteristics. When it was expected that information on relevant variables would be available through various sources, however this information was not found, the category 'no' was also met. Comparably, the 'unknown' category was met when the information regarding a characteristic or behaviour was unknown and/or unclear, and this category appeared within variables such as modus operandi, educational level, childhood issues, weapon ownership, and

23 Note that the exception to this is the 'unclear' category, which was only coded as present if other motivation categories were coded as not present. 
mental health status.

Interrater Reliability. In order to evaluate the reliability of the coding scheme, a second coder was trained on a randomly selected sample of five of the cases. Following this, some modifications to the coding scheme were implemented and just under 10 percent of the final cases $(n=13)$ were randomly selected in order to evaluate inter-rater reliability using Cohen's kappa ( $\kappa)$. A second coder (i.e. the supervisor of the current study) followed similar search strategies in obtaining information about these 13 cases and coded them on the list of developed variables. For four variables, $\kappa$ could not be computed because there were no variations in the codes selected by the two coders. For the remaining variables $(n=40),{ }^{24}$ the average $\kappa$ score was $0.69 .35 \%$ of the variables obtained $\kappa$ scores of higher than 0.80 indicating almost perfect agreement, $35 \%$ of the scores fell between 0.61 and 0.80 indicating substantial agreement, $20 \%$ of the scores fell between 0.41 and 0.60 suggesting moderate agreement, and $10 \%$ of the scores were lower than 0.40 indicating fair to no agreement (Cohen, 1960). Differences among the coders were discussed, with the final codes determined by the primary author (i.e. myself) who was responsible for coding all of the final sample. It was concluded that given the inherent limitations of employing open-source data (Capellan \& Gomez, 2018), that a generally acceptable level of agreement was obtained and that other researchers using the coding framework would obtain similar results.

\section{Data Analysis}

A series of bivariate comparative analyses tests were conducted to compare the sociodemographic, event, and perpetrator characteristics of lone actor and rampage shooting groups, and investigate the degree to which these groups differ. Prior to conducting the bivariate analyses, categorical variables were collapsed where necessary to maintain appropriate cell sizes for each category within the variables. Alongside this, the methodological decision was made to treat the 'unknown' categories of specific variables as effectively 'no' in both bivariate and multivariate analyses, to ensure that the variables represent either presence of the characteristic or

24 Some of the variables were not coded by the second coder because they related to factual information that would not have differed between coders (for example, sex, case ID, location, the time of day the incident occurred, and the duration of the incident). 
issue, or no evidence of the presence of the characteristic or issue. ${ }^{25}$ Variables that contained 'unknown' categories that could not be collapsed were excluded from significance testing analyses, however the frequencies of these categories were listed in the relevant tables in the 'Results' section. Group differences were evaluated using independent-samples t-tests for continuous variables, and chi-square $\left(\chi^{2}\right)$ tests for categorical variables. Additional analyses were conducted to determine the role of location in lone actor and rampage shooting incidents, and to examine whether there are significant differences in personal attributes and behaviours between perpetrators who commit their attacks in North America versus Europe. The differences between these groups were evaluated using two-way between-groups analysis of variance for continuous variables, and chi-square $\left(\chi^{2}\right)$ tests for categorical variables. Multivariate analysis was also relied on to assess the key distinguishing characteristics associated with lone actors and rampage shooters. Given the main objective of this study was to examine group differences on a wide range of characteristics between a sample of lone actors and rampage shooters, a logistic regression model was employed in order to shed light on the nature of these groups and establish the extent to which these two groups of individuals are similar or different. The dependent variable in this model was incident type, and a small sub-sample of the overall set of variables were used to capture key personal and psychological aspects and experiences of the perpetrators, to investigate to what extent these individuals reflect similar psychological and social processes. Prior to running the logistic regression, the categorical variables were collapsed and dichotomised to simplify the analysis and ensure there were large enough cell counts for each category.

The data analytic strategy employed for this study was IBM SPSS Statistics for Mac, Version 25. I chose to upload the current study's data onto this program because SPSS is a powerful tool for data analysis and visualization. Using SPSS allowed for conclusions to be drawn based upon statistical analysis of the data, and allowed for meanings and relationships within the data to be uncovered.

Missing data. Missing data is often an unavoidable problem in the study of mass murder, and lone-actor terrorism in particular. There are various methods for

25 This methodological decision was also made by Silver et al. (2019). A full set of the categories for each variable can be found in the tables in the 'Results' section of this paper. 
treating missing data within empirical research, and these often rely on implicit assumptions about the nature of the missing data (Safer-Lichtenstein, LaFree, \& Loughran, 2017). Due to the open-source data collection strategies used in the current study and the unavailability of information for a number of events and/or perpetrators, individual-level data on specific variables of interest were missing (in particular, information surrounding sociodemographic or psychological characteristics). In order to address this issue, any missing data in the current dataset was excluded from analysis, and this was done by filtering out the 'unknown' categories of variables when carrying out significance testing (as mentioned in the previous section). Excluding the missing data ensured that bivariate analyses were carried out using only the available event and offender-level information on all variables, and where needed categories on variables were collapsed to ensure the sample sizes for each category were not too small. 


\section{Results}

The following sections will discuss the findings of the current research and their relevance to the main research questions (i.e. to what extent do lone actor and rampage shooting perpetrators differ on psychological and social characteristics and motivational patterns), and consider these findings in the context of the underlying characteristics of lone-actor terrorism and rampage shooting events. At the beginning of each section all event, sociodemographic, personal, psychological, and motivational characteristics of the sample as a whole will be examined. Next, in order to explore key differences between lone actor and rampage shooting perpetrators and incidents, I will discuss key event and offender characteristics associated with both groups and use bivariate analyses to investigate how these differ between the groups. To investigate the third main research question (i.e. the role geographic location plays in lone actor and rampage shooting incidents), I will explore the findings of various analyses as they relate to location and examine whether there are key differences in the attributes and behaviours between North American versus European lone actor perpetrators, and North American versus European rampage shooting perpetrators.

\section{Event Characteristics}

As shown in Table 7, during the period January 2010 to May 2018, 155 perpetrators were responsible for 134 incidents across North America and Europe (76 lone actor and 58 rampage shooting incidents). In these events the number of casualties (i.e. injured victims) ranged from o to 800, the number of fatalities ranged from 1 to 87 , and the total number of victims ranged from 1 to 822 . The most common years for incidents to occur were 2015 and 2017 ( $n=22 ; 16.4 \%)$ compared to 2010 and $2018,{ }^{26}$ which were the least common years for incidents to occur ( $\left.n=5 ; 3.7 \%\right)$. In the studied time period, the majority of incidents took place in North America $(n=80$; 59.7\%), whereas only 54 incidents (40.3\%) took place across Europe. Of the incidents which occurred within North America, the most common place for incidents to occur

${ }^{26}$ Note that data collection stopped in May 2018, so any incidents that have occurred from June 2018 to present are not included in the current study. 
was within the State of California $(n=10 ; 7.5 \%)$. The number of perpetrators across incidents ranged from 1 to 6 , however the majority of incidents only involved one perpetrator ( $n=117 ; 87.3 \%$ ). Incidents fell predominantly under the attack type 'armed assault' ( $n=123 ; 91.8 \%$ ), whereas the least likely attack types were assassination, and combination (for both, $n=2 ; 1.5 \%$ ).

\section{Table 7}

Event Characteristics of Lone-Actor Terrorism Events Versus Rampage Shooting Events

\begin{tabular}{|c|c|c|c|c|c|c|}
\hline Incidents & Lone & $\begin{array}{l}\text { tor events } \\
=76)\end{array}$ & & $\begin{array}{r}\mathrm{Re} \\
\text { shoot } \\
(r\end{array}$ & $\begin{array}{l}\text { mpage } \\
\text { ng events } \\
=58)\end{array}$ & \\
\hline Event characteristics & $M$ & Range & Significant & $M$ & Range & Significant \\
\hline Number of fatalities ${ }^{a}$ & 6.6 & $(1-87)$ & $n s$ & 7.5 & $(3-59)$ & $n s$ \\
\hline Number of fatalities ${ }^{d}$ & 12.7 & $(3-87)$ & $n s$ & & & \\
\hline Number of casualties & 28.5 & $(0-800)$ & $n s$ & 17.3 & $(0-546)$ & $n s$ \\
\hline Total number of victims ${ }^{a}$ & 35.1 & $(1-822)$ & $n s$ & 25.6 & $(3-605)$ & $n s$ \\
\hline Total number of victims ${ }^{\mathrm{d}}$ & 67.6 & $(3-822)$ & $n s$ & & & \\
\hline Event characteristics & $n$ & $\%$ & Significant & $n$ & $\%$ & Significant \\
\hline $\begin{array}{c}\text { Yearc }^{c} \\
2010 \\
2011 \\
2012 \\
2013 \\
2014 \\
2015 \\
2016 \\
2017 \\
2018\end{array}$ & $\begin{array}{r}1 \\
5 \\
7 \\
8 \\
14 \\
14 \\
13 \\
13 \\
1\end{array}$ & $\begin{array}{c}1.3 \\
6.6 \\
9.2 \\
10.5 \\
18.4 \\
18.4 \\
17.1 \\
17.1 \\
1.3\end{array}$ & ns & $\begin{array}{c}4 \\
4 \\
10 \\
10 \\
4 \\
8 \\
5 \\
9 \\
4\end{array}$ & $\begin{array}{r}6.9 \\
6.9 \\
17.2 \\
17.2 \\
6.9 \\
13.8 \\
8.6 \\
15.5 \\
6.9\end{array}$ & $n s$ \\
\hline $\begin{array}{l}\text { Location (region)b } \\
\text { North America } \\
\text { Europe }\end{array}$ & $\begin{array}{l}32 \\
44\end{array}$ & $\begin{array}{l}42.1 \\
57.9\end{array}$ & $* * *$ & $\begin{array}{l}48 \\
10\end{array}$ & $\begin{array}{l}82.8 \\
17.2\end{array}$ & $* * *$ \\
\hline $\begin{array}{l}\text { Number of perpetrators } \\
\text { One offender } \\
\text { Two offenders } \\
\text { Three or more offenders }\end{array}$ & $\begin{array}{r}61 \\
10 \\
5\end{array}$ & $\begin{array}{l}80.3 \\
13.2 \\
6.5\end{array}$ & $* *$ & $\begin{array}{r}56 \\
1 \\
1\end{array}$ & $\begin{array}{l}96.6 \\
1.7 \\
1.7\end{array}$ & $* *$ \\
\hline
\end{tabular}


Table 7 (continued)

\begin{tabular}{|c|c|c|c|c|c|c|}
\hline \multicolumn{7}{|l|}{ Modus operandib } \\
\hline Firearm & 42 & $55 \cdot 3$ & *** & 52 & 89.7 & *** \\
\hline Knife & 8 & 10.5 & & - & - & \\
\hline Fire & - & - & & - & - & \\
\hline Explosives/bombs & 8 & 10.5 & & - & - & \\
\hline Vehicle & 6 & 7.9 & & - & - & \\
\hline Other & 1 & 1.3 & & - & - & \\
\hline Combination & 11 & 14.5 & & 3 & 5.2 & \\
\hline Unknown & - & - & & 3 & 5.2 & \\
\hline \multicolumn{7}{|l|}{ Weapon subtype ${ }^{b}$} \\
\hline Automatic weapon & 9 & 11.8 & $n s$ & 21 & 36.2 & $n s$ \\
\hline Handgun & 12 & 15.8 & & 11 & 19 & \\
\hline $\begin{array}{l}\text { Rifle/shotgun (non- } \\
\text { automatic) }\end{array}$ & 6 & 7.9 & & 6 & 10.3 & \\
\hline Unknown & 8 & 10.5 & & 1 & 1.7 & \\
\hline Combination & 11 & 14.5 & & 16 & 27.6 & \\
\hline \multicolumn{7}{|l|}{ Specific target(s) ${ }^{b}$} \\
\hline Yes & 52 & 68.4 & $n s$ & 40 & 69.0 & $n s$ \\
\hline No & 24 & 31.6 & & 18 & 31 & \\
\hline \multicolumn{7}{|l|}{ Relationship to victimb ${ }^{\mathrm{b}}$} \\
\hline Stranger/random & 71 & 93.4 & *** & 27 & 46.6 & *** \\
\hline Personal & 1 & 1.3 & & 3 & 5.2 & \\
\hline Professional & 3 & 3.9 & & 11 & 19 & \\
\hline School-related & - & - & & 4 & 6.9 & \\
\hline Combination & 1 & 1.3 & & 13 & 22.4 & \\
\hline \multicolumn{7}{|l|}{ Location type $^{\mathrm{b}}$} \\
\hline Open commercial & 36 & 47.4 & *** & 24 & 41.4 & $* * *$ \\
\hline Educational institution & 3 & 3.9 & & 8 & 13.8 & \\
\hline Military setting & - & - & & 3 & 5.2 & \\
\hline Public street & 24 & 31.6 & & 5 & 8.6 & \\
\hline Office & 3 & 3.9 & & 1 & 1.7 & \\
\hline Warehouse/factory & - & - & & 5 & 8.6 & \\
\hline Other & 7 & 9.2 & & 7 & 12.1 & \\
\hline Combination & 3 & 3.9 & & 5 & 8.6 & \\
\hline \multicolumn{7}{|l|}{ Attack type ${ }^{b}$} \\
\hline Assassination & 2 & 2.6 & * & - & - & * \\
\hline Armed assault & 67 & 88.2 & & 56 & 96.6 & \\
\hline Bombing/explosion & 7 & 9.2 & & - & - & \\
\hline Unarmed assault & - & - & & - & - & \\
\hline Combination & - & - & & 2 & 3.4 & \\
\hline Unknown & - & - & & - & - & \\
\hline \multicolumn{7}{|l|}{ Level of prañning - - :- } \\
\hline Medium-level & 45 & 59.2 & & 26 & 44.8 & \\
\hline High-level & 10 & 13.2 & & 6 & 10.3 & \\
\hline Unknown & 13 & 17.1 & & 8 & 13.8 & \\
\hline \multicolumn{7}{|l|}{ Duration of incident ${ }^{b}$} \\
\hline Less than 30 minutes & 67 & 88.2 & $n s$ & 44 & 75.9 & $n s$ \\
\hline 31-6o minutes & - & - & & 2 & 3.4 & \\
\hline $1-5$ hours & 7 & 9.2 & & 9 & 15.5 & \\
\hline 6-12 hours & 1 & 1.3 & & 1 & 1.7 & \\
\hline 13-24 hours & - & - & & 2 & 3.4 & \\
\hline Unknown & 1 & 1.3 & & - & - & \\
\hline
\end{tabular}


Table 7 (continued)

\begin{tabular}{|c|c|c|c|c|c|c|}
\hline \multicolumn{7}{|l|}{ Time of incident ${ }^{\mathrm{b}}$} \\
\hline Morning & 16 & 21.1 & $n s$ & 25 & 43.1 & $n s$ \\
\hline Afternoon & 22 & 28.9 & & 12 & 20.7 & \\
\hline Evening & 16 & 21.1 & & 11 & 19 & \\
\hline Late night & 16 & 21.1 & & 9 & 15.5 & \\
\hline Unknown & 6 & 7.9 & & 1 & 1.7 & \\
\hline \multicolumn{7}{|l|}{ Outcome of incident $\mathrm{t}^{\mathrm{b}}$} \\
\hline Arrest & 27 & 35.5 & $* * *$ & 21 & 36.2 & $* * *$ \\
\hline $\begin{array}{l}\text { Lethal force/suicide by } \\
\text { cop }\end{array}$ & 20 & 26.3 & & 7 & 12.1 & \\
\hline $\begin{array}{l}\text { Suicide/attempted } \\
\text { suicide }\end{array}$ & 11 & 14.5 & & 24 & 41.4 & \\
\hline Other & 18 & 23.7 & & 6 & 10.3 & \\
\hline \multicolumn{7}{|l|}{ Claims of responsibilityb } \\
\hline Yes & 17 & 22.4 & $* * *$ & 1 & 1.7 & *** \\
\hline No & 59 & 77.6 & & 57 & 98.3 & \\
\hline \multicolumn{7}{|l|}{ Threatening statements ${ }^{b}$} \\
\hline No statements & 47 & 61.8 & $n s$ & 43 & 74.1 & $n s$ \\
\hline Direct statements & 23 & 30.3 & & 8 & 13.8 & \\
\hline Indirect statements & 6 & 7.9 & & 7 & 12.1 & \\
\hline
\end{tabular}

Note. Significance tests based on whether there is a statistically significant relationship between incident type and event variables. All 'unknown' categories for every variable were excluded from significance testing analyses.

$n s=$ nonsignificant.

aWhen the minimum number of fatalities for lone actors is set to one $(n=76)$.

bChi-square.

cThe $t$ test.

dWhen the minimum number of fatalities for lone actors is set to three $(n=35)$.

${ }^{*} p \leq .05 .{ }^{* *} p \leq .01 .{ }^{* * *} p \leq .001$ (two-tailed).

Concerning modus operandi for the incidents overall, events were typically carried out using firearms ( $n=94 ; 70.1 \%$ ), and the most common types were semiautomatic and automatic $(n=30 ; 22.4 \%)$. This was followed by a combination of methods ( $n=14 ; 10.4 \%$ ) and to a lesser extent by knives, explosives/bombs, and vehicles (see Table 7). The majority of perpetrators targeted specific victims for their attacks $(n=92,68.7 \%)$, and predominantly attacked strangers $(n=98 ; 73.1 \%)$, whereas school-related and personal victims were the least likely to be targeted $(n=$ $4 ; 3 \%)$. Open commercial ( $n=60 ; 44.8 \%)$ or public streets $(n=29 ; 21.6 \%)$ were the most prevalent location targets, while military settings were the least prevalent $(n=3$; 2.2\%). The most common level of planning ${ }^{27}$ perpetrators dedicated to the incident was medium-level (this level concerns perpetrators who planned the event months in advance and bought weapons to practice with; $n=71 ; 53 \%$ ); followed by low-level (i.e.

${ }^{27}$ The distinction between the levels of planning refers to the amount of time and dedication placed into planning the incident. 
planning which occurred minutes or hours prior to the incident; $n=26 ; 19.4 \%$ ); and high-level (i.e. perpetrators who planned the event at least a year in advance, and who engaged in event rehearsals, bought weapons, and acquired tactical information; $n=$ $16 ; 11.9 \%)$.

In terms of the outcome of incidents, the majority of incidents resulted in arrest ( $n=48 ; 35.8 \%$ ), followed by suicide $(n=35 ; 26.1 \%)$, lethal force/suicide by cop ( $n=$ 27; 20.1\%), and other ${ }^{28}(n=24 ; 17.9 \%$, see Table 7$)$. The majority of incidents lasted less than 30 minutes $(n=111 ; 82.8 \%)$, followed by a duration of 1 to 5 hours $(n=16$; $11.9 \%$ ). The most common time of day for incidents to occur was in the morning ( $\mathrm{n}=$ $41 ; 30.6 \%)$, followed by afternoon ( $n=34 ; 25.4 \%)$, evening ( $n=27 ; 20.1 \%)$ and late night ( $n=25 ; 18.7 \%)$. Claims of responsibility only occurred in 18 incidents $(13.4 \%)$, as an individual and/or group did not claim responsibility for the majority of the attacks. Perpetrators delivered direct threatening statements to their victims prior to and/or during the attack in 31 incidents (23.1\%), and indirect threatening statements were made in 13 incidents (9.7\%); however, the majority of perpetrators did not deliver threatening statements to their victims ( $n=90 ; 67.2 \%)$.

Between-groups differences. The following section will examine differences between lone actor and rampage shooting incidents regarding event characteristics, using independent samples t-tests and chi-square tests (see Table 7 for levels of significance). Statistically significant differences were found between groups in terms of location, ${ }^{29}$ number of perpetrators, modus operandi, the relationship between the perpetrator and victim, location type, attack type, level of planning, the outcome of the incident, and claims of responsibility (see Table 8 for a full list of significant variables). An independent samples t-test was conducted to compare the number of perpetrators for lone actor and rampage shooting incidents, and results revealed a significant difference in the number of perpetrators for lone actor $(M=1.33$, $S D=.855)$ and rampage shooting events $(M=1.05, S D=.292) ; t(96.66)=2.63, p=$ .01 (two-tailed), $\eta^{2}=.05$. For lone actor events, over $80 \%$ were committed by one offender, and the remaining events by two or more offenders; comparably,

28 This includes incidents where perpetrators were not captured for an extended period of time.

29 Note: Differences regarding location are discussed in the location analyses section of the results. 
approximately $97 \%$ of rampage shooting events were committed by one offender, and few events were committed by two or more offenders.

Table 8

Significant Variables in Bivariate Analyses Comparing Rampage Shootings and Lone-Actor Terrorism

\begin{tabular}{|c|c|c|c|}
\hline Event & Sociodemographic & Personal & Motivational \\
\hline Location (region) $* * *$ & $\operatorname{Age}^{* *}$ & Work/school & Emotional triggers ${ }^{* * *}$ \\
\hline Number of & Race/ethnicity ${ }^{* * *}$ & issues* ${ }^{*}$ & Relationship and/or \\
\hline perpetrators ${ }^{* *}$ & Job status* & Substance use ${ }^{*}$ & domestic issues ${ }^{* * *}$ \\
\hline Modus operandi ${ }^{* * *}$ & Religious & Fascination with & Personal grievances ${ }^{* * *}$ \\
\hline Relationship to & affiliation ${ }^{* * *}$ & weapons/war*** & Political and/or \\
\hline victim $* * *$ & & Low self-esteem ${ }^{* *}$ & religious $^{* * *}$ \\
\hline Location type ${ }^{* * *}$ & & Precipitating & Unclear and/or \\
\hline Attack type ${ }^{*}$ & & events ${ }^{* * *}$ & unknown ${ }^{* * *}$ \\
\hline \multicolumn{4}{|l|}{ Level of planning ${ }^{* *}$} \\
\hline \multicolumn{4}{|l|}{ Outcome of incident ${ }^{* * *}$} \\
\hline Claims of & & & \\
\hline responsibility*** & & & \\
\hline
\end{tabular}

Note. A statistically significant relationship was found between incident type and the above event, sociodemographic, personal, and motivational variables.

${ }^{*} p \leq .05 .{ }^{* *} p \leq .01 .{ }^{* * *} p \leq .001$ (two-tailed).

Other event-based differences between lone actor and rampage shooting attacks included the number of fatalities (see Table 7). Results revealed that there was not a significant difference in the average number of fatalities for lone actor $(M=6.59$, $S D=13.72)$ and rampage shooting events $(M=7.50, S D=8.46)$, when the fatality criteria for lone actor events was one or more fatalities; $t(132)=-.44, p=.66$ (twotailed), $\eta^{2}=-.001$ (see Figure 2 for a depiction of the average number of fatalities for incidents between 2010 and 2018). There was also no significant difference in the average number of fatalities for lone actor $(M=12.74, S D=18.52)$ and rampage shooting events $(M=7.50, S D=8.46)$ when the criteria for lone actor events was restricted to three or more fatalities to make the analysis more comparable; $t(42.7)=$ $1.58, p=.12$ (two-tailed), $\eta^{2}=.03$. 


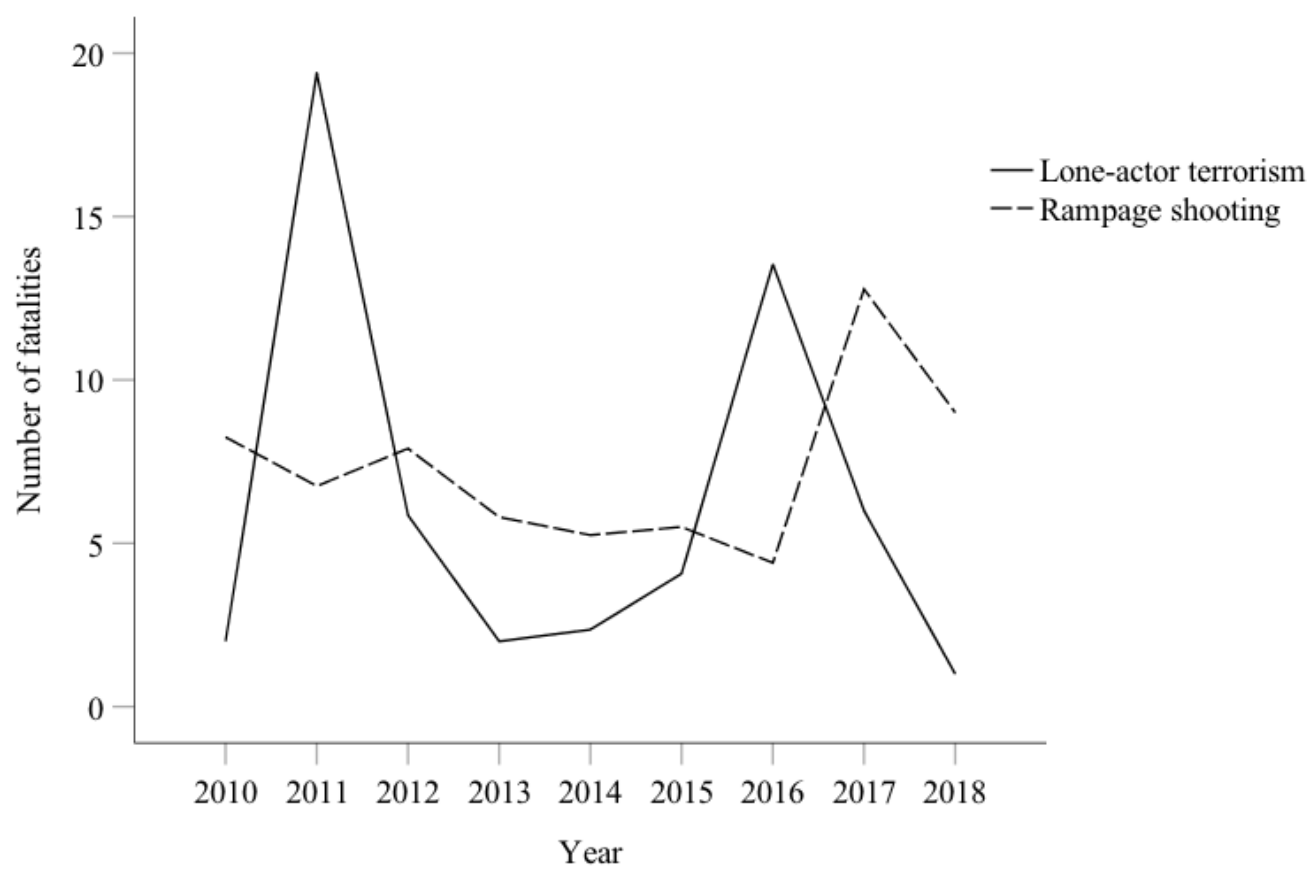

Figure 2. Average number of fatalities for lone actor and rampage shooting incidents across the years (2010 to 2018).

Alongside this, there was no significant difference in the number of casualties for lone actor $(M=28.53, S D=105.06)$ and rampage shooting events $(M=17.28, S D$ $=73.05$ ); $t(132)=.70, p=.49$ (two-tailed), $\eta^{2}=.004$ (see Figure 3 for an illustration of the average number of casualties for incidents between 2010 and 2018). There was no significance difference found between the total number of victims for lone actor ( $M$ $=35.12, S D=112.61)$ and rampage shooting events $(M=25.59, S D=80.10)$, when the fatality criteria for lone actor events was one or more fatalities; $t(132)=.55, p=.59$ (two-tailed), $\eta^{2}=.002$. There was also no significant difference in the total number of victims for lone actor $(M=67.57, S D=159.54)$ and rampage shooting events $(M=$ 25.59, $S D=80.1)$ when the criteria for lone actor events was restricted to three or more fatalities; $t(44.5)=1.45, p=.15$ (two-tailed), $\eta^{2}=.004$. 


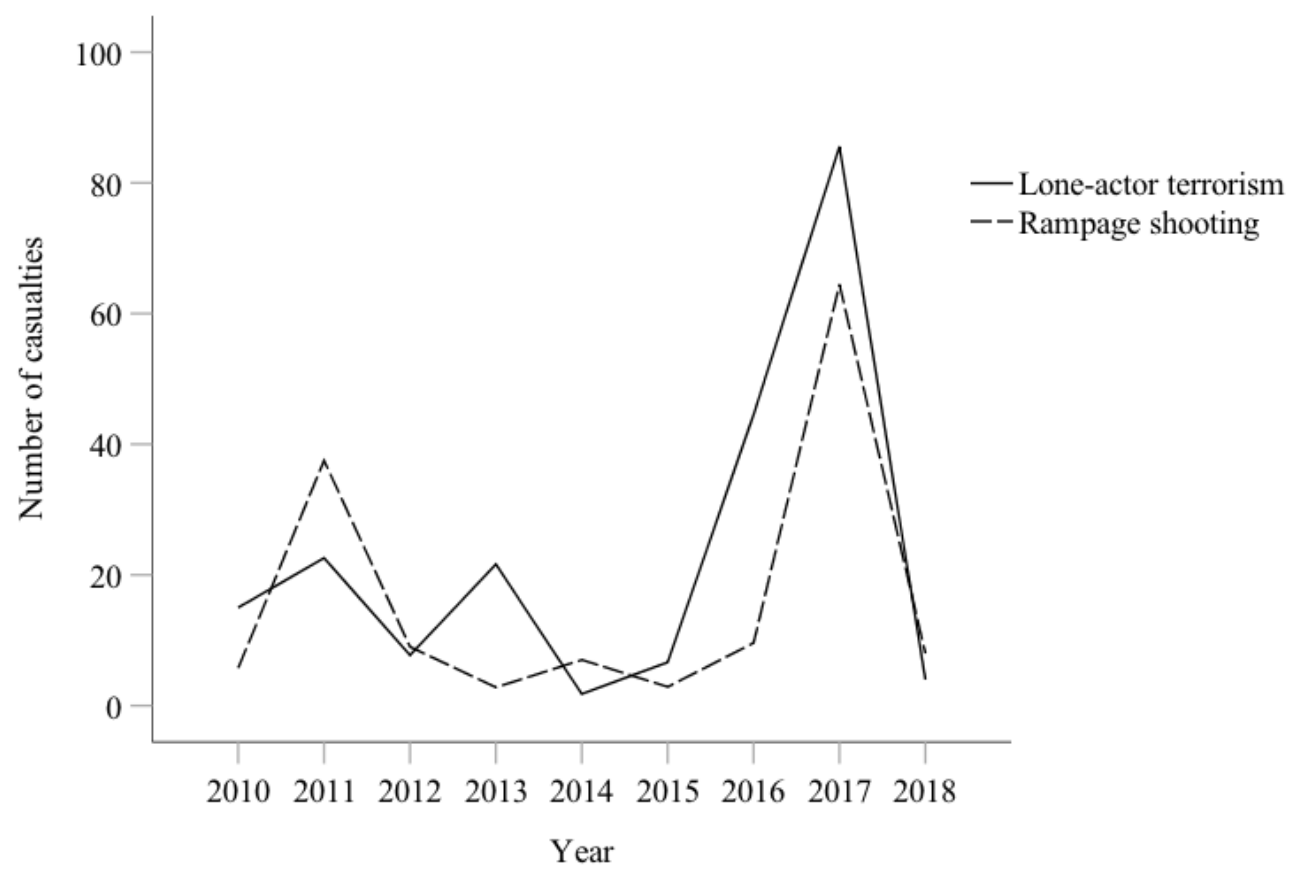

Figure 3. Average number of casualties for lone actor and rampage shooting incidents across the years (2010 to 2018).

In terms of modus operandi, a significant difference was found for weapons used in lone actor events versus rampage shooting events, $\chi^{2}(5)=25.94, p<.001$ (see Table 7). The most commonly-used weapons in rampage shootings were firearms ( $n=$ $52 ; 89.7 \%)$, compared to lone actor events which alongside firearms ( $n=42 ; 55.3 \%)$, were more likely to involve the use of sharp instruments such as knives ( $n=8 ; 10.5 \%$ ), explosives/bombs ( $n=8 ; 10.5 \%)$, or vehicles $(n=6 ; 7.9 \%)$. A significant difference was found between lone actor and rampage shooting events in terms of the relationship between the perpetrator and victim, $\chi^{2}(4)=41.94, p<.001$. While lone actor events were predominantly aimed toward strangers $(n=71 ; 93.4 \%)$, a lesser percentage of rampage shootings targeted strangers $(n=27 ; 46.6 \%)$. Rampage shootings were typically aimed toward individuals the perpetrators had a professional relationship with ( $n=11 ; 19 \%)$ or individuals they were related to in various ways (i.e. personal or school relationships). As for location type, a significant difference was found regarding the type of location lone actor and rampage shooting events took place, $\chi^{2}(7)=24.65, p \leq .001$. Although lone actor and rampage shooting perpetrators were more likely to commit their attacks in open commercial settings ( $n=36 ; 47.4 \%$ and $n=24 ; 41.4 \%$, respectively), lone actor events were more likely to occur on a public street $(n=24 ; 31.6 \%)$ or in private areas such as offices $(n=3 ; 3.9 \%)$. Comparably, rampage shootings were more likely to be carried out at educational institutions (i.e. 
university campuses or schools; $n=8 ; 13.8 \%)$, military settings ( $n=3 ; 5.2 \%)$, or at a warehouse/factory $(n=5 ; 8.6 \%)$.

Significant differences were also found between lone actor and rampage shooting events regarding attack type, $\chi^{2}(3)=9.74, p=.021$. While rampage shootings were predominantly armed assault attacks ( $n=56$; 96.6\%), attack types used by loneactor terrorists varied between armed assault ( $n=67 ; 88.2 \%$ ), bombing/explosion ( $n$ $=7 ; 9.2 \%$ ), and assassination ( $n=2 ; 2.6 \%$ ) types (see Table 7 ). The level of planning dedicated to incidents also differed significantly between groups, $\chi^{2}(2)=9.54, p=.01$. Although both lone actors and rampage shooters were more likely to dedicate a medium-level of planning to their attacks $(n=50 ; 69.4 \%$ and $n=27 ; 50.9 \%$, respectively), lone actors were more likely to engage in a high-level of planning ( $n=$ $12 ; 16.7 \%)$ compared to rampage shooters $(n=6 ; 11.3 \%)$, whereas rampage shooters were more likely to engage in low-levels of planning $(n=20 ; 37.7 \%)$. Significant differences were also found regarding the outcome of lone actor and rampage shooting incidents, $\chi^{2}(3)=15.70, p \leq .001$. The majority of lone actor events ended in arrest ( $n$ $=27 ; 35.5 \%$ ), whereas the majority of rampage shooting events ended in the perpetrator committing suicide $(n=24 ; 41.4 \%)$. For rampage shooting incidents, arrest was the second most likely outcome ( $n=21 ; 36.2 \%$ ), followed by lethal force/suicide by cop ( $n=7 ; 12.1 \%)$, and 'other' outcomes ( $n=6 ; 10.3 \%)$. Comparably, lethal force/suicide by cop was the second most likely outcome for lone actors $(n=20$; $26.3 \%$ ), followed by 'other' outcomes ( $n=18 ; 23.7 \%)$, and suicide ( $n=11 ; 14.5 \%)$. Lone actor incidents were significantly more likely than rampage shooting incidents to have perpetrators and/or groups claim responsibility for the attacks, $\chi^{2}(1)=12.06, p \leq .001$. Claims of responsibility were made by an individual and/or group in $22.4 \%$ of lone actor incidents, compared to only one rampage shooting incident (1.7\%).

Other event-based differences between lone actor and rampage shooting incidents included weapon subtypes used, whether there were specific targets for each incident, the duration and time of incidents, whether threatening statements were made prior to and/or during the attack, and the year incidents occurred in (see Figure 4 for an illustration of the number of incidents for both groups between 2010 and 2018). However, these differences were not statistically significant at the $p \leq .05$ level. 


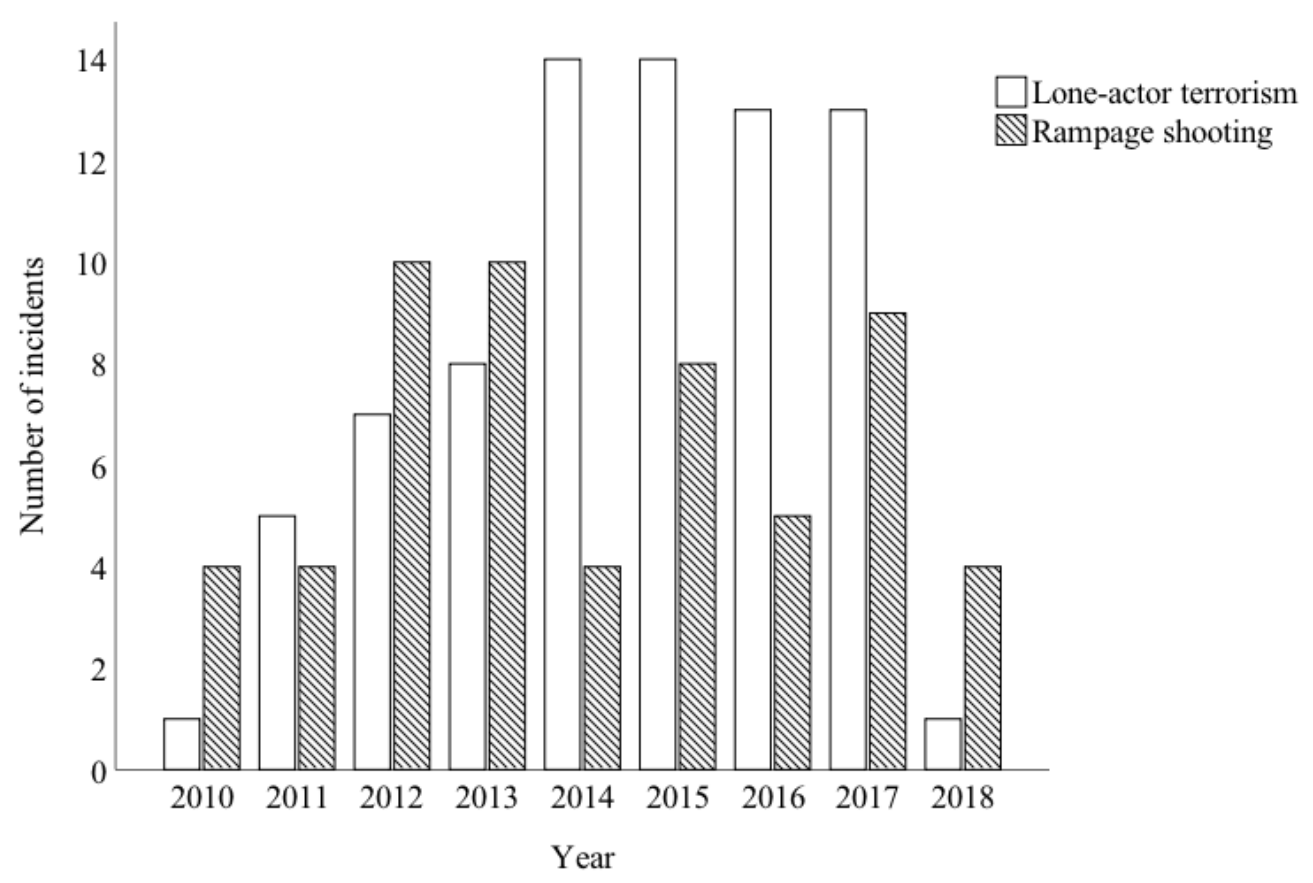

Figure 4. Lone actor and rampage shooting incidents across the years (2010 to 2018).

\section{Sociodemographic Characteristics}

Lone actor and rampage shooting perpetrators were almost exclusively male ( $n$ $=150 ; 96.8 \%)$ and on average were 32 years old $(M=32.34 ; S D=11.35)$. In terms of race/ethnicity, the majority of perpetrators were 'other' $(n=60 ; 38.7 \%)$, followed by White ( $n=59 ; 38.1 \%$ ), and Black/African American ( $n=21 ; 13.5 \%)$; perpetrators were less likely to be American Indian or Alaska Native $(n=6 ; 3.9 \%)$, Hispanic or Latino ( $n$ $=4 ; 2.6 \%)$, Asian ( $n=2 ; 1.3 \%)$, or mixed race/ethnicity $(n=2 ; 1.3 \%)$. As illustrated in Table 9, for the majority of perpetrators, the highest form of education they held was secondary education $(n=102 ; 65.8 \%)$, followed by tertiary education $(n=33 ; 21.3 \%)$. The majority of perpetrators did not have children and/or dependents ( $n=105 ; 67.7 \%)$ and were single ( $n=84 ; 54.2 \%) ; 22.6 \%$ were married and only $11 \%$ were in a relationship (but not married). In terms of job status, over $40 \%$ of perpetrators were unemployed $(n=63)$ and the majority of perpetrators who were employed were bluecollar workers ( $n=38 ; 24.5 \%$ ). The most prevalent religious affiliation of perpetrators was Muslim ( $n=63 ; 40.6 \%)$, whereas perpetrators were less likely to identify as Christian, Buddhist, Atheist, Agnostic, non-religious, or 'other.' 
Table 9

Sociodemographic Characteristics of Lone-Actor Terrorism Versus Rampage Shooting Perpetrators

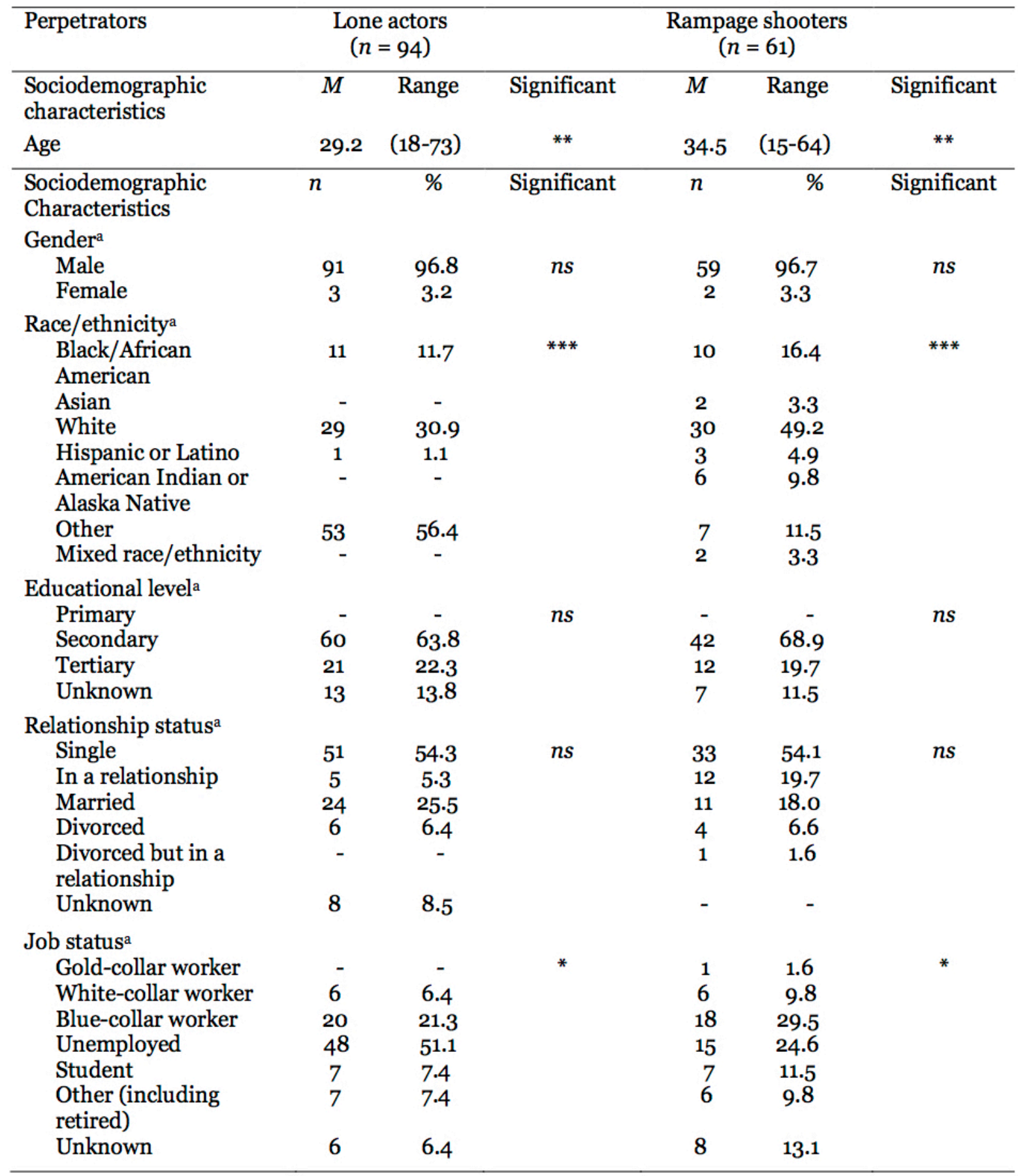


Table 9 (continued)

\begin{tabular}{lcccccc}
\hline Religious affiliation & a & & & & & \\
$\quad$ Christian & 5 & $5 \cdot 3$ & $* *$ & 8 & 13.1 & $* *$ \\
Muslim & 58 & 61.7 & & 5 & 8.2 & \\
Buddhist & - & - & & 1 & 1.6 & \\
Atheist & - & - & & 4 & 6.6 & \\
Agnostic & - & - & & 1 & 1.6 & \\
Hindu & - & - & & - & - & \\
Jewish & - & - & & - & - & \\
Non-religious & 2 & 2.1 & & 5 & 8.2 & \\
Other & 6 & 6.4 & & 2 & 3.3 & \\
$\quad$ Unknown & 23 & 24.5 & & 35 & 57.4 & \\
Children/dependents & \\
Yes & & & & & & \\
No & 24 & 25.5 & $n s$ & 20 & 32.8 & \\
Unknown & 64 & 68.1 & & 41 & 67.2 & - \\
\hline
\end{tabular}

Note. Significance tests based on whether there is a statistically significant relationship between incident type and sociodemographic variables.

$n s=$ nonsignificant.

${ }^{a}$ Chi-square.

${ }^{*} p \leq .05 .{ }^{* *} p \leq .01 .{ }^{* * *} p \leq .001$ (two-tailed).

Between-groups differences. The next section will analyse differences between lone actor and rampage shooters based on sociodemographic characteristics using an independent samples t-test and chi-square tests (see Table 9 for levels of significance). Statistically significant differences were found between lone-actor terrorists and rampage shooters in terms of age, race/ethnicity, job status, and religious affiliation (refer to Table 8). Figure 5 illustrates the number of lone-actor terrorists and rampage shooters who fall under each age group. As this graph indicates, lone-actor terrorists $(M=29.23 ; S D=9.63)$ were significantly younger on average than rampage shooters $(M=34.54 ; S D=12.47) ; t(108)=-2.79, p=.006$ (twotailed), $\eta^{2}=-.06$. On average, lone-actor terrorists were in their late 20s, whereas rampage shooters were older and were typically in their young to mid $30 s$. 


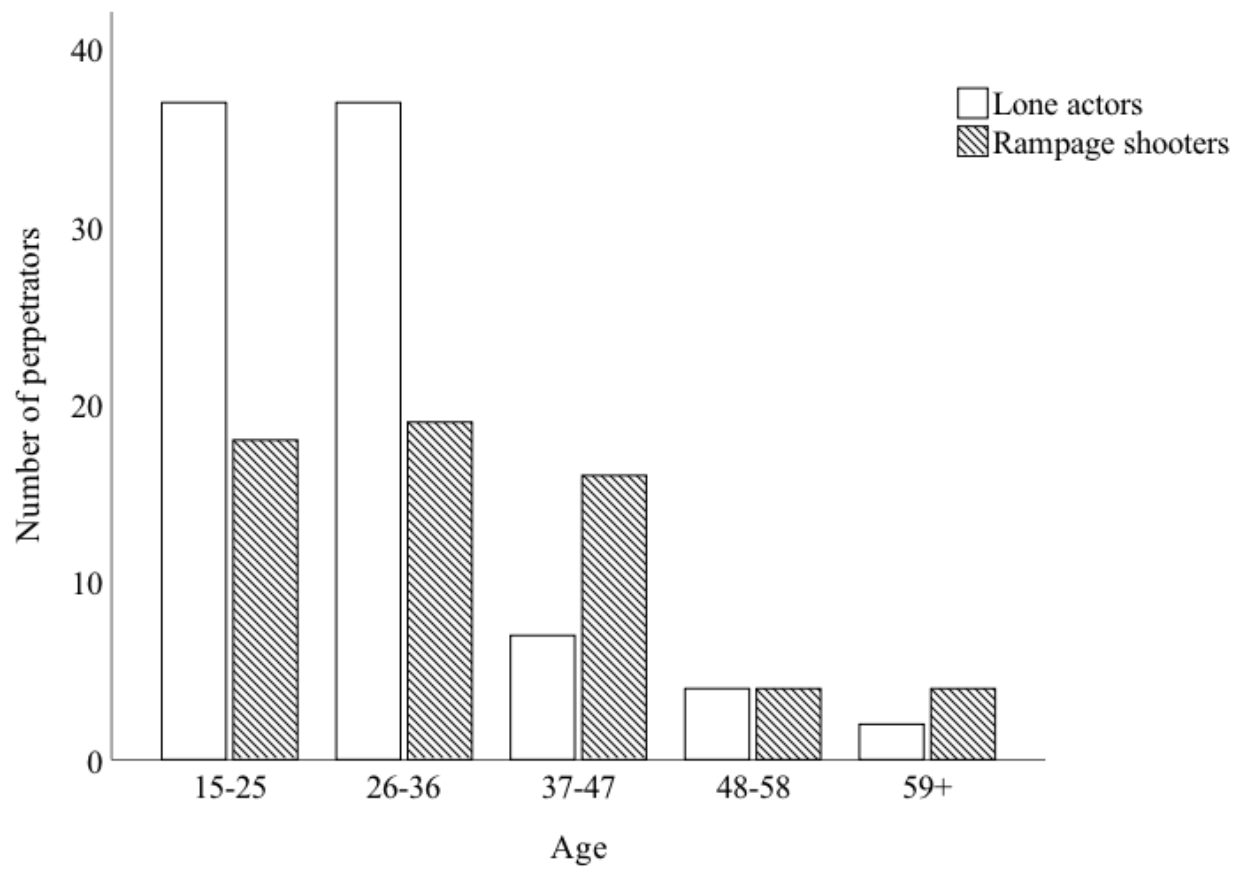

Figure 5. The number of lone actor terrorism and rampage shooting perpetrators who fall under each age group.

A significant difference was found between lone actor and rampage shooting perpetrators regarding race/ethnicity, $\chi^{2}(6)=40.81, p \leq .001$ (see Table 9). The majority of lone-actor terrorists were part of the 'other' group ( $n=53 ; 56.4 \%)$, followed by White $(n=29 ; 30.9 \%)$, and a small percentage of these individuals were Black/African American ( $n=11 ; 11.7 \%)$, or Hispanic or Latino $(n=1 ; 1.1 \%)$. In comparison to this, the majority of rampage shooters were White $(n=30 ; 49.2 \%)$, followed by Black/African American ( $n=10,16.4 \%)$. A small percentage of rampage shooters were part of the 'other' group ( $n=7 ; 11.5 \%)$, or Hispanic or Latino ( $n=3$; $4.9 \%$ ), however unlike lone actors, a small portion of rampage shooters also belonged to Asian, American Indian or Alaska Native, and mixed race/ethnicity groups. For those whom data were available, a significant difference was found between lone actors and rampage shooters regarding job status, $\chi^{2}(3)=9.27, p=.026$. In terms of unemployment levels, lone-actor terrorists were significantly more likely to be unemployed $(n=48 ; 51.1 \%)$ than rampage shooters $(n=15 ; 24.6 \%)$. Rampage shooters were more likely to occupy blue-collar (29.5\%) and white-collar jobs (9.8\%) when compared to lone actors (21.3\% of lone actors were blue-collar workers, and $6.4 \%$ were white-collar workers). The percentage of perpetrators who were students in both groups was also slightly higher for rampage shooters ( $n=7 ; 11.5 \%)$ compared to lone actors $(n=7 ; 7.4 \%)$. 
A significant difference was found between lone actors and rampage shooters concerning religious affiliation, $\chi^{2}(6)=42.93, p<.001$ (see Table 9). Rampage shooters were more likely to identify as Christian $(n=8 ; 13.1 \%)$ than lone actors $(n=$ $5 ; 5.3 \%$ ), whereas lone actors were more likely to identify as Muslim ( $n=58 ; 61.7 \%)$ compared to rampage shooters $(n=5 ; 8.2 \%)$. A small number of rampage shooters identified as Buddhist, Atheist, and Agnostic, whereas no lone actors in the sample identified as these religions, and neither lone actor nor rampage shooters identified as Hindu or Jewish. Furthermore, rampage shooters were more likely to identify as nonreligious $(n=5 ; 8.2 \%)$ than lone actors $(n=2 ; 2.1 \%)$, whereas lone actors were more likely to belong to 'other' religions ( $n=6 ; 6.4 \%$ ) when compared to rampage shooters $(n=2 ; 3.3 \%)$.

As for gender, educational level, relationship status, and children/dependents, the two groups did not differ significantly across these variables at the $p \leq .05$ level (see Table 9).

\section{Personal Characteristics}

For the most part, perpetrators either did not experience any issues and/or grievances with individuals at their workplace or school in the six months leading up to the incident ( $n=49 ; 31.6 \%$ ), or these issues were not applicable to their current situation (i.e. they were not in school or were unemployed; $n=48 ; 31 \%$ ). As indicated in Table 10, the number of perpetrators who experienced workplace or school issues ( $n=46)$ was slightly less than those who did not $(n=49)$. As for childhood issues, there was no evidence that the majority of perpetrators experienced issues and/or troubles during their upbringing $(n=101 ; 65.2 \%)$. However, approximately a quarter of perpetrators experienced some form of issues and/or troubles ( $n=40 ; 25.8 \%)$, and just under 10 percent experienced significant issues and/or troubles ( $n=14 ; 9 \%)$. For the majority of perpetrators, there were no indications they had engaged in either substance or alcohol abuse in the past or prior to the incident ( $n=99 ; 63.9 \%)$. However, 21.9\% of perpetrators displayed indications of having engaged in illegal substance use and/or abuse $(n=34), 3.2$ percent displayed indications of having engaged in alcohol abuse $(n=5)$, and $11 \%$ displayed indications of having engaged in both illegal substance use and/or abuse and alcohol abuse $(n=17)$. 
Table 10

Personal Characteristics of Lone-Actor Terrorism Versus Rampage Shooting Perpetrators

\begin{tabular}{|c|c|c|c|c|c|c|}
\hline \multirow{2}{*}{$\begin{array}{l}\text { Perpetrators } \\
\text { Personal characteristics }\end{array}$} & \multicolumn{2}{|c|}{$\begin{array}{l}\text { Lone actors } \\
\qquad(n=94)\end{array}$} & \multicolumn{4}{|c|}{$\begin{array}{c}\text { Rampage shooters } \\
(n=61)\end{array}$} \\
\hline & $n$ & $\%$ & Significant & $n$ & $\%$ & Significant \\
\hline \multicolumn{7}{|l|}{ Work/school issues ${ }^{\mathrm{a}}$} \\
\hline Issues were present & 20 & 21.3 & * & 26 & 42.6 & * \\
\hline $\begin{array}{l}\text { Issues were not } \\
\text { present }\end{array}$ & 33 & 35.1 & & 16 & 26.2 & \\
\hline Not applicable & 32 & 34 & & 16 & 26.2 & \\
\hline Unknown & 9 & 9.6 & & 3 & 4.9 & \\
\hline \multicolumn{7}{|l|}{ Childhood issues ${ }^{\mathrm{a}}$} \\
\hline $\begin{array}{l}\text { Evidence of } \\
\text { significant issues }\end{array}$ & 8 & 8.5 & $n s$ & 6 & 9.8 & $n s$ \\
\hline $\begin{array}{l}\text { Evidence of some } \\
\text { form of issues }\end{array}$ & 29 & 30 & & 11 & 18 & \\
\hline No evidence of issues & 57 & 60.6 & & 44 & 72.1 & \\
\hline \multicolumn{7}{|l|}{ Substance use ${ }^{a}$} \\
\hline $\begin{array}{l}\text { Indications of illegal } \\
\text { substance use and/or } \\
\text { abuse }\end{array}$ & 28 & 29.8 & * & 6 & 9.8 & $*$ \\
\hline $\begin{array}{l}\text { Indications of } \\
\text { alcohol abuse }\end{array}$ & 2 & 2.1 & & 3 & 4.9 & \\
\hline $\begin{array}{l}\text { Indications of both of } \\
\text { the above }\end{array}$ & 8 & 8.5 & & 9 & 14.8 & \\
\hline No indications & 56 & 59.6 & & 43 & 70.5 & \\
\hline \multicolumn{7}{|l|}{ Weapon ownership ${ }^{a}$} \\
\hline Yes & 73 & 77.7 & $n s$ & 46 & 75.4 & $n s$ \\
\hline No & 6 & 6.4 & & 10 & 16.4 & \\
\hline Unknown & 15 & 16 & & 5 & 8.2 & \\
\hline \multicolumn{7}{|l|}{$\begin{array}{l}\text { Fascination with } \\
\text { weapons/war }\end{array}$} \\
\hline Yes & 71 & $75 \cdot 5$ & ** & 44 & 72.1 & ** \\
\hline No & 1 & 1.1 & & 6 & 9.8 & \\
\hline Unknown & 22 & 23.4 & & 11 & 18 & \\
\hline \multirow{2}{*}{\multicolumn{7}{|c|}{$\begin{array}{l}\text { Familiarity with } \\
\text { firearm } \mathrm{s}^{\mathrm{a}}\end{array}$}} \\
\hline \multicolumn{2}{|l|}{ firearms ${ }^{\mathrm{a}}$} & & & & & \\
\hline Yes & 58 & 61.7 & $n s$ & 58 & 95.1 & $n s$ \\
\hline No & 2 & 2.1 & & - & - & \\
\hline Unknown & 34 & 36.2 & & 3 & 4.9 & \\
\hline \multicolumn{7}{|l|}{ Military experience ${ }^{a}$} \\
\hline $\begin{array}{l}\text { Did have prior } \\
\text { experience }\end{array}$ & 14 & 14.9 & $n s$ & 13 & 21.3 & $n s$ \\
\hline $\begin{array}{l}\text { Did not have prior } \\
\text { experience }\end{array}$ & 73 & $77 \cdot 7$ & & 46 & $75 \cdot 4$ & \\
\hline Unknown & 7 & 7.4 & & 2 & $3 \cdot 3$ & \\
\hline
\end{tabular}


Table 10 (continued)

\begin{tabular}{|c|c|c|c|c|c|c|}
\hline \multicolumn{7}{|l|}{$\begin{array}{l}\text { Ideological } \\
\text { connections/group } \\
\text { affiliations }^{\mathrm{a}}\end{array}$} \\
\hline $\begin{array}{l}\text { Evidence of group } \\
\text { connections }\end{array}$ & 5 & $5 \cdot 3$ & $n s$ & - & - & $n s$ \\
\hline $\begin{array}{l}\text { No evidence of group } \\
\text { connections }\end{array}$ & 89 & 94.7 & & 61 & 100 & \\
\hline \multicolumn{7}{|l|}{ Precipitating events ${ }^{\mathrm{a}}$} \\
\hline No clear event & 65 & 69.1 & *** & 18 & 29.5 & *** \\
\hline Relationship-related & 5 & $5 \cdot 3$ & & 7 & 11.5 & \\
\hline Occupation-related & 3 & 3.2 & & 5 & 8.2 & \\
\hline School-related & - & - & & 2 & $3 \cdot 3$ & \\
\hline Personal-related & 17 & 18.1 & & 16 & 26.2 & \\
\hline Combination & 4 & 4.3 & & 13 & 21.3 & \\
\hline
\end{tabular}

Note. Significance tests based on whether there is a statistically significant relationship between incident type and perpetrator-level variables.

$n s=$ nonsignificant.

${ }^{a}$ Chi-square.

${ }^{*} p \leq .05 .{ }^{* *} p \leq .01 .{ }^{* * *} p \leq .001$ (two-tailed).

In terms of weapon ownership, the majority of perpetrators owned weapons prior to the incident ( $n=119 ; 76.8 \%$ ), and $74.8 \%$ of perpetrators had a pre-existing familiarity with firearms ( $n=116$, see Table 10). Alongside this, the majority of perpetrators also displayed a fascination/interest with violence30 $(n=115 ; 74.2 \%)$, however the majority of perpetrators did not have prior military experience $(n=119$; $76.8 \%)$. There was no evidence that the vast majority of perpetrators held ideological connections and/or affiliations with ideological groups (96.8\%), and only five out of 155 perpetrators in this sample [allegedly] held group connections (3.2\%). Just over half of the sample of perpetrators experienced no clear precipitating circumstances or events that occurred in their life in the six months prior to the incident which could have affected their decision to carry out the attack ( $n=68 ; 50.7 \%)$. However, of the perpetrators that did experience a precipitating event, the majority experienced a personal-related event (21.6\%), followed by a relationship-related event (9\%). Small percentages of perpetrators also experienced an occupation-related event, a schoolrelated event, or an event which classifies as 'other' and $11.2 \%$ of perpetrators experienced a combination of precipitating events.

Between-groups differences. The following section will examine differences between lone actor and rampage shooting perpetrators regarding personal

30 This also includes the ownership of material associated with war and/or terrorism, or weapons. 
characteristics, through the use of chi-square tests (see Table 10 for levels of significance). Comparing lone actor and rampage shooting perpetrators, statistically significant differences were found between groups in terms of work/school issues, substance use, fascination with weapons/war, and precipitating events (refer to Table 8). A significant difference was found between lone actors and rampage shooters in relation to workplace and/or school issues, $\chi^{2}(2)=7.17, p=.028$. Rampage shooters were significantly more likely to experience workplace and/or school issues $(n=26$; 42.6\%) than lone actors $(n=20 ; 21.3 \%)$. The majority of lone actors did not experience any workplace and/or school issues ( $n=33 ; 35.1 \%)$, compared to a smaller percentage of rampage shooters $(n=16 ; 26.2 \%)$.

A significant difference between groups was also found in terms of substance use and/or abuse, $\chi^{2}(3)=9.61, p=.022$ (see Table 10). When examining differences between lone actors and rampage shooters, a higher percentage of rampage shooters ( $n=43 ; 70.5 \%$ ) displayed no indications of engaging in either substance or alcohol abuse, when compared to the lone actor group ( $n=56 ; 59.6 \%)$. Lone actors were more likely to display indications of engaging in illegal substance use and/or abuse $(n=28$; 29.8\%), compared to rampage shooters ( $n=6$; 9.8\%). However, rampage shooters were more likely to display indications of alcohol abuse $(n=3 ; 4.9 \%)$ than lone actors ( $n=2 ; 2.1 \%$ ), and were also more likely to display indications of both illegal substance use and/or abuse and alcohol abuse $(n=9 ; 14.8 \%)$ when compared to lone actors $(n=$ $8 ; 8.5 \%)$.

Significant differences were found between lone actors and rampage shooters when comparing the two groups regarding whether they had a fascination with weapons and/or war, $\chi^{2}(1)=6.14, p=.013$ (see Table 10). Lone actors were more likely to have a fascination with weapons and/or war ( $n=71 ; 75.5 \%)$ compared to rampage shooters ( $n=44 ; 72.1 \%)$. There was also a significant difference between lone actors and rampage shooters in their experiences of precipitating events prior to the attack, $\chi^{2}(5)=28.51, p<$.001. Lone actors were more likely to experience no clear event in the lead up to the incident ( $n=65 ; 69.1 \%$ ) compared to rampage shooters ( $n=18 ; 29.5 \%$ ), and less likely to experience relationship-related events (5.3\% versus $11.5 \%)$, occupation-related events (3.2\% versus $8.2 \%)$, personal-related events $(18.1 \%$ versus 26.2\%), and a combination of events (4.3\% versus 21.3\%). Alongside this, a small percentage of rampage shooters also experienced school-related events (3.3\%), 
whereas no lone actors experienced school-related events.

As for childhood issues, weapon ownership, familiarity with firearms, military experience, and ideological connections and/or group affiliations, the two groups of perpetrators did not differ significantly across these variables at the $p \leq .05$ level (see Table 10).

\section{Psychological Background and Violent History}

As displayed in Table 11, the majority of lone actor and rampage shooting perpetrators displayed antisocial personality traits prior to the incident $(n=101$, $65.2 \%)$. In approximately a quarter of all perpetrators $(n=39 ; 25.2 \%)$ there was evidence of mental health issues and/or disorder(s) (i.e. there was evidence of an official diagnosis by a mental health professional), and approximately one third displayed indications of mental health issues and/or disorder(s) ( $n=53 ; 34.2 \%)$. Comparably, 29\% of perpetrators displayed no indications or evidence of mental health issues and/or disorder(s) $(n=45)$. Evidence that the perpetrators experienced some form of social isolation in their lives was reported for approximately one third of perpetrators ( $n=54 ; 34.8 \%$ ), and a small percentage of perpetrators displayed indications that they experienced extreme social isolation $(n=4,2.6 \%)$. However, the majority of perpetrators did not display any indications of social isolation $(n=83$; $53 \cdot 5 \%)$. 
Table 11

Psychological Background and Violent History of Lone-Actor Terrorism Versus Rampage Shooting Perpetrators

\begin{tabular}{|c|c|c|c|c|c|c|}
\hline \multirow{2}{*}{$\begin{array}{l}\text { Perpetrators } \\
\text { Perpetrator } \\
\text { characteristics } \\
\text { Antisocial personality } \\
\text { traits }^{\mathrm{a}}\end{array}$} & \multicolumn{2}{|c|}{$\begin{array}{l}\text { Lone actors } \\
(n=94)\end{array}$} & \multicolumn{4}{|c|}{$\begin{array}{l}\text { Rampage shooters } \\
\qquad(n=61)\end{array}$} \\
\hline & $n$ & $\%$ & Significant & $n$ & $\%$ & Significant \\
\hline $\begin{array}{l}\text { Traits displayed } \\
\text { prior to incident }\end{array}$ & 56 & 59.6 & $n s$ & 45 & 73.8 & $n s$ \\
\hline $\begin{array}{l}\text { No traits displayed } \\
\text { prior to incident }\end{array}$ & 29 & 30.9 & & 15 & 24.6 & \\
\hline Unknown & 9 & 9.6 & & 1 & 1.6 & \\
\hline \multicolumn{7}{|l|}{ Low self-esteem ${ }^{a}$} \\
\hline Yes & 9 & 9.6 & ** & 14 & 23 & ** \\
\hline No & 66 & 70.2 & & 32 & 52.5 & \\
\hline Unknown & 19 & 20.2 & & 15 & 24.6 & \\
\hline \multicolumn{7}{|l|}{ Social isolation ${ }^{\mathrm{a}}$} \\
\hline $\begin{array}{l}\text { Indications of } \\
\text { extreme social } \\
\text { isolation }\end{array}$ & - & - & $n s$ & 4 & 6.6 & ns \\
\hline $\begin{array}{l}\text { Indications of some } \\
\text { form of social } \\
\text { isolation }\end{array}$ & 29 & 30.9 & & 25 & 41 & \\
\hline $\begin{array}{l}\text { No indications of } \\
\text { social isolation }\end{array}$ & 54 & 57.4 & & 29 & 47.5 & \\
\hline Unknown & 11 & 11.7 & & 3 & 4.9 & \\
\hline \multicolumn{7}{|l|}{ Mental health statusa } \\
\hline $\begin{array}{l}\text { Evidence of mental } \\
\text { health issues or } \\
\text { disorder(s) }\end{array}$ & 17 & 18.1 & $n s$ & 22 & 36.1 & $n s$ \\
\hline $\begin{array}{l}\text { Indications of } \\
\text { mental health issues } \\
\text { or disorder(s) }\end{array}$ & 31 & $33 \cdot 3$ & & 22 & 36.1 & \\
\hline $\begin{array}{l}\text { No evidence of } \\
\text { mental health issues } \\
\text { or disorder(s) }\end{array}$ & 31 & $33 \cdot 3$ & & 14 & 23 & \\
\hline Unknown & 15 & 16 & & 3 & 4.9 & \\
\hline \multicolumn{7}{|l|}{ Suicide indications ${ }^{a}$} \\
\hline $\begin{array}{l}\text { Indications were } \\
\text { found }\end{array}$ & 4 & $5 \cdot 3$ & $n s$ & 6 & 10.3 & $n s$ \\
\hline $\begin{array}{l}\text { Indications were } \\
\text { not found }\end{array}$ & 72 & $94 \cdot 7$ & & 52 & 89.7 & \\
\hline \multicolumn{7}{|l|}{ Previous violent acts ${ }^{\mathrm{a}}$} \\
\hline Yes & 40 & 42.6 & $n s$ & 27 & 44.3 & $n s$ \\
\hline No & 54 & 57.4 & & 34 & $55 \cdot 7$ & \\
\hline \multicolumn{7}{|l|}{ Previous abuse $^{\mathrm{a}}$} \\
\hline $\begin{array}{l}\text { Yes } \\
\text { No }\end{array}$ & $\begin{array}{r}7 \\
87\end{array}$ & $\begin{array}{l}7.4 \\
92.6\end{array}$ & $n s$ & $\begin{array}{c}7 \\
54\end{array}$ & $\begin{array}{l}11.5 \\
88.5\end{array}$ & $n s$ \\
\hline
\end{tabular}


Table 11 (continued)

\begin{tabular}{lllllll}
\hline Criminal history $^{\mathrm{b}}$ & & & & & & \\
Yes & 36 & 38.3 & $n s$ & 25 & 41 & $n s$ \\
No & 58 & 61.7 & & 36 & 59 & \\
\hline
\end{tabular}

Note. Significance tests based on whether there is a statistically significant relationship between incident type and psychological background and violent history variables.

$n s=$ nonsignificant.

aChi-square.

${ }^{*} p \leq .05 .{ }^{* *} p \leq .01 .{ }^{* *} p \leq .001$ (two-tailed).

Furthermore, evidence that the perpetrators suffered from low self-esteem was found in $14.8 \%$ of available cases ( $n=23$, see Table 11). As for suicide indications, the perpetrators left indications of their suicide (in events where suicide occurred) in $7.5 \%$ of cases $(n=10)$; for the majority of incidents which resulted in suicide, indications were not found ( $n=124$ ). In terms of violent history, the majority of perpetrators had not committed previous violent acts prior to the incident ( $n=88 ; 56.8 \%)$, and the majority of perpetrators did not have a criminal record $(n=94 ; 60.6 \%)$. Alongside this, the vast majority of perpetrators did not suffer from previous abuse (i.e. psychological, physical, or sexual abuse) $(n=141 ; 91 \%)$.

Between-groups differences. Using chi-square tests, this section will examine differences between lone actors and rampage shooters based on psychological backgrounds and characteristics regarding the violent history of perpetrators (see Table 11 for levels of significance). Significant differences between lone actors and rampage shooters were found for low self-esteem, $\chi^{2}(1)=6.29, p=.012$. Lone actors were significantly less likely to suffer from low self-esteem $(n=9 ; 9.6 \%)$ when compared to rampage shooters $(n=14 ; 23 \%)$. As for antisocial personality traits, social isolation, mental health status, suicide indications, previous violent acts, previous abuse, and criminal history, the two groups did not differ significantly at the $p \leq .05$ level. For whom data was available for mental health status, there appeared to be at least some indication of mental health issues and/or disorders for both lone actors $(n=48)$ and rampage shooters $(n=44)$. Rampage shooters were more likely to display both indications and evidence of mental health issues and/or disorders (for both, $n=22$; $36.1 \%$ ) compared to lone actors (for indications, $n=31 ; 33.3 \%$, and for evidence, $n=17 ; 18.1 \%$ ), although the groups did not differ significantly in this regard. 
Although not significant, key differences were present between lone actors and rampage shooters in relation to social isolation. As shown in Table 11, the majority of lone actors displayed no indications of social isolation (57.4\%), approximately 30\% displayed indications of some form of social isolation, and no perpetrators displayed indications of extreme social isolation. In comparison to this, a lesser percentage of rampage shooters displayed no indications of social isolation (47.5\%), a higher percentage displayed indications of some form of social isolation (41\%), and $6.6 \%$ displayed indications of extreme social isolation.

\section{Motivational Characteristics}

As demonstrated in Table 12, the majority of lone actor and rampage shooting perpetrators committed incidents due to political and/or religious motivations, with the intention of opposing and/or challenging the government or other organisational groups, in some manner ( $n=96 ; 61.9 \%)$. The second most prevalent motivation across groups was revenge and/or payback for perceived wrongs the perpetrators experienced by the victims $(n=41 ; 26.5 \%)$. This was closely followed by perpetrators experiencing negative emotional triggers prior to the incident which contributed to their decision to commit the attack $(n=40 ; 25.8 \%)$. Over a quarter of perpetrators committed attacks due to their perceived suffering from a personal grievance $(n=38$; 24.5\%), $13.5 \%$ of perpetrators carried out their attacks due to experiencing relationship and/or domestic issues prior to the incident $(n=21)$, and only three perpetrators committed attacks with the intent of gaining some sort of benefit or reward as a result of carrying out the attack (1.9\%). Lastly, the motivation behind the perpetrators committing the attack was unknown and/or unclear for 17 incidents (11\%). 
Table 12

Motivational Patterns of Lone-Actor Terrorism Versus Rampage Shooting Perpetrators

\begin{tabular}{|c|c|c|c|c|c|c|}
\hline \multirow{2}{*}{$\begin{array}{l}\text { Perpetrators } \\
\text { Motivational } \\
\text { characteristics } \\
\text { Motivation: emotional } \\
\text { triggersa }^{\text {a }}\end{array}$} & \multicolumn{2}{|c|}{$\begin{array}{l}\text { Lone actors } \\
(n=94)\end{array}$} & \multicolumn{4}{|c|}{$\begin{array}{l}\text { Rampage shooters } \\
(n=61)\end{array}$} \\
\hline & $n$ & $\%$ & Significant & $n$ & $\%$ & Significant \\
\hline Yes & 4 & 4.3 & *** & 36 & 59 & $* * *$ \\
\hline No & 90 & $95 \cdot 7$ & & 25 & 41 & \\
\hline $\begin{array}{l}\text { Motivation: relationship } \\
\text { or domestic issues }^{\text {a }}\end{array}$ & & & & & & \\
\hline Yes & 3 & 3.2 & *** & 18 & 29.5 & *** \\
\hline No & 91 & 96.8 & & 43 & 70.5 & \\
\hline $\begin{array}{l}\text { Motivation: } \\
\text { revenge/payback }\end{array}$ & & & & & & \\
\hline Yes & 23 & 24.5 & $n s$ & 18 & 29.5 & $n s$ \\
\hline No & 71 & 75.5 & & 43 & 70.5 & \\
\hline $\begin{array}{l}\text { Motivation: personal } \\
\text { grievances }^{\mathrm{a}}\end{array}$ & & & & & & \\
\hline Yes & 12 & 12.8 & *** & 26 & 42.6 & $* * *$ \\
\hline No & 82 & 87.2 & & 35 & 57.4 & \\
\hline $\begin{array}{l}\text { Motivation: criminal } \\
\text { gain }{ }^{\mathrm{a}}\end{array}$ & & & & & & \\
\hline Yes & 3 & 3.2 & $n s$ & - & - & $n s$ \\
\hline No & 91 & 96.8 & & 61 & 100 & \\
\hline $\begin{array}{l}\text { Motivation: political or } \\
\text { religious }^{\mathrm{a}}\end{array}$ & & & & & & \\
\hline Yes & 90 & 95.7 & *** & 6 & 9.8 & *** \\
\hline No & 4 & 4.3 & & 55 & 90.2 & \\
\hline $\begin{array}{l}\text { Motivation: unclear or } \\
\text { unknown }\end{array}$ & & & & & & \\
\hline Yes & 2 & 2.1 & $* * *$ & 15 & 24.6 & $* * *$ \\
\hline No & 92 & 97.9 & & 46 & 75.4 & \\
\hline
\end{tabular}

Note. Significance tests based on whether there is a statistically significant relationship between incident type and motivation variables.

$n s=$ nonsignificant.

aChi-square.

${ }^{*} p \leq .05 .{ }^{* *} p \leq .01 .{ }^{* * *} p \leq .001$ (two-tailed).

Between-groups differences. The majority of perpetrators had identifiable motives for committing their attack. Through the use of chi-square tests, the following section will investigate differences between lone actors and rampage shooters based on motivations (see Table 12 for levels of significance). Significant differences between lone actors and rampage shooting perpetrators were found for five out of seven motivation categories: emotional triggers, relationship and/or domestic issues, personal grievances, political and/or religious motivations, and unclear and/or 
unknown motivations (refer to Table 8).

As illustrated in Table 12, rampage shooters were significantly more likely to commit their attacks due to emotional triggers ( $n=36 ; 59 \%)$ when compared to lone actors $(n=4 ; 4.3 \%), \chi^{2}(1)=57.94, p \leq .001$. Rampage shooters were also significantly more likely to carry out their attacks due to relationship and/or domestic issues ( $n=$ $18 ; 29.5 \%)$ when compared to lone actors $(n=3 ; 3.2 \%), \chi^{2}(1)=21.87, p \leq .001$. Additionally, rampage shooters were significantly more likely to commit an attack due to personal grievances $(n=26 ; 42.6 \%)$ in comparison to lone actors $(n=12 ; 12.8 \%)$, $\chi^{2}(1)=17.82, p \leq .001$. Lone actors were significantly more likely to commit an attack as a result of political and/or religious motivations $(n=90 ; 95.7)$ when compared to rampage shooters $(n=6 ; 9.8 \%), \chi^{2}(1)=115.81, p \leq .001$; only four out of 94 lone actors were motivated by factors that were not political and/or religious. ${ }^{31}$ Motivations were significantly more likely to be unknown and/or unclear for rampage shooting perpetrators $(n=15 ; 24.6 \%)$ compared to lone actors $(n=2 ; 2.1 \%), \chi^{2}(1)=19.11, p \leq$ .001 .

\section{Multivariate Analysis}

A logistic regression was carried out using incident type as the dependent variable, and a subset of variables from the larger set of variables, used in this study to capture key personal and psychological attributes and experiences of lone actor and rampage shooting perpetrators. As presented in Table 13, the full model significantly predicted incident type, $\left.\chi^{2}(18, N=142)=56.54, p<.001\right)$, accounting for between $32.8 \%$ and $44.3 \%$ of the variance in group membership. Overall, $73.2 \%$ of the predictions were accurate. As Table 13 indicates, four variables significantly predicted incident type: age $(\mathrm{OR}=1.05, p<.05)$, workplace and/or school issues $(\mathrm{OR}=3.16, p$ $<.05)$, childhood issues (OR = .26, $p<.05)$, and precipitating events (OR $=5.70, p$ $<.001)$. Results indicated that rampage shooters were more likely to be older; to have experienced workplace and/or school issues at the time of, or in the six months leading up to the incident; and to have experienced clear precipitating circumstances or events in the six months prior to the incident. They were, however, less likely to have

${ }^{31}$ These four incidents were not categorised as being motivated by political and/or religious motivations as the motivations were uncertain, or it was unclear the extent to which they were political and/or religious. 
experienced childhood issues or trouble during their upbringing.

Table 13

Logistic Regression Analysis Predicting Key Psychological Aspects of Rampage Shooting Versus Lone-Actor Terrorism Perpetrators

\begin{tabular}{lcccccccc}
\hline & B & S.E & Wald & df & Sig. & Exp(B) & \multicolumn{2}{c}{$\begin{array}{c}95.0 \% \text { C.I for } \\
\text { Exp(B) } \\
\text { Lower }\end{array}$} \\
& & & & & & & & Upper \\
\hline Educational level & -.91 & .60 & 2.28 & 1 & .13 & .40 & .12 & 1.31 \\
Relationship status & .49 & .55 & .80 & 1 & .37 & 1.63 & .56 & 4.79 \\
Job status & .59 & .46 & 1.47 & 1 & .23 & 1.80 & .70 & 4.65 \\
Children/dependents & -.52 & .56 & .87 & 1 & .35 & .59 & .20 & 1.78 \\
Social isolation & .41 & .55 & .57 & 1 & .45 & 1.51 & .52 & 4.44 \\
Low self-esteem & .81 & .67 & 1.50 & 1 & .22 & 2.26 & .61 & 8.30 \\
Workplace and/or & 1.15 & .54 & 4.54 & 1 & .03 & 3.16 & 1.10 & 9.10 \\
school issues & & & & & & & & .09 \\
Childhood issues & -1.34 & .57 & 5.56 & 1 & .02 & .26 & .09 & .80 \\
Criminal history & .53 & .58 & .84 & 1 & .36 & 1.71 & .55 & 5.33 \\
Previous violent acts & -.30 & .60 & .25 & 1 & .62 & .74 & .23 & 2.41 \\
Previous abuse & .24 & .82 & .08 & 1 & .77 & 1.27 & .26 & 6.27 \\
Substance use & -1.05 & .58 & 3.25 & 1 & .07 & .35 & .11 & 1.10 \\
Mental health status & 1.01 & .62 & 2.65 & 1 & .10 & 2.75 & .81 & 9.29 \\
Antisocial personality & .05 & .63 & .01 & 1 & .94 & 1.05 & .30 & 3.64 \\
traits & & & & & & & & \\
Precipitating events & 1.74 & .48 & 12.96 & 1 & .00 & 5.70 & 2.21 & 14.68 \\
Suicide indications & 1.00 & .90 & 1.22 & 1 & .27 & 2.71 & .46 & 15.95 \\
Age & .05 & .02 & 5.15 & 1 & .02 & 1.05 & 1.01 & 1.10 \\
Fascination with & -.35 & .55 & .41 & 1 & .52 & .70 & .24 & 2.06 \\
weapons and/or war & & & & & & & & \\
\hline
\end{tabular}

\section{Location Analyses}

A final set of location comparisons were undertaken to determine the role geographical location plays in lone actor and rampage shooting incidents, and whether there are significant differences in personal attributes and behaviours between perpetrators who commit their attacks in North America and Europe (for a full list of significant variables for event, sociodemographic, $3^{2}$ personal, psychological, and

$3^{2}$ As sociodemographic and personal characteristics are not discussed within the location analyses, the list of significant sociodemographic and personal characteristics can be found in Tables 17 and 18, respectively, at the end of this section. 
motivational characteristics, refer to Tables 14-18).33 A significant difference was found between incident type and location, $\chi^{2}(1)=22.60, p<.001$. As depicted in Figure 6 , the majority of rampage shooting events occurred within North America $(n=48$; $82.8 \%$ ), whereas only $42.1 \%$ of lone actor events occurred within North America. Comparably, the majority of lone actor incidents occurred across Europe $(n=44$; $57.9 \%$ ), whereas only $17.2 \%$ of rampage shootings occurred across Europe.

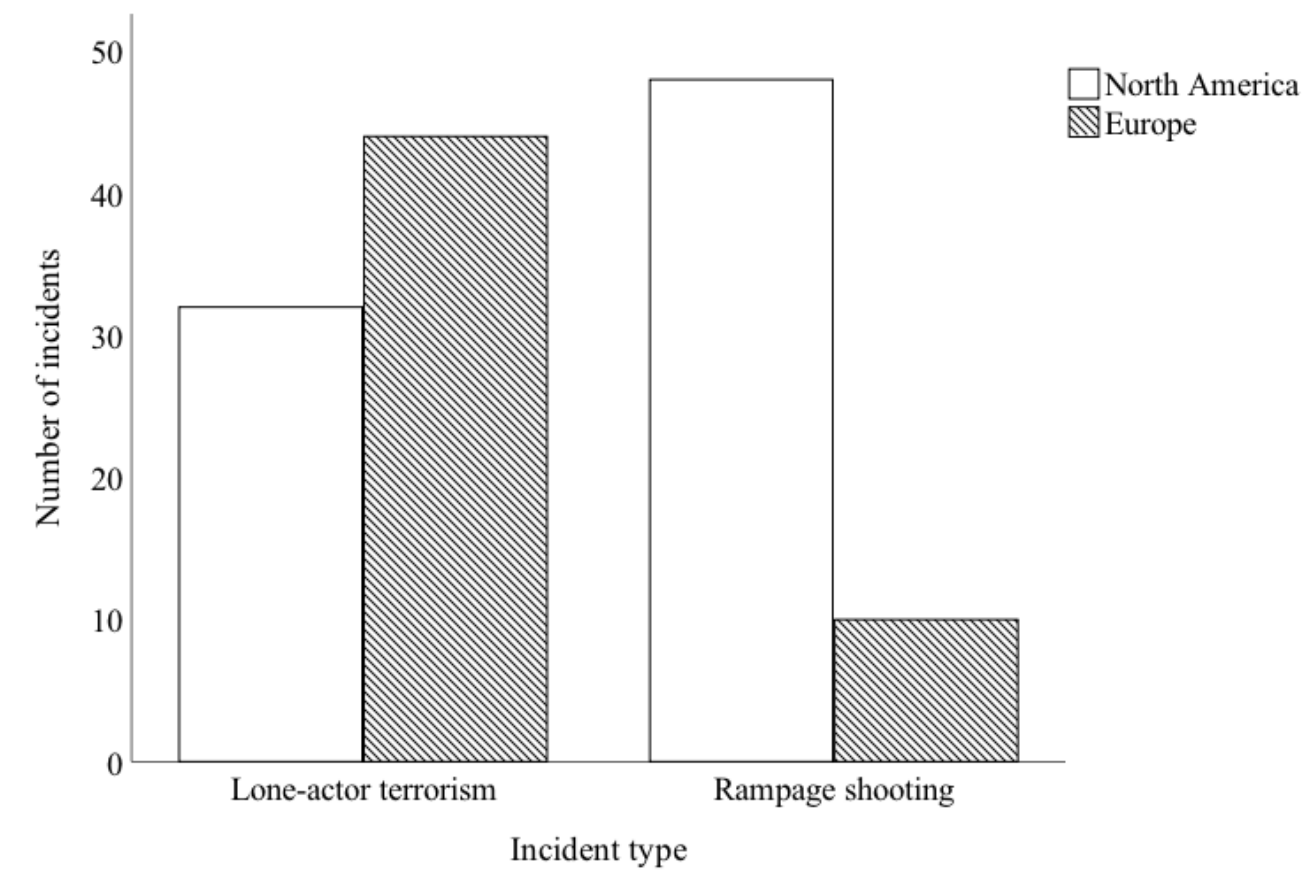

Figure 6. Total number of lone actor and rampage shooting incidents in North America versus Europe between 2010 to 2018.

Impact of incident type and location on number of fatalities. A twoway between-groups analysis of variance was conducted to explore the impact of incident type and location on the number of fatalities for each incident, and to determine whether location moderates the relationship between incident type and number of fatalities (see Figure 7 for an indication of the average number of fatalities between 2010 and 2018).

33 Additionally, for a full list of significant variables for rampage shooting region analyses, see Appendix C, Tables 1-5. For a full list of significant variables for lone actor region analyses, see Appendix C, Tables 6-10. 


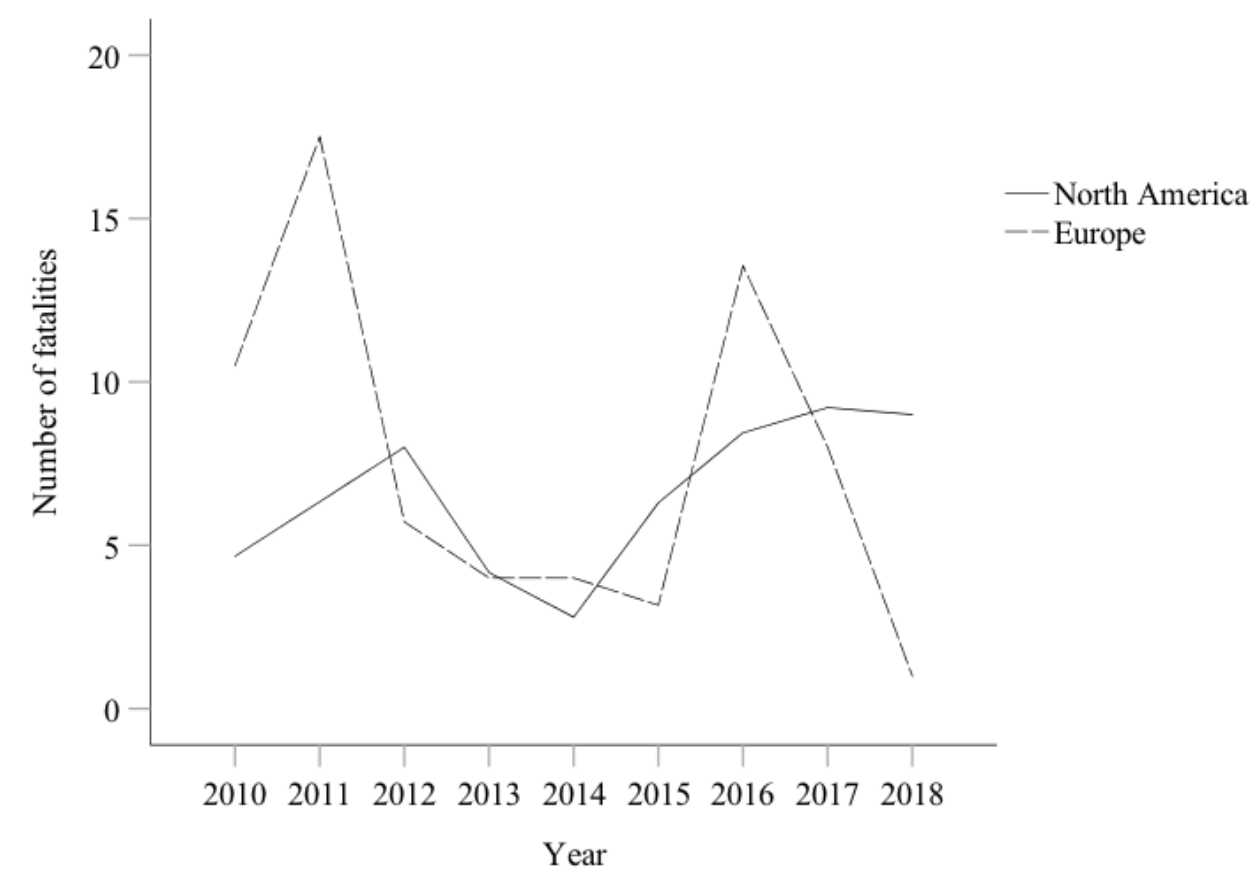

Figure 7. Average number offatalities for North American versus European incidents across the years (2010 to 2018).

When including lone actor events with at least one fatality, there was a nonsignificant main effect of incident type on the number of fatalities for lone actor $(M=$ $6.59, S D=13.72)$ and rampage shooting events $(M=7.50, S D=8.46), F(1,130)=.18$, $p=.68$ (see Table 14). This effect indicates that the mean number of fatalities for lone actor and rampage shooting events did not significantly differ, and when we ignore the location of incidents, incident type did not influence the number of fatalities for events. There was also a non-significant main effect of location on the number of fatalities for events which occurred within North America $(M=6.36, S D=9.17)$ and Europe $(M=$ $7.91, S D=14.73), F(1,130)=.39, p=.53$. This effect reveals that the mean number of fatalities for North American and European events did not significantly differ, and when we ignore incident type, the geographic location of events did not influence fatality numbers. There was a non-significant interaction effect between incident type and the location of lone actor and rampage shooting events, on the number of fatalities, $F(1,130)=.68, p=.41$. From this effect we can conclude that the number of fatalities for lone actor events compared to rampage shooting events were not affected by the location of the events. 
Table 14

Event Characteristics of Lone-Actor Terrorism and Rampage Shooting Events in North America Versus Europe

\begin{tabular}{|c|c|c|c|c|c|c|}
\hline \multirow{2}{*}{$\begin{array}{l}\text { Location } \\
\text { Event Characteristics }\end{array}$} & \multicolumn{2}{|c|}{$\begin{array}{l}\text { North America } \\
\quad(n=80)\end{array}$} & \multicolumn{4}{|c|}{$\begin{array}{l}\text { Europe } \\
(n=54)\end{array}$} \\
\hline & $M$ & Range & Significant & $M$ & Range & Significant \\
\hline Number of fatalities ${ }^{a}$ & 6.4 & $(1-59)$ & $n s$ & 7.91 & $(1-87)$ & $n s$ \\
\hline Number of fatalities ${ }^{d}$ & 8.1 & $(3-59)$ & $n s$ & 11.85 & $(3-87)$ & $n s$ \\
\hline Number of casualties & 14.1 & $(0-546)$ & $n s$ & 37.8 & $(0-800)$ & $n s$ \\
\hline Total number of victims ${ }^{a}$ & 21 & $(1-605)$ & ns & 45.9 & $(1-822)$ & ns \\
\hline Total number of victims ${ }^{d}$ & 24.5 & $(3-605)$ & $n s$ & 70.8 & $(3-822)$ & ns \\
\hline Event Characteristics & $n$ & $\%$ & Significant & $n$ & $\%$ & Significant \\
\hline \multicolumn{7}{|l|}{ Yearc $^{\mathrm{c}}$} \\
\hline 2010 & 3 & 3.8 & $n s$ & 2 & 3.7 & $n s$ \\
\hline 2011 & 3 & 3.8 & & 6 & 11.1 & \\
\hline 2012 & 10 & 12.5 & & 7 & 13 & \\
\hline 2013 & 12 & 15 & & 6 & 11.1 & \\
\hline 2014 & 15 & 18.8 & & 3 & 5.6 & \\
\hline 2015 & 10 & 12.5 & & 12 & 22.2 & \\
\hline 2016 & 9 & 11.3 & & 9 & 16.7 & \\
\hline 2017 & 14 & 17.5 & & 8 & 14.8 & \\
\hline 2018 & 4 & 5 & & 1 & 1.9 & \\
\hline \multicolumn{7}{|l|}{ Number of perpetrators ${ }^{c}$} \\
\hline One offender & 72 & 90 & $n s$ & 45 & 83.3 & $n s$ \\
\hline Two offenders & 6 & 7.5 & & 5 & 9.3 & \\
\hline Three or more offenders & 2 & 2.5 & & 4 & 7.4 & \\
\hline \multicolumn{7}{|l|}{ Modus operandib } \\
\hline Firearm & 68 & 85 & $* * *$ & 26 & 48.1 & $* * *$ \\
\hline Knife & 1 & 1.3 & & 7 & 13 & \\
\hline Fire & - & - & & - & - & \\
\hline Explosives/bombs & 2 & 2.5 & & 6 & 11.1 & \\
\hline Vehicle & 3 & 3.8 & & 3 & 5.6 & \\
\hline Other & - & - & & 1 & 1.9 & \\
\hline Combination & 3 & 3.8 & & 11 & 20.4 & \\
\hline Unknown & 3 & 3.8 & & - & - & \\
\hline \multicolumn{7}{|l|}{ Weapon subtype ${ }^{\mathrm{b}}$} \\
\hline Automatic weapon & 20 & 25 & $n s$ & 10 & 18.5 & $n s$ \\
\hline Handgun & 14 & 17.5 & & 9 & 16.7 & \\
\hline $\begin{array}{l}\text { Rifle/shotgun (non- } \\
\text { automatic) }\end{array}$ & 10 & 12.5 & & 2 & 3.7 & \\
\hline Unknown & 6 & 7.5 & & 3 & 5.6 & \\
\hline Combination & 20 & 25 & & 7 & 13 & \\
\hline \multicolumn{7}{|l|}{ Specific target(s)b } \\
\hline Yes & 59 & 73.8 & $n s$ & 33 & 61.1 & $n s$ \\
\hline No & 21 & 26.3 & & 21 & 38.9 & \\
\hline
\end{tabular}


Table 14 (continued)

\begin{tabular}{|c|c|c|c|c|c|c|}
\hline \multicolumn{7}{|l|}{ Relationship to victimb } \\
\hline Stranger/random & 50 & 62.5 & * & 48 & 88.9 & * \\
\hline Personal & 3 & 3.8 & & 1 & 1.9 & \\
\hline Professional & 11 & 13.8 & & 3 & 5.6 & \\
\hline School-related & 4 & 5 & & - & - & \\
\hline Combination & 12 & 15 & & 2 & 3.7 & \\
\hline \multicolumn{7}{|l|}{ Location type $^{b}$} \\
\hline Open commercial & 35 & 43.8 & $n s$ & 25 & 46.3 & $n s$ \\
\hline Educational institution & 9 & 11.3 & & 2 & $3 \cdot 7$ & \\
\hline Military setting & 3 & 3.8 & & - & - & \\
\hline Public street & 13 & 16.3 & & 16 & 29.6 & \\
\hline Office & 3 & 3.8 & & 1 & 1.9 & \\
\hline Warehouse/factory & 4 & 5 & & 1 & 1.9 & \\
\hline Other & 9 & 11.3 & & 5 & 9.3 & \\
\hline Combination & 4 & 5 & & 4 & 7.4 & \\
\hline \multicolumn{7}{|l|}{ Attack type ${ }^{\mathrm{b}}$} \\
\hline Assassination & - & - & * & 2 & 3.7 & * \\
\hline Armed assault & 78 & 97.5 & & 45 & 83.3 & \\
\hline Bombing/explosion & 1 & 1.3 & & 6 & 11.1 & \\
\hline Unarmed assault & - & - & & - & - & \\
\hline Combination & 1 & 1.3 & & 1 & 1.9 & \\
\hline \multicolumn{7}{|l|}{ Level of planningb } \\
\hline Low-level & 21 & 26.3 & * & 5 & 9.3 & * \\
\hline Medium-level & 40 & 50 & & 31 & 57.4 & \\
\hline High-level & 10 & 12.5 & & 6 & 11.1 & \\
\hline Unknown & 9 & 11.3 & & 12 & 22.2 & \\
\hline \multicolumn{7}{|l|}{ Duration of incident $\mathrm{t}^{\mathrm{b}}$} \\
\hline Less than 30 minutes & 65 & 81.3 & $n s$ & 46 & 85.2 & $n s$ \\
\hline 31-6o minutes & 1 & 1.3 & & 1 & 1.9 & \\
\hline $1-5$ hours & 10 & 12.5 & & 6 & 11.1 & \\
\hline 6-12 hours & 2 & 2.5 & & - & - & \\
\hline 13-24 hours & 1 & 1.3 & & 1 & 1.9 & \\
\hline Unknown & 1 & 1.3 & & - & - & \\
\hline \multicolumn{7}{|l|}{ Time of incident ${ }^{\mathrm{b}}$} \\
\hline Morning & 31 & 38.8 & $* *$ & 10 & 18.5 & ** \\
\hline Afternoon & 14 & 17.5 & & 20 & 37 & \\
\hline Evening & 15 & 18.8 & & 12 & 22.2 & \\
\hline Late night & 17 & 21.3 & & 8 & 14.8 & \\
\hline Unknown & 3 & 3.8 & & 4 & 7.4 & \\
\hline \multicolumn{7}{|l|}{ Outcome of incident ${ }^{b}$} \\
\hline Arrest & 31 & 38.8 & $n s$ & 17 & 31.5 & $n s$ \\
\hline $\begin{array}{l}\text { Lethal force/suicide by } \\
\text { cop }\end{array}$ & 15 & 18.8 & & 12 & 22.2 & \\
\hline $\begin{array}{l}\text { Suicide/attempted } \\
\text { suicide }\end{array}$ & 22 & $27 \cdot 5$ & & 13 & 24.1 & \\
\hline Other & 12 & 15 & & 12 & 22.2 & \\
\hline \multicolumn{7}{|l|}{ Claims of responsibility } \\
\hline Yes & 2 & 2.5 & $* * *$ & 16 & 29.6 & *** \\
\hline No & 78 & $97 \cdot 5$ & & 38 & 70.4 & \\
\hline \multicolumn{7}{|l|}{ Threatening statementsb } \\
\hline No statements & 54 & 67.5 & $n s$ & 36 & 66.7 & $n s$ \\
\hline Direct statements & 15 & 18.8 & & 16 & 29.6 & \\
\hline Indirect statements & 11 & 13.8 & & 2 & 3.7 & \\
\hline
\end{tabular}


Table 14 (continued)

Note. Significance tests based on whether there is a statistically significant relationship between incident type and event variables. All 'unknown' categories for every variable were excluded from significance testing analyses.

$n s=$ nonsignificant.

aWhen the minimum number of fatalities for lone actors is set to one.

bChi-square.

cThe $t$ test.

dWen the minimum number of fatalities for lone actors is set to three.

${ }^{*} p \leq .05 .{ }^{* *} p \leq .01 .{ }^{* * *} p \leq .001$ (two-tailed).

When including lone actor events with at least three fatalities (identical to criteria for rampage shootings), there was a non-significant main effect of incident type on the number of fatalities for lone actor $(M=12.74, S D=18.52)$ and rampage shooting events $(M=7.50, S D=8.46), F(1,89)=2.0, p=.16$. There was also a nonsignificant main effect of location on the number of fatalities for events within North America $(M=8.10, S D=10.14)$ and Europe $(M=11.85, S D=17.47), F(1,89)=.20, p$ $=.66$. Alongside this, there was a non-significant interaction effect between incident type and location, on the number of fatalities for events, $F(1,89)=.35, p=.55 .{ }^{34}$

Impact of incident type and location on number of casualties. A twoway between-groups analysis of variance was conducted to explore the impact of incident type and location on the number of casualties for each incident, and to determine whether location moderates the relationship between incident type and number of casualties (see Figure 8 for an indication of the average number of casualties between 2010 and 2018). There was a non-significant main effect of incident type on the number of casualties for lone actor $(M=28.53, S D=105.06)$ and rampage shooting events $(M=17.28, S D=73.05), F(1,130)=.17, p=.68$. This effect indicates that the average number of casualties for lone actor and rampage shooting events did not significantly differ, and when we ignore the location of incidents, incident type did not influence the number of casualties for events. There was also a non-significant main effect of location on the number of casualties for events which occurred within North America $(M=14.14, S D=62.74)$ and Europe $(M=37.76, S D=123.42), F(1$, $130)=.78, p=.38$. This effect reveals that the average number of casualties for North American and European events did not significantly differ, and when we ignore

34 Post-hoc comparisons were not performed because there were fewer than three groups in each independent variable. 
incident type, the location of events did not influence casualty numbers. There was a non-significant interaction effect between incident type and the location of events, on the number of casualties, $F(1,130)=.59, p=.44$. From this effect we can conclude that the number of casualties for lone actor events compared to rampage shootings were not affected by the location of the events. 35

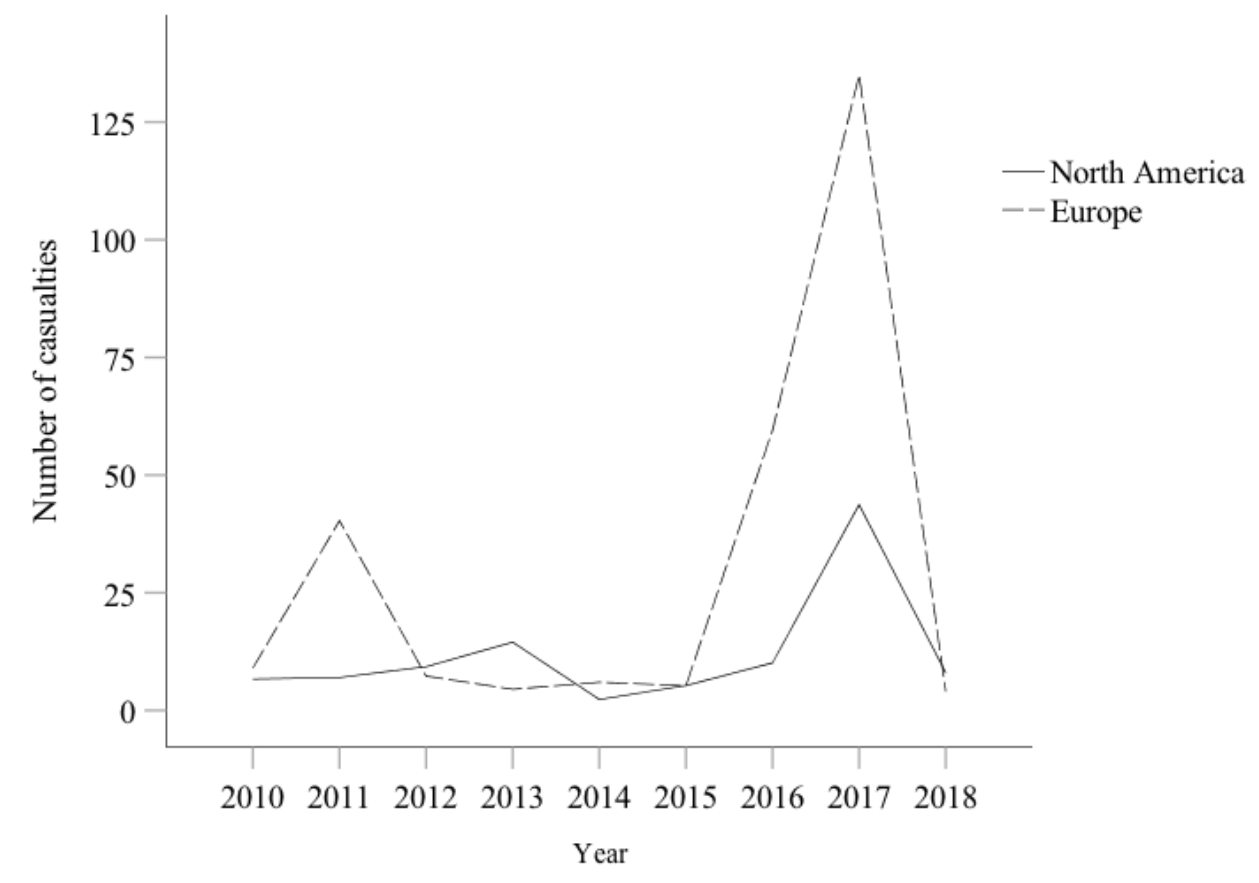

Figure 8. Average number of casualties for North American versus European incidents across the years (2010 to 2018).

Location analyses for modus operandi. ${ }^{36}$ A chi-square test for independence was conducted to examine the differences in modus operandi between North American and European incidents. Results indicated that there was a statistically significant association between modus operandi for incidents which occur within North America versus Europe, $\chi^{2}(2, n=130)=24.28, p=\leq .001$, phi $=.43$ (see Table 14 for levels of significance). These results indicate that the types of weapons used (i.e. firearms versus other weapon types) in North American incidents were significantly different from the types of weapons used in European incidents. Of the total sample, $72.3 \%$ of incidents involved the use of a firearm as the weapon of choice,

35 Post-hoc comparisons were not performed because there were only two groups in each independent variable.

${ }^{6} 6$ The discussion on location analyses for modus operandi will only focus on results which were found to be statistically significant at the $p \leq .05$ level. 
16.9\% involve other weapon types, and $10.8 \%$ involve a combination of weapon types. Incidents which occurred in North America were significantly more likely to be carried out using a firearm ( $n=68 ; 88.3 \%)$, compared to incidents which occurred across Europe ( $n=26 ; 49.1 \%)$. Incidents which occurred across Europe were significantly more likely to be carried out using other weapon types ( $n=16 ; 30.2 \%$ ) than North American incidents ( $n=6 ; 7.8 \%$ ), and European incidents were also more likely to involve the use of a combination of weapons $(n=11 ; 20.8 \%)$ in comparison to North American incidents $(n=3 ; 3.9 \%)$.

A chi-square test for independence revealed a statistically significant association between modus operandi for lone actor events within North America and Europe, $\chi^{2}(2, n=75)=12.08, p=.002, \mathrm{phi}=.40$ (see Appendix $\mathrm{C}$, Table 6 for levels of significance). These results indicate that the types of weapons used in North American lone actor incidents were significantly different from the types of weapons used in European lone actor incidents. Lone actor incidents which occurred within North America were significantly more likely to involve the use of a firearm as the weapon of choice than incidents which occurred across Europe. Incidents within North America were predominantly carried out using a firearm (78.1\%), compared to other weapon types (18.8\%), or a combination of weapon types (3.1\%). Differences between weapon types used in European incidents were less predominant; a similar number of events used firearms ( $n=17 ; 39.5 \%)$ and other ( $n=16 ; 37.2 \%)$ weapon types, and the remaining $23.3 \%$ of events involved a combination of weapons.

In terms of the association between modus operandi for rampage shooting incidents within North America versus Europe, no significant difference was found between regions at the $p \leq .05$ level (see Appendix C, Table 1 for levels of significance), as rampage shooting incidents across both North America and Europe predominantly involved the use of firearms as the weapon of choice.

Location analyses for mental health status. 37 A chi-square test for independence (with Yates Continuity Correction) was conducted to examine the differences in mental health status between North American and European perpetrators. Results indicated that there was a statistically significant association

37 The discussion on location analyses for mental health status will only focus on results which were found to be statistically significant at the $p \leq .05$ level. 
between mental health status for perpetrators who commit their attacks within North America and Europe, $\chi^{2}(1, \mathrm{n}=155)=16.40, \mathrm{p}=\leq .001$, phi $=-.34$ (see Table 15 for levels of significance). These results indicate that the mental health status of perpetrators within North America is significantly different from the mental health status of perpetrators across Europe. Of the total sample, 54.5\% of perpetrators displayed indications of suffering from mental health issues, and $40.6 \%$ displayed no indications. Perpetrators who committed their attacks within North America were significantly more likely to display indications of suffering from mental health issues and/or disorder(s) ( $n=65 ; 73.9 \%)$, compared to perpetrators who committed their attacks across Europe ( $n=27 ; 40.3 \%)$.

Table 15

Psychological Background and Violent History of Lone-Actor Terrorism and Rampage Shooting Perpetrators in North America Versus Europe

\begin{tabular}{|c|c|c|c|c|c|c|}
\hline \multirow{2}{*}{$\begin{array}{l}\text { Perpetrators } \\
\begin{array}{l}\text { Perpetrator } \\
\text { characteristics }\end{array}\end{array}$} & \multicolumn{2}{|c|}{$\begin{array}{l}\text { North America } \\
\quad(n=88)\end{array}$} & \multicolumn{4}{|c|}{$\begin{array}{l}\text { Europe } \\
(n=67)\end{array}$} \\
\hline & $n$ & $\%$ & Significant & $n$ & $\%$ & Significant \\
\hline \multicolumn{7}{|l|}{$\begin{array}{l}\text { Antisocial personality } \\
\text { traits }\end{array}$} \\
\hline $\begin{array}{l}\text { Traits displayed } \\
\text { prior to incident }\end{array}$ & 67 & 76.1 & $* *$ & 34 & 50.7 & $* *$ \\
\hline $\begin{array}{l}\text { No traits displayed } \\
\text { prior to incident }\end{array}$ & 20 & 22.7 & & 24 & 35.8 & \\
\hline Unknown & 1 & 1.1 & & 9 & 13.4 & \\
\hline \multicolumn{7}{|l|}{ Low self-esteem ${ }^{a}$} \\
\hline Yes & 16 & 18.2 & $n s$ & 7 & 10.4 & $n s$ \\
\hline No & 53 & 60.2 & & 45 & 67.2 & \\
\hline Unknown & 19 & 21.6 & & 15 & 22.4 & \\
\hline \multicolumn{7}{|l|}{ Social isolation ${ }^{\mathrm{a}}$} \\
\hline $\begin{array}{l}\text { Indications of } \\
\text { extreme social } \\
\text { isolation }\end{array}$ & 4 & 4.5 & $n s$ & - & - & $n s$ \\
\hline $\begin{array}{l}\text { Indications of some } \\
\text { form of social } \\
\text { isolation }\end{array}$ & 33 & 37.5 & & 21 & 31.3 & \\
\hline $\begin{array}{l}\text { No indications of } \\
\text { social isolation }\end{array}$ & 48 & 54.5 & & 35 & 52.2 & \\
\hline Unknown & 3 & 3.4 & & 11 & 16.4 & \\
\hline
\end{tabular}


Table 15 (continued)

\begin{tabular}{|c|c|c|c|c|c|c|}
\hline \\
\hline $\begin{array}{l}\text { Mental health status }{ }^{\mathrm{a}} \\
\text { Evidence of mental } \\
\text { health issues or } \\
\text { disorder(s) }\end{array}$ & 25 & 28.4 & $* * *$ & 14 & 20.9 & $* * *$ \\
\hline $\begin{array}{l}\text { Indications of } \\
\text { mental health issues } \\
\text { or disorder(s) }\end{array}$ & 40 & $45 \cdot 5$ & & 13 & 19.4 & \\
\hline $\begin{array}{l}\text { No evidence of } \\
\text { mental health issues } \\
\text { or disorder(s) }\end{array}$ & 17 & 19.3 & & 28 & 41.8 & \\
\hline Unknown & 6 & 6.8 & & 12 & 17.9 & \\
\hline \multicolumn{7}{|l|}{ Suicide indications ${ }^{a}$} \\
\hline $\begin{array}{l}\text { Indications were } \\
\text { found }\end{array}$ & 8 & 9.1 & $n s$ & 2 & 3 & $n s$ \\
\hline $\begin{array}{l}\text { Indications were } \\
\text { not found }\end{array}$ & 80 & 90.9 & & 65 & 97 & \\
\hline \multicolumn{7}{|l|}{ Previous violent acts $^{\mathrm{a}}$} \\
\hline Yes & 43 & 48.9 & $n s$ & 24 & 35.8 & $n s$ \\
\hline No & 45 & 51.1 & & 43 & 64.2 & \\
\hline \multicolumn{7}{|l|}{ Previous abuse ${ }^{a}$} \\
\hline Yes & 8 & 9.1 & $n s$ & 6 & 9 & $n s$ \\
\hline No & 80 & 90.9 & & 61 & 91 & \\
\hline \multicolumn{7}{|l|}{ Criminal historya } \\
\hline Yes & 37 & 42 & $n s$ & 24 & 35.8 & $n s$ \\
\hline No & 51 & 58 & & 43 & 64.2 & \\
\hline
\end{tabular}

Note. Significance tests based on whether there is a statistically significant relationship between incident type and psychological background and violent history variables.

$n s=$ nonsignificant.

aChi-square.

${ }^{*} p \leq .05 .{ }^{* *} p \leq .01 .{ }^{* * *} p \leq .001$ (two-tailed).

A chi-square test for independence (with Yates Continuity Correction) revealed a statistically significant association between the mental health status of lone-actor terrorists within North America and Europe, $\chi^{2}(1, \mathrm{n}=94)=10.32, \mathrm{p} \leq .001$, phi $=-.35$ (see Appendix C, Table 9 for levels of significance). These results indicate that the proportion of lone actors who suffer from mental health issues and/or disorder(s) within North America is significantly different from the proportion of lone actors who suffer from mental health issues and/or disorder(s) across Europe. Of the total sample, $51.1 \%$ of lone actors displayed indications of suffering from mental health issues, and 48.9\% displayed no indications. The majority of lone actors within North America displayed indications of suffering from mental health issues, and were significantly more likely to display indications of suffering from mental health issues $(n=27 ; 73 \%)$, compared to lone actors across Europe $(n=21 ; 36.8 \%)$. Comparably, the majority of 
lone actors across Europe did not display indications of suffering from mental health issues ( $n=36 ; 63.2 \%$ ), compared to the low amount of lone actors within North America who did not show indications of mental health issues $(n=10 ; 27 \%)$.

In terms of the association between the mental health status of rampage shooters within North America and Europe, no significant difference was found between regions at the $p \leq .05$ level (see Appendix C, Table 4 for levels of significance), as rampage shooters across both North America and Europe predominantly displayed indications of mental health issues and/or disorder(s).

Location analyses for motivational patterns. ${ }^{8} \mathrm{~A}$ chi-square test for independence (with Yates Continuity Correction) was conducted to examine the differences in motivations between North American and European perpetrators. A statistically significant difference was found between perpetrators in North America and Europe in terms of being motivated by emotional triggers, $\chi^{2}(1, n=155)=10.61$, $p=.001$, phi $=.28$ (see Table 16). The majority of perpetrators across both North America $(n=56 ; 63.6 \%)$ and Europe $(n=59 ; 88.1 \%)$ were not motivated by emotional triggers, however perpetrators within North America ( $n=32 ; 36.4 \%$ ) were significantly more likely to be motivated by emotional triggers than perpetrators across Europe ( $n=8 ; 11.9 \%)$. A statistically significant difference was also found between North American and European perpetrators in terms of being driven by personal grievances, $\chi^{2}(1, n=155)=14.00, p \leq .001$, phi $=.32$. The majority of perpetrators across both North America $(n=56 ; 63.6 \%)$ and Europe $(n=61 ; 91 \%)$ were not driven by personal grievances, however perpetrators within North America ( $n=32 ; 36.4 \%$ ) were significantly more likely to be driven by personal grievances than perpetrators across Europe $(n=6 ; 9 \%)$.

38 The discussion on location analyses for motivational patterns of both rampage shooters and lone actors will primarily focus on results which were found to be statistically significant at the $p \leq .05$ level. 
Table 16

Motivational Patterns of Lone-Actor Terrorism and Rampage Shooting

Perpetrators in North America Versus Europe

\begin{tabular}{|c|c|c|c|c|c|c|}
\hline \multirow{2}{*}{$\begin{array}{l}\text { Perpetrators } \\
\begin{array}{l}\text { Motivational } \\
\text { characteristics }\end{array}\end{array}$} & \multicolumn{2}{|c|}{$\begin{array}{l}\text { North America } \\
\quad(n=88)\end{array}$} & \multicolumn{4}{|c|}{$\begin{array}{l}\text { Europe } \\
(n=67)\end{array}$} \\
\hline & $n$ & $\%$ & Significant & $n$ & $\%$ & Significant \\
\hline \multicolumn{7}{|c|}{$\begin{array}{l}\text { Motivation: emotional } \\
\text { triggers }{ }^{\mathrm{a}}\end{array}$} \\
\hline $\begin{array}{l}\text { Yes } \\
\text { No }\end{array}$ & $\begin{array}{l}32 \\
56\end{array}$ & $\begin{array}{l}36.4 \\
63.6\end{array}$ & $* * *$ & $\begin{array}{c}8 \\
59\end{array}$ & $\begin{array}{l}11.9 \\
88.1\end{array}$ & $* * *$ \\
\hline \multicolumn{7}{|c|}{$\begin{array}{l}\text { Motivation: relationship } \\
\text { or domestic issues }^{\mathrm{a}}\end{array}$} \\
\hline $\begin{array}{l}\text { Yes } \\
\text { No }\end{array}$ & $\begin{array}{l}16 \\
72\end{array}$ & $\begin{array}{l}18.2 \\
81.8\end{array}$ & $n s$ & $\begin{array}{r}5 \\
62\end{array}$ & $\begin{array}{l}7.5 \\
92.5\end{array}$ & $n s$ \\
\hline \multicolumn{7}{|c|}{$\begin{array}{l}\text { Motivation: } \\
\text { revenge/payback }\end{array}$} \\
\hline $\begin{array}{l}\text { Yes } \\
\text { No }\end{array}$ & $\begin{array}{l}25 \\
63\end{array}$ & $\begin{array}{l}28.4 \\
71.6\end{array}$ & $n s$ & $\begin{array}{l}16 \\
51\end{array}$ & $\begin{array}{l}23.9 \\
76.1\end{array}$ & $n s$ \\
\hline \multicolumn{7}{|c|}{$\begin{array}{l}\text { Motivation: personal } \\
\text { grievances }^{\mathrm{a}}\end{array}$} \\
\hline $\begin{array}{l}\text { Yes } \\
\text { No }\end{array}$ & $\begin{array}{l}32 \\
56\end{array}$ & $\begin{array}{l}36.4 \\
63.6\end{array}$ & $* * *$ & $\begin{array}{l}6 \\
61\end{array}$ & $\begin{array}{c}9 \\
91\end{array}$ & $* * *$ \\
\hline \multicolumn{7}{|c|}{$\begin{array}{l}\text { Motivation: criminal } \\
\text { gain }^{\mathrm{a}}\end{array}$} \\
\hline $\begin{array}{l}\text { Yes } \\
\text { No }\end{array}$ & $\begin{array}{r}1 \\
87\end{array}$ & $\begin{array}{c}1.1 \\
98.9\end{array}$ & $n s$ & $\begin{array}{l}2 \\
65\end{array}$ & $\begin{array}{r}3 \\
97\end{array}$ & $n s$ \\
\hline \multicolumn{7}{|c|}{$\begin{array}{l}\text { Motivation: political or } \\
\text { religious }^{\mathrm{a}}\end{array}$} \\
\hline $\begin{array}{l}\text { Yes } \\
\text { No }\end{array}$ & $\begin{array}{l}42 \\
46\end{array}$ & $\begin{array}{l}47.7 \\
52.3\end{array}$ & $* * *$ & $\begin{array}{l}54 \\
13\end{array}$ & $\begin{array}{l}80.6 \\
19.4\end{array}$ & $* * *$ \\
\hline \multicolumn{7}{|c|}{$\begin{array}{l}\text { Motivation: unclear or } \\
\text { unknown }\end{array}$} \\
\hline $\begin{array}{l}\text { Yes } \\
\text { No }\end{array}$ & $\begin{array}{c}12 \\
76\end{array}$ & $\begin{array}{l}13.6 \\
86.4\end{array}$ & $n s$ & $\begin{array}{r}5 \\
62\end{array}$ & $\begin{array}{l}7.5 \\
92.5\end{array}$ & $n s$ \\
\hline
\end{tabular}

Note. Significance tests based on whether there is a statistically significant relationship between incident type and motivation variables.

$n s=$ nonsignificant.

aChi-square.

${ }^{*} p \leq .05 .{ }^{* *} p \leq .01 .{ }^{* * *} p \leq .001$ (two-tailed).

Lastly, a statistically significant difference was also found between perpetrators in North America and Europe in terms of being motivated by political and/or religious reasons, $\chi^{2}(1, n=155)=16.07, p \leq .001$, phi $=-.34$ (see Table 16). Perpetrators across Europe were predominantly motivated by political and/or religious reasons $(n=54$; 80.6\%), and were significantly more likely to be driven by these motivations than perpetrators within North America ( $n=42 ; 47.7 \%)$. In comparison to this, the majority 
of perpetrators within North America were not motivated by political and/or religious reasons ( $n=46 ; 52.3 \%$ ), compared to only $19.4 \%$ of perpetrators across Europe ( $n=$ 13). No statistically significant associations were found across the remaining four motivation categories for perpetrators within North America and Europe, at the $p \leq$ .05 level (see Table 16).

A chi-square test for independence (with Yates Continuity Correction) revealed a statistically significant difference was found between lone actors in North America and Europe in terms of being motivated by personal grievances, $\chi^{2}(1, n=94)=9.13, p$ $=.003, \mathrm{phi}=.344$ (see Appendix C, Table 10 for levels of significance). The majority of lone actors across both Europe $(n=55 ; 96.5 \%)$ and North America $(n=27 ; 73 \%)$ were not driven by personal grievances, however lone actors within Europe were significantly less likely to be motivated by personal grievances. Comparably, lone actors in North America were significantly more likely to be motivated by personal grievances $(n=10 ; 27 \%)$, compared to lone actors in Europe ( $n=2 ; 3.5 \%)$. No statistically significant associations were found across the remaining six motivation categories for lone actors within North America and Europe, at the $p \leq .05$ level (see Appendix C, Table 10).

A chi-square test for independence (with Yates Continuity Correction) revealed that no statistically significant associations were found across all seven motivation categories for rampage shooters within North America and Europe, at the $p \leq .05$ level (see Appendix C, Table 5 for levels of significance). Although not significant, rampage shooters within North America were slightly more likely to commit their attacks due to emotional triggers, revenge/payback, and political and/or religious motivations. No measures of association were computed for criminal gain, as no rampage shooters in North America or Europe were motivated by this factor. 
Table 17

Sociodemographic Characteristics of Lone-Actor Terrorism and Rampage Shooting Perpetrators in North America Versus Europe

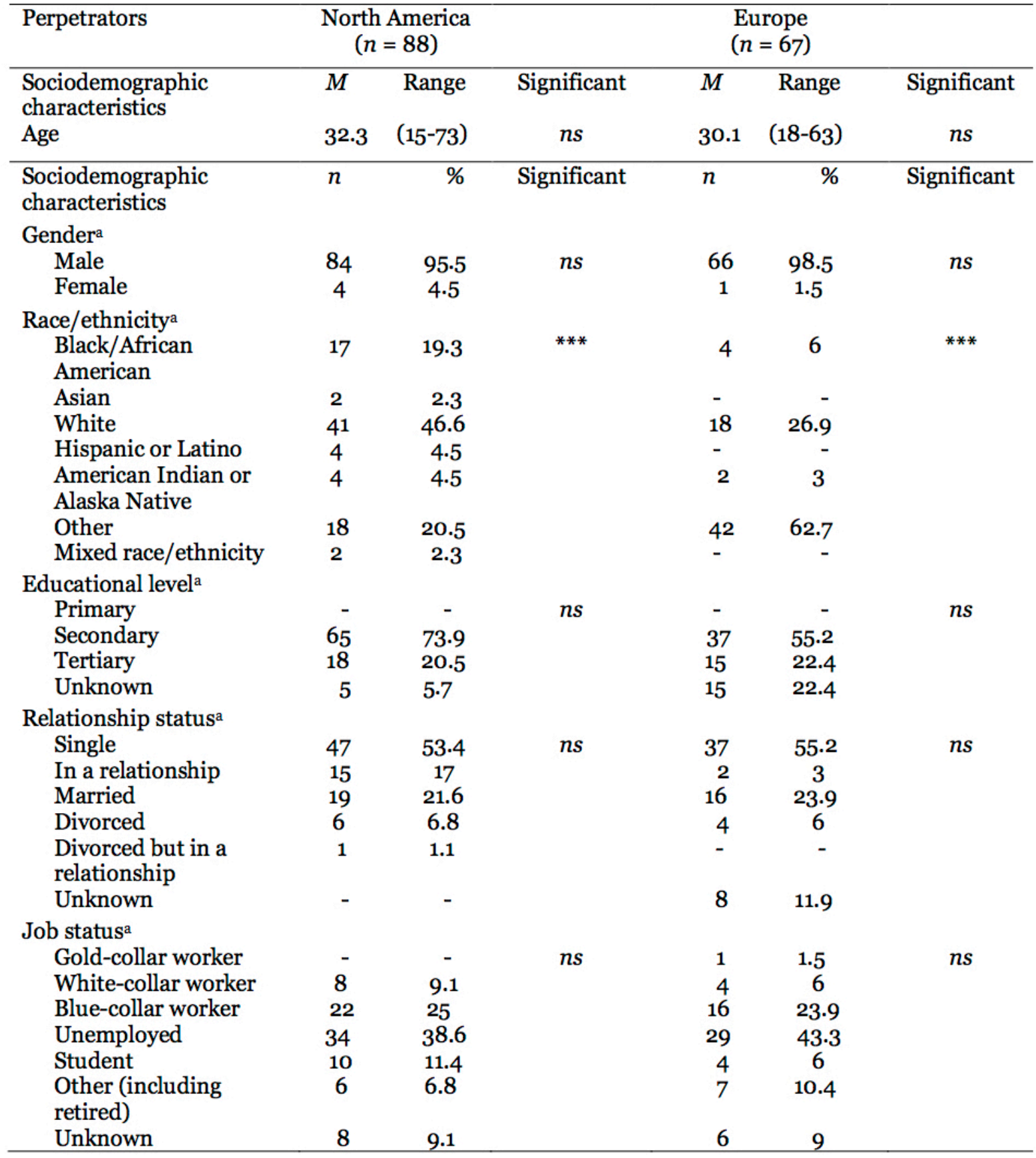


Table 17 (continued)

\begin{tabular}{|c|c|c|c|c|c|c|}
\hline \multicolumn{7}{|c|}{ Religious affiliation ${ }^{a}$} \\
\hline Christian & 11 & 12.5 & *** & 2 & 3 & $* * *$ \\
\hline Muslim & 21 & 23.9 & & 42 & 62.7 & \\
\hline Buddhist & 1 & 1.1 & & - & - & \\
\hline Atheist & 4 & 4.5 & & - & - & \\
\hline Agnostic & 1 & 1.1 & & - & - & \\
\hline Hindu & - & - & & - & - & \\
\hline Jewish & - & - & & - & - & \\
\hline Non-religious & 6 & 6.8 & & 1 & 1.5 & \\
\hline Other & 5 & $5 \cdot 7$ & & 3 & 4.5 & \\
\hline Unknown & 39 & 44.3 & & 19 & 28.4 & \\
\hline \multicolumn{7}{|c|}{ Children/dependents ${ }^{a}$} \\
\hline Yes & 29 & 33 & $n s$ & 15 & 22.4 & $n s$ \\
\hline No & 59 & 67 & & 46 & 68.7 & \\
\hline Unknown & - & - & & 6 & 9 & \\
\hline
\end{tabular}

Note. Significance tests based on whether there is a statistically significant relationship between incident type and sociodemographic variables.

$n s=$ nonsignificant.

aChi-square.

${ }^{*} p \leq .05 .{ }^{* *} p \leq .01 .{ }^{* * *} p \leq .001$ (two-tailed).

Table 18

Personal Characteristics of Lone Actor and Rampage Shooting Perpetrators in North America Versus Europe

\begin{tabular}{|c|c|c|c|c|c|c|}
\hline \multirow{2}{*}{$\begin{array}{l}\text { Perpetrators } \\
\text { Personal characteristics }\end{array}$} & \multicolumn{2}{|c|}{$\begin{array}{l}\text { North America } \\
\quad(n=88)\end{array}$} & \multicolumn{4}{|c|}{$\begin{array}{l}\text { Europe } \\
(n=67)\end{array}$} \\
\hline & $n$ & $\%$ & Significant & $n$ & $\%$ & Significant \\
\hline \multicolumn{7}{|l|}{ Work/school issues ${ }^{\mathrm{a}}$} \\
\hline Issues were present & 34 & 38.6 & * & 12 & 17.9 & * \\
\hline $\begin{array}{l}\text { Issues were not } \\
\text { present }\end{array}$ & 26 & 29.5 & & 23 & $34 \cdot 3$ & \\
\hline Not applicable & 26 & 29.5 & & 22 & 32.8 & \\
\hline Unknown & 2 & 2.3 & & 10 & 14.9 & \\
\hline \multicolumn{7}{|l|}{ Childhood issues $^{\mathrm{a}}$} \\
\hline $\begin{array}{l}\text { Evidence of } \\
\text { significant issues }\end{array}$ & 8 & 9.1 & $n s$ & 6 & 9 & ns \\
\hline $\begin{array}{l}\text { Evidence of some } \\
\text { form of issues }\end{array}$ & 24 & $27 \cdot 3$ & & 16 & 23.9 & \\
\hline No evidence of issues & 56 & 63.6 & & 45 & 67.2 & \\
\hline \multicolumn{7}{|l|}{ Substance use ${ }^{\mathrm{a}}$} \\
\hline $\begin{array}{l}\text { Indications of illegal } \\
\text { substance use and/or } \\
\text { abuse }\end{array}$ & 16 & 18.2 & $n s$ & 18 & 26.9 & $n s$ \\
\hline $\begin{array}{l}\text { Indications of } \\
\text { alcohol abuse }\end{array}$ & 4 & 4.5 & & 1 & 1.5 & \\
\hline $\begin{array}{l}\text { Indications of both of } \\
\text { the above }\end{array}$ & 13 & 14.8 & & 4 & 6 & \\
\hline No indications & 55 & 62.5 & & 44 & 65.7 & \\
\hline
\end{tabular}


Table 18 (continued)

\begin{tabular}{|c|c|c|c|c|c|c|}
\hline \multicolumn{7}{|l|}{ Weapon ownership ${ }^{\mathrm{a}}$} \\
\hline Yes & 72 & 81.8 & $n s$ & 47 & 70.1 & $n s$ \\
\hline No & 11 & 12.5 & & 5 & 7.5 & \\
\hline Unknown & 5 & $5 \cdot 7$ & & 15 & 22.4 & \\
\hline \multicolumn{7}{|l|}{$\begin{array}{l}\text { Fascination with } \\
\text { weapons/wara }\end{array}$} \\
\hline Yes & 63 & 71.6 & $n s$ & 52 & 77.6 & $n s$ \\
\hline No & 6 & 6.8 & & 1 & 1.5 & \\
\hline Unknown & 19 & 21.6 & & 14 & 20.9 & \\
\hline \multicolumn{7}{|l|}{$\begin{array}{l}\text { Familiarity with } \\
\text { firearms }\end{array}$} \\
\hline Yes & 76 & 86.4 & ns & 40 & 59.7 & $n s$ \\
\hline No & 12 & 13.6 & & 2 & 3 & \\
\hline Unknown & - & - & & 25 & $37 \cdot 3$ & \\
\hline \multicolumn{7}{|l|}{ Military experience } \\
\hline $\begin{array}{l}\text { Did have prior } \\
\text { experience }\end{array}$ & 19 & 21.6 & $n s$ & 8 & 11.9 & $n s$ \\
\hline $\begin{array}{l}\text { Did not have prior } \\
\text { experience }\end{array}$ & 67 & 76.1 & & 52 & 77.6 & \\
\hline Unknown & 2 & 2.3 & & 7 & 10.4 & \\
\hline \multicolumn{7}{|l|}{$\begin{array}{l}\text { Ideological } \\
\text { connections/group } \\
\text { affiliations }^{\mathrm{a}}\end{array}$} \\
\hline $\begin{array}{l}\text { Evidence of group } \\
\text { connections }\end{array}$ & 2 & 2.3 & $n s$ & 3 & 4.5 & $n s$ \\
\hline $\begin{array}{l}\text { No evidence of group } \\
\text { connections }\end{array}$ & 86 & 97.7 & & 64 & 95.5 & \\
\hline \multicolumn{7}{|l|}{ Precipitating events ${ }^{a}$} \\
\hline No clear event & 36 & 40.9 & $* * *$ & 47 & 70.1 & $* * *$ \\
\hline Relationship-related & 8 & 9.1 & & 4 & 6 & \\
\hline Occupation-related & 8 & 9.1 & & - & - & \\
\hline School-related & 2 & 2.3 & & - & - & \\
\hline Personal-related & 21 & 23.9 & & 12 & 17.9 & \\
\hline Combination & 13 & 14.8 & & 3 & $4 \cdot 5$ & \\
\hline Other & - & - & & 1 & 1.5 & \\
\hline
\end{tabular}

Note. Significance tests based on whether there is a statistically significant relationship between incident type and perpetrator-level variables.

$n s=$ nonsignificant.

aChi-square.

${ }^{*} p \leq .05 .{ }^{* *} p \leq .01 .{ }^{* * *} p \leq .001$ (two-tailed). 


\section{Discussion}

The following sections will consider the implications of the similarities and differences found in the current study between lone-actor terrorism and rampage shooting events and perpetrators, from an investigative perspective. The aim of the current study (i.e. comparing how these two groups differ in terms of characteristics and motivations) will be considered in the context of previous research and theoretical explanations of lone-actor terrorism and rampage shooting events, in order to explore whether lone-actor terrorists and rampage shooters are two groups of fundamentally different individuals. In particular, emphasis will be placed on exploring the research questions which guide this study, such as how these individuals differ in terms of psychological and social characteristics and motivational patterns, and the role of location in these events.

\section{Lone-Actor Terrorism versus Rampage Shootings: Event Characteristics}

\section{Significant Differences Between Groups}

Lone-actor terrorism and rampage shooting events significantly differ from one another on a number of event-based characteristics, including: the number of perpetrators involved in the event, modus operandi, location and attack type, the outcome of the event, the relationship between the perpetrator and victims, the level of planning dedicated to the event, and claims of responsibility. The current study found that lone-actor terrorism events are significantly more likely to involve multiple perpetrators than rampage shooting events. Gruenewald (2011) similarly found that over half of far-right homicides involved multiple perpetrators, compared to only 16 percent of 'common' homicides. A possible explanation for why lone actor events are more likely to involve multiple perpetrators may be because lone actors often act in small cells with like-minded individuals who wish to achieve similar outcomes through their actions. In this sense lone actors are more likely to share a specific motivation compared to rampage shooters, who are often responding to perceived personal 
grievances. It is also possible that individuals who act in small cells have decided to commit lone acts of terrorism due to an inability to join larger groups or movements.

Significant differences were found between lone-actor terrorism and rampage shooting events regarding the weapons used in the commission of the event. Findings reveal the most commonly-used weapons in rampage shootings are firearms, and these are significantly more likely to be the weapon of choice for rampage shootings than lone-actor terrorism events. Alongside firearms, lone-actor terrorism events often involve the use of explosives/bombs, vehicles, or sharp instruments. These findings are consistent with previous research which indicates that the majority of rampage shooters use firearms as their weapon of choice for shooting events (Fox \& DeLateur, 2014; Kalish \& Kimmel, 2010; Meloy, Hempel, Mohandie, Shiva, \& Gray, 2001; Silver, Horgan, \& Gill, 2019), in comparison to lone-actor terrorism attacks which usually involve firearms or additional weapons such as explosives (Capellan, 2015; Gruenewald \& Pridemore, 2012; Liem, van Buuren, \& Schonberger, 2018; Liem, van Buuren, de Roy van Zuijdewijn, et al., 2018; Spaaij, 2010). Although both loneactor terrorists and rampage shooting perpetrators are often driven by the desire to commit an attack that results in a significant number of fatalities, explosives may be one of the most prevalent weapon types used in acts of lone-actor terrorism because they can be deadlier than firearms, and can also be seen as a less personal way of committing an attack. Alternatively, lone actors may not have access to specialized information on how to assemble weapons, or may be denied access to weapons such as firearms (Horgan, Gill, Bouhana, Silver, \& Corner, 2016).

The current study found significant differences between groups regarding the type of location chosen to carry out the event. Although both lone-actor terrorism and rampage shooting events are more likely to occur in open commercial settings, lone actor events are more likely to take place on a public street or in private areas (such as offices). In comparison to this, rampage shootings are more likely to occur at educational institutions, military settings, or a warehouse/factory, and this could be due to rampage shooting events being aimed toward more specific targets. In accordance with these findings, previous research indicates the most common incident sites for rampage shootings were open commercial locations, military settings, schools, and public streets (Lankford 2015, 2016b). In comparison to this, researchers found that lone actor attacks are often carried out in public places and are 
more likely to occur in outside settings (Gruenewald \& Pridemore, 2012; Liem, van Buuren, \& Schonberger, 2018; Parkin \& Freilich, 2015; Spaaij, 2010). Interestingly, Lankford (2016b) found that rampage shooters in the U.S. were significantly more likely to attack at offices, a warehouse/factory, and open commercial sites, compared to rampage shooters in other countries who were more likely to attack at military settings and other locations. A possible explanation for this could be the differing motivations driving rampage shooters in various countries. For example, rampage shooters in the U.S. may be motivated by revenge and/or payback and may target locations occupied by individuals they wish to harm (such as their workplace), which may motivate them to carry out their attack in the above locations. In comparison to this, rampage shooters in other countries may be driven by personal grievances (such as workplace issues) or emotional triggers, which motivate them to carry out an attack at their workplace, or 'other' places where their targets spend time (such as a place of worship or an apartment complex).

Gibb's (1989) theory of social control can assist in explaining the current study's findings, as this theory contends that perpetrators of extreme acts of violence who attack victims at open commercial sites may be lashing out against perceived failures of social control at a societal level, and may feel hopeless about their ability to have a healthy future within society. In contrast to this, perpetrators who target victims in educational institutions or office buildings may be responding to failures of social control on a local level, and therefore may not be as hopeless about the prospect of living elsewhere. Findings from Capellan (2015) differ from those of the current study, as Capellan found that spatial distribution does not usually differ between lone actor and rampage shooting events, and claimed that both groups tend to attack places they have access to. The attack type used for incidents also significantly differed between lone actor and rampage shooting events in the current study. Findings indicate that the method of attack employed in rampage shootings is predominantly armed assault, whereas lone actor events vary between armed assault, explosion/bombing, and a small number of assassination attacks. This variation of methods used across lone actor events may potentially be due to the desire of the perpetrator to employ explosions/bombings alongside armed assaults to maximise the impact of the attack. Alongside this, lone-actor terrorism events are more common across Europe, where 
perpetrators have less access to firearms in comparison to perpetrators within North America.

The outcome of events significantly differed between lone-actor terrorism and rampage shooting events. The majority of lone actor events result in arrest, followed by lethal force, 'other' outcomes (i.e. fleeing the attack), and suicide. In comparison to this, the majority of rampage shooting events result in the perpetrator committing suicide, followed by arrest, lethal force, and 'other' outcomes. These findings are supported by previous research which has found that the majority of rampage shooting incidents resulted in the shooter committing suicide (Capellan, 2015; Osbourne \& Capellan, 2016). Duwe (2007) argued that the rate of suicidal behaviour amongst rampage shooters is high, and suggested that these perpetrators are often tormented individuals who want to end their lives as well as seek revenge on those they believed were responsible for their misery. Comparable to the current findings on lone actor event outcomes, researchers found the majority of lone actor events resulted in lethal force by police (Gruenewald et al., 2013a; Osbourne \& Capellan, 2016). Additionally, Capellan (2015) found that arresting lone actor perpetrators frequently required more lethal force in comparison to other shooting perpetrators, which may explain why the current study found that lone actor events are significantly more likely to result in lethal force in comparison to rampage shooting events.

Findings reveal that lone-actor terrorism and rampage shooting events significantly differ in terms of the relationship between the perpetrator and the victim(s). Lone actor events are predominantly aimed towards strangers, whereas rampage shootings are typically aimed towards individuals the perpetrators had a personal or professional relationship with. These findings are comparable to previous research which has found that the majority of rampage shooters knew their victims (Meloy et al., 2001; Meloy et al., 2004), whereas lone actors were more likely to victimize individuals they had no prior relationship with, such as civilians, religious targets, or government agencies (Capellan, 2015; Gruenewald \& Pridemore, 2012; Gruenewald, Chermak, \& Freilich, 2013a, 2013b; Liem, van Buuren, \& Schonberger, 2018; Spaaij, 2010). Similar to findings in the present study, Osbourne and Capellan 
(2016) found that the majority of ideological events 39 were targeted towards strangers, whereas victim-specific events40 were predominantly aimed towards professionalrelated targets, followed by intimate, stranger, personal, and school-related targets. Researchers argue that although the victims of lone actor attacks are often strangers, they are not necessarily chosen at random and can often represent certain groups (Liem, van Buuren, \& Schonberger, 2018).

Although the majority of both lone-actor terrorism and rampage shooting perpetrators dedicate a medium-level of planning to their events, rampage shooters are more likely to only dedicate low-levels of planning to their attack in comparison to lone actors, who are significantly more likely to dedicate both medium and high-levels of planning to their events. Such findings are consistent with previous research which has found that lone actor events are rarely impulsive and often involve higher levels of planning, research, and training (Capellan, 2015; Gill, Horgan, \& Deckert, 2014; Gruenewald et al., 2013a, Liem, van Buuren, \& Schonberger, 2018; Osbourne \& Capellan, 2016). Alongside this, researchers argue that rampage shooting events are also planned and preceded by significant amounts of deliberation, and rarely involve a sudden 'explosion' of rage (Duwe, 2017; Fox \& DeLateur, 2014). The planning stage of the cumulative stress model can also be used to understand why rampage shooting events are often preceded by large amounts of planning, as this model contends that the planning stage is often lengthy and involved due to perpetrators needing to plan the logistics of the attack (Levin \& Madfis, 2009). The findings of Silver et al. (2019) support those of the current study, as researchers found that compared to lone actor events, public mass shooters display less planning behaviours and dedicate less time and effort to preparing their attack. Researchers suggested that a possible explanation for this is that perpetrators of mass public shootings already know how they want to carry out the attack and who they want to target, and suggest that factors which are unique to lone-actor terrorism (such as a desire to maximise symbolic effort, and target selection related to ideology) may drive operational decisions that require a

39 Ideological events are similar to lone-actor terrorism events in the current study, as these researchers refer to ideological events as incidents that are motivated by ideological beliefs and revenge against an abstract issue. $4^{\circ}$ Victim-specific events are similar to rampage shootings in the current study. In their study, researchers refer to victim-specific events as those aimed toward a specific target, often precipitated by an event, and where the perpetrator holds a desire for revenge against specific people. 
higher level of planning compared to mass public shootings (Silver et al., 2019). Rampage shootings may involve less planning and preparation as they are often more likely to be driven by emotional factors, whereas lone actor events are often less emotional and are designed to have a significant impact and shock factor, and therefore they may require meticulous levels of planning.

Lone actor events are significantly more likely to have perpetrators and/or groups claim responsibility for the attack, in comparison to rampage shooting events. An individual and/or group claimed responsibility in just under a quarter of lone actor events, whereas claims of responsibility are only made in one rampage shooting event. Liem, van Buuren, de Roy van Zuijdewijn, et al. (2018) argued that groups and/or larger movements can claim responsibility for acts of lone-actor terrorism, often because the lone actor has expressed support for the group, and the group wants the public to know that they are capable of such violent acts. However, lone actor events are often not planned, supported, or executed directly by these groups, and these events are often only loosely connected to their ideological cause (Liem, van Buuren, de Roy van Zuijdewijn, et al., 2018). Alongside this, lone actors may support certain groups and/or movements, however the group's actual involvement in lone actor events can rarely be established. Claims of responsibility may not emerge for rampage shooting incidents as it is often evident that the motives behind these events are personal and are rarely political and/or religious.

\section{Non-Significant Differences Between Groups}

Lone actor and rampage shooting events do not differ significantly on event characteristics such as weapon subtypes used, the duration of the event and the time of day it occurs, whether there are specific targets, and whether threatening statements are made to the victims prior to and/or during the event. Findings reveal that the majority of both lone actor and rampage shooting events last less than 30 minutes. These findings are supported by previous research such as Osbourne and Capellan (2016) who found that the majority of active shooting events lasted less than 30 minutes, and no ideological active shooter events lasted between 31-60 minutes. The current study found that the majority of rampage shootings occur in the morning, whereas the majority of lone actor events occur in the afternoon. If the aim of the attack was to ensure maximum harm and impact, perpetrators may have chosen to 
attack at times where their target location was the busiest and a significant number of people were around. Lone actor and rampage shooting events appear to be similar in terms of whether they have specific targets in mind for the attacks, as the majority of both events are aimed towards specific targets. Such findings differ from those of Osbourne and Capellan (2016) who found that only a small portion of ideological events had specific targets. Researchers argue that for lone actor events in particular, the chosen victims often represent strategic targets against whom revenge is sought, or are chosen to send an ideological message of terror (Fein \& Vossekuil, 1999; Liem, 2010). The majority of rampage shooting perpetrators make no threatening statements to victims prior to and/or during the event, and these findings are consistent with previous research which has found that direct threatening statements were scarcely made to the victims of rampage shooting events prior to the event (Meloy \& Gill, 2016; Meloy et al.,2004).

\section{Sociodemographic Characteristics of Lone Actor versus Rampage Shooting Perpetrators}

\section{Significant Differences Between Groups}

Lone actor and rampage shooting perpetrators significantly differ from one another on approximately half of all sociodemographic characteristics, such as age, race/ethnicity, religious affiliation, and job status. Lone actors are significantly younger than rampage shooters, and on average are approximately 29 years old, whereas rampage shooters tend to be older and on average are approximately 35 years old. Such findings are consistent with previous research which has indicated that the average age for rampage shooters is early-mid 30s (Duwe, 2017; Lankford, 2016b). Although the current study found that lone actors tend to be in their late 20s, previous research has found that the majority of lone actors were in their mid-late $30 \mathrm{~s}$ (Capellan, 2015; Gill et al., 2014; Gruenewald et al., 2013a, 2013b; Horgan et al., 2016; Liem, van Buuren, de Roy van Zuijdewijn, et al., 2018). A possible explanation for the older ages of rampage shooters in the current study could be the perceptions of status failure among older rampage shooters. Men can be concerned with the need to achieve or maintain status, and violence is often employed as a high-risk strategy of status attainment. A failure to achieve status by an older age or a loss of status can leave men feeling as though they have nothing left to invest in their community other than anger 
and resentment, and this can lead to the belief that they have less to lose in enacting violence, and doing so allows them to regain a sense a power (Lindekilde et al., 2017; McCauley \& Moskalenko, 2011).

Lone actor and rampage shooting perpetrators significantly differ from one another in terms of race/ethnicity. Over half of lone actors belong to the 'other' group (i.e. ethnicity groups such as Turkic, Arab, or Palestinian), followed by White, Black/African American, and Hispanic or Latino groups. In comparison to this, approximately half of rampage shooters are White, followed by Black/African American, 'other,' and Hispanic or Latino. Such figures are consistent with previous research which concluded that rampage shooters were predominantly White (Capellan, 2015; Duwe, 2017; McCauley, Moskalenko, \& Van Son, 2013; Meloy et al., 2001; Newman \& Fox, 2009; Rocque \& Duwe, 2018; Taylor, 2016), and the majority of far-right perpetrators were non-White (Gruenewald \& Pridemore, 2012). However, unlike the findings of the current study, several researchers have found that the majority of lone actors in their studies were White (Gruenewald, 2011; Gruenewald et al., 2013b; Hamm and Spaaij, 2015). In terms of religious affiliation, rampage shooters are significantly more likely to identify as non-religious compared to lone actors. Of those who are religious, rampage shooters are significantly more likely to identify as Christian when compared to lone actors, whereas lone actors are significantly more likely to identify as Muslim and 'other' religions. Such findings suggest that lone actors are significantly more religious than rampage shooters, which is unsurprising considering the relatively high prevalence of religious motivations underlying lone actor attacks. Alongside this, the current sample may have contained more religious lone-actor terrorists because of the prevalence of religiously-motivated attacks across Europe.

Findings of the present study reveal that lone actors are significantly more likely to be unemployed compared to rampage shooters, and rampage shooters are more likely to have blue and white-collar jobs in comparison to lone actors. Similarly, Silver et al. (2019) found that the majority of public mass murderers in their study worked in the service industry, and the rest were either unemployed or held a professional position. In accordance with the current findings, researchers found that the majority of lone actors in their study were unemployed (Hamm \& Spaaij, 2015; Horgan et al., 2016; Gill et al., 2014; Gruenewald et al., 2013b; Liem, van Buuren, de Roy van 
Zuijdewijn, et al., 2018). Gill et al. (2014) stated that lone actors who were employed mainly worked within the service industry, while smaller percentages were in professional occupations, construction, or administrative positions. Additionally, lone actors who were without a job were often chronically unemployed, and struggled to maintain any form of employment for a significant amount of time (Gill et al., 2014).

\section{Non-Significant Differences Between Groups}

Both types of perpetrators do not significantly differ on characteristics such as gender, whether they had children and/or dependents, relationship status, and educational level. Lone actors and rampage shooters are similar in terms of gender, as both groups are almost exclusively male. ${ }^{41}$ This is consistent with previous research which has found that the majority of lone actors are male (Capellan, 2015; Corner \& Gill, 2015; Gill et al., 2014; Gruenewald \& Pridemore, 2012; Liem, van Buuren, de Roy van Zuijdewijn, et al., 2018; Meloy \& Gill, 2016), and that rampage shooters are almost exclusively male (Duwe, 2017; Fox \& DeLateur, 2014; Lankford, 2015; Lankford, 2016b; McCauley et al., 2013; Meloy et al., 2001; Rocque \& Duwe, 2018; Taylor, 2016). These findings are consistent with the same pattern for violent crimes in general. Gender differences can be viewed as the outcome of a complex interplay of biological and social factors, and evolutionary perspectives assert that in general, men are more likely to perpetrate violent crimes such as homicide (Durrant, 2018). Researchers argue that these differences can be explained through the process of sexual selection, and violence can be seen as the result of the competition between males for dominance, status, and resources (Archer, 2004). Researchers argue that rampage shootings are predominantly committed by males due to the 'interaction effect' between community approval and gender, which asserts that males have been traditionally socialized in ways that increase their likelihood of violent behaviour (Lankford \& Hakim, 2011).

Findings reveal that a similar portion of lone actors and rampage shooters are single when they carry out the event (just over half of both groups), and both groups appear to be similar in terms of exhibiting lower levels of social bonding factors (i.e. perpetrators tend to be unemployed and not in a relationship). Consistent with the

${ }^{41}$ There were only five female perpetrators in the entire sample, and only three of these individuals were the sole perpetrators of the incident. 
current findings, researchers found that rampage shooting perpetrators are usually single at the time of the event (Lankford, 2015; Lankford \& Hakim, 2011; McCauley et al., 2013; Taylor, 2016), and lone actors are usually single or divorced (Corner \& Gill, 2015; Gill et al., 2014; Gruenewald et al., 2013b; Hamm \& Spaaij, 2015; Liem, van Buuren, de Roy van Zuijdewijn, et al., 2018; Meloy \& Gill, 2016). The relationship status' of both groups suggest that a decent portion of lone actors and rampage shooters are able to establish a significant connection with others (indicated by the portion of individuals who have partners), however it is possible to be in a relationship or marriage that does not have a prosocial effect.

Although not significant, slight differences exist between lone actors and rampage shooters regarding educational level. Of the available data on educational levels, rampage shooters are more likely to obtain secondary levels of education compared to lone actors, whereas lone actors are more likely to obtain higher levels of education. Although the average educational level for the current lone actor sample is impressive, the educational success of lone actors does not appear to translate into direct success within the job market, as over half of lone actors are unemployed. Such findings suggest that overall, lone actors in the current sample are well-educated, however this does not necessarily translate into real-life success. Despite the lower educational achievement of rampage shooters, these perpetrators appear to be more successful than lone actor perpetrators in terms of job status. Although the educational achievement of lone actors may not translate into real-life success, the relatively high levels of education that lone actors obtain may explain how they are able to successfully plan and carry out attacks. Consistent with the current study, Capellan (2015) found that the majority of non-ideological shooters' highest level of education was secondary education, followed by higher education. Ideological shooters were also more likely to obtain secondary levels of education, however were more likely to achieve higher levels of education than their non-ideological counterparts.

\section{Personal Characteristics of Lone Actor versus Rampage Shooting Perpetrators}

\section{Significant Differences Between Groups}

The current findings indicate significant differences between groups regarding the following: fascination with weapons and/or war, substance use, work and/or 
school issues, and precipitating events. Findings reveal that lone actors are significantly more likely to have a fascination with weapons and/or war compared to rampage shooters. Previous research has found that it is common for lone actors to possess a stockpile of weapons, and this portrays their interest in weaponry in particular (Corner \& Gill, 2015; Gill et al., 2014). Researchers have also found that rampage shooters often obtain a strong fascination with violence prior to the event, including an interest in weaponry (Fox \& DeLateur, 2014; Langman, 2009; Leary, Kowalski, Smith, \& Phillips, 2003; Newman \& Fox, 2004). Similar to the current research, Horgan et al. (2016) found that lone actors were significantly more likely to possess a stockpile of weapons compared to solo mass murderers; however, McCauley et al. (2013) found that both groups tend to show a history of interest in violence and weapons.

The findings of the current study reveal that the majority of both lone actors and rampage shooters display no indications of engaging in either illegal substance or alcohol abuse. However, lone-actor terrorists are significantly more likely to engage in illegal substance use and/or abuse in comparison to rampage shooters, whereas rampage shooters are significantly more likely to engage in alcohol abuse. Unlike the current study, Horgan et al. (2016) found that mass murderers were significantly more likely to have a history of substance abuse compared to lone-actor terrorists. Alongside this, Liem, van Buuren, and Schonberger (2018) also found that there was a substantially higher prevalence of substance use among homicide offenders in comparison to lone-actor terrorists. Additionally, Meloy et al. (2001) found that 62 percent of adolescent mass murderers in their study had a history of substance use, which is a substantially larger portion than perpetrators in the current study. However, this could be due to a range of factors, including the age difference of perpetrators and the possibility that individuals are more likely to experiment with various substances during adolescence.

The majority of rampage shooters experience workplace and/or school issues, and are significantly more likely to experience issues in comparison to lone actors. Of the available information in the current study, work issues rampage shooters face include being demoted or dismissed from their job, receiving mistreatment from coworkers, and experiencing grievances with co-workers or employers. The 2010 Hartford Beer Distributors shooting in Connecticut illustrates how work issues can act 
as a catalyst for some rampage shooters. Omar Thornton had faced disciplinary issues at his workplace regarding theft, and was given the choice to either resign or be fired. Instead of leaving the building, a disgruntled Thornton opened fire on his co-workers, and asserted that he did so due to the racism he and other black employees had experienced within the workplace. Comparably, work issues lone actors tend to face include being dismissed from their job and experiencing grievances with co-workers or employers. School issues faced by rampage shooters include bullying from peers or staff at school, issues with academic performance, and disciplinary issues. Nikolas Cruz revealed that he planned the Marjory Stoneman Douglas High School shooting partly in retaliation to the bullying he experienced during his time at the school, and this portrays the serious impact school issues can have on individuals, especially if they already suffer from issues with aggression. School issues faced by lone actors are similar to those experienced by rampage shooters, and include isolation due to extremist views, bullying from peers, anger management issues, disciplinary issues, issues with academic performance, and being suspended or expelled from school. Such findings are consistent with previous research which found that school issues are often a motive in shootings that are specifically targeted at certain individuals, due to the perpetrator wanting to gain revenge on a specific school. Alongside this, researchers found that school shooters committed acts of violence due to feeling ostracised, intimidated, publicly humiliated, and harassed by fellow students for an extended period of time (Bockler, Seeger, Sitzer, \& Heitmeyer, 2013; Larkin, 2009; Leary et al., 2003; Newman, 2004).

Bockler et al. (2013) argued that school shooters in their study displayed a cognitive fixation on previous humiliations, and stated that negative feelings can lead to the school being deemed as problematic from the perpetrator's perspective and can initiate a process of social withdrawal. Researchers argue that these experiences can create a continuous point of reference for violent thoughts, as perpetrators often remember negative feelings they experienced while they were at school (Bockler et al., 2013). The culture of hegemonic masculinity is often applied to rampage shootings within school environments. This theory supports the current findings as it asserts that males who feel humiliated and mistreated within school contexts often retaliate with acts of violence in an attempt to demonstrate their masculinity. Alongside this, this culture can create a sense of aggrieved entitlement which encourages violence in 
order to avenge the challenge to their masculine identity (Kalish \& Kimmel, 2010; Kimmel \& Mahler, 2003; Newman \& Fox, 2009). The findings of the current study suggest that if individuals experience what they perceive to be extreme forms of victimization from their school peers for an extended period of time, this may produce feelings of hopelessness and vulnerability, and eventually lead to individuals resorting to violence as a form of retaliation against their peers.

Lone actors and rampage shooters differ significantly in terms of whether they experience precipitating events prior to the incident, and the types of events they experience. Lone actors are significantly more likely to experience no clear event in the lead up to the incident in comparison to rampage shooters. Additionally, lone actors are less likely to experience relationship and/or domestic-related events, personalrelated events, and a combination of events. Alongside this, a small portion of rampage shooters also experience school-related events, whereas no lone actors in the current study experienced this type of precipitating event. In accordance with the current findings, researchers found that the majority of shooters experience a traumatic event that precipitates their act of violence (Duwe, 2017; Osbourne \& Capellan, 2016). Osbourne and Capellan (2016) found that the majority of victim-specific shooting events were caused by a precipitating event, and the majority of these events were occupation-related events, followed by relationship-related events. Similar to the current findings, researchers also found that the majority of ideological events did not have identifiable precipitators. Although the majority of lone actors in the current study experienced no clear precipitator to their attack, researchers have used situational explanations of crime to argue that short-term events can significantly affect individuals, as lone actors are often impacted by stressors they face in the months leading up to the attack (Gill et al., 2014). In terms of cumulative strain theory, researchers assert that precipitating events can act as a catalyst to a mass murder rampage, as these acute strains are troubling for individuals who are unable to cope with adversity. Although these strains or events may be minor, the event is perceived as significant in the perpetrator's mind due to the cumulative effect of the strains they have faced (Fox \& Levin, 2015; Levin \& Madfis, 2009; Madfis \& Arford, 2008; Rocque \& Duwe, 2018; Vossekuil, Fein, Reddy, Borum, \& Modzeleski, 2004). 


\section{Non-Significant Differences Between Groups}

Both groups of perpetrators do not significantly differ on characteristics such as childhood issues, weapon ownership, familiarity with firearms, and military experience. Findings indicate that lone actors are more likely to have experienced childhood issues overall in comparison to rampage shooters. Similarly, findings of the regression analysis revealed that rampage shooters were less likely to have experienced childhood issues during their upbringing, however in this analysis childhood issues significantly predicted incident type. Researchers argue that perpetrators usually grow up in oppressive social environments that can increase the likelihood of violence and can be a significant motivator due to feeling vulnerable, trapped, and oppressed, and assert that this is an important link between these two types of perpetrators (Lankford and Hakim, 2011; Meloy et al., 2001).

The majority of both lone actors and rampage shooters own weapons, and Lankford (2016b) argued that acquiring weapons may be easier due to America's gun culture, and stated that the availability of guns can be seen to be a contributing factor toward rampage shootings as this makes it easier for perpetrators to not only gain access to high-powered weapons, but also ammunition (Lankford, 2016b). Of the available information, almost all rampage shooters in the current study are familiar with firearms, compared to approximately two thirds of lone actors. In line with the current study, Leary et al. (2003) found a significant amount of events involved individuals who were familiar with firearms. Unlike the current findings, Osbourne and Capellan (2016) found that all ideological perpetrators were familiar with firearms, and Capellan (2015) found that ideological shooters were more likely to be familiar with firearms than non-ideological shooters. Researchers have suggested that the reason rampage shooters are familiar with firearms is because they have access to these and may be more likely to act on aggressive impulses as they are comfortable dealing with instruments of destruction (Leary et al., 2003). 


\section{Psychological Characteristics of Lone Actor versus Rampage Shooting Perpetrators}

\section{Significant Differences Between Groups}

Findings of the current study reveal that lone-actor terrorism and rampage shooting perpetrators only significantly differ from each other in terms of low selfesteem, and tend to be similar on the remaining psychological characteristics. The findings from the logistic regression analysis, which focused on whether key personal and psychological attributes of both groups differ, also indicated that these individuals tend to experience similar underlying psychological mechanisms. Findings indicate that lone actors are significantly less likely to suffer from low self-esteem than rampage shooters. Previous research concerning low self-esteem faced by these groups of perpetrators is limited, however Lankford and Hakim (2011) found that both lone actors and rampage shooters tend to suffer from low self-esteem, which can eventually lead to engagement in violence and/or suicide in extreme cases. The findings of the current study suggest that low self-esteem may indirectly play a role in these events, particularly in cases where the perpetrator experienced negative feelings such as humiliation or shame, or were bullied for an extended period of time. Although previous research has suggested that individuals who suffer from low self-esteem are more likely to engage in violent behaviour, researchers have challenged this idea, and instead argue that high self-esteem makes an individual more prone to violence (Baumeister, Bushman, \& Campbell, 2000). These researchers suggest that individuals who have high but unstable self-esteem (i.e. may be insecure and hold an inflated view of themselves) are more likely to be aggressive when this inflated view of themselves is threatened by other individuals. Moreover, Baumeister explains that men who are violent often have a strong sense of superiority, and their violence can come from their sense of wounded pride (Baumeister, 2000). This notion of the violent side of high self-esteem is illustrated through the Breivik case. Breivik suffered from grandiose delusions regarding his role in the world, and held an elevated and heroic view of himself. According to psychiatrists, Breivik suffered from severe narcissistic personality disorder, marked by grandiosity, heightened self-worth, a willingness to exploit others, and an unstable sense of self-esteem (Melle, 2013). Breivik was also thought to have suffered from a condition known as 'narcissistic decompensation' which occurs when an individual with a narcissistic personality disorder suffers a 
major injury to their self-esteem, which can lead to isolation and paranoia. Breivik's idea that Europe must be saved from terrorism may have led him to believe that violence was the only way to remedy this situation and restore his manhood (Richards, 2014).

\section{Non-Significant Differences Between Groups}

Findings of the current study demonstrate that both groups of perpetrators do not significantly differ on the remaining characteristics, such as anti-social personality traits, previous violent acts, previous abuse, criminal history, social isolation, mental health status, and whether they displayed indications of their suicide. The current findings indicate that the majority of both lone actors and rampage shooters display no indications of experiencing social isolation. Although both groups of perpetrators suffer from some form of social isolation, a small portion of rampage shooters also display indications of suffering from extreme levels of social isolation. In line with the current findings, previous research indicates that both rampage shooters and lone actors often suffer from some form of social isolation (Fox \& DeLateur, 2014; Gill et al., 2014; Meloy \& Gill, 2016). Liem, van Buuren, de Roy van Zuijdewijn, et al. (2018) found that lone actors who were inspired by religious motivations were rarely socially isolated when compared to lone actors motivated by other causes. This may explain why the majority of lone actors in the current study display no indications of social isolation, as lone actors are predominantly driven by political and/or religious motivations.

Aspects of cumulative strain theory can contribute to the understanding of how various factors can build upon one another in a cumulative way. In the current study, strains faced by perpetrators often lead to feelings of aggression, anger, and social isolation. Individuals who suffer from extreme levels of social isolation often feel hostility towards individuals they perceive to be the cause of this, and researchers argue that this can result in blame externalisation and the deflection of responsibility onto the victims (Hamm \& Spaaij, 2015; Levin \& Madfis, 2009; Peddell, Eyre, McManus, \& Bonworth, 2016). The cybernetic theory of violence can also be used to explain how social isolation can contribute to mass shootings. This theory asserts that the social loop of being isolated and rejected can lead to alienation, and as this 
increases the likelihood of this leading to repeated rejection also increases, and this can result in a negative spiral for the perpetrator (Scheff, 2011).

Although there is no significant difference between groups regarding mental health status, both lone actors and rampage shooters appear to display some indication of suffering from mental health issues. Rampage shooters are more likely to display both indications (36.1\%) and evidence $(36.1 \%)$ of suffering from mental health issues, whereas lone actors were slightly less likely to display indications (33.3\%) and evidence (18.1\%) of mental health issues. In line with the current findings, previous research has found that just under two thirds of perpetrators suffer from some form of mental health issues (Duwe, 2017; Meloy et al., 2001; Rocque \& Duwe, 2018). Findings of the current study indicate that individuals tend to suffer from illnesses such as depression, anxiety, posttraumatic stress disorder, paranoid schizophrenia, psychopathy, and bipolar disorder. These findings are consistent with previous research which has found that rampage shooters tend to exhibit high rates of mental illness, in particular paranoid schizophrenia, delusional disorder, and depression (Declercq \& Audenaert, 2011; Fox, Brook, Stratton, \& Hanlon, 2016; Lankford \& Hakim, 2011; Meloy et al., 2004). In the current study, a significant number of rampage shooters suffer from a mental illness that had been undetected or untreated for an extended period of time. Alongside this, numerous perpetrators refuse to take their medication or seek help, which adds to the prolonged period of time mental health issues are undetected or undiagnosed. Duwe (2017) argues that although improvements can be made regarding mental health treatment and the assessment of risk, the rate of untreated mental illness indicates a significant problem. The current study found that lone actors tend to suffer from similar mental health issues to rampage shooters, including depression, anxiety, bipolar disorder, schizophrenia, posttraumatic stress disorder, and narcissistic personality disorder. In accordance with the current findings, previous research has found that although lone actors are likely to suffer from some form of mental illness, mental health issues are not as common in lone actors as they are rampage shooters, and often only one third of lone actors suffer from these (Corner \& Gill, 2015; Gill et al., 2014; Gruenewald et al., 2013a; Lankford \& Hakim, 2011; Liem, van Buuren, de Roy van Zuijdewijn, et al., 2018). Researchers argue that their findings, combined with the observation that the majority of lone actors showed no indication of suffering from mental health issues, 
challenge the popular notion that lone actors are 'crazy' (Alonso et al., 2004; Liem, van Buuren, de Roy van Zuijdewijn, et al., 2018).

Psychological explanations behind lone-actor terrorism and rampage shootings assert that the existence of mental health issues and/or disorders can be a critical contributing factor to these events, as these issues can exacerbate problems in the perpetrator's life and reduce their ability to cope with issues that arise (Corner \& Gill, 2015; Langman, 2009). Additionally, perpetrators who suffer from mental health issues may be more susceptible to negative reactions to stressors; this idea is conveyed through stress models within the literature, and is reflected through the current study's findings (Borum, Fein, \& Vossekuil, 2012; Peddell et al., 2016; Roberts, McLaughlin, Conron, \& Koenen, 2011). The findings of the current study regarding mental health issues can contribute to the understanding of what drives perpetrators to commit violent acts. In many cases, individuals who suffer from severe depression indicate that they not only want to take their own life, but also the life of others. Individuals who suffer from paranoid schizophrenia and experience extreme delusions and hallucinations pose a significant threat, as these individuals have usually lost contact with reality and often struggle to cope with the 'evil voices' in their head which urge them to commit murder against certain individuals. However, it is important to note that despite the elevated risk of violence for individuals with schizophrenia, the majority of individuals suffering from this do not commit violent crimes (Langman, 2009).

The 2018 Marjory Stoneman Douglas High School shooting illustrates the severity and serious nature of mental health issues, as Cruz's severe depression that he refused treatment for led him to want to commit suicide, and kill other people (Shugerman, 2018). According to Cruz, the 'evil voices' in his head are what drove him to commit the attack, and he claims they told him to "burn, kill, destroy anything" (James \& Cardona, 2018). Aaron Alexis's commission of the Washington Navy Yard shooting was also partly due to suffering from extreme paranoia and delusions, those of which led him to believe he was in danger. As indicated by the above cases, the perceptions of perpetrators who are struggling with these types of disorders can be easily distorted, and this can lead to exaggerated perceptions of their own victimization and persecution, and contribute to their decision to target individuals who symbolize their persecutors (Langman, 2009; Newman \& Fox, 2009). These 
findings suggest that even though a portion of perpetrators do not suffer from mental health issues, the violent acts of those who do can result in a significant level of harm. Potential perpetrators who are experiencing a triggering event would likely benefit from mental health treatment, however an issue with this may be that an individual considering violence after experiencing a form of strain is unlikely to go to the effort of seeking help before committing a violent act. It is therefore critical for mental health services to be easily accessible to a potential offender following a triggering event so that situations can be deescalated to the point where an individual no longer poses an immediate threat, and alternative solutions to violence can be identified.

\section{Motivational Characteristics of Lone Actor versus Rampage Shooting Perpetrators}

\section{Significant Differences Between Groups}

The extent to which motivational patterns of lone-actor terrorists and rampage shooters differ is one of the main research questions guiding the current research. Findings of the current study reveal motivational patterns of lone-actor terrorists differ from rampage shooters in a number of ways, and significant differences were found regarding the following: emotional triggers, relationship and/or domestic issues, personal grievances, political and/or religious motivations, and whether motivations were unclear and/or unknown. In comparison to lone actors, rampage shooters are significantly more likely to carry out their attacks due to experiencing emotional triggers. These triggers often include experiencing certain events which have triggered their emotions in a negative way and contributed to their decision to carry out the attack. Osbourne and Capellan (2016) found that a small percentage of non-ideological events in their study occurred due to self-generated conflict and as a result of the perpetrator's psychological processes and issues. Although the above study differed in the sense that less perpetrators were driven by emotional triggers, the findings of the current study suggest that rampage shooters may be more susceptible to the negative emotions they experience, or may be easily triggered by emotional events, in comparison to lone actors.

Rampage shooters are also significantly more likely to carry out their attacks due to relationship and/or domestic issues, when compared to lone actors. The majority of perpetrators in the current study who are motivated by relationship and/or 
domestic issues, are driven by a breakup with their partner in particular. In these situations the perpetrator often becomes overly jealous and obsessed with the victim, and this drives them to carry out an attack in places where they know their target will be (i.e. their workplace). Alongside this, disputes within the perpetrator's family can also drive them to carry out a violent attack, and in these cases the perpetrator becomes obsessed with retaliating against the victim and also targets places they know the victim will be. These findings reveal that the perpetrators of rampage shootings are driven to commit violence due to personal struggles they are facing. The current findings suggest that rampage shooters are potentially less able to control their emotions in comparison to lone actors, and the negative feelings the relationship and/or domestic issues create tend to consume these individuals to the point where committing mass violence becomes the only viable option in their mind.

The current findings indicate that rampage shooters are also significantly more likely to commit an attack due to experiencing personal grievances, in comparison to lone actors. Unlike the small percentage of lone actors who commit an attack due to personal grievances in the current study, Peddell et al. (2016) argued that possessing a grievance was seen as the overriding motivational characteristic for lone actors, and proposed that lone-actor terrorism can be understood as part of a wider phenomenon of lone actor grievance-fuelled violence. Although lone actors and rampage shooters significantly differ on this motivational characteristic in the current study, McCauley et al. (2013) concluded that the common denominators between both groups of perpetrators are personal grievances (i.e. perceived mistreatment by individuals close to them) and outrage. Although both groups tend to experience grievances, rampage shooters often experience specific grievances themselves, whereas the grievances lone actors experience are usually group-based. These conclusions support the current study's findings, as perpetrators in the current study experienced personal grievances that acted as a catalyst for these types of events. Gibb's (1989) theory of social control can partially explain why rampage shooters are more likely to commit an attack due to perceived grievances. This theory contends that often mass murderers act in response to perceived failures of social control, and believe they can no longer rely on the system to protect them through controlling the behaviour of others, and take matters into their own hands. Through this view, mass murder is seen as an individual's violent exercise of direct control, and an attempt to right past wrongs. In relation to rampage 
shooters, many of these perpetrators were motivated by a desire to correct grievances and previous injustices, and felt hopeless about the system's willingness to protect them. Consequently, these individuals feel they have to exercise the most direct control themselves, through rampage shootings, and these individuals reach the point where they feel hopeless about their future and believe society is unjust.

Lone-actor terrorists are significantly more likely to commit an attack as a result of political and/or religious motivations in comparison to rampage shooters, which is unsurprising given the specific inclusion criteria for this study. The current findings indicate that lone actors are predominantly motivated by political and/or religious motivations, and only four out of 94 lone actors are motivated by factors that are not political or religious. In support of the current findings, researchers found that rampage shootings often lack religious motive (Lankford, 2015; Lankford \& Hakim, 2011; McCauley et al., 2013; Taylor, 2016), whereas lone actor events are often ideologically or religiously motivated (Liem, van Buuren, de Roy van Zuijdewijn, et al., 2018). Researchers argue that this motivation is the primary distinction between lone actor and rampage shooting perpetrators, as lone actors are predominantly motivated by ideological extremism and by sentiments against certain ethnic groups, alongside anti-government, anti-homosexual, and anti-abortion sentiments (Capellan, 2015; Gruenewald \& Pridemore, 2012). Additionally, researchers argue that lone actors are often motivated to sacrifice themselves for a religious cause and are willing to protect sacred values through extreme acts of violence (Juergensmeyer, 2003). Interestingly, researchers have suggested that some lone actors cover their motives with political rhetoric and construct a narrative to legitimize their attacks; Joosse (2007) found that lone actors can be interested in upgrading their violence by adding political motivation, when in reality they were driven by personal motives.

\section{Non-Significant Differences Between Groups}

Lone actor and rampage shooting perpetrators do not significantly differ regarding whether or not they commit their attacks due to criminal gain, however findings indicate that no rampage shooters are motivated by criminal gain, whereas a small percentage of lone actors are. Unlike the current findings, Peddell et al. (2016) state that lone actors are often motivated by personal reward, and believe they will receive rewards for engaging in violence. In comparison to this, rampage shooters tend 
to lack this motivation as they are often driven by personal rather than group-based motivations, and researchers suggest that this may reflect cultural differences between the two groups (Lankford, 2015; Lankford \& Hakim, 2011; McCauley et al., 2013; Osborne \& Capellan, 2016; Taylor, 2016).

Lone actors and rampage shooters do not differ significantly regarding whether they commit an attack due to revenge and/or payback, as similar percentages of both lone actor (approximately 25\%) and rampage shooting perpetrators (approximately $30 \%$ ) commit their attacks due to this motivation. Consistent with perpetrators in the current study, Duwe $(2007,2017)$ found that the majority of rampage shooters carried out their attacks as an act of vengeance against individuals the perpetrator holds responsible for their perceived mistreatment. Similarly, Osbourne and Capellan (2016) found that victim-specific events involved perpetrators who were seeking revenge or retribution, and that these were the most common motivations for events. Researchers also argue that both lone actors and rampage shooters tend to be motivated by desires for revenge against those who have harmed them, and that they tend to blame other individuals for their issues (Lankford \& Hakim, 2011). The current findings are consistent with Knoll's (2010) discussion on the psychology of revenge, as in the current study over a quarter of the overall sample of perpetrators were motivated to commit their attack due to revenge and/or payback. Similar to Knoll's discussion, the perpetrators in the current study who were driven by revenge engaged in a significant amount of planning prior to the event, and were driven by overwhelming feelings of resentment and humiliation. An example of this was the Umpqua Community College shooting in Oregon, North America. In his manifesto, Chris Harper-Mercer revealed that the shooting he perpetrated was motivated by feelings of revenge and the mistreatment he received from individuals. Harper-Mercer suffered from extreme forms of social isolation, and indicated that he felt a lack of fulfilment in his isolated life, stating “Don't be afraid to give in to your darkest impulses. Human life means nothing," and that committing the shooting would result in him being known by everyone and for once he would be the focus of attention (Harper-Mercer, n.d.). Harper-Mercer stated that he also resented society as a whole for denying him the things he wants (for example, a girlfriend, friends, and a job).

The current findings demonstrate that overall, the motivational patterns of lone actors and rampage shooters differ from one another to a great extent. Researchers 
argue that the difference between perpetrators can be summarized by instrumental versus expressive motivations. Researchers assert that the expressive nature of violent events can be observed in the direction of the aggression, and that rampage shootings often occur in response to anger-inducing events, where the main objective is to make the victim suffer. In comparison to this, lone actors are mostly motivated by instrumental aims and are usually driven by the desire to achieve a particular goal as opposed to attempting to exact harm on individuals. In these cases, researchers assert that the victim can be seen as a hindrance to the perpetrator's ulterior motive (Liem, van Buuren, de Roy van Zuijdewijn, et al., 2018; Salfati, 2000). However, although motivations can differ significantly between lone actor and rampage shooting perpetrators, researchers contend that the expressive versus instrumental dynamic is not always clear-cut and in some cases lone actors can be driven by expressive motivations (Leenars \& Reed, 2016; McCauley et al., 2013).

\section{Summary of Key Findings}

The findings in the current study shed light on the nature of both lone-actor terrorism and rampage shooting events and perpetrators, and through these findings new understandings and insights of these groups have emerged. This study assists in determining the extent to which lone-actor terrorism and rampage shooting perpetrators differ; are these individuals cut from the same cloth, despite being perpetrators of different types of violent acts? When comparing groups based on background characteristics, lone actors and rampage shooters appear to be similar on an underlying psychological level (see table 19 for a list of similarities and differences between groups). Although these individuals differ on some sociodemographic characteristics (such as age, race/ethnicity, and religious affiliation) and personal issues they face (such as work or school issues), in many respects these individuals display similar psychological profiles. Perpetrators in both groups are almost exclusively male, display a high rate of weak social bonds (i.e. are often unemployed, single, and have no dependents), often suffer from mental health issues (which can be risk factors), are often fascinated with weapons and/or war, and have a high familiarity with firearms. These individuals appear to be relatively young and disenfranchised males who are likely to experience cumulative strains in different ways. Lone actors often experience strains in combination with a specific set of political and religious motivations and often identify with particular ideas and movements, whereas rampage 
shooters often share similar background characteristics and experience particular setbacks in terms of personal grievances, relationship, and emotional issues. The work and/or school issues rampage shooters tend to face often act as precipitating events driving these individuals to commit a mass shooting, and rampage shooters are more likely to respond to these precipitating factors in comparison to lone actors. In relation to strain theory, rampage shooters often experience more acute personal strains and stressors. These can increase the likelihood of crime as they lead to negative emotions, and can reduce an individual's ability to cope or any attempt to alleviate or reduce these emotional states (Agnew \& Brezina, 2010; Durrant, 2018).

Table 19

Similarities and Differences Between Lone-Actor Terrorism and Rampage Shooting Groups

\begin{tabular}{|c|c|c|}
\hline Background characteristics & $\begin{array}{l}\text { Precipitating and motivational } \\
\text { characteristics }\end{array}$ & Event characteristics \\
\hline Age & Precipitating events & Number of fatalities \\
\hline Gender & Emotional triggers & Number of casualties \\
\hline Race/ethnicity & $\begin{array}{l}\text { Relationship and/or domestic } \\
\text { issues }\end{array}$ & Total number of victims \\
\hline Educational level & Revenge and/or payback & Year \\
\hline Relationship status & Personal grievances & Location (region) \\
\hline Job status & Criminal gain & Number of perpetrators \\
\hline Religious affiliation & $\begin{array}{l}\text { Political and/or religious } \\
\text { motivations }\end{array}$ & Modus operandi \\
\hline Children and/or dependents & Unclear and/or unknown & Weapon subtype \\
\hline Work/school issues & & Specific target(s) \\
\hline Childhood issues & & Relationship to victim \\
\hline Substance use & & Location type \\
\hline Weapon ownership & & Attack type \\
\hline $\begin{array}{l}\text { Fascination with } \\
\text { weapons and/or war }\end{array}$ & & Level of planning \\
\hline Familiarity with firearms & & Duration of incident \\
\hline Military experience & & Time of incident \\
\hline
\end{tabular}


Table 19 (continued)

Ideological connections

Anti-social personality traits

Low-self esteem

Social isolation

Mental health status

Suicide indications

Previous violent acts

Previous abuse

Criminal history
Outcome of incident

Claims of responsibility

Threatening statements

The differences between both groups mainly lie in the motivations behind the attack. When comparing motivational characteristics of these groups, significant differences were found for five out of seven categories. These differences largely centred on either holding personal grievances toward certain individuals, experiencing issues within their relationship or domestic environment, suffering from something which triggers their emotions in a negative way prior to the event, and political and religious motives. Although both groups experience grievances and anger against others, rampage shooters tend to engage in profound levels of self-loathing (i.e. shame regarding their weaknesses and inadequacies) and tend to exhibit uncontrolled anger and violent tendencies. Rampage shooters are often driven by powerful perceptions of personal victimization, feelings of hopelessness, and the desire for revenge. Comparably, lone actors are propelled by perceived social injustices and political or religious causes, and these findings reflect fundamental differences in the motives and intent between the two groups.

The different motivations and precipitating characteristics of both groups tends to lead to both similarities and differences in terms of event characteristics. Rampage shooters and lone actors tend to be similar in terms of offending patterns and logistics behind the event. The number of fatalities and casualties that result from both types of events are often similar as both of these events are motivated by a desire to inflict significant levels of harm. However, both groups differ from one another at a behavioural level. The differing motivational characteristics between the groups ensures that the perpetrators target different groups of individuals (i.e. strangers versus non-strangers), arm themselves with different weapons, place differing levels 
of planning and preparation into events (lone actors tend to be more organised), and often strike their attacks at different geographical locations and location types. Although the prevalence of mental health issues between both groups does not differ significantly, rampage shooters are more likely to suffer from these issues, and this may in part reflect the different outcomes of the events (for example, rampage shooters are more likely to commit suicide following the event when compared to lone actors). These differences may be partly due to the different scripts ${ }^{42}$ used for the different types of events which can represent and define situations, and influence criminal behaviour (Durant, 2018). Rampage shooters predominantly use firearms, whereas lone actors also use explosives and vehicles. Rampage shooters in the U.S. may have easier access to firearms than lone actors (especially if a lone actor is on a watch-list), and therefore lone actors may resort to using vehicles due to the accessibility of this method of attack. In summary, lone actors and rampage shooters appear to be similar individuals in terms of psychological and social characteristics, who tend to experience different precipitating characteristics and events, and are driven by different motivations. Aside from the differing motivational patterns of perpetrators, these individuals appear to be 'cut from the same cloth' in that they closely resemble each other on certain characteristics. 43

\section{The Role of Location in Lone Actor and Rampage Shooting Events}

One of the main research questions which guides the current research is the role geographical location plays in lone-actor terrorism and rampage shooting events, and whether there are significant differences in the traits and behaviours between perpetrators who commit their attacks in North America versus Europe. In terms of comparable groupings, the population of Europe is greater than that of North America, however Europe as a whole has a much lower homicide rate than North America (United Nations, 2017; United Nations Office on Drugs and Crime, 2018). This is reflected in the findings of the current study, as approximately 60 percent of all lone

42 Scripts are viewed as knowledge constructs that describe certain sequences of action that are associated with particular events (Goldstein, 2005).

43 It is also worth noting the heterogeneous nature of both groups to some extent, and the diversity of individuals in these groups. 
actor and rampage shooting incidents occur within North America, compared to approximately 40 percent of all incidents which occur across Europe.

The current findings reveal that the majority of rampage shootings occur within North America, and are significantly more likely to occur within North America than lone actor events. Comparably, the majority of lone actor events occur across Europe, and are significantly more likely to occur in this location than rampage shootings. From these findings we can conclude that lone actor events are more common within Europe, and rampage shooting events are more common across North America. These findings pose the question: is there something different about American culture that makes individuals more likely to commit rampage shootings? A possibility for this finding is the nature of American strains, which may help explain why the U.S. produces a higher amount of rampage shooters. Although individuals in all countries suffer from strain, rampage shooters may emerge from the particular type of strain that results from the gap between individuals' aspirations and the reality of their struggles (Pratt \& Godsey, 2003). Two key sources of strain experienced by rampage shooters in the U.S. that can lead to violence are blocked goal achievement (i.e. being suspended or expelled from school, or fired from work), and negative social interactions (i.e. experiencing work and/or school issues such as being bullied). Researchers state that when these individuals attack, they also choose targets that symbolize the source of their strain and failures, such as the workplaces, schools, or institutions they associate with their perceived mistreatment (Duwe, 2007; Langman, 2009; Lankford \& Hakim, 2011; Levin \& Madfis, 2009; Newman \& Fox, 2009). This notion derives from Merton's original conception of strain theory, which contends that crime occurs when individuals who strive to meet culturally-defined goals lack the legitimate means to do so. In the U.S., this gap may be large due to aspirations seeming endless for individuals.

Current findings reveal that there is a significant association between modus operandi for events which occur within North America versus Europe. These findings indicate that the type of weapons used (i.e. firearms versus other weapon types) in events within North America are significantly different from the types of weapons used in events across Europe. Events which occur within North America are significantly more likely to be carried out using a firearm, compared to events which occur across Europe. In comparison to this, events which occur across Europe are significantly 
more likely to be carried out using other weapon types (for example, explosives/bombs), and are more likely to involve the use of a combination of weapon types. These findings are unsurprising considering that the majority of events which occur in North America are rampage shootings, and the most prevalent weapon type used in these events are firearms, which are easier to access within the U.S. Alongside this, the majority of events which occur across Europe are acts of lone-actor terrorism, and these are usually carried out with both firearms and explosives/bombs. The types of weapons used in lone actor events within North America are significantly different from the types of weapons used in lone actor events across Europe. Lone actor events within North America are significantly more likely to involve firearms as the weapon of choice in comparison to events across Europe, which are significantly more likely to use other weapons. Interestingly, the types of weapons used in rampage shooting events within North America do not significantly differ from the types of weapons used in rampage shooting events across Europe, as findings reveal that rampage shootings in both locations predominantly involve firearms as the weapon of choice. This could be due to the fact that all rampage shootings in the current study used firearms as their primary weapon of attack.

Findings reveal that the mental health status' of perpetrators within North America significantly differ from the mental health status' of perpetrators across Europe. Perpetrators who commit their attacks within North America are significantly more likely to display indications of suffering from mental health issues and/or disorders compared to perpetrators who commit their attacks across Europe. The majority of lone actors within North America display indications of suffering from mental health issues and are significantly more likely to display indications of suffering from mental health issues, compared to lone actors across Europe. Comparably, the majority of lone actors across Europe do not display indications of suffering from mental health issues, compared to a small amount of lone actors within North America who display no indications of suffering from mental health issues. An explanation for this finding may be that lone actors within North America are far-right extremists, whereas lone-actor terrorists in Europe share similarities with terrorists in general, and these individuals may be less likely to experience mental health issues. Alongside this, differences could partially be due to cultural differences surrounding 
the willingness to diagnose mental health issues and/or disorders, as these may be more commonly diagnosed in North America.

Significant differences also emerged regarding the motivational patterns between perpetrators who commit their attacks within North America versus Europe. Perpetrators within North America are significantly more likely to be motivated by emotional triggers and personal grievances than perpetrators across Europe, however perpetrators across Europe are significantly more likely to be motivated by political and/or religious motivations in comparison to perpetrators within North America. An explanation for this finding could be that there are more rampage shooters in North America, and rampage shootings are rarely motivated by ideological causes. Findings indicate that lone actors across Europe are significantly less likely to be motivated by personal grievances compared to lone actors within North America, however lone actors within North America versus Europe do not significantly differ from one another of the remaining six categories. Rampage shooters within North America versus Europe do not significantly differ from one another on any of the seven motivation categories.

The above findings indicate that geographical location can play a significant role in lone-actor terrorism and rampage shooting events. The aspirations and broken dreams of individuals within America, such as workers and students, combined with any mental health issues, perceived victimization, and access to firearms, makes these individuals more likely to commit attacks compared to individuals in other countries or continents, such as Europe. From the current findings, we can conclude that important differences exist between North American and European lone-actor terrorism events and perpetrators across several characteristics, such as modus operandi and mental health status. However, important differences are not observed between North American and European rampage shooting events and perpetrators across these characteristics. These findings are indicative of the possibility that rampage shooting events and perpetrators within North America and Europe may obtain similar traits and behaviours, however lone-actor terrorism events and perpetrators within North America versus Europe tend to display different traits and behaviours. 


\section{Limitations of the Current Research}

A key limitation of the current research is the limited nature of the existing empirical literature on lone-actor terrorism. The limited research on this phenomenon to date meant that there was less information available on lone-actor terrorism incidents and perpetrators (especially within Europe), and made it difficult to compare findings of the current study to those of previous studies. Another key limitation was the challenges which arose when dealing with open-source information. Accessing individual-level data on incidents and perpetrators through various reliable databases proved difficult due to having limited access to primary-level and official data, and due to the shortage of available databases which supply detailed information on individual incidents. Accessing data on lone-actor terrorism and rampage shooting incidents within Europe was also difficult; the majority of databases focus on incidents which occur within the U.S., and there are currently a minimal number of databases which provide information on European incidents, and the number of internationallycomparable databases is also limited. As a result of this, information on European lone actors and rampage shooters was only able to be gathered using supplementary materials.

The lack of media attention and reporting of lone actor incidents and perpetrators across Europe also added to the difficulties of accessing information and resulted in several variables with missing information, as incidents across North America tended to receive the most media attention and subsequently had more indepth profiles of the perpetrators. Lastly, a minor limitation for the current research was the difficulty regarding the classification of incidents. Although the current study employed strict criteria regarding whether incidents would be classified as a lone-actor terrorism event or a rampage shooting, a number of events could be classified as both and were difficult to place into one category due to there not being a standard method of classification. Several cases in the current study demonstrated the crucial role subjectivity plays in labelling an event as an act of lone-actor terrorism or a rampage shooting (for example, the case of Jared Loughner), and discrepancies also arose in previous research on whether to categorize certain events as terrorism or mass murder. This limitation highlights a major inconsistency in which some perpetrators are labelled lone-actor terrorists, whereas others with similar motivations are labelled as rampage shooters. 


\section{Conclusion}

Although the current study offers crucial insights into the research at hand, it also highlights unanswered questions and issues. This study provides a starting point for future research; although preventing these acts of violence through effective treatment of mental health issues is not the main solution to preventing these events, the current study highlights the role of mental illness in lone-actor terrorism and rampage shooting events as an area of concern that warrants further attention. In cases where the perpetrator suffers from significant mental health issues, the question remains as to what causes one individual to commit these types of violent crimes, while another individual suffering from similar mental health issues does not resort to extreme levels of violence. Additionally, it is unknown why some perpetrators with extreme mental health issues commit political and/or religiously motivated acts aimed toward strangers, whereas other perpetrators suffering from these issues resort to victimizing individuals known to them.

The exploration of the motivational patterns of both types of perpetrators would also be a valuable area of inquiry in future studies in terms of prevention implications, especially considering the factors and motivations which drive individuals to commit acts of extreme violence are one of the most profound differences between lone-actor terrorists and rampage shooters. The heterogeneity of perpetrators calls for future comparisons of lone-actor terrorism sub-groups compared to rampage shooting sub-groups; the focus of the current study being on lone actor and rampage shooting perpetrators in general, has meant that the investigation of different perpetrators who may fall under various sub-groups has been excluded from this research.

The findings of the current research may help clarify where scholars, professionals, and government officials should place their efforts for future research. Although these are high-impact and tragic events, it seems more realistic to attempt to reduce the prevalence of these types of events, instead of attempting to stop them altogether. In particular, important progress could be made in attempting to reduce mass shootings in the U.S., (in particular school and workplace shootings) where they 
tend to occur more often compared to other countries. Future research that focuses on potential explanations of this seemingly disproportionate American problem (i.e. the influence of 'lofty' aspirations, desire for fame and glory, 'broken' dreams, and easy access to firearms) could be valuable. Although it is difficult to make immediate changes to cultural factors, it may be worthwhile for teachers, parents, leaders, and politicians to attempt to reduce the pressure some individuals in the U.S. feel to reach high levels of societal success in order to maintain a satisfying life, and perhaps emphasise the importance of intrinsic goals (i.e. personal growth and wellbeing).

The impact of certain policies on lone-actor terrorism and rampage shooting events should also be considered for future research in this area. The findings of the current study conveyed that although there can be a long build up to the event in the majority of cases, often it is a specific precipitating or traumatic event which acts as the catalyst for perpetrating an extreme act of violence. As a result of these findings, research could examine whether restrictions on gun ownership act as a deterrent effect for perpetrators, and whether these restrictions can prevent mass murder events in states or countries that do not have these types of restrictions. Furthermore, the impact these policies have on these events could be examined through comparisons of before and after policies are implemented, in order to determine whether they deter these types of events. While preventing these types of events is as complex as the issues of mass murder and terrorism themselves, this does not mean that efforts to prevent these types of acts should be overlooked because of their difficulty. While no single prevention effort is the full answer to diminishing acts of lone-actor terrorism and rampage shootings, the benefits of certain prevention efforts must be noted in assisting to reduce the prevalence of these rare but deadly acts of violence.

The current study contributes to the literature by providing the first quantitative inquiry into the similarities and differences between lone-actor terrorism and rampage shooting events and perpetrators within North America and Europe over the last nine years. The rich and updated quantitative dataset, in conjunction with the existing gaps the findings fill and the insights these offer, provides a solid foundation for the investigation of the two distinct literatures of lone-actor terrorism and rampage shootings. The current research sheds light on numerous incident and offender-level characteristics that contribute to these events, such as mental health issues and negative stressors and precipitators within the offender's life, and ultimately the forces 
which drive individuals to extreme acts of violence. Alongside this, the current research provides a unique contribution to the literature by comparing lone-actor terrorism and rampage shooting events and perpetrators within North America versus Europe. Although there is little known regarding the extent to which these two behaviourally-similar phenomena are similar or different, this research indicates that lone-actor terrorism and rampage shooting perpetrators appear to be similar on an underlying psychological level. The main difference between these groups lies in their motivation and intent, which can significantly influence the way perpetrators organize, execute, and conclude their attacks. Rampage shooters appear to be driven by perceptions of personal victimization and the desire for revenge, whereas lone-actor terrorists are often driven by perceived social injustices, and political and/or religious motivations. Interestingly, the current findings reveal that rampage shooting events and perpetrators within North America obtain similar characteristics and behaviours to those across Europe, however lone-actor terrorism events and perpetrators within North America tend to display different characteristics and behaviours to those across Europe. Rampage shootings and lone-actor terrorism attacks may be two different types of events, however these groups of individuals are 'cut from the same cloth' in that they possess many of the same fundamental traits, characteristics, and behaviours. Conducting detailed comparisons on both types of groups and disaggregating these different types of events by a wide range of offender and incident characteristics has furthered the understanding of these relatively rare but extremely high-impact events, and assists in facilitating the investigation and prevention of these types of violent acts. 


\section{References}

Agnew, R. (2010). A general strain theory of terrorism. Theoretical Criminology, 14(2), 131-153. doi:10.1177/1362480609350163

Agnew, R., \& Brezina, T. (2010). Strain theories. In E. McLaughlin \& T. Newburn (eds.), The Sage Handbook of Criminological Theory (pp. 96-113). London: Sage Publications.

Allely, C. S., Minnis, H., Thompson, L., Wilson, P., \& Gillberg, C. (2014). Neurodevelopmental and psychosocial risk factors in serial killers and mass murderers. Aggression and Violent Behavior, 19(3), 288-301. doi:10.1016/j.avb.2014.04.004

Alonso, J., Angermeyer, M. C., Bernert, S., Bruffaerts, R., Brugha, T. S., Bryson, H., . . . Vollebergh, W. A. (2004). Prevalence of mental disorders in Europe: Results from the European Study of the Epidemiology of Mental Disorders (ESEMeD) project. Acta Psychiatrica Scandinavica, 109(420), 21-27. doi:10.1111/j.16000047.2004.00327.x

Andriolo, K. R. (1998). Gender and the Cultural Construction of Good and Bad Suicides. Suicide and Life-Threatening Behavior, 28(1), 37-49. doi:10.1111/j.1943-278X.1998.tboo624.x

Anisin, A. (2018). A configurational analysis of 44 US mass shootings: 1975-2015. International Journal of Comparative and Applied Criminal Justice, 42(1), 5573. doi:10.1080/01924036.2016.1233444

Archer, J. (2004). Sex Differences in Aggression in Real-World Settings: A MetaAnalytic Review. Review of General Psychology, 8(4), 291-322. doi:10.1037/1089-2680.8.4.291

Atran, S., Sheikh, H., \& Gomez, A. (2014). Devoted actors sacrifice for close comrades and sacred cause. Proceedings of the National Academy of Sciences of the United States of America, 111(50), 17702-17703. doi:10.1073/pnas.1420474111

Bakker, E., \& de Graaf, B. (2010). Lone Wolves: How to Prevent This Phenomenon? The Netherlands: International Centre for Counter-Terrorism - The Hague.

Bakker, E., \& de Roy van Zuijdewijn, J. (2015). Lone-Actor Terrorism: Definitional Workshop. London, United Kingdom: Royal United Services Institute for 
Defence and Security Studies.

Baumeister, R. F., Bushman, B. J., \& Campbell, W. K. (2000). Self-esteem, narcissism, and aggression: Does violence result from low self-esteem or from threatened egotism? Current Directions in Psychological Science, 9(1), 26-29. doi:10.1111/1467-8721.00053

Berwick, A. (2011). 2083: A European Declaration of Independence. Retrieved from https://info.publicintelligence.net/AndersBehringBreivikManifesto.pdf

Bockler, N., Seeger, T., Sitzer, P., Heitmeyer, W. (2013). School Shootings: International Research, Case Studies, and Concepts for Prevention. New York: Springer Science \& Business Media.

Borum, R., Fein, R., \& Vossekuil, B. (2012). A dimensional approach to analysing lone offender terrorism. Aggression and Violent Behavior, $17(5)$, 389-396. doi:10.1016/j.avb.2012.04.003

Bowers, T. G., Holmes, E. S., \& Rhom, A. (2010). The Nature of Mass Murder and Autogenic Massacre. Journal of Police and Criminal Psychology, 25(2), 59-66. doi:10.1007/s11896-009-9059-6

Brady H. E., Schlozman, K. L., \& Verba, S. (1999). Prospecting for Participants: Rational Expectations and the Recruitment of Political Activists. The American Political Science Review, 93(1), 153-168. doi:10.2307/2585767

Brown, G. R., Dickins, T. E., Sear, R., \& Laland, K. N. (2011). Evolutionary accounts of behavioural diversity. Philosophical Transactions of the Royal Society B, 366(1563), 313-314. doi:10.1098/rstb.2010.0267

Bushman, B. J., \& Anderson, C. A. (2001). Is it time to pull the plug on the hostile versus instrumental dichotomy? Psychological Review, 108(1), 273-279. doi:10.1037/0033-295X.108.1.273

Capellan, J. A. (2015). Lone Wolf Terrorist or Deranged Shooter? A Study of Ideological Active Shooter Events in the United States, 1970-2014. Studies in Conflict \& Terrorism, 38(6), 395-413. doi:10.1080/1057610X.2015.1008341

Capellan, J. A., \& Gomez, S. (2018). Change and stability in offender, behaviours, and incident-level characteristics of mass public shootings in the United States, 1984-2015. Journal of Investigative Psychology and Offender Profiling, 15, 5172. doi:10.1002/jip.1491 
Chermak, S., \& Gruenewald, J. A. (2015). Laying a Foundation for the Criminological Examination of Right-Wing, Left-Wing, and Al Qaeda-Inspired Extremism in the United States. Terrorism and Political Violence, 27(1), 133-159. doi:10.1080/09546553.2014.975646

Cohen, J. (1960). A Coefficient of Agreement for Nominal Scales. Educational and Psychological Measurement, 2O(1), 37-46. doi:10.1177/001316446002000104

Corner, E., \& Gill, P. (2015). A False Dichotomy? Mental Illness and Lone-Actor Terrorism. Law and Human Behavior, 39(1), 23-34. doi:10.1037/lhboooo102

Corner, E., Gill, P., \& Mason, O. (2016). Mental Health Disorders and the Terrorist: A Research Note Probing Selection Effects and Disorder Prevalence. Studies in Conflict \& Terrorism, 39(6), 560-568. doi:10.1080/1057610X.2015.1120099

Dearen, J., Breed, A., \& Lush, T. (2018, February 17). Florida school shooting suspect was investigated by state after self-harming. Chicago Tribune. Retrieved from https://www.chicagotribune.com/news/nationworld/ct-florida-schoolshooter-nikolas-cruz-20180217-story.html

Declercq, F., \& Audenaert, K. (2011). A case of mass murder: Personality disorder, psychopathology and violence mode. Aggression and Violent Behavior, 16(2), 135-143. doi:10.1016/j.avb.2011.02.001

de Roy van Zuijdewijn, J., \& Bakker, E. (2016). Lone-Actor terrorism: Policy paper 1: Personal characteristics of Lone-Actor terrorists (Countering Lone-Actor Terrorism, Series No. 5). The Netherlands: International Centre for CounterTerrorism - The Hague.

Durrant, R. (2018). An Introduction to Criminal Psychology (2nd ed.). New York: Routledge.

Durrant, R., \& Ward, T. (2015). Evolutionary Criminology: Toward a Comprehensive Explanation for Crime. London: Academic Press.

Dutton, D. G., White, K. R., \& Fogarty, D. (2013). Paranoid thinking in mass shooters. Aggression and Violent Behavior, 18(5), 548-553. doi:10.1016/j.avb.2013.07.012

Duwe, G. (2000). Body-count journalism: The presentation of mass murder in the news media. Homicide Studies, 4(4), 364-399. doi:10.1177/1088767900004004004 
Duwe, G. (2007). Mass murder in the United States: A history. Jefferson, NC: McFarland \& Company.

Duwe, G. (2014, October 28). The truth about mass public shootings. Reason. Retrieved from http://reason.com/archives/2014/10/28/the-truth-aboutmass- public-shootings

Duwe, G. (2017). The Patterns and Prevalence of Mass Public Shootings in the United States, 1915-2013. In L. C. Wilson (Ed.), The Wiley Handbook of the Psychology of Mass Shootings (pp. 20-35). West Sussex, UK: John Wiley \& Sons, Inc.

Duwe, G., Kovandzic, T., \& Moody, C. (2002). The Impact of Right-to-Carry Concealed Firearm Laws on Mass Public Shootings. Homicide Studies, 6(4), 271-296. doi:10.1177/108876702237341

Ellis, C., Pantucci, R., de Roy van Zuijdewijn, J., Bakker, E., Gomis, B., Palombi, S., \& Smith, M. (2016). Lone-Actor Terrorism: Final Report (Countering LoneActor Terrorism Series No. 11). London, United Kingdom: Royal United Services Institute for Defence and Security Studies.

Faria, M. A. (2013). Shooting rampages, mental health, and the sensationalization of violence. Surgical Neurology International, 4(16). doi:10.4103/21527806.106578

Fein, R. A., \& Vossekuil, B. (1999). Assassination in the United States: An Operational Study of Recent Assassins, Attackers, and Near-Lethal Approachers. Journal of Forensic Sciences, 44(2), 321-333. doi:10.1520/JFS14457J

Follman, M., Aronsen, G., \& Pan, D. (2019). US Mass Shootings, 1982-2019: Data From Mother Jones' Investigation. Retrieved from https://www.motherjones.com/politics/2012/12/mass-shootings-motherjones-full-data/

Fox, J. A., \& DeLateur, M. J. (2014). Mass Shootings in America: Moving Beyond Newtown. Homicide Studies, 18(1), 125-145. doi:10.1177/1088767913510297

Fox, J. A., \& Levin, J. (2015). Extreme Killing: Understanding Serial and Mass Murder (3rd ed.). Thousand Oaks, California: SAGE Publications, Inc.

Fox, J. M., Brook, M., Stratton, J., \& Hanlon, R. E. (2016). Neuropsychological profiles and descriptive classifications of mass murderers. Aggression and Violent Behavior, 30, 94-104. doi:10.1016/j.avb.2016.06.014 
Gibbs, J. P. (1989). Control: Sociology's Central Notion. Urbana, Illinois: University of Illinois Press.

Gill, P., \& Corner, E. (2016). Lone-Actor Terrorist Target Choice. Behavioral Sciences \& the Law, 34(5), 693-705. doi:10.1002/bsl.2268

Gill, P., Horgan, J., \& Deckert, P. (2014). Bombing Alone: Tracing the Motivations and Antecedent Behaviors of Lone-Actor Terrorists. Journal of Forensic Sciences, 59(2), 425-435. doi:10.1111/1556-4029.12312

Goldstein, E. B. (2005). Cognitive Psychology: Connecting Mind, Research, and Everyday Experience. Belmont, CA: Thomson/Wadsworth.

Gomez, A., Lopez-Rodriguez, L., Sheikh, H., Ginges, J., Wilson, L., Waziri, H., .. . Atran, S. The devoted actor's will to fight and the spiritual dimension of human conflict. Nature Human Behaviour, 1(9), 673-679. doi:10.1038/s41562-0170193-3

Gruenewald, J. (2011). A Comparative Examination of Homicides Perpetrated by FarRight Extremists. Homicide Studies, 15(2), 177-203. doi:10.1177/1088767911408029

Gruenewald, J., Chermak, S., \& Freilich, J. D. (2013a). Far-Right Lone Wolf Homicides in the United States. Studies in Conflict \& Terrorism, 36(12), 1005- 1024. doi:10.1080/1057610X.2013.842123

Gruenewald, J., Chermak, S., \& Freilich, J. D. (2013b). Distinguishing “Loner” Attacks from Other Domestic Extremist Violence: A Comparison of Far-Right Homicide Incident and Offender Characteristics. Criminology \& Public Policy, 12(1), 6591. doi:10.1111/1745-9133.12008

Gruenewald, J., \& Pridemore, W. A. (2012). A Comparison of Ideologically-Motivated Homicides from the New Extremist Crime Database and Homicides from the Supplementary Homicide Reports Using Multiple Imputation by Chained Equations to Handle Missing Values. Journal of Quantitative Criminology, 28(1), 141-162. doi:10.1007/s10940-011-9155-5

Hamm, M., \& Spaaij, R. (2015). Lone Wolf Terrorism in America: Using Knowledge of Radicalization Pathways to Forge Prevention Strategies. Indiana, U.S.: Indiana State University.

Hamm, M., \& Spaaij, R. (2017). The Age of Lone Wolf Terrorism. New York: Columbia 
University Press.

Harper-Mercer, C. (n.d.). [Chris Harper-Mercer's Manifesto]. Retrieved from https://schoolshooters.info/sites/default/files/Christopher-Sean-HarperMercer-My-Manifesto.pdf

Hilal, S. M., Densley, J. A., Li, S. D., \& Ma, Y. (2014). The Routine of Mass Murder in China. Homicide Studies, 18(1), 83-104. doi:10.1177/1088767913505092

Horgan, J. G., Gill, P., Bouhana, N., Silver, J., \& Corner, E. (2016). Across the Universe? A Comparative Analysis of Violent Behaviour and Radicalization Across Three Offender Types with Implications for Criminal Justice Training and Education. Retrieved from https://www.ncjrs.gov/pdffiles1/nij/grants/249937.pdf

James, M., \& Cardona, A. C. (2018, August 8). 'Burn, kill, destroy': Parkland school shooter video released. USA Today. Retrieved from https://www.usatoday.com/story/news/2018/o8/o8/burn-kill-destroyparkland-school-shooter-video-released/939527002/

Joosse, P. (2007). Leaderless Resistance and Ideological Inclusion: The Case of the Earth Liberation Front. Terrorism and Political Violence, 19(3), 351-368. doi:10.1080/09546550701424042

Juergensmeyer, M. (2003). Terror in the Mind of God: The Global Rise of Religious Violence. Oakland, California: University of California Press.

Kalish, R., \& Kimmel, M. (2010). Suicide by mass murder: Masculinity, aggrieved entitlement, and rampage school shootings. Health Sociology Review, 19(4), 451-464. doi:10.5172/hesr.2010.19.4.451

Kimmel, M. S., \& Mahler, M. (2003). Adolescent Masculinity, Homophobia, and Violence: Random School Shootings, 1982-2001. American Behavioral Scientist, 46(10), 1439-1458. doi:10.1177/0002764203046010010

Klarevas, L. (2016). Rampage Nation: Securing America From Mass Shootings. New York: Prometheus Books.

Kleck, G. (2009). Mass Shootings in Schools: The Worst Possible Case for Gun Control. American Behavioral Scientist, 52(10), 1447-1464. doi:10.1177/0002764209332557 
Knoll, J. L. (2010). The "Pseudocommando" Mass Murderer: Part 1, The Psychology of Revenge and Obliteration. Journal of the American Academy of Psychiatry and the Law, 38(1), 87-94.

LaFree, G., Jensen, M. A., James, P. A., \& Safer-Lichtenstein, A. (2018). Correlates of Violent Political Extremism in the United States. Criminology, 56(2), 233-268. doi:10.1111/1745-9125.12169

Langman, P. (2009). Rampage school shooters: A typology. Aggression and Violent Behavior, 14(1), 79-86. doi:10.1016/j.avb.2008.10.003

Lankford, A. (2015). Mass Shooters in the USA, 1966-2010: Differences Between Attackers Who Live and Die. Justice Quarterly, 32(2), 360-379. doi:10.1080/07418825.2013.806675

Lankford, A. (2016a). Fame-seeking rampage shooters: Initial findings and empirical predictions. Aggression and Violent Behavior, 27, 122-129. doi:10.1016/j.avb.2016.02.002

Lankford, A. (2016b). Are America's public mass shooters unique? A comparative analysis of offenders in the United States and other countries. International Journal of Comparative and Applied Criminal Justice, 4O(2), 171-183. doi:10.1080/01924036.2015.1105144

Lankford, A., \& Hakim, N. (2011). From Columbine to Palestine: A Comparative Analysis of Rampage Shooters in the United States and Volunteer Suicide Bombers in the Middle East. Aggression and Violent Behavior, 16(2), 98-107. doi:10.1016/j.avb.2010.12.006

Larkin, R. W. (2009). The Columbine Legacy: Rampage Shootings as Political Acts. American Behavioral Scientist, $\quad$ 52(9), $\quad$ 1309-1326. doi:10.1177/0002764209332548

Leary, M. R., Kowalski, R. M., Smith, L., \& Phillips, S. (2003). Teasing, Rejection, and Violence: Case Studies of the School Shootings. Aggressive Behavior, 29(3), 202-214. doi:10.1002/ab.10061

Leenars, J., \& Reed, A. (2016). Understanding Lone Wolves: Towards a Theoretical Framework for Comparative Analysis. The Netherlands: International Centre for Counter-Terrorism - The Hague.

Levin, J., \& Madfis, E. (2009). Mass Murder at School and Cumulative Strain. 
American Behavioral Scientist, $\quad$ 52(9), $\quad$ 1227-1245. doi:10.1177/0002764209332543

Liddle, J. R., Bush, L. S., Shackelford, T. K. (2011). An introduction to evolutionary psychology and its application to suicide terrorism. Behavioral Sciences of Terrorism and Political Aggression, 3(3), 176-197. doi:10.108o/19434472.2010.512157

Liddle, J. R., \& Shackelford, T. K. (2009). Why evolutionary psychology is "true." [Review of the book Why Evolution is True, by J. Coyne]. Evolutionary Psychology, 7(2), 288-294. doi:10.1177/147470490900700211

Liem, M. (2010). Homicide followed by suicide: A review. Aggression and Violent Behavior, 15(3), 153-161. doi:10.1016/j.avb.2009.10.001

Liem, M., van Buuren, J., \& Schonberger, H. (2018). Cut from the same cloth? Lone Actor Terrorists versus Common Homicide Offenders. The Netherlands: International Centre for Counter-Terrorism - The Hague.

Liem, M., van Buuren, J., van Zuijdewijn, J., Schonberger, H., \& Bakker, E. (2018). European Lone Actor Versus "Common” Homicide Offenders: An Empirical Analysis. Homicide Studies, 22(1), 45-49. doi:10.1177/1088767917736797

Lindekilde, L., O’Connor, F., \& Schuurman, B. (2017). Radicalization patterns and modes of attack planning and preparation among lone-actor terrorists: an exploratory analysis. Behavioral Sciences of Terrorism and Political Aggression, 1-21. doi:10.1080/19434472.2017.1407814

Madfis, E., \& Arford, T. (2008, February). Investigating precipitating factors in mass murder: Do "last straws" get to the bottom of rampage killing or merely scratch the surface? Paper presented at the conference of the Eastern Sociological Society (ESS), New York.

McCauley, C., \& Moskalenko, S. (2011). Friction: How radicalization happens to them and us. New York: Oxford University Press.

McCauley, C., Moskalenko, S., \& Van Son, B. (2013). Characteristics of Lone-Wolf Violent Offenders: a Comparison of Assassins and School Attackers. Perspectives on Terrorism, 7(1), 4-24.

McCullough, M. (2008). Beyond Revenge: The Evolution of the Forgiveness Instinct. San Francisco: Jossey Bass. 
Melle, I. (2013). The Breivik case and what psychiatrists can learn from it. World Psychiatry, 12(1), 16-21. doi:10.1002/wps.20002

Meloy, J. R. (2006). Empirical Basis and Forensic Application of Affective and Predatory Violence. Australian and New Zealand Journal of Psychiatry, 4O(67), 539-547. doi:10.1080/j.1440-1614.2006.01837.x

Meloy, J. R., \& Gill, P. (2016). The Lone-Actor Terrorist and the TRAP-18. Journal of Threat Assessment and Management, 3(1), 37-52. doi:10.1037/tamooooo61

Meloy, J. R., Hempel, A. G., Gray, B. T., Mohandie, K., Shiva, A. A., \& Richards, T. C. (2004). A Comparative Analysis of North American Adolescent and Adult Mass Murderers. Behavioral Sciences \& the Law, 22(3), 291-309. doi:10.1002/bsl.586

Meloy, J. R., Hempel, A. G., Mohandie, K., Shiva, A. A., \& Gray, B. T. (2001). Offender and Offense Characteristics of a Nonrandom Sample of Adolescent Mass Murderers. Journal of the American Academy of Child and Adolescent Psychiatry, 40(6), 719-728. doi:10.1097/00004583-200106000-00018

Metzl, J. M., \& MacLeish, K. T. (2015). Mental Illness, Mass Shootings, and the Politics of American Firearms. American Journal of Public Health, 105(2), 240-249. doi:10.2105/AJPH.2014.302242

Nestor, P. G. (2002). Mental Disorder and Violence: Personality Dimensions and Clinical Features. American Journal of Psychiatry, 159(12), 1973-1978. doi:10.1176/appi.ajp.159.12.1973

Newman, K. S. (2004). Rampage: The social roots of school shootings. New York: Basic Books.

Newman, K. S., \& Fox, C. (2009). Repeat Tragedy: Rampage Shootings in American High School and College Settings, 2002-2008. American Behavioral Scientist, 52(9), 1286-1308. doi:10.1177/0002764209332546

Osbourne, J. R., \& Capellan, J. A. (2016). Examining active shooter events through the rational choice perspective and crime script analysis. Security Journal, 3o(3), 880-902. doi:10.1057/sj.2015.12

Pantucci, R., Ellis, C., \& Chaplais, L. (2015). Lone-Actor Terrorism: Literature Review (Countering Lone-Actor Terrorism, Series No.1). London, UK: Royal United Services Institute for Defence and Security Studies. 
Parkin, W. S., \& Freilich, J. D. (2015). Routine Activities and Right-Wing Extremists: An Empirical Comparison of the Victims of Ideologically- and NonIdeologically-Motivated Homicides Committed by American Far-Rightists. Terrorism and Political Violence, 27(1), 182-203. doi:10.1080/09546553.2014.975649

Peddell, D., Eyre, M., McManus, M., \& Bonworth, J. (2016). Influences and vulnerabilities in radicalised lone-actor terrorists: UK practitioner perspectives. International Journal of Police Science \& Management, 18(2), 63-76. doi:10.1177/1461355716638686

Pratt, T. C., \& Godsey, T. W. (2003). Social support, inequality, and homicide: A crossnational test of an integrated theoretical model. Criminology, 41(3), 611-644. doi:10.1111/j.1745-9125.2003.tboo999.x

Quillen, C. (2002). A Historical Analysis of Mass Casualty Bombers. Studies in Conflict \& Terrorism, 25(2), 279-292. doi:10.1080/10576100290101197

Richards, B. (2014). What drove anders breivik? Contexts, 13(4), 42-47. doi:10.1177/1536504214558216

Roberts, A. L., McLaughlin, K. A., Conron, K. J., \& Koenen, K. C. (2011). Adulthood Stressors, History of Childhood Adversity, and Risk of Perpetration of Intimate Partner Violence. American Journal of Preventive Medicine, 4O(2), 128-138. doi:10.1016/j.amepre.2010.10.016

Rocque, M., \& Duwe, G. (2018). Rampage shootings: an historical, empirical, and theoretical overview. Current Opinion in Psychology, 19, 28-33. doi:10.1016/j.copsyc.2017.03.025

Safer-Lichtenstein, A., LaFree, G., \& Loughran, T. (2017). Studying Terrorism Empirically: What We Know About What We Don't Know. Journal of Contemporary Criminal Justice, 33(3), 273-291. doi:10/1177/1043986217697873

Salfati, C. G. (2000). The Nature of Expressiveness and Instrumentality in Homicide: Implications for Offender Profiling. Homicide Studies, 4(3), 265-293. doi:10.1177/1088767900004003004

Scheff, T. J. (2011). Social-Emotional Origins of Violence: A Theory of Multiple Killing. Aggression and Violent Behavior, 16(6), 453-460. 
doi:10.1016/j.avb.2011.03.007

Shugerman, E. (2018, March 20). Florida shooting suspect Nikolas Cruz's guardian details troubling 'warning signs' in months before massacre. The Independent. Retrieved from https://www.independent.co.uk/news/world/americas/florida-shootingnikolas-cruz-warning-signs-rocxanne-deschamps-zachary-cruz-gloria-allreda8265841.html

Silver, J., Horgan, J., \& Gill, P. (2019). Shared Struggles? Cumulative Strain Theory and Public Mass Murderers From 1990 to 2014. Homicide Studies, 23(1), 6484. doi:10.1177/1088767918802881

Spaaij, R. (2010). The Enigma of Lone Wolf Terrorism: An Assessment. Studies in Conflict \& Terrorism, 33(9), 854-870. doi:10.1080/1057610X.2010.501426

Spaaij, R. (2011). Understanding Lone Wolf Terrorism: Global Patterns, Motivations and Prevention. New York: Springer Science \& Business Media.

Spaaij, R., \& Hamm, M. S. (2015). Key Issues and Research Agendas in Lone Wolf Terrorism. Studies in Conflict \& Terrorism, 38(3), 167-178. doi:10.1080/1057610X.2014.986979

Substance Abuse and Mental Health Services Administration Center for Behavioral Health Statistics and Quality. (2014). Results from the 2013 National Survey on Drug Use and Health: Summary of National Findings. Retrieved from https://www.samhsa.gov/data/sites/default/files/NSDUHresultsPDFWHTM L2013/Web/NSDUHresults2013.pdf

Swanson, J. W. (2011). Explaining Rare Acts of Violence: The Limits of Evidence From Population Research. Psychiatric Services, 62(11), 1369-1371. doi:10.1176/ps.62.11.pss6211_1369

Taylor, M. A. (2018). A Comprehensive Study of Mass Murder Precipitants and Motivations of Offenders. International Journal of Offender Therapy and Comparative Criminology, 62(2), 427-449. doi:10.1177/0306624X16646805

United Nations, Department of Economic and Social Affairs, Population Division. (2017). World Population Prospects: Key Findings \& Advance Tables. Retrieved from https://population.un.org/wpp/Publications/Files/WPP2017_KeyFindings.p 
$\mathrm{df}$

United Nations Office on Drugs and Crime. (2018). The World Drug Report. Retrieved from

https://www.unodc.org/wdr2018/prelaunch/WDR18_Booklet_1_EXSUM.pd $\mathrm{f}$

Vossekuil, B., Fein, R. A., Reddy, M., Borum, R., \& Modzeleski, W. (2004). The Final Report and Findings of the Safe School Initiative: Implications for Prevention of School Attacks in the United States. Retrieved from https://www2.ed.gov/admins/lead/safety/preventingattacksreport.pdf

Wheeler, L. (1966). Toward a theory of behavioral contagion. Psychological Review, 73(2), 179-192. doi:10.1037/hoo23023

Wold, L. (2012, April 16). Inside the mind of Anders Breivik. The Independent. Retrieved from https://www.independent.co.uk/news/world/europe/insidethe-mind-of-anders-breivik-7646637.html 


\section{Appendix A}

Table 1

List of Cases in the Current Study $(n=134)$

\begin{tabular}{|c|c|c|c|c|c|}
\hline $\begin{array}{l}\text { Case } \\
\text { ID }\end{array}$ & Date & Incident name & $\begin{array}{l}\text { Number of } \\
\text { fatalities }\end{array}$ & $\begin{array}{l}\text { Number of } \\
\text { casualties }\end{array}$ & Name of offender(s) \\
\hline 1 & $17 / 07 / 16$ & $\begin{array}{l}\text { Baton Rouge } \\
\text { shooting }\end{array}$ & 4 & 3 & Gavin Long \\
\hline 2 & $12 / 06 / 16$ & $\begin{array}{l}\text { Orlando nightclub } \\
\text { massacre }\end{array}$ & 50 & 53 & Omar Mateen \\
\hline 3 & $02 / 12 / 15$ & $\begin{array}{l}\text { San Bernardino } \\
\text { shooting }\end{array}$ & 16 & 22 & $\begin{array}{l}\text { Syed Rizwan Farook and } \\
\text { Tashfeen Malik }\end{array}$ \\
\hline 4 & $17 / 06 / 15$ & $\begin{array}{l}\text { Charleston church } \\
\text { shooting }\end{array}$ & 9 & o & Dylann Storm Roof \\
\hline 5 & $10 / 02 / 15$ & $\begin{array}{l}\text { Chapel Hill } \\
\text { shooting }\end{array}$ & 3 & $\mathrm{O}$ & Craig Stephen Hicks \\
\hline 6 & $04 / 06 / 14$ & $\begin{array}{l}\text { Moncton City } \\
\text { shooting }\end{array}$ & 3 & 2 & Justin Bourque \\
\hline 7 & $08 / 01 / 11$ & Tucson shooting & 6 & 13 & Jared Lee Loughner \\
\hline 8 & $05 / 08 / 12$ & $\begin{array}{l}\text { Sikh temple } \\
\text { shooting }\end{array}$ & 7 & 4 & Wade Michael Page \\
\hline 9 & $03 / 08 / 10$ & $\begin{array}{l}\text { Hartford Beer } \\
\text { Distributors } \\
\text { shooting }\end{array}$ & 9 & 2 & Omar Thornton \\
\hline 10 & $06 / 09 / 11$ & IHOP shooting & 5 & 7 & Eduardo Sencion \\
\hline 11 & $12 / 10 / 11$ & Seal Beach shooting & 8 & 1 & Scott Evans Dekraai \\
\hline 12 & $02 / 04 / 12$ & $\begin{array}{l}\text { Oikos University } \\
\text { shooting }\end{array}$ & 7 & 3 & One L. Goh \\
\hline 13 & $30 / 05 / 12$ & $\begin{array}{l}\text { Seattle café } \\
\text { shooting }\end{array}$ & 6 & 1 & Ian Lee Stawicki \\
\hline 14 & $20 / 07 / 12$ & $\begin{array}{l}\text { Aurora theatre } \\
\text { shooting }\end{array}$ & 12 & 70 & James Eagan Holmes \\
\hline 15 & 27/09/12 & $\begin{array}{l}\text { Accent Signage } \\
\text { Systems shooting }\end{array}$ & 7 & 1 & Andrew Engeldinger \\
\hline
\end{tabular}




\begin{tabular}{|c|c|c|c|c|c|}
\hline 16 & $14 / 12 / 12$ & $\begin{array}{l}\text { Sandy Hook } \\
\text { Elementary } \\
\text { massacre }\end{array}$ & 28 & 2 & Adam Lanza \\
\hline 17 & $13 / 03 / 13$ & $\begin{array}{l}\text { Mohawk Valley } \\
\text { shootings }\end{array}$ & 5 & 2 & Kurt Myers \\
\hline 18 & 07/06/13 & $\begin{array}{l}\text { Santa Monica } \\
\text { rampage }\end{array}$ & 6 & 3 & John Zawahiri \\
\hline 19 & $26 / 07 / 13$ & $\begin{array}{l}\text { Hialeah apartment } \\
\text { shooting }\end{array}$ & 7 & o & Pedro Vargas \\
\hline 20 & $16 / 09 / 13$ & $\begin{array}{l}\text { Washington Navy } \\
\text { Yard shooting }\end{array}$ & 13 & 8 & Aaron Alexis \\
\hline 21 & $20 / 02 / 14$ & $\begin{array}{l}\text { Alturas tribal } \\
\text { shooting }\end{array}$ & 5 & 2 & Cherie Lash Rhoades \\
\hline 22 & $02 / 04 / 14$ & $\begin{array}{l}\text { Fort Hood shooting } \\
\text { (2014) }\end{array}$ & 4 & 12 & Ivan Lopez \\
\hline 23 & $23 / 05 / 14$ & $\begin{array}{l}\text { Isla Vista mass } \\
\text { murder }\end{array}$ & 7 & 13 & Elliot Rodger \\
\hline 24 & $24 / 10 / 14$ & $\begin{array}{l}\text { Marysville-Pilchuck } \\
\text { High School } \\
\text { shooting }\end{array}$ & 5 & 1 & Jaylen Fryberg \\
\hline 25 & 03/05/15 & $\begin{array}{l}\text { Trestle Trail bridge } \\
\text { shooting }\end{array}$ & 4 & 1 & Sergio Valencia del Toro \\
\hline 26 & $16 / 07 / 15$ & $\begin{array}{l}\text { Chattanooga } \\
\text { military } \\
\text { recruitment centre }\end{array}$ & 6 & 3 & $\begin{array}{l}\text { Muhammad Youssuf } \\
\text { Abdulazeez }\end{array}$ \\
\hline 27 & $01 / 10 / 15$ & $\begin{array}{l}\text { Umpqua } \\
\text { Community College } \\
\text { shooting }\end{array}$ & 10 & 9 & Chris Harper Mercer \\
\hline 28 & $31 / 10 / 15$ & $\begin{array}{l}\text { Colorado Springs } \\
\text { shooting rampage }\end{array}$ & 4 & o & Noah Harpham \\
\hline 29 & $27 / 11 / 15$ & $\begin{array}{l}\text { Planned } \\
\text { Parenthood clinic } \\
\text { shooting }\end{array}$ & 3 & 9 & Robert Lewis Dear \\
\hline 30 & $07 / 07 / 16$ & $\begin{array}{l}\text { Dallas police } \\
\text { shooting }\end{array}$ & 6 & 11 & Micah Xavier Johnson \\
\hline 31 & 23/09/16 & $\begin{array}{l}\text { Cascade Mall } \\
\text { shooting }\end{array}$ & 6 & o & Arcan Cetin \\
\hline 32 & 06/01/17 & $\begin{array}{l}\text { Fort Lauderdale } \\
\text { airport shooting }\end{array}$ & 5 & 6 & Esteban Santiago \\
\hline 33 & $18 / 04 / 17$ & $\begin{array}{l}\text { Fresno downtown } \\
\text { shooting }\end{array}$ & 3 & o & Kori Ali Muhammad \\
\hline
\end{tabular}




\begin{tabular}{|c|c|c|c|c|c|}
\hline 34 & $12 / 05 / 17$ & $\begin{array}{l}\text { Ohio nursing home } \\
\text { shooting }\end{array}$ & 4 & o & Thomas Hartless \\
\hline 35 & $05 / 06 / 17$ & $\begin{array}{l}\text { Florida awning } \\
\text { manufacturer } \\
\text { shooting }\end{array}$ & 6 & o & John Robert Neumann \\
\hline 36 & 06/07/17 & $\begin{array}{l}\text { Pennsylvania } \\
\text { supermarket } \\
\text { shooting }\end{array}$ & 4 & o & Randy Stair \\
\hline 37 & 14/o6/17 & $\begin{array}{l}\text { San Francisco UPS } \\
\text { shooting }\end{array}$ & 4 & 5 & Jimmy Lam \\
\hline 38 & $01 / 10 / 17$ & $\begin{array}{l}\text { Las Vegas Strip } \\
\text { Massacre }\end{array}$ & 59 & 546 & Stephen Craig Paddock \\
\hline 39 & $18 / 10 / 17$ & $\begin{array}{l}\text { Edgewood Business } \\
\text { Park shooting }\end{array}$ & 3 & 3 & Radee Labeeb Prince \\
\hline 40 & $01 / 11 / 17$ & $\begin{array}{l}\text { Denver Walmart } \\
\text { shooting }\end{array}$ & 3 & o & Scott Allen Ostrem \\
\hline 41 & $05 / 11 / 17$ & $\begin{array}{l}\text { Texas First Baptist } \\
\text { Church Massacre }\end{array}$ & 27 & 20 & Devin Patrick Kelley \\
\hline 42 & 28/01/18 & $\begin{array}{l}\text { Pennsylvania } \\
\text { carwash shooting }\end{array}$ & 5 & 1 & Timothy O'Brien Smith \\
\hline 43 & $14 / 02 / 18$ & $\begin{array}{l}\text { Stoneman Douglas } \\
\text { High School } \\
\text { shooting }\end{array}$ & 17 & 14 & Nikolas Cruz \\
\hline 44 & $22 / 04 / 18$ & $\begin{array}{l}\text { Waffle house } \\
\text { shooting }\end{array}$ & 4 & 4 & Travis Reinking \\
\hline 45 & $27 / 02 / 12$ & $\begin{array}{l}\text { Chardon High } \\
\text { School shooting }\end{array}$ & 3 & 3 & Thomas Lane \\
\hline 46 & 06/04/12 & $\begin{array}{l}\text { North Tulsa } \\
\text { shooting }\end{array}$ & 3 & 2 & Jake England \\
\hline 47 & 09/06/12 & $\begin{array}{l}\text { University Heights } \\
\text { shooting }\end{array}$ & 3 & 3 & Desmonte Leonard \\
\hline 48 & $21 / 10 / 12$ & Azana Spa shooting & 4 & 4 & $\begin{array}{l}\text { Radcliffe Franklin } \\
\text { Haughton }\end{array}$ \\
\hline 49 & $18 / 05 / 18$ & $\begin{array}{l}\text { Santa Fe High } \\
\text { School shooting }\end{array}$ & 10 & 13 & Dimitrios Pagourtzis \\
\hline 50 & $21 / 04 / 13$ & $\begin{array}{l}\text { Pinewood Village } \\
\text { apartments } \\
\text { shooting }\end{array}$ & 5 & o & Dennis Clark \\
\hline 51 & $05 / 08 / 13$ & $\begin{array}{l}\text { Ross Township } \\
\text { shooting }\end{array}$ & 3 & 3 & Rockne Newell \\
\hline
\end{tabular}




\begin{tabular}{|c|c|c|c|c|c|}
\hline 52 & $28 / 12 / 13$ & $\begin{array}{l}\text { Centennial Hill Car } \\
\text { \& Grill shooting }\end{array}$ & 3 & 5 & $\begin{array}{l}\text { Darius Thomas, Jason } \\
\text { McWilliams, and Taboris } \\
\text { Mock }\end{array}$ \\
\hline 56 & $15 / 11 / 15$ & $\begin{array}{l}\text { Tennessee Colony } \\
\text { shooting }\end{array}$ & 6 & o & William Hudson \\
\hline 59 & $25 / 02 / 16$ & $\begin{array}{l}\text { Excel Industries } \\
\text { shooting }\end{array}$ & 3 & 14 & Cedric Ford \\
\hline 60 & $12 / 02 / 10$ & $\begin{array}{l}\text { University of } \\
\text { Alabama shooting }\end{array}$ & 3 & 3 & Amy Bishop Anderson \\
\hline 61 & $23 / 04 / 16$ & $\begin{array}{l}\text { Auburn club } \\
\text { shooting }\end{array}$ & 3 & 1 & Tarabein Latrent Cobb \\
\hline 63 & $19 / 12 / 16$ & $\begin{array}{l}\text { Breitscheidplatz } \\
\text { Christmas Market } \\
\text { shooting }\end{array}$ & 13 & 48 & Anis Amri \\
\hline 64 & $14 / 07 / 16$ & Bastille Day attack & 87 & 433 & $\begin{array}{l}\text { Mohamed Lahouaiej- } \\
\text { Bouhlel }\end{array}$ \\
\hline 67 & $17 / 08 / 16$ & $\begin{array}{l}\text { Balashika police } \\
\text { post attack }\end{array}$ & 3 & 1 & $\begin{array}{l}\text { Usman Murdalov, and } \\
\text { Sulim Israilov }\end{array}$ \\
\hline 68 & $22 / 07 / 16$ & $\begin{array}{l}\text { Munich shopping } \\
\text { mall shooting }\end{array}$ & 10 & 27 & David Ali Sonboly \\
\hline 69 & $16 / 06 / 16$ & $\begin{array}{l}\text { British Parliament } \\
\text { attack }\end{array}$ & 1 & 1 & Tommy Mair \\
\hline 71 & $10 / 05 / 16$ & $\begin{array}{l}\text { Grafing train } \\
\text { station attack }\end{array}$ & 1 & 3 & Paul H \\
\hline 72 & $24 / 03 / 16$ & $\begin{array}{l}\text { Glasgow } \\
\text { shopkeeper attack }\end{array}$ & 1 & 1 & Tanveer Ahmed \\
\hline 73 & $18 / 02 / 16$ & Rochdale attack & 1 & o & $\begin{array}{l}\text { Mohammed Syeedy, and } \\
\text { Mohammed Abdul Kadir }\end{array}$ \\
\hline 74 & $18 / 11 / 15$ & Rajlovac shooting & 2 & 3 & Enes Omeragic \\
\hline 82 & $22 / 10 / 15$ & $\begin{array}{l}\text { Kronan school } \\
\text { attack }\end{array}$ & 4 & 1 & Anton Lundin-Pettersson \\
\hline 83 & $26 / 06 / 15$ & $\begin{array}{l}\text { Air Products } \\
\text { factory attack }\end{array}$ & 1 & 2 & Yassin Salhi \\
\hline 84 & $27 / 04 / 15$ & $\begin{array}{l}\text { Zvornik police } \\
\text { station shooting }\end{array}$ & 2 & 2 & Nerdin Ibric \\
\hline 85 & $19 / 04 / 15$ & $\begin{array}{l}\text { Villejuif } \\
\text { neighbourhood } \\
\text { shooting }\end{array}$ & 1 & o & Sid Ahmed Ghlam \\
\hline 87 & $27 / 02 / 15$ & $\begin{array}{l}\text { Bolshoi } \\
\text { Moskavoretsky }\end{array}$ & 1 & o & $\begin{array}{l}\text { Zaur Dadeav, and Anzor } \\
\text { Gubashev }\end{array}$ \\
\hline
\end{tabular}




\begin{tabular}{|c|c|c|c|c|c|}
\hline & & $\begin{array}{l}\text { bridge } \\
\text { assassination }\end{array}$ & & & \\
\hline 88 & $15 / 02 / 15$ & $\begin{array}{l}\text { Copenhagen city } \\
\text { shooting }\end{array}$ & 1 & 2 & Omar El-Hussein \\
\hline 89 & $14 / 02 / 15$ & $\begin{array}{l}\text { Copenhagen city } \\
\text { debate shooting }\end{array}$ & 1 & 3 & Omar El-Hussein \\
\hline 91 & o8/01/15 & $\begin{array}{l}\text { Montrouge area } \\
\text { shooting }\end{array}$ & 1 & 1 & Amedy Coulibaly \\
\hline 92 & 07/01/15 & $\begin{array}{l}\text { Charlie Hebdo } \\
\text { shooting }\end{array}$ & 12 & 12 & $\begin{array}{l}\text { Cherif Kouachi, and Said } \\
\text { Kouachi }\end{array}$ \\
\hline 93 & $05 / 10 / 14$ & $\begin{array}{l}\text { Grozny city suicide } \\
\text { bombing }\end{array}$ & 6 & 12 & Opti Mudarov \\
\hline 94 & $16 / 09 / 16$ & $\begin{array}{l}\text { Philadelphia police } \\
\text { shooting }\end{array}$ & 2 & 5 & Nicholas Glenn \\
\hline 95 & $13 / 08 / 16$ & Queens shooting & 2 & $\mathrm{O}$ & Oscar Morel \\
\hline 96 & $07 / 07 / 16$ & $\begin{array}{l}\text { Bristol police } \\
\text { shooting }\end{array}$ & 1 & 4 & Lakeem Keon Scott \\
\hline 97 & $23 / 07 / 15$ & $\begin{array}{l}\text { Lafayette movie } \\
\text { shooting }\end{array}$ & 3 & 9 & John Russel Houser \\
\hline 98 & $20 / 12 / 14$ & NYPD shooting & 2 & o & Ismaaiyl Brinsley \\
\hline 99 & $18 / 12 / 14$ & $\begin{array}{l}\text { Morganton city } \\
\text { shooting }\end{array}$ & 1 & o & Justin Nojan Sullivan \\
\hline 100 & $22 / 10 / 14$ & $\begin{array}{l}\text { Parliament Hill } \\
\text { shooting }\end{array}$ & 2 & 3 & Michael Zehaf-Bibeau \\
\hline 101 & $20 / 10 / 14$ & $\begin{array}{l}\text { Canadian Armed } \\
\text { Forces attack }\end{array}$ & 2 & 1 & Martin Couture-Rouleau \\
\hline 102 & $12 / 09 / 14$ & $\begin{array}{l}\text { State troopers } \\
\text { shooting }\end{array}$ & 1 & 1 & Eric Fein \\
\hline 103 & $25 / 06 / 14$ & $\begin{array}{l}\text { West Orange } \\
\text { shooting }\end{array}$ & 1 & o & $\begin{array}{l}\text { Ali Muhammad Brown, } \\
\text { Jeremy Villagran, and } \\
\text { Eric Williams }\end{array}$ \\
\hline 104 & o8/o6/14 & $\begin{array}{l}\text { Las Vegas police } \\
\text { attack }\end{array}$ & 5 & o & Jerad and Amanda Miller \\
\hline 105 & $01 / 06 / 14$ & Seattle shooting & 2 & $\mathrm{O}$ & Ali Muhammad Brown \\
\hline 106 & $27 / 04 / 14$ & $\begin{array}{l}\text { Skyway } \\
\text { neighbourhood } \\
\text { shooting }\end{array}$ & 1 & O & Ali Muhammad Brown \\
\hline 107 & $13 / 04 / 14$ & $\begin{array}{l}\text { Overland Park } \\
\text { Jewish Community } \\
\text { Center shooting }\end{array}$ & 3 & $\mathrm{O}$ & Frazier Glenn Miller Jr. \\
\hline
\end{tabular}




\begin{tabular}{|c|c|c|c|c|c|}
\hline 109 & $01 / 11 / 13$ & $\begin{array}{l}\text { Transportation } \\
\text { Security } \\
\text { Administration } \\
\text { shooting }\end{array}$ & 1 & 4 & Paul Ciancia \\
\hline 110 & $19 / 04 / 13$ & Watertown attack & 2 & 16 & $\begin{array}{l}\text { Tamerlan and Dzhokhar } \\
\text { Tsarneav }\end{array}$ \\
\hline 111 & $18 / 04 / 13$ & $\begin{array}{l}\text { Cambridge MIT } \\
\text { campus shooting }\end{array}$ & 1 & o & $\begin{array}{l}\text { Tamerlan and Dzhokhar } \\
\text { Tsarneav }\end{array}$ \\
\hline 112 & $15 / 04 / 13$ & $\begin{array}{l}\text { Boston marathon } \\
\text { attack }\end{array}$ & 2 & 132 & $\begin{array}{l}\text { Tamerlan and Dzhokhar } \\
\text { Tsarneav }\end{array}$ \\
\hline 113 & $07 / 02 / 13$ & $\begin{array}{l}\text { Riverside Country } \\
\text { shooting }\end{array}$ & 2 & 1 & Christopher Dorner \\
\hline 114 & $18 / 02 / 10$ & $\begin{array}{l}\text { Internal Revenue } \\
\text { Service building } \\
\text { attack }\end{array}$ & 2 & 15 & Joseph Stack \\
\hline 115 & $24 / 05 / 14$ & $\begin{array}{l}\text { Jewish Museum } \\
\text { shooting }\end{array}$ & 4 & o & Mehdi Nenmouche \\
\hline 116 & $09 / 02 / 14$ & $\begin{array}{l}\text { Resurrection } \\
\text { Cathedral shooting }\end{array}$ & 2 & 6 & Stepan Komarov \\
\hline 121 & $21 / 10 / 13$ & $\begin{array}{l}\text { Volgograd city bus } \\
\text { bombing }\end{array}$ & 6 & 20 & Naida Asiyalova \\
\hline 123 & $22 / 05 / 12$ & $\begin{array}{l}\text { Woolwich area } \\
\text { attack }\end{array}$ & 1 & o & Michael Olumide \\
\hline 124 & $29 / 04 / 13$ & $\begin{array}{l}\text { Small Heath area } \\
\text { attack }\end{array}$ & 1 & o & Pavlo Lapsyn \\
\hline 125 & $28 / 08 / 12$ & $\begin{array}{l}\text { Belidzhi village } \\
\text { military shooting }\end{array}$ & 7 & o & Razman Aliyev \\
\hline 126 & $03 / 05 / 12$ & $\begin{array}{l}\text { Makhachkala } \\
\text { checkpoint } \\
\text { bombing }\end{array}$ & 14 & 50 & Muslimat Aliyev \\
\hline 127 & 19/03/12 & $\begin{array}{l}\text { Toulouse city } \\
\text { shooting }\end{array}$ & 4 & o & Mohammed Merah \\
\hline 128 & $15 / 03 / 12$ & $\begin{array}{l}\text { Montauban } \\
\text { shooting }\end{array}$ & 3 & o & Mohammed Merah \\
\hline 129 & $11 / 03 / 12$ & $\begin{array}{l}\text { Midi-Pyrenees } \\
\text { shooting }\end{array}$ & 1 & o & Mohammed Merah \\
\hline 130 & $30 / 08 / 11$ & $\begin{array}{l}\text { Grozy suicide } \\
\text { bombings }\end{array}$ & 12 & 23 & $\begin{array}{l}\text { Magomed Dashayev, and } \\
\text { Adlan Khamidov }\end{array}$ \\
\hline 131 & $22 / 07 / 11$ & $\begin{array}{l}\text { Oslo province } \\
\text { explosion }\end{array}$ & 8 & 15 & Anders Behring Breivik \\
\hline 132 & $22 / 07 / 11$ & Utoya island attack & 69 & 60 & Anders Behring Breivik \\
\hline
\end{tabular}




\begin{tabular}{|c|c|c|c|c|c|}
\hline 134 & $02 / 03 / 11$ & $\begin{array}{l}\text { Frankfurt } \\
\text { International } \\
\text { Airport shooting }\end{array}$ & 2 & 2 & Arid Uka \\
\hline 142 & $22 / 02 / 17$ & $\begin{array}{l}\text { Olathe restaurant } \\
\text { shooting }\end{array}$ & 1 & 2 & Adam Purinton \\
\hline 143 & 20/03/17 & $\begin{array}{l}\text { Midtown } \\
\text { Manhattan attack }\end{array}$ & 1 & $\mathrm{o}$ & James Harris Jackson \\
\hline 144 & 22/03/17 & Westminster attack & 5 & 50 & Khalid Masood \\
\hline 145 & 07/04/17 & Stockholm attack & 5 & 14 & Rakhmat Akilov \\
\hline 146 & $22 / 05 / 17$ & $\begin{array}{l}\text { Manchester Arena } \\
\text { bombing }\end{array}$ & 22 & 800 & Salman Abedi \\
\hline 147 & 19/06/17 & $\begin{array}{l}\text { Finsbury Park } \\
\text { attack }\end{array}$ & 1 & 10 & Darren Osborne \\
\hline 148 & 28/07/17 & Hamburg attack & 1 & 6 & Ahmad Alhaw \\
\hline 149 & $12 / 08 / 17$ & $\begin{array}{l}\text { Charlottesville } \\
\text { attack }\end{array}$ & 1 & 19 & James Alex Fields \\
\hline 150 & $17 / 08 / 17$ & Barcelona attack & 15 & 131 & Younes Abouyaaqoub \\
\hline 151 & $01 / 10 / 17$ & Marseille stabbing & 3 & $\mathrm{o}$ & Ahmed Hanachi \\
\hline 152 & $31 / 10 / 17$ & $\begin{array}{l}\text { New York City } \\
\text { truck attack }\end{array}$ & 8 & 11 & $\begin{array}{l}\text { Sayfello Habibullaevich } \\
\text { Saipov }\end{array}$ \\
\hline 153 & $12 / 05 / 18$ & Paris knife attack & 1 & 4 & Khamzat Azimor \\
\hline 154 & $30 / 08 / 10$ & Bratislava shooting & 8 & 17 & Lubomir Harman \\
\hline 155 & $02 / 06 / 10$ & Cumbria shootings & 13 & 11 & Derrick Bird \\
\hline 156 & $13 / 12 / 11$ & $\begin{array}{l}\text { Liege bus shelter } \\
\text { attack }\end{array}$ & 7 & 125 & Nordine Amrani \\
\hline 157 & $09 / 04 / 11$ & $\begin{array}{l}\text { Alphen aan den } \\
\text { Rijn shopping mall } \\
\text { shooting }\end{array}$ & 7 & 17 & Tristan van der Vlis \\
\hline 158 & $22 / 04 / 13$ & Belgorod shooting & 6 & 1 & Sergei Pomzaun \\
\hline 160 & $12 / 04 / 12$ & $\begin{array}{l}\text { Smilkovci lake } \\
\text { attack }\end{array}$ & 5 & o & $\begin{array}{l}\text { Alil Demiri, Afrim } \\
\text { Ismailoviq, Agim } \\
\text { Ismailoviq, Fejzi Aziri, } \\
\text { Haki Aziri, and Sami Luta }\end{array}$ \\
\hline 161 & $07 / 11 / 12$ & $\begin{array}{l}\text { Moscow warehouse } \\
\text { shooting }\end{array}$ & 6 & 1 & Dmitry Vinogradov \\
\hline 162 & $27 / 02 / 13$ & Menznau shooting & 5 & 5 & Viktor Berisha \\
\hline
\end{tabular}




\begin{tabular}{|c|c|c|c|c|c|}
\hline 163 & 20/06/15 & Graz attack & 3 & 36 & Alen Rizvanovic \\
\hline 165 & $24 / 02 / 15$ & $\begin{array}{l}\text { Uhersky Brod } \\
\text { shooting }\end{array}$ & 9 & 1 & Zdenek Kovar \\
\hline 166 & $02 / 07 / 16$ & $\begin{array}{l}\text { Zitiste café } \\
\text { shooting }\end{array}$ & 5 & 22 & Sinisa Zlatic \\
\hline 167 & $16 / 09 / 13$ & Annaberg shooting & 5 & 1 & Alois Huber \\
\hline 168 & 03/o6/17 & $\begin{array}{l}\text { London bride } \\
\text { attack }\end{array}$ & 11 & 48 & $\begin{array}{l}\text { Khuram Shazad, Rachid } \\
\text { Redouane, and Youssef } \\
\text { Zaghba }\end{array}$ \\
\hline
\end{tabular}




\section{Appendix B}

Table 1

Event-Level Variables and Codes in the Current Dataset

\begin{tabular}{|c|c|c|}
\hline Event Characteristics & Description & Codes \\
\hline Case ID & Case identification number & $\begin{array}{l}1=\text { Male } \\
2=\text { Female }\end{array}$ \\
\hline Incident Type & The type of incident that occurred & $\begin{array}{l}1=\text { Lone-actor terrorism } \\
2=\text { Rampage shooting }\end{array}$ \\
\hline Incident Summary & $\begin{array}{l}\text { Brief summary of the incident, } \\
\text { including 'what, when, where, who, } \\
\text { how, and why' factors }\end{array}$ & \\
\hline Number of fatalities & $\begin{array}{l}\text { Number of total confirmed fatalities for } \\
\text { the incident. This number includes all } \\
\text { victims and perpetrators who died as a } \\
\text { result of the incident }\end{array}$ & \\
\hline Number of casualties & $\begin{array}{l}\text { Number of total confirmed casualties } \\
\text { (non-fatal injuries) as a result of the } \\
\text { incident }\end{array}$ & \\
\hline Total number of victims & $\begin{array}{l}\text { Total number of fatalities and casualties } \\
\text { for each incident, combined }\end{array}$ & \\
\hline Specific target(s) & $\begin{array}{l}\text { If the perpetrator(s) had a specific } \\
\text { individual or group as their } \\
\text { target/victim }\end{array}$ & $\begin{array}{l}1=\text { Yes } \\
2=\text { No } \\
3=\text { Unknown }\end{array}$ \\
\hline $\begin{array}{l}\text { Relationship between } \\
\text { perpetrator and victim }\end{array}$ & $\begin{array}{l}\text { The relationship the perpetrator has } \\
\text { with the victims or target population }\end{array}$ & $\begin{array}{l}1=\text { Stranger } / \text { random } \\
2=\text { Personal } \\
3=\text { Professional } \\
4=\text { School-related } \\
5=\text { Combination }\end{array}$ \\
\hline $\begin{array}{l}\text { Location (city, state, } \\
\text { region) }\end{array}$ & $\begin{array}{l}\text { Details surrounding the geographical } \\
\text { location (region) where the incident } \\
\text { occurred. Alongside this, the city and } \\
\text { state will also be mentioned }\end{array}$ & $\begin{array}{l}1=\text { North America } \\
2=\text { Europe }\end{array}$ \\
\hline Location (type) & $\begin{array}{l}\text { Details surrounding the type of } \\
\text { location/target location the incident } \\
\text { took place in } \\
\text { (Note: 'Open commercial' includes any } \\
\text { type of semi-public place where there is } \\
\text { public access) }\end{array}$ & $\begin{array}{l}\text { 1=Open commercial } \\
2=\text { Educational institution } \\
3=\text { Military setting } \\
4=\text { Public street } \\
5=\text { Office } \\
6=\text { Warehouse/factory } \\
7=\text { Police } \\
8=\text { Other } \\
9=\text { Combination }\end{array}$ \\
\hline Attack type & $\begin{array}{l}\text { The type of attack the perpetrator(s) } \\
\text { committed }\end{array}$ & $\begin{array}{l}1=\text { Assassination } \\
2=\text { Armed assault } \\
3=\text { Bombing/explosion } \\
4=\text { Unarmed assault } \\
5=\text { Combination } \\
6=\text { Unknown }\end{array}$ \\
\hline
\end{tabular}




Number of perpetrators
Modus operandi and
weapon(s) used

Weapon subtype (firearms)

Level of planning

Duration of incident

Time of day

Outcome of incident

Arrest/conviction details

Claims of responsibility
Number of perpetrators per incident

The method of attack used by the perpetrator(s) and the type of weapons used to carry out the attack

More specific values for the firearm weapon type

No planning $=$ no time to plan the attack as the precipitator was immediately prior to the shooting. Lowlevel $=$ planning which occurs minutes/hours before the incident. Medium-level $=$ individuals who bought guns and practised with them. Highlevel = individuals who also acquired tactical information, carried out event rehearsals, and brought additional materials needed

The estimated duration of the incident

The estimated time of day the incident occurred

What happened to the perpetrator(s) following the incident

Information surrounding the arrest/conviction details of the perpetrator(s) as a result of the incident

Whether a group and/or individual(s) claimed responsibility for the incident

\author{
$1=$ Firearm \\ 2=Knife \\ $3=$ Fire \\ 4=Explosives/bombs \\ $5=$ Vehicle \\ $6=$ Other \\ $7=$ Combination \\ $8=$ Unknown
}

1=Automatic weapon (including semi-automatic)

$2=$ Handgun

3=Rifle/shotgun (non-

automatic)

4=Unknown gun type

$5=$ Other gun type

$6=$ Combination

$1=$ No planning

2=Low-level of planning

$3=$ Medium level of planning

$4=$ High level of planning

$5=$ Unknown

$1=$ Less than 30 minutes

$2=31-60$ minutes

$3=1-5$ hours

$4=6-12$ hours

$5=13-24$ hours

$6=$ Unknown

1=Morning (5:00-11:59)

2=Afternoon (12:00-16:59)

3=Evening (17:00-21:59)

4=Late night (22:00-4:59)

$5=$ Unknown

$1=$ Arrest

2 =Lethal force/suicide by cop $3=$ Suicide/attempted suicide $4=$ Other

$1=$ Yes

$2=\mathrm{No}$ 
Threatening statements

Whether threatening statements were made by the perpetrator(s) toward the victims in the six months prior to, or during, the incident

Suicide note

Whether the perpetrator(s) left indications of their suicide in events where suicide occurred. These could include notes, letters, manifestos, emails, online posts, or videotapes
$\mathrm{O}=$ No threatening statements were made

$1=$ Direct threatening statements were made

$2=$ Indirect threatening statements were made $3=$ Unknown

$1=$ Indications were found $2=$ No indications were found 
Table 2

Perpetrator-Level Variables and Codes in the Current Dataset

\begin{tabular}{|c|c|c|}
\hline Perpetrator Characteristics & Description & Codes \\
\hline Age & Age (years) & $\begin{array}{l}1=\text { Male } \\
2=\text { Female }\end{array}$ \\
\hline Sex & Gender of the perpetrator(s) & $\begin{array}{l}1=\text { Male } \\
2=\text { Female }\end{array}$ \\
\hline Race/ethnicity & $\begin{array}{l}\text { Race/ethnicity the perpetrator(s) } \\
\text { identify as }\end{array}$ & $\begin{array}{l}\text { 1=Black or African American } \\
2=\text { Asian } \\
3=\text { White } \\
4=\text { Hispanic or Latino } \\
5=\text { American Indian or Alaska } \\
\text { Native } \\
7=\text { Other } \\
\text { 8=Mixed race/ethnicity }\end{array}$ \\
\hline Educational level & $\begin{array}{l}\text { Highest level of education the } \\
\text { perpetrator(s) hold } \\
\text { (Note: If the perpetrator(s) attended } \\
\text { secondary school but did not graduate, } \\
\text { this still counts) }\end{array}$ & $\begin{array}{l}1=\text { Primary education } \\
2=\text { Secondary education } \\
3=\text { Tertiary education } \\
4=\text { Unknown }\end{array}$ \\
\hline Relationship status & The perpetrator(s) relationship status & $\begin{array}{l}1=\text { Single } \\
2=\text { In a relationship } \\
3=\text { Married } \\
4=\text { Divorced } \\
5=\text { Divorced but in a } \\
\text { relationship } \\
6=\text { Unknown }\end{array}$ \\
\hline Job status & $\begin{array}{l}\text { The job status of the perpetrator(s)/type } \\
\text { of employment they work in }\end{array}$ & $\begin{array}{l}\text { 1=Gold-collar worker } \\
2=\text { White-collar worker } \\
3=\text { Blue-collar worker } \\
\text { 4=Unemployed } \\
5=\text { Student } \\
6=\text { Other } \\
7=\text { Unknown }\end{array}$ \\
\hline Religious affiliation & $\begin{array}{l}\text { What religion (if any) the perpetrator(s) } \\
\text { identify with }\end{array}$ & $\begin{array}{l}1=\text { Christian } \\
\text { 2=Muslim } \\
\text { 3=Buddhist } \\
\text { 4=Atheist } \\
\text { 5=Agnostic } \\
6=\text { Hindu } \\
7=\text { Jewish } \\
8=\text { Sikh } \\
\text { 9=Non-religious } \\
\text { 10=Other } \\
\text { 11=Unknown }\end{array}$ \\
\hline Children/dependents & $\begin{array}{l}\text { Whether the perpetrator(s) has any } \\
\text { children or dependents }\end{array}$ & $\begin{array}{l}1=\text { Yes } \\
2=\text { No } \\
3=\text { Unknown }\end{array}$ \\
\hline
\end{tabular}


Social isolation

Low self-esteem

Work/school issues

Childhood issues

Living situation

Criminal history

Previous violent acts

Previous abuse
Whether there is evidence that the perpetrator(s) experienced social isolation in their everyday life

Whether there is evidence that the perpetrator(s) suffered from low selfesteem

This was coded as present if there were indications that the perpetrator(s) were experiencing issues or grievances with individuals at their workplace or school in the six months leading up to, or at the time of, the incident

Whether there was evidence/indications of the perpetrator(s) experiencing childhood issues or trouble during their upbringing (Note: This includes bullying)
$1=$ There are indications the perpetrator(s) experienced extreme social isolation 2=There are indications the perpetrator(s) experienced some form of social isolation $3=$ There are no indications the perpetrator(s) experienced social isolation 4=Unknown

$1=$ Yes

$2=\mathrm{No}$

3=Unknown

1=Issues and/or grievances were present $2=$ Issues and/or grievances were not present $3=$ Not applicable 4=Unknown

$1=$ There is evidence that the perpetrator(s) experienced significant childhood issues/troubles during their upbringing

$2=$ There is evidence that the perpetrator(s) experienced some forms of issues/troubles during their upbringing 3 =There is no evidence that the perpetrator(s) experienced issues/troubles during their upbringing

$1=$ Yes

$2=\mathrm{No}$

$1=$ Yes

$2=\mathrm{No}$

$1=$ Yes indications that the perpetrator(s) has $\quad 2=$ No suffered from previous abuse (i.e. psychological, physical, or sexual abuse) 
Substance use

Weapon ownership

Fascination with

weapons/war

Familiarity with firearms

Military experience

Ideological connections/group affiliations

Mental health status

Mental health status (diagnosis)
Whether there are some indications that the perpetrator(s) engaged in illegal substance use and/or abuse, and alcohol abuse at any point in the past or prior to the incident

Whether the perpetrator(s) owned weapons prior to the incident

Whether the perpetrator(s) displayed a fascination/interest with violence (this could include the ownership of material associated with war/terrorism or weapons)

The perpetrator(s) had a pre-existing familiarity with firearms

Whether the perpetrator(s) had previous military experience

Whether the perpetrator(s) held ideological connections/affiliations with ideological groups

These are categorised into four main categories. Note: The first requires evidence of an official diagnosis by a mental health professional; the second is an indicator that issues may be present based on other sources (i.e. family and friends) mentioning this

The specific diagnosis/details about the perpetrator(s) mental health issues $\mathbf{1 =}$ There are indications that the perpetrator has engaged in illegal substance use and/or abuse $2=$ There are indications that the perpetrator has engaged in alcohol abuse $3=$ There are indications that the perpetrator has engaged in both illegal substance use and/or abuse, and alcohol abuse 4=There are no indications that the perpetrator has engaged in either substance or alcohol abuse

$1=$ Yes

$2=\mathrm{No}$

$3=$ Unknown

$1=$ Yes

$2=\mathrm{No}$

$3=$ Unknown

$1=$ Yes

$2=\mathrm{No}$

$3=$ Unknown

1=Did have prior military

experience

2=Did not have prior military

experience

3=Unknown

$1=$ There is evidence that the perpetrator(s) has group connections

$2=$ There is no evidence that the perpetrator(s) has group connections 3=Unknown

$1=$ There is evidence of mental health issues or disorder(s) $2=$ There are indications of mental health issues or disorder(s) $3=$ There is no evidence of mental health issues or disorder(s) 4=Unknown 
Antisocial personality traits Whether the perpetrator(s) displayed any antisocial personality traits prior to the incident. This includes traits such as lying, deceit, disregard for right and wrong, callousness, manipulation, impulsiveness, aggression, lack of empathy, and lack of remorse

Precipitating events

Motivation (emotional triggers)

Motivation

(relationship/domestic issues)

Motivation

(revenge/payback)

Motivation (personal grievances)

Motivation (criminal gain)

Motivation (political or religious)

Motivation (unclear)
Any precipitating circumstances or events that occurred in the perpetrator(s) life in the six months prior to the incident (i.e. the loss of a relationship, school or work suspension or termination) which could have led to or affected their decision to carry out the attack

Accounts of the perpetrator(s) expressed motivation for carrying out the attack or other source's accounts of this (i.e. family or friends). This motivation is whether the perpetrator(s) experienced emotional triggers in the week prior to the attack that has contributed to their decision to carry out the attack)

Whether the perpetrator(s) experienced relationship issues or issues within their domestic environment prior to the incident that contributed to the attack

Whether the perpetrator(s) carried out the attack to seek individual revenge/payback for perceived wrongs they have experienced by the victim(s)

Whether the perpetrator(s) perceive to have suffered from a personal grievance which has contributed to their decision to carry out the attack

Whether the perpetrator(s) committed the attack with the intent to gain a benefit/reward as a result of this

Whether the perpetrator(s) carried out the attack due to political or religious motivations/grievances, with the intention of challenging the government in some manner

The motivations behind the perpetrator(s) committing an attack are unknown or unclear (Note: If other motivations are coded 'yes' then the motivation is clear
1=The perpetrator(s) displayed antisocial personality traits prior to the incident 2=The perpetrator(s) displayed no antisocial personality traits prior to the incident $3=$ Unknown

$1=$ No clear event 2=Relationship-related event 3=Occupation-related event 4=School-related event $5=$ Personal-related event $6=$ Other

$7=$ Combination

8=Unknown

$1=$ Yes

$2=\mathrm{No}$

$1=$ Yes

$2=\mathrm{No}$

$1=$ Yes

$2=\mathrm{No}$

$1=$ Yes

$2=$ No

$1=$ Yes

$2=$ No

$1=$ Yes

$2=$ No

$1=$ Yes

$2=\mathrm{No}$ 


\section{Appendix C}

Table 1

Event Characteristics of Rampage Shooting Incidents in North America Versus Europe

\begin{tabular}{|c|c|c|c|c|c|}
\hline \multirow{2}{*}{$\begin{array}{l}\text { Location } \\
\text { Event characteristics }\end{array}$} & \multicolumn{2}{|c|}{$\begin{array}{l}\text { North America } \\
\quad(n=48)\end{array}$} & \multicolumn{2}{|c|}{$\begin{array}{l}\text { Europe } \\
(n=10)\end{array}$} & \multirow[b]{2}{*}{ Significant } \\
\hline & $M$ & Range & $M$ & Range & \\
\hline Number of fatalities & 7.6 & $(3-59)$ & 7.1 & $(5-13)$ & $n s$ \\
\hline Number of casualties & 16.9 & $(0-546)$ & 19.1 & $(1-125)$ & $n s$ \\
\hline Total number of victims & $25 \cdot 3$ & $(3-605)$ & 27.2 & $(6-132)$ & $n s$ \\
\hline Event Characteristics & $n$ & $\%$ & $n$ & $\%$ & Significant \\
\hline \multicolumn{6}{|l|}{ Yearc } \\
\hline 2010 & 2 & 4.2 & 2 & 20 & $* *$ \\
\hline 2011 & 2 & 4.2 & 2 & 20 & \\
\hline 2012 & 9 & 18.8 & 1 & 10 & \\
\hline 2013 & 7 & 14.6 & 3 & 30 & \\
\hline 2014 & 4 & 8.3 & - & - & \\
\hline 2015 & 7 & 14.6 & 1 & 10 & \\
\hline 2016 & 4 & 8.3 & 1 & 10 & \\
\hline 2017 & 9 & 18.8 & - & - & \\
\hline 2018 & 4 & 8.3 & - & - & \\
\hline \multicolumn{6}{|l|}{ Number of perpetrators ${ }^{c}$} \\
\hline One offender & 46 & 95.8 & 10 & 100 & $n s$ \\
\hline Two offenders & 1 & 2.1 & - & - & \\
\hline Three or more offenders & 1 & 2.1 & - & - & \\
\hline \multicolumn{6}{|l|}{ Modus operandi ${ }^{b}$} \\
\hline Firearm & 43 & 89.6 & 9 & 90 & $n s$ \\
\hline Knife & - & - & - & - & \\
\hline Fire & - & - & - & - & \\
\hline Explosives/bombs & - & - & - & - & \\
\hline Vehicle & - & - & - & - & \\
\hline Other & - & - & - & - & \\
\hline Combination & 2 & 4.2 & 1 & 10 & \\
\hline Unknown44 & 3 & 6.3 & - & - & \\
\hline
\end{tabular}

44 Note that all 'unknown' categories for every variable were excluded from significance testing analyses. 


\begin{tabular}{|c|c|c|c|c|c|}
\hline \multicolumn{6}{|l|}{ Weapon subtype ${ }^{\mathrm{b}}$} \\
\hline Automatic weapon & 17 & $35 \cdot 4$ & 4 & 40 & \multirow{5}{*}{$n s$} \\
\hline Handgun & 9 & 18.8 & 2 & 20 & \\
\hline $\begin{array}{l}\text { Rifle/shotgun (non- } \\
\text { automatic) }\end{array}$ & 5 & 10.4 & 1 & 10 & \\
\hline Unknown & - & - & 1 & 10 & \\
\hline Combination & 14 & 29.2 & 2 & 20 & \\
\hline \multicolumn{6}{|l|}{ Specific target(s)b } \\
\hline Yes & 34 & 70.8 & 6 & 60 & \multirow[t]{2}{*}{$n s$} \\
\hline No & 14 & 29.2 & 4 & 40 & \\
\hline \multicolumn{6}{|l|}{ Relationship to victim ${ }^{b}$} \\
\hline Stranger/random & 21 & 43.8 & 6 & 60 & \multirow[t]{5}{*}{$n s$} \\
\hline Personal & 2 & 4.2 & 1 & 10 & \\
\hline Professional & 9 & 18.8 & 2 & 20 & \\
\hline School-related & 4 & 8.3 & - & - & \\
\hline Combination & 12 & 25 & 1 & 10 & \\
\hline \multicolumn{6}{|l|}{ Location type } \\
\hline Open commercial & 20 & 41.7 & 4 & 40 & \multirow{8}{*}{$n s$} \\
\hline Educational institution & 8 & 16.7 & - & - & \\
\hline Military setting & 3 & 6.3 & - & - & \\
\hline Public street & 3 & 6.3 & 2 & 20 & \\
\hline Office & 1 & 2.1 & - & - & \\
\hline Warehouse/factory & 4 & 8.3 & 1 & 10 & \\
\hline Other & 6 & 12.5 & 1 & 10 & \\
\hline Combination & 3 & 6.3 & 2 & 20 & \\
\hline \multicolumn{6}{|l|}{ Attack type ${ }^{b}$} \\
\hline Assassination & - & - & - & - & \multirow{5}{*}{$n s$} \\
\hline Armed assault & 47 & 97.9 & 9 & 90 & \\
\hline Bombing/explosion & - & - & - & - & \\
\hline Unarmed assault & - & - & - & - & \\
\hline Combination & 1 & 2.1 & 1 & 10 & \\
\hline \multicolumn{6}{|l|}{ Level of planning $b$} \\
\hline Low-level & 15 & 31.3 & 3 & 30 & \multirow[t]{4}{*}{ * } \\
\hline Medium-level & 21 & 43.8 & 5 & 50 & \\
\hline High-level & 5 & 10.4 & 1 & 10 & \\
\hline Unknown & 7 & 14.6 & 1 & 10 & \\
\hline \multicolumn{6}{|l|}{ Duration of incident ${ }^{\mathrm{b}}$} \\
\hline Less than 30 minutes & 38 & 79.2 & 6 & 60 & \multirow[t]{6}{*}{$n s$} \\
\hline 31-6o minutes & 1 & 2.1 & 1 & 10 & \\
\hline 1-5 hours & 7 & 14.6 & 2 & 20 & \\
\hline 6-12 hours & 1 & 2.1 & - & - & \\
\hline 13-24 hours & 1 & 2.1 & 1 & 10 & \\
\hline Unknown & - & - & - & - & \\
\hline \multicolumn{6}{|l|}{ Time of incident ${ }^{\mathrm{b}}$} \\
\hline Morning & 21 & 43.8 & 4 & 40 & \multirow[t]{5}{*}{$* *$} \\
\hline Afternoon & 8 & 16.7 & 4 & 40 & \\
\hline Evening & 10 & 20.8 & 1 & 10 & \\
\hline Late night & 8 & 16.7 & 1 & 10 & \\
\hline Unknown & 1 & 2.1 & - & - & \\
\hline
\end{tabular}




\begin{tabular}{|c|c|c|c|c|c|}
\hline \multicolumn{6}{|l|}{ Outcome of incident ${ }^{b}$} \\
\hline Arrest & 19 & 39.6 & 2 & 20 & \multirow{4}{*}{$n s$} \\
\hline $\begin{array}{l}\text { Lethal force/suicide by } \\
\text { cop }\end{array}$ & 7 & 14.6 & - & - & \\
\hline $\begin{array}{l}\text { Suicide/attempted } \\
\text { suicide }\end{array}$ & 18 & $37 \cdot 5$ & 6 & 60 & \\
\hline Other & 4 & 8.3 & 2 & 20 & \\
\hline \multicolumn{6}{|l|}{ Claims of responsibilityb } \\
\hline Yes & 1 & 2.1 & - & - & \multirow{2}{*}{$n s$} \\
\hline No & 47 & 97.9 & 10 & 100 & \\
\hline \multicolumn{6}{|l|}{ Threatening statements ${ }^{b}$} \\
\hline No statements & 34 & 70.8 & 9 & 90 & \multirow{3}{*}{$n s$} \\
\hline Direct statements & 7 & 14.6 & 1 & 10 & \\
\hline Indirect statements & 7 & 14.6 & - & - & \\
\hline
\end{tabular}

Note. Significance tests based on whether there is a statistically significant relationship between incident type and event variables.

$n s=$ nonsignificant.

${ }^{\mathrm{b}}$ Chi-square.

cThe $t$ test.

${ }^{*} p \leq .05 .{ }^{* *} p \leq .01 .{ }^{* * *} p \leq .001$ (two-tailed). 
Table 2

Sociodemographic Characteristics of Rampage Shooting Perpetrators in North America Versus Europe

\begin{tabular}{|c|c|c|c|c|c|}
\hline \multirow{2}{*}{$\begin{array}{l}\text { Perpetrators } \\
\begin{array}{l}\text { Sociodemographic } \\
\text { characteristics }\end{array}\end{array}$} & \multicolumn{2}{|c|}{$\begin{array}{l}\text { North America } \\
\quad(n=51)\end{array}$} & \multicolumn{2}{|c|}{$\begin{array}{l}\text { Europe } \\
(n=10)\end{array}$} & \multirow[b]{2}{*}{ Significant } \\
\hline & $M$ & Range & $M$ & Range & \\
\hline Age & 33.2 & $(15-64)$ & 41.5 & $(24-63)$ & $*$ \\
\hline $\begin{array}{l}\text { Sociodemographic } \\
\text { characteristics }\end{array}$ & $n$ & $\%$ & $n$ & $\%$ & Significant \\
\hline \multicolumn{6}{|l|}{ Genderb } \\
\hline Male & 49 & 96.1 & 10 & 100 & \multirow{2}{*}{$n s$} \\
\hline Female & 2 & 3.9 & - & - & \\
\hline \multicolumn{6}{|l|}{ Race/ethnicityb } \\
\hline Black/African American & 10 & 19.6 & - & - & \multirow[t]{7}{*}{$n s$} \\
\hline Asian & 2 & 3.9 & - & - & \\
\hline White & 26 & 51 & 4 & 40 & \\
\hline Hispanic or Latino & 3 & $5 \cdot 9$ & - & - & \\
\hline $\begin{array}{l}\text { American Indian or } \\
\text { Alaska Native }\end{array}$ & 4 & 7.8 & 2 & 20 & \\
\hline Other & 4 & 7.8 & 3 & 30 & \\
\hline Mixed race/ethnicity & 2 & 3.9 & - & - & \\
\hline \multicolumn{6}{|l|}{ Educational level ${ }^{\mathrm{b}}$} \\
\hline Primary & - & - & - & - & \multirow{4}{*}{$n s$} \\
\hline Secondary & 37 & 72.5 & 5 & 50 & \\
\hline Tertiary & 9 & 17.6 & 3 & 30 & \\
\hline Unknown & 5 & 9.8 & 2 & 20 & \\
\hline \multicolumn{6}{|l|}{ Relationship statusb } \\
\hline Single & 29 & 56.9 & 4 & 40 & \multirow{6}{*}{$n s$} \\
\hline In a relationship & 11 & 21.6 & 1 & 10 & \\
\hline Married & 7 & 13.7 & 4 & 40 & \\
\hline Divorced & 3 & 5.9 & 1 & 10 & \\
\hline $\begin{array}{l}\text { Divorced but in a } \\
\text { relationship }\end{array}$ & 1 & 2 & - & - & \\
\hline Unknown & - & - & - & - & \\
\hline \multicolumn{6}{|l|}{ Job status ${ }^{b}$} \\
\hline Gold-collar worker & - & - & 1 & 10 & \multirow{7}{*}{$n s$} \\
\hline White-collar worker & 5 & 9.8 & 1 & 10 & \\
\hline Blue-collar worker & 15 & 29.4 & 3 & 30 & \\
\hline Unemployed & 11 & 21.4 & 4 & 40 & \\
\hline Student & 7 & 13.7 & - & - & \\
\hline Other (including retired) & 5 & 9.8 & 1 & 10 & \\
\hline Unknown & 8 & $15 \cdot 7$ & - & - & \\
\hline
\end{tabular}




\begin{tabular}{lccccc}
\hline Religious affiliation $^{\mathrm{b}}$ & 6 & 11.8 & 2 & 20 & $n s$ \\
Christian & 3 & 5.9 & 2 & 20 & \\
Muslim & 1 & 2 & - & - & \\
Buddhist & 4 & 7.8 & - & - & \\
Atheist & 1 & 2 & - & - & \\
Agnostic & - & - & - & - & \\
Hindu & - & - & - & - & \\
Jewish & 5 & 9.8 & - & - & \\
Non-religious & 2 & 3.9 & - & - & \\
Other & 29 & 56.9 & 6 & 60 & \\
$\quad$ Unknown & & & & & \\
Children/dependentsb & 16 & 31.4 & 4 & 40 & 60 \\
$\quad$ Yes & 35 & 68.6 & 6 & 60 & \\
No & &
\end{tabular}

Note. Significance tests based on whether there is a statistically significant relationship between incident type and sociodemographic variables.

$n s=$ nonsignificant.

bChi-square.

${ }^{*} p \leq .05 .{ }^{* *} p \leq .01 .{ }^{* * *} p \leq .001$ (two-tailed). 
Table 3

Personal Characteristics of Rampage Shooting Perpetrators in North America Versus Europe

\begin{tabular}{|c|c|c|c|c|c|}
\hline \multirow{2}{*}{$\begin{array}{l}\text { Perpetrators } \\
\text { Personal characteristics }\end{array}$} & \multicolumn{2}{|c|}{$\begin{array}{l}\text { North America } \\
\quad(n=51)\end{array}$} & \multicolumn{2}{|c|}{$\begin{array}{l}\text { Europe } \\
(n=10)\end{array}$} & \multirow[b]{2}{*}{ Significant } \\
\hline & $n$ & $\%$ & $n$ & $\%$ & \\
\hline \multicolumn{6}{|l|}{ Work/school issues ${ }^{b}$} \\
\hline Issues were present & 24 & 47.1 & 2 & 20 & \multirow[t]{4}{*}{$n s$} \\
\hline Issues were not present & 13 & 25.5 & 3 & 30 & \\
\hline Not applicable & 12 & 23.5 & 4 & 40 & \\
\hline Unknown & 2 & 3.9 & 1 & 10 & \\
\hline \multicolumn{6}{|l|}{ Childhood issues ${ }^{\mathrm{b}}$} \\
\hline $\begin{array}{l}\text { Evidence of significant } \\
\text { issues }\end{array}$ & 6 & 11.8 & - & - & \multirow[t]{3}{*}{$n s$} \\
\hline $\begin{array}{l}\text { Evidence of some form of } \\
\text { issues }\end{array}$ & 10 & 19.6 & 1 & 10 & \\
\hline No evidence of issues & 35 & 68.6 & 9 & 90 & \\
\hline \multicolumn{6}{|l|}{ Substance use $\mathrm{e}^{\mathrm{b}}$} \\
\hline $\begin{array}{l}\text { Indications of illegal } \\
\text { substance use and/or } \\
\text { abuse }\end{array}$ & 5 & 9.8 & 1 & 10 & \multirow[t]{4}{*}{$n s$} \\
\hline $\begin{array}{l}\text { Indications of alcohol } \\
\text { abuse }\end{array}$ & 2 & 3.9 & 1 & 10 & \\
\hline $\begin{array}{l}\text { Indications of both of the } \\
\text { above }\end{array}$ & 8 & $15 \cdot 7$ & 1 & 10 & \\
\hline No indications & 36 & 70.6 & 7 & 70 & \\
\hline \multicolumn{6}{|l|}{ Weapon ownership ${ }^{b}$} \\
\hline Yes & 38 & 74.5 & 8 & 80 & \multirow{3}{*}{$n s$} \\
\hline No & 8 & 15.7 & 2 & 20 & \\
\hline Unknown & 5 & 9.8 & - & - & \\
\hline \multicolumn{6}{|l|}{$\begin{array}{l}\text { Fascination with } \\
\text { weapons/warb }\end{array}$} \\
\hline Yes & 38 & 74.5 & 6 & 60 & \multirow{3}{*}{$n s$} \\
\hline No & 5 & 9.8 & 1 & 10 & \\
\hline Unknown & 8 & $15 \cdot 7$ & 3 & 30 & \\
\hline \multicolumn{6}{|l|}{ Familiarity with firearms ${ }^{b}$} \\
\hline Yes & 48 & 94.1 & 10 & 100 & \multirow{2}{*}{$n s$} \\
\hline No & 3 & 5.9 & - & - & \\
\hline \multicolumn{6}{|l|}{ Military experience } \\
\hline Did have prior experience & 11 & 21.6 & 2 & 20 & \multirow{3}{*}{$n s$} \\
\hline $\begin{array}{l}\text { Did not have prior } \\
\text { experience }\end{array}$ & 38 & 74.5 & 8 & 80 & \\
\hline Unknown & 2 & 3.9 & - & - & \\
\hline
\end{tabular}




\begin{tabular}{|c|c|c|c|c|c|}
\hline \multicolumn{6}{|l|}{$\begin{array}{l}\text { Ideological } \\
\text { connections/group } \\
\text { affiliations }^{b}\end{array}$} \\
\hline $\begin{array}{l}\text { Evidence of group } \\
\text { connections }\end{array}$ & - & - & - & - & \multirow{2}{*}{$n s$} \\
\hline $\begin{array}{l}\text { No evidence of group } \\
\text { connections }\end{array}$ & 51 & 100 & 10 & 100 & \\
\hline \multicolumn{6}{|l|}{ Precipitating events $\mathrm{b}$} \\
\hline No clear event & 15 & 29.4 & 3 & 30 & \multirow{6}{*}{$n s$} \\
\hline Relationship-related & 7 & 13.7 & - & - & \\
\hline Occupation-related & 5 & 9.8 & - & - & \\
\hline School-related & 2 & 3.9 & - & - & \\
\hline Personal-related & 11 & 21.6 & 5 & 50 & \\
\hline Combination & 11 & 21.6 & 2 & 20 & \\
\hline
\end{tabular}

Note. Significance tests based on whether there is a statistically significant relationship between incident type and perpetrator-level variables.

$n s=$ nonsignificant.

bChi-square.

${ }^{*} p \leq .05 .{ }^{* *} p \leq .01 .{ }^{* * *} p \leq .001$ (two-tailed). 
Table 4

Psychological Background and Violent History of Rampage Shooting Perpetrators in North America Versus Europe

\begin{tabular}{|c|c|c|c|c|c|}
\hline \multirow{2}{*}{$\begin{array}{l}\text { Perpetrators } \\
\text { Perpetrator characteristics }\end{array}$} & \multicolumn{2}{|c|}{$\begin{array}{l}\text { North America } \\
\quad(n=51)\end{array}$} & \multicolumn{2}{|c|}{$\begin{array}{l}\text { Europe } \\
(n=10)\end{array}$} & \multirow[b]{2}{*}{ Significant } \\
\hline & $n$ & $\%$ & $n$ & $\%$ & \\
\hline \multicolumn{6}{|l|}{ Antisocial personality traits ${ }^{b}$} \\
\hline $\begin{array}{l}\text { Traits displayed prior to } \\
\text { incident }\end{array}$ & 38 & 74.5 & 7 & 70 & \multirow{3}{*}{$n s$} \\
\hline $\begin{array}{l}\text { No traits displayed prior } \\
\text { to incident }\end{array}$ & 12 & 23.5 & 3 & 30 & \\
\hline Unknown & 1 & 2 & - & - & \\
\hline \multicolumn{6}{|l|}{ Low self-esteem ${ }^{b}$} \\
\hline Yes & 13 & 25.5 & 1 & 10 & \multirow{3}{*}{$n s$} \\
\hline No & 25 & 49 & 7 & 70 & \\
\hline Unknown & 13 & 25.5 & 2 & 20 & \\
\hline \multicolumn{6}{|l|}{ Social isolation ${ }^{\mathrm{b}}$} \\
\hline $\begin{array}{l}\text { Indications of extreme } \\
\text { social isolation }\end{array}$ & 4 & 7.8 & - & - & \multirow[t]{4}{*}{$n s$} \\
\hline $\begin{array}{l}\text { Indications of some form } \\
\text { of social isolation }\end{array}$ & 20 & 39.2 & 5 & 50 & \\
\hline $\begin{array}{l}\text { No indications of social } \\
\text { isolation }\end{array}$ & 24 & 47.1 & 5 & 50 & \\
\hline Unknown & 3 & 5.9 & - & - & \\
\hline \multicolumn{6}{|l|}{ Mental health status ${ }^{b}$} \\
\hline $\begin{array}{l}\text { Evidence of mental health } \\
\text { issues or disorder(s) }\end{array}$ & 19 & $37 \cdot 3$ & 3 & 30 & \multirow[t]{4}{*}{$n s$} \\
\hline $\begin{array}{l}\text { Indications of mental } \\
\text { health issues or } \\
\text { disorder(s) }\end{array}$ & 19 & $37 \cdot 3$ & 3 & 30 & \\
\hline $\begin{array}{l}\text { No evidence of mental } \\
\text { health issues or } \\
\text { disorder(s) }\end{array}$ & 10 & 19.6 & 4 & 40 & \\
\hline Unknown & 3 & $5 \cdot 9$ & - & - & \\
\hline \multicolumn{6}{|l|}{ Suicide indications ${ }^{\mathrm{b}}$} \\
\hline Indications were found & 5 & 9.8 & 1 & 10 & \multirow{2}{*}{$n s$} \\
\hline $\begin{array}{l}\text { Indications were not } \\
\text { found }\end{array}$ & 46 & 90.2 & 9 & 90 & \\
\hline \multicolumn{6}{|l|}{ Previous violent acts ${ }^{\mathrm{b}}$} \\
\hline Yes & 23 & 45.1 & 4 & 40 & \multirow[t]{2}{*}{$n s$} \\
\hline No & 28 & 54.9 & 6 & 60 & \\
\hline \multicolumn{6}{|l|}{ Previous abuse $\mathrm{b}^{\mathrm{b}}$} \\
\hline Yes & 6 & 11.8 & 1 & 10 & \multirow{2}{*}{$n s$} \\
\hline No & 45 & 88.2 & 9 & 90 & \\
\hline
\end{tabular}




\begin{tabular}{lccccc}
\hline Criminal historyb $^{\mathrm{b}}$ & & & & \\
Yes & 21 & 41.2 & 4 & 40 & $n s$ \\
No & 30 & 58.8 & 6 & 60 & \\
\hline
\end{tabular}

Note. Significance tests based on whether there is a statistically significant relationship between incident type and psychological background and violent history variables.

$n s=$ nonsignificant.

bChi-square.

${ }^{*} p \leq .05 .{ }^{* *} p \leq .01 .{ }^{* * *} p \leq .001$ (two-tailed). 
Table 5

Motivational Patterns of Rampage Shooting Perpetrators in North America Versus Europe

\begin{tabular}{|c|c|c|c|c|c|}
\hline \multirow{2}{*}{$\begin{array}{l}\text { Perpetrators } \\
\text { Motivational characteristics }\end{array}$} & \multicolumn{2}{|c|}{$\begin{array}{l}\text { North America } \\
\quad(n=51)\end{array}$} & \multicolumn{2}{|c|}{$\begin{array}{l}\text { Europe } \\
(n=10)\end{array}$} & \multirow[b]{2}{*}{ Significant } \\
\hline & $n$ & $\%$ & $n$ & $\%$ & \\
\hline \multicolumn{6}{|l|}{$\begin{array}{l}\text { Motivation: emotional } \\
\text { triggers }\end{array}$} \\
\hline Yes & 29 & 56.9 & 7 & 70 & \multirow{2}{*}{$n s$} \\
\hline No & 22 & 43.1 & 3 & 30 & \\
\hline \multicolumn{6}{|l|}{$\begin{array}{l}\text { Motivation: relationship or } \\
\text { domestic issues }\end{array}$} \\
\hline Yes & 15 & 29.4 & 3 & 30 & \multirow[b]{2}{*}{$n s$} \\
\hline No & 36 & 70.6 & 7 & 70 & \\
\hline \multicolumn{6}{|l|}{ Motivation: revenge/payback } \\
\hline Yes & 16 & 31.4 & 2 & 20 & \multirow{2}{*}{$n s$} \\
\hline No & 35 & 68.6 & 8 & 80 & \\
\hline \multicolumn{6}{|l|}{$\begin{array}{l}\text { Motivation: personal } \\
\text { grievances }\end{array}$} \\
\hline Yes & 22 & 43.1 & 4 & 40 & \multirow[b]{2}{*}{$n s$} \\
\hline No & 29 & 56.9 & 6 & 60 & \\
\hline \multicolumn{6}{|l|}{ Motivation: criminal gain } \\
\hline Yes & - & - & - & - & \multirow{2}{*}{$n s$} \\
\hline No & 51 & 100 & 10 & 100 & \\
\hline \multicolumn{6}{|l|}{$\begin{array}{l}\text { Motivation: political or } \\
\text { religious }\end{array}$} \\
\hline Yes & 6 & 11.8 & - & - & \multirow[b]{2}{*}{$n s$} \\
\hline No & 45 & 88.2 & 10 & 100 & \\
\hline \multicolumn{6}{|l|}{$\begin{array}{l}\text { Motivation: unclear or } \\
\text { unknown }\end{array}$} \\
\hline Yes & 12 & 23.5 & 3 & 30 & \multirow[b]{2}{*}{$n s$} \\
\hline No & 39 & 76.5 & 7 & 70 & \\
\hline
\end{tabular}

Note. Significance tests based on whether there is a statistically significant relationship between incident type and motivation variables.

$n s=$ nonsignificant.

bChi-square.

${ }^{*} p \leq .05 .{ }^{* *} p \leq .01 .{ }^{* * *} p \leq .001$ (two-tailed). 
Table 6

Event Characteristics of Lone Actor Incidents in North America Versus Europe

\begin{tabular}{|c|c|c|c|c|c|}
\hline \multirow{2}{*}{$\begin{array}{l}\text { Location } \\
\text { Event characteristics }\end{array}$} & \multicolumn{2}{|c|}{$\begin{array}{l}\text { North America } \\
\quad(n=32)\end{array}$} & \multicolumn{2}{|c|}{$\begin{array}{l}\text { Europe } \\
(n=44)\end{array}$} & \multirow[b]{2}{*}{ Significant } \\
\hline & $M$ & Range & $M$ & Range & \\
\hline Number of fatalities 45 & 4.5 & $(1-50)$ & 8.1 & $(1-87)$ & $n s$ \\
\hline Number of fatalities ${ }^{46}$ & 10.4 & $(3-50)$ & 13.8 & $(3-87)$ & $n s$ \\
\hline Number of casualties & 10 & $(0-132)$ & 42 & $(0-800)$ & $n s$ \\
\hline Total number of victims 47 & 14.5 & $(1-134)$ & 50.1 & $(1-822)$ & $n s$ \\
\hline Total number of victims 48 & 21 & $(3-103)$ & 88.9 & $(3-822)$ & $n s$ \\
\hline Event Characteristics & $n$ & $\%$ & $n$ & $\%$ & Significant \\
\hline \multicolumn{6}{|l|}{ Yearc } \\
\hline 2010 & 1 & 3.1 & - & - & \multirow{9}{*}{$n s$} \\
\hline 2011 & 1 & 3.1 & 4 & 9.1 & \\
\hline 2012 & 1 & 3.1 & 6 & 13.6 & \\
\hline 2013 & 5 & 15.6 & 3 & 6.8 & \\
\hline 2014 & 11 & 34.4 & 3 & 6.8 & \\
\hline 2015 & 3 & 9.4 & 11 & 25 & \\
\hline 2016 & 5 & 15.6 & 8 & 18.2 & \\
\hline 2017 & 5 & 15.6 & 8 & 18.2 & \\
\hline 2018 & - & - & 1 & 2.3 & \\
\hline \multicolumn{6}{|l|}{ Number of perpetrators ${ }^{c}$} \\
\hline One offender & 26 & 81.3 & 35 & 79.5 & \multirow[t]{3}{*}{$n s$} \\
\hline Two offenders & 5 & 15.6 & 5 & 11.4 & \\
\hline Three or more offenders & 1 & 3.1 & 4 & 9.1 & \\
\hline \multicolumn{6}{|l|}{ Modus operandi ${ }^{b}$} \\
\hline Firearm & 25 & 78.1 & 17 & 38.6 & \multirow[t]{7}{*}{$* *$} \\
\hline Knife & 1 & 3.1 & 7 & 15.9 & \\
\hline Fire & - & - & - & - & \\
\hline Explosives/bombs & 2 & 6.3 & 6 & 13.6 & \\
\hline Vehicle & 3 & 9.4 & 3 & 6.8 & \\
\hline Other & - & - & 1 & 2.3 & \\
\hline Combination & 1 & 3.1 & 10 & 22.7 & \\
\hline
\end{tabular}

45 Results apply when the minimum number of fatalities for lone actors is set to one. 46 Results apply when the minimum number of fatalities for lone actors is set to three.

47 Results apply when the minimum number of fatalities for lone actors is set to one. 48 Results apply when the minimum number of fatalities for lone actors is set to three. 


\begin{tabular}{|c|c|c|c|c|c|}
\hline \multicolumn{6}{|l|}{ Weapon subtype ${ }^{\mathrm{b}}$} \\
\hline Automatic weapon & 3 & 9.4 & 6 & 13.6 & \multirow{5}{*}{$n s$} \\
\hline Handgun & 5 & 15.6 & 7 & 15.9 & \\
\hline $\begin{array}{l}\text { Rifle/shotgun (non- } \\
\text { automatic) }\end{array}$ & 5 & 15.6 & 1 & 2.3 & \\
\hline Unknown gun type & 6 & 18.8 & 2 & 4.5 & \\
\hline Combination & 6 & 18.8 & 5 & 11.4 & \\
\hline \multicolumn{6}{|l|}{ Specific target(s) ${ }^{\mathrm{b}}$} \\
\hline Yes & 25 & 78.1 & 27 & 61.4 & \multirow[t]{2}{*}{$n s$} \\
\hline No & 7 & 21.9 & 17 & 38.6 & \\
\hline \multicolumn{6}{|l|}{ Relationship to victim ${ }^{b}$} \\
\hline Stranger/random & 29 & 90.6 & 42 & $95 \cdot 5$ & \multirow[t]{5}{*}{$n s$} \\
\hline Personal & 1 & 3.1 & - & - & \\
\hline Professional & 2 & 6.3 & 1 & 2.3 & \\
\hline School-related & - & - & - & - & \\
\hline Combination & - & - & 1 & 2.3 & \\
\hline \multicolumn{6}{|l|}{ Location type $^{\mathrm{b}}$} \\
\hline Open commercial & 15 & 46.9 & 21 & $47 \cdot 7$ & \multirow[t]{8}{*}{$n s$} \\
\hline Educational institution & 1 & 3.1 & 2 & 4.5 & \\
\hline Military setting & - & - & - & - & \\
\hline Public street & 10 & 31.3 & 14 & 31.8 & \\
\hline Office & 2 & 6.3 & 1 & 2.3 & \\
\hline Warehouse/factory & - & - & - & - & \\
\hline Other & 3 & 9.4 & 4 & 9.1 & \\
\hline Combination & 1 & 3.1 & 2 & 4.5 & \\
\hline \multicolumn{6}{|l|}{ Attack type ${ }^{b}$} \\
\hline Assassination & - & - & 2 & $4 \cdot 5$ & \multirow[t]{5}{*}{$n s$} \\
\hline Armed assault & 31 & 96.9 & 36 & 81.8 & \\
\hline Bombing/explosion & 1 & 3.1 & 6 & 13.6 & \\
\hline Unarmed assault & - & - & - & - & \\
\hline Combination & - & - & - & - & \\
\hline \multicolumn{6}{|l|}{ Level of planningb } \\
\hline Low-level & 6 & 18.8 & 2 & 4.5 & \multirow[t]{4}{*}{$*$} \\
\hline Medium-level & 19 & 59.4 & 26 & 59.1 & \\
\hline High-level & 5 & 15.6 & 5 & 11.4 & \\
\hline Unknown49 & 2 & 6.3 & 11 & 25 & \\
\hline \multicolumn{6}{|l|}{ Duration of inciden $\mathrm{t}^{\mathrm{b}}$} \\
\hline Less than 30 minutes & 27 & 84.4 & 40 & 90.9 & \multirow[t]{6}{*}{$n s$} \\
\hline 31-6o minutes & - & - & - & - & \\
\hline $1-5$ hours & 3 & 9.4 & 4 & 9.1 & \\
\hline 6-12 hours & 1 & 3.1 & - & - & \\
\hline $13-24$ hours & - & - & - & - & \\
\hline Unknown & 1 & 3.1 & - & - & \\
\hline
\end{tabular}

49 Note that all 'unknown' categories for every variable were excluded from significance testing analyses. 


\begin{tabular}{lccccc}
\hline Time of incident ${ }^{\mathrm{b}}$ & & & & & \\
$\quad$ Morning & 10 & 31.3 & 6 & 13.6 & \\
Afternoon & 6 & 18.8 & 16 & 36.4 & \\
Evening & 5 & 15.6 & 11 & 25 & \\
Late night & 9 & 28.1 & 7 & 15.9 & \\
$\quad$ Unknown & 2 & 6.3 & 4 & 9.1 & \\
Outcome of incident & & & & & \\
$\quad$ Arrest & 12 & 37.5 & 15 & 34.1 & \\
$\quad$ Lethal force/suicide by cop & 8 & 25 & 12 & 27.3 & \\
$\quad$ Suicide/attempted suicide & 4 & 12.5 & 7 & 15.9 & \\
$\quad$ Other & 8 & 25 & 10 & 22.7 & \\
Claims of responsibility & & & & & \\
$\quad$ Yes & 1 & 3.1 & 16 & 36.4 & \\
$\quad$ No & 31 & 96.9 & 28 & 63.6 & \\
Threatening statements & & & & & \\
$\quad$ No statements & 20 & 62.5 & 27 & 61.4 & \\
$\quad$ Direct statements & 8 & 25 & 15 & 34.1 & \\
Indirect statements & 4 & 12.5 & 2 & 4.5 & \\
\hline
\end{tabular}

Note. Significance tests based on whether there is a statistically significant relationship between incident type and event variables.

$n s=$ nonsignificant

bChi-square.

cThe $t$ test.

${ }^{*} p \leq .05 .{ }^{* *} p \leq .01 .{ }^{* * *} p \leq .001$ (two-tailed). 
Table 7

Sociodemographic Characteristics of Lone Actor Perpetrators in North America Versus Europe

\begin{tabular}{|c|c|c|c|c|c|}
\hline \multirow{2}{*}{$\begin{array}{l}\text { Perpetrators } \\
\begin{array}{l}\text { Sociodemographic } \\
\text { characteristics }\end{array}\end{array}$} & \multicolumn{2}{|c|}{$\begin{array}{l}\text { North America } \\
\quad(n=37)\end{array}$} & \multicolumn{2}{|c|}{$\begin{array}{l}\text { Europe } \\
(n=57)\end{array}$} & \multirow[b]{2}{*}{ Significant } \\
\hline & $M$ & Range & $M$ & Range & \\
\hline Age & 31.1 & $(19-73)$ & 27.8 & $(18-52)$ & $n s$ \\
\hline $\begin{array}{l}\text { Sociodemographic } \\
\text { characteristics }\end{array}$ & $n$ & $\%$ & $n$ & $\%$ & Significant \\
\hline \multicolumn{6}{|l|}{ Gender ${ }^{b}$} \\
\hline $\begin{array}{l}\text { Male } \\
\text { Female }\end{array}$ & $\begin{array}{c}35 \\
2\end{array}$ & $\begin{array}{c}94.6 \\
5.4\end{array}$ & $\begin{array}{c}56 \\
1\end{array}$ & $\begin{array}{c}98.2 \\
1.8\end{array}$ & $n s$ \\
\hline \multicolumn{6}{|l|}{ Race/ethnicity } \\
\hline $\begin{array}{l}\text { Black/African American } \\
\text { Asian }\end{array}$ & 7 & 18.9 & 4 & 7 & \multirow[t]{7}{*}{ * } \\
\hline White & - & - & - & - & \\
\hline Hispanic or Latino & 15 & 40.5 & 14 & 24.6 & \\
\hline American Indian or & 1 & 2.7 & - & - & \\
\hline Alaska Native & - & - & - & - & \\
\hline Other & 14 & 37.8 & 39 & 68.4 & \\
\hline Mixed race/ethnicity & - & - & - & - & \\
\hline \multicolumn{6}{|l|}{ Educational levelb } \\
\hline Primary & - & - & - & - & \multirow{4}{*}{$n s$} \\
\hline Secondary & 28 & $75 \cdot 7$ & 32 & 56.1 & \\
\hline Tertiary & 9 & $24 \cdot 3$ & 12 & 21.1 & \\
\hline Unknown & - & - & 13 & 22.8 & \\
\hline \multicolumn{6}{|l|}{ Relationship status ${ }^{\mathrm{b}}$} \\
\hline Single & 18 & 48.6 & 33 & 57.9 & \multirow{6}{*}{$n s$} \\
\hline In a relationship & 4 & 10.8 & 1 & 1.8 & \\
\hline Married & 12 & 32.4 & 12 & 21.1 & \\
\hline Divorced & 3 & 8.1 & 3 & $5 \cdot 3$ & \\
\hline $\begin{array}{l}\text { Divorced but in a } \\
\text { relationship }\end{array}$ & - & - & - & - & \\
\hline Unknown & - & - & 8 & 14 & \\
\hline \multicolumn{6}{|l|}{ Job status ${ }^{\mathrm{b}}$} \\
\hline Gold-collar worker & - & - & - & - & \multirow{7}{*}{$n s$} \\
\hline White-collar worker & 3 & 8.1 & 3 & $5 \cdot 3$ & \\
\hline Blue-collar worker & 7 & 18.9 & 13 & 22.8 & \\
\hline Unemployed & 23 & 62.2 & 25 & 43.9 & \\
\hline Student & 3 & 8.1 & 4 & 7 & \\
\hline Other (including retired) & 1 & 2.7 & 6 & 10.5 & \\
\hline Unknown & - & - & 6 & 10.5 & \\
\hline
\end{tabular}




\begin{tabular}{|c|c|c|c|c|c|}
\hline \multicolumn{6}{|c|}{ Religious affiliation ${ }^{\mathrm{b}}$} \\
\hline Christian & 5 & 13.5 & - & - & \multirow[t]{10}{*}{ * } \\
\hline Muslim & 18 & 48.6 & 40 & 70.2 & \\
\hline Buddhist & - & - & - & - & \\
\hline Atheist & - & - & - & - & \\
\hline Agnostic & - & - & - & - & \\
\hline Hindu & - & - & - & - & \\
\hline Jewish & - & - & - & - & \\
\hline Non-religious & 1 & 2.7 & 1 & 1.8 & \\
\hline Other & 3 & 8.1 & 3 & $5 \cdot 3$ & \\
\hline Unknown & 10 & 27 & 13 & 22.8 & \\
\hline \multicolumn{6}{|c|}{ Children/dependents } \\
\hline Yes & 13 & 35.1 & 11 & 19.3 & \multirow[t]{3}{*}{$n s$} \\
\hline No & 24 & 64.9 & 40 & 70.2 & \\
\hline Unknown & - & - & 6 & 10.5 & \\
\hline
\end{tabular}

Note. Significance tests based on whether there is a statistically significant relationship between incident type and sociodemographic variables.

$n s=$ nonsignificant

bChi-square.

${ }^{*} p \leq .05 .{ }^{* *} p \leq .01 .{ }^{* * *} p \leq .001$ (two-tailed). 
Table 8

Personal Characteristics of Lone Actor Perpetrators in North America Versus Europe

\begin{tabular}{|c|c|c|c|c|c|}
\hline \multirow{2}{*}{$\begin{array}{l}\text { Perpetrators } \\
\text { Personal characteristics }\end{array}$} & \multicolumn{2}{|c|}{$\begin{array}{l}\text { North America } \\
\quad(n=37)\end{array}$} & \multicolumn{2}{|c|}{$\begin{array}{l}\text { Europe } \\
(n=57)\end{array}$} & \multirow[b]{2}{*}{ Significant } \\
\hline & $n$ & $\%$ & $n$ & $\%$ & \\
\hline \multicolumn{6}{|l|}{ Work/school issues ${ }^{b}$} \\
\hline Issues were present & 10 & 27 & 10 & 17.5 & \multirow{4}{*}{$n s$} \\
\hline Issues were not present & 13 & 35.1 & 20 & 35.1 & \\
\hline Not applicable & 14 & 37.8 & 18 & 31.6 & \\
\hline Unknown & - & - & 9 & 15.8 & \\
\hline \multicolumn{6}{|l|}{ Childhood issues $^{\mathrm{b}}$} \\
\hline $\begin{array}{l}\text { Evidence of significant } \\
\text { issues }\end{array}$ & 2 & $5 \cdot 4$ & 6 & 10.5 & \multirow[t]{3}{*}{$n s$} \\
\hline $\begin{array}{l}\text { Evidence of some form of } \\
\text { issues }\end{array}$ & 14 & 37.8 & 15 & 26.3 & \\
\hline No evidence of issues & 21 & 56.8 & 36 & 63.2 & \\
\hline \multicolumn{6}{|l|}{ Substance use ${ }^{\mathrm{b}}$} \\
\hline $\begin{array}{l}\text { Indications of illegal } \\
\text { substance use and/or } \\
\text { abuse }\end{array}$ & 11 & 29.7 & 17 & 29.8 & \multirow[t]{4}{*}{$n s$} \\
\hline $\begin{array}{l}\text { Indications of alcohol } \\
\text { abuse }\end{array}$ & 2 & 5.4 & - & - & \\
\hline $\begin{array}{l}\text { Indications of both of the } \\
\text { above }\end{array}$ & 5 & 13.5 & 3 & $5 \cdot 3$ & \\
\hline No indications & 19 & 51.4 & 37 & 64.9 & \\
\hline \multicolumn{6}{|l|}{ Weapon ownership ${ }^{b}$} \\
\hline Yes & 34 & 91.9 & 39 & 68.4 & \multirow{3}{*}{$n s$} \\
\hline No & 3 & 8.1 & 3 & $5 \cdot 3$ & \\
\hline Unknown & - & - & 15 & 26.3 & \\
\hline \multicolumn{6}{|l|}{$\begin{array}{l}\text { Fascination with } \\
\text { weapons/warb }\end{array}$} \\
\hline Yes & 25 & 67.6 & 46 & 80.7 & \multirow{3}{*}{$n s$} \\
\hline No & 1 & 2.7 & 11 & 19.3 & \\
\hline Unknown & 11 & 29.7 & - & - & \\
\hline \multicolumn{6}{|l|}{ Familiarity with firearms $\mathrm{s}^{\mathrm{b}}$} \\
\hline Yes & 28 & $75 \cdot 7$ & 30 & 52.6 & \multirow[t]{3}{*}{$n s$} \\
\hline No & - & - & 2 & $3 \cdot 5$ & \\
\hline Unknown & 9 & 24.3 & 25 & 43.9 & \\
\hline \multicolumn{6}{|l|}{ Military experience ${ }^{b}$} \\
\hline Did have prior experience & 8 & 21.6 & 6 & 10.5 & \multirow{3}{*}{$n s$} \\
\hline $\begin{array}{l}\text { Did not have prior } \\
\text { experience }\end{array}$ & 29 & 78.4 & 44 & 77.2 & \\
\hline Unknown & - & - & 7 & 12.3 & \\
\hline
\end{tabular}




\begin{tabular}{|c|c|c|c|c|c|}
\hline \multicolumn{6}{|l|}{$\begin{array}{l}\text { Ideological } \\
\text { connections/group } \\
\text { affiliations }\end{array}$} \\
\hline $\begin{array}{l}\text { Evidence of group } \\
\text { connections }\end{array}$ & 2 & 5.4 & 3 & $5 \cdot 3$ & \multirow[t]{2}{*}{$n s$} \\
\hline $\begin{array}{l}\text { No evidence of group } \\
\text { connections }\end{array}$ & 35 & 94.6 & 54 & 94.7 & \\
\hline \multicolumn{6}{|l|}{ Precipitating events ${ }^{\mathrm{b}}$} \\
\hline No clear event & 21 & 56.8 & 44 & 77.2 & \multirow{7}{*}{$n s$} \\
\hline Relationship-related & 1 & 2.7 & 4 & 7 & \\
\hline Occupation-related & 3 & 8.1 & - & - & \\
\hline School-related & - & - & - & - & \\
\hline Personal-related & 10 & 27 & 7 & 12.3 & \\
\hline Combination & 2 & $5 \cdot 4$ & 1 & 1.8 & \\
\hline Other & - & - & 1 & 1.8 & \\
\hline
\end{tabular}

Note. Significance tests based on whether there is a statistically significant relationship between incident type and perpetrator-level variables.

$n s=$ nonsignificant.

bChi-square.

${ }^{*} p \leq .05 .{ }^{* *} p \leq .01 .{ }^{* * *} p \leq .001$ (two-tailed). 
Table 9

Psychological Background and Violent History of Lone Actor Perpetrators in North America Versus Europe

\begin{tabular}{|c|c|c|c|c|c|}
\hline \multirow{2}{*}{$\begin{array}{l}\text { Perpetrators } \\
\text { Perpetrator characteristics }\end{array}$} & \multicolumn{2}{|c|}{$\begin{array}{l}\text { North America } \\
\quad(n=37)\end{array}$} & \multicolumn{2}{|c|}{$\begin{array}{l}\text { Europe } \\
(n=57)\end{array}$} & \multirow[b]{2}{*}{ Significant } \\
\hline & $n$ & $\%$ & $n$ & $\%$ & \\
\hline \multicolumn{6}{|l|}{ Antisocial personality traits } \\
\hline $\begin{array}{l}\text { Traits displayed prior to } \\
\text { incident }\end{array}$ & 29 & 78.4 & 27 & 47.4 & \multirow{3}{*}{$* *$} \\
\hline $\begin{array}{l}\text { No traits displayed prior } \\
\text { to incident }\end{array}$ & 8 & 21.6 & 21 & 36.8 & \\
\hline Unknown & - & - & 9 & 15.8 & \\
\hline \multicolumn{6}{|l|}{ Low self-esteem ${ }^{b}$} \\
\hline Yes & 3 & 8.1 & 6 & 10.5 & \multirow{3}{*}{$n s$} \\
\hline No & 28 & $75 \cdot 7$ & 38 & 66.7 & \\
\hline Unknown & 6 & 16.2 & 13 & 22.8 & \\
\hline \multicolumn{6}{|l|}{ Social isolation ${ }^{\mathrm{b}}$} \\
\hline $\begin{array}{l}\text { Indications of extreme } \\
\text { social isolation }\end{array}$ & - & - & - & - & \multirow[t]{4}{*}{$n s$} \\
\hline $\begin{array}{l}\text { Indications of some form } \\
\text { of social isolation }\end{array}$ & 13 & 35.1 & 16 & 28.1 & \\
\hline $\begin{array}{l}\text { No indications of social } \\
\text { isolation }\end{array}$ & 24 & 64.9 & 30 & 52.6 & \\
\hline Unknown & - & - & 11 & 19.3 & \\
\hline \multicolumn{6}{|l|}{ Mental health status ${ }^{b}$} \\
\hline $\begin{array}{l}\text { Evidence of mental health } \\
\text { issues or disorder(s) }\end{array}$ & 6 & 16.2 & 11 & 19.3 & \multirow[t]{4}{*}{$* * *$} \\
\hline $\begin{array}{l}\text { Indications of mental } \\
\text { health issues or } \\
\text { disorder(s) }\end{array}$ & 21 & 56.8 & 10 & 17.5 & \\
\hline $\begin{array}{l}\text { No evidence of mental } \\
\text { health issues or } \\
\text { disorder(s) }\end{array}$ & 7 & 18.9 & 24 & 42.1 & \\
\hline Unknown & 3 & 8.1 & 12 & 21.1 & \\
\hline \multicolumn{6}{|l|}{ Suicide indications ${ }^{\mathrm{b}}$} \\
\hline $\begin{array}{l}\text { Indications were found } \\
\text { Indications were not }\end{array}$ & 3 & 8.1 & 1 & 1.8 & \multirow[t]{2}{*}{$n s$} \\
\hline found & 34 & 91.9 & 56 & 98.2 & \\
\hline \multicolumn{6}{|l|}{ Previous violent acts ${ }^{b}$} \\
\hline Yes & 20 & 54.1 & 20 & 35.1 & \multirow[t]{2}{*}{$n s$} \\
\hline No & 17 & $45 \cdot 9$ & 37 & 64.9 & \\
\hline \multicolumn{6}{|l|}{ Previous abuse $\mathrm{b}^{\mathrm{b}}$} \\
\hline Yes & 2 & $5 \cdot 4$ & 5 & 8.8 & \multirow{2}{*}{$n s$} \\
\hline No & 35 & 94.6 & 52 & 91.2 & \\
\hline
\end{tabular}




\begin{tabular}{llllll}
\hline Criminal history $^{\mathrm{b}}$ & & & & \\
Yes & 16 & 43.2 & 20 & 35.1 & $n s$ \\
No & 21 & 56.8 & 37 & 64.9 & \\
\hline
\end{tabular}

Note. Significance tests based on whether there is a statistically significant relationship between incident type and psychological and violent history variables.

$n s=$ nonsignificant.

bChi-square.

${ }^{*} p \leq .05 .{ }^{* *} p \leq .01 .{ }^{* * *} p \leq .001$ (two-tailed). 
Table 10

Motivational Patterns of Lone Actor Perpetrators in North America Versus Europe

\begin{tabular}{|c|c|c|c|c|c|}
\hline \multirow{2}{*}{$\begin{array}{l}\text { Perpetrators } \\
\text { Motivational characteristics }\end{array}$} & \multicolumn{2}{|c|}{$\begin{array}{l}\text { North America } \\
\quad(n=37)\end{array}$} & \multicolumn{2}{|c|}{$\begin{array}{l}\text { Europe } \\
(n=57)\end{array}$} & \multirow[b]{2}{*}{ Significant } \\
\hline & $n$ & $\%$ & $n$ & $\%$ & \\
\hline \multicolumn{6}{|l|}{$\begin{array}{l}\text { Motivation: emotional } \\
\text { triggers }\end{array}$} \\
\hline Yes & 3 & 8.1 & 1 & 1.8 & \\
\hline No & 34 & 91.9 & 56 & 98.2 & \\
\hline \multicolumn{6}{|l|}{$\begin{array}{l}\text { Motivation: relationship or } \\
\text { domestic issues }\end{array}$} \\
\hline Yes & 1 & 2.7 & 2 & 3.5 & \\
\hline No & 36 & $97 \cdot 3$ & 55 & 96.5 & \\
\hline \multicolumn{6}{|l|}{ Motivation: revenge/payback } \\
\hline Yes & 9 & $24 \cdot 3$ & 14 & 24.6 & $n s$ \\
\hline No & 28 & $75 \cdot 5$ & 43 & $75 \cdot 4$ & \\
\hline \multicolumn{6}{|l|}{$\begin{array}{l}\text { Motivation: personal } \\
\text { grievances }\end{array}$} \\
\hline Yes & 10 & 27 & 2 & 3.5 & \\
\hline No & 27 & 73 & 55 & 96.5 & \\
\hline \multicolumn{6}{|l|}{ Motivation: criminal gain } \\
\hline Yes & 1 & 2.7 & 2 & 3.5 & $n s$ \\
\hline No & 36 & $97 \cdot 3$ & 55 & 96.5 & \\
\hline \multicolumn{6}{|l|}{$\begin{array}{l}\text { Motivation: political or } \\
\text { religious }\end{array}$} \\
\hline Yes & 36 & $97 \cdot 3$ & 54 & 94.7 & \\
\hline No & 1 & 2.7 & 3 & $5 \cdot 3$ & \\
\hline \multicolumn{6}{|l|}{$\begin{array}{l}\text { Motivation: unclear or } \\
\text { unknown }\end{array}$} \\
\hline Yes & - & - & 2 & 3.5 & tho \\
\hline No & 37 & 100 & 55 & 96.5 & \\
\hline
\end{tabular}

Note. Significance tests based on whether there is a statistically significant relationship between incident type and motivation variables.

$n s=$ nonsignificant.

bChi-square.

${ }^{*} p \leq .05 .{ }^{* *} p \leq .01 .{ }^{* * *} p \leq .001$ (two-tailed). 